MARIANA PERES DINIZ

\title{
PERFIL ELETROCARDIOGRÁFICO DE EQÜINOS DE SALTO CRIADOS EM SÃO PAULO
}

SÃO PAULO

2006 


\section{MARIANA PERES DINIZ}

\section{PERFIL ELETROCARDIOGRÁFICO DE EQÜINOS DE SALTO CRIADOS EM SÃO PAULO}

Dissertação apresentada ao Programa de Pós-graduação em Clínica Veterinária da Faculdade de Medicina Veterinária e Zootecnia da Universidade de São Paulo para obtenção do título de Mestre em Medicina Veterinária.

Departamento:

Clínica Médica

Área de concentração:

Clínica Veterinária

Orientador:

Prof. Dr. Wilson Roberto Fernandes 
Autorizo a reprodução parcial ou total desta obra, para fins acadêmicos, desde que citada a fonte.

DADOS INTERNACIONAIS DE CATALOGAÇÃO-NA-PUBLICAÇÃO

(Biblioteca Virginie Buff D’Ápice da Faculdade de Medicina Veterinária e Zootecnia da Universidade de São Paulo)

T.1705 Diniz, Mariana Peres

FMVZ Perfil eletrocardiográfico de eqüinos de salto criados em São

Paulo / Mariana Peres Diniz. - São Paulo: M. P. Diniz, 2006.

134 f. : il.

Dissertação (mestrado) - Universidade de São Paulo. Faculdade de Medicina Veterinária e Zootecnia. Departamento de Clínica Médica, 2006.

Programa de Pós-graduação: Clínica Veterinária.

Área de concentração: Clínica Veterinária.

Orientador: Prof. Dr. Wilson Roberto Fernandes.

1. Eqüinos. 2. Eletrocardiografia. 3. Salto. I. Título. 


\section{UNIVERSIDADE DE SÃO PAULO \\ Faculdade de Medicina Veterinária e Zootecnia \\ Comissão Bioética}

\section{CERTIFICADO}

Certificamos que o Projeto intitulado "Perfil eletrocardiográfico de eqüinos de salto criados em São Paulo", protocolado sob o n923/2006, utilizando 100 (cem) eqüinos, sob a responsabilidade do Prof. Dr. Wilson Roberto Fernandes, está de acordo com os princípios éticos de experimentação animal da Comissão de Bioética da Faculdade de Medicina Veterinária e Zootecnia da Universidade de São Paulo e foi aprovado "ad referendun".

(We certify that the Research "Electrocardiographic profile of show jumping horses raised in São Paulo", protocol number 923/2006, utilizing 100 (one hundred) equines, under the responsibility of Prof. Dr. Wilson Roberto Fernandes, agree with Ethical Principles in Animal Research adopted by Bioethic Commission of the Faculty of Veterinary Medicine and Zootechny of University of São Paulo and was approved "ad referendum", meeting.

São Paulo, 30 de maio de 2006

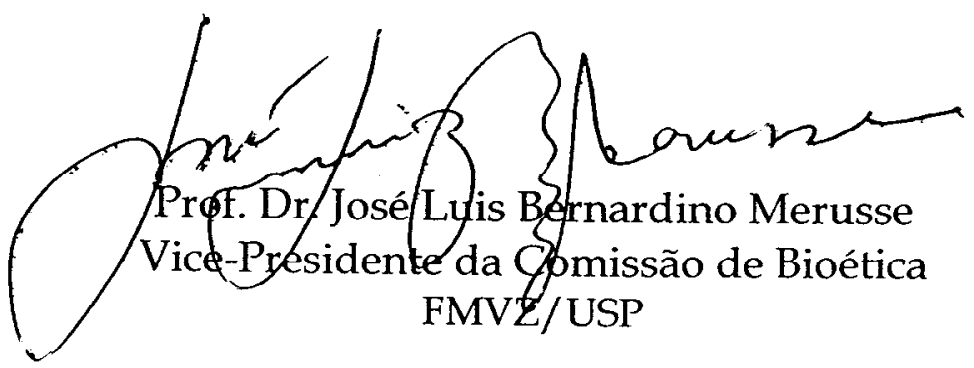

Av. Prof. Dr. Orlando Marques de Paiva, $\mathrm{n}^{\circ} 87$ - 05508-270 - Cidade Universitária "Armando de Salles Oliveira". Fax: (11) 3032-2224 - fones: (11) 309107676/7671 - e-mail: fmvz@edu.usp.br 


\section{FOLHA DE AVALIAÇÃO}

Nome: DINIZ, Mariana Peres

Título: Perfil eletrocardiográfico de eqüinos de salto criados em São Paulo

Dissertação apresentada ao Programa de Pós-graduação em Clínica Veterinária da

Faculdade de Medicina Veterinária e

Zootecnia da Universidade de São Paulo para obtenção do título de Mestre em Medicina Veterinária.

Data:

Banca Examinadora

Prof. Dr.

Julgamento:

Prof. Dr. Julgamento:

Prof. Dr.

Julgamento:
Instituição:

Assinatura:

Instituição:

Assinatura:

Instituição:

Assinatura: 
Ao André, meu marido e ao Rafael, meu filho, que são a razão de tudo 


\section{AGRADECIMENTOS}

A Deus, que sempre guiou meus caminhos.

Aos meus pais por todos os ensinamentos e aos meus irmãos, companheiros de toda vida.

Ao Prof. Wilson, que me deu uma das mais importantes oportunidades da vida e depositou em mim uma confiança gratuita que espero poder retribuir. Obrigado pelos conselhos, ensinamentos, conversas e acima de tudo paciência.

A equipe Azevedo \& Montello por todo aprendizado, aqui foi minha casa e minha escola. Em especial ao Thomaz Montello e a Priscila Azevedo por toda ajuda, sem vocês nada disso seria possível.

A Lílian Michima por toda ajuda neste trabalho e sua grande paciência em todas as minhas dúvidas.

A Prof ${ }^{a}$. Maria Helena Larsson pela colaboração, com seu enorme conhecimento.

Ao Getulio, meu grande amigo e pai postiço, sem sua ajuda não teria chegado aqui.

A Beatriz d'Utra Vaz que foi minha professora e acima de tudo amiga me ajudando a concretizar meu sonho.

A Prof ${ }^{a}$ Ruthnéa por sua amizade e por ter me conduzido e me ajudado a dar meus primeiros passos na cardiologia.

Ao Prof. Geraldo Eleno, por seus ensinamentos que levarei para o resto da vida.

A Adriana, Patrícia e Kitty, pela ajuda nas intermináveis segundas-feiras. 


\section{RESUMO}

DINIZ, M. P. Perfil eletrocardiográfico de eqüinos de salto criados em São Paulo. [Electrocardiographic profile of show jumping horses raised in São Paulo]. 2006. $134 \mathrm{f}$. Dissertação (Mestrado em Medicina Veterinária) - Faculdade de Medicina Veterinária e Zootecnia, Universidade de São Paulo, São Paulo, 2006.

Este trabalho teve como objetivo avaliar o perfil eletrocardiográfico dos eqüinos praticantes de hipismo clássico em São Paulo e também se estes parâmetros sofrem influências em relação ao tipo de atividade física desempenhada pelo animal (provas de salto abaixo de 1,20 metros e provas acima de 1,20 metros), faixa etária e fatores sexuais. Foram utilizados 100 eqüinos de hipismo clássico, representados por 61 machos e 39 fêmeas, com idades entre 4 e 19 anos. A freqüência cardíaca variou de 18,50 batimentos por minuto (bpm) a $89,45 \mathrm{bpm}$, com média de $40,2077 \pm 13,3321$, o ritmo cardíaco mais freqüente foi o sinusal com $56 \%$, seguido de taquicardia sinusal $23 \%$, arritmia sinusal $20 \%$ e bradicardia sinusal com $1 \%$. As alterações encontradas foram: marcapasso migratório $25 \%$, bloqueio átrio-ventricular de $2^{\circ}$ grau (BAV de $2^{\circ}$ grau) $9 \%$, BAV de $1^{\circ}$ grau $7 \%$, complexos ventriculares prematuros $2 \%$ e bloqueio sinoatrial/ "sinus arrest" e complexos atrial prematuro com 1\%. O eixo elétrico no plano frontal em $87 \%$ dos casos esteve entre o e +90 graus. O score cardíaco médio foi de

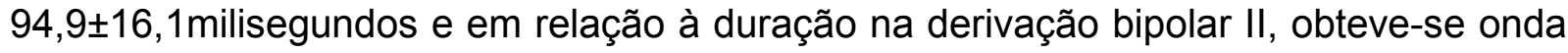
$P$ com $0,1100 \pm 0,0242$ segundos, intervalo $P-R$ com $0,3140 \pm 0,0744$ seg., complexo QRS com 0,0908 $\pm 0,0250$ seg., intervalo QT com 0,4908 $\pm 0,0536$ seg. e onda T com

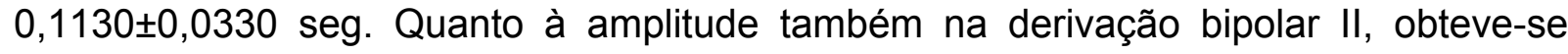
onda $\mathrm{P}$ única em $35 \%$ dos casos com média de $0,2671 \pm 0,0747$ milivolts, onda $P$ bifásica em $11 \%$ dos eqüinos com média de $0,3136 \pm 0,1098 \mathrm{mV}$ e onda $\mathrm{P}$ bífida em $54 \%$ 
dos animais, sendo esta dividida em porção 1 e 2 (P1 e P2), P1 teve média de $0,1352 \pm 0,0492 \mathrm{mV}$ e P2 teve média de $0,2259 \pm 0,0502 \mathrm{mV}$. A onda $R$ e a onda $T$ estiveram presentes em $100 \%$ dos eqüinos obtendo média de $1,0220 \pm 0,5028 \mathrm{mV}$ e $0,4425 \pm 0,2042 \mathrm{mV}$, respectivamente. Quanto à morfologia, considerando-se todas as derivações analisadas, encontraram-se 11 configurações distintas para a onda $P$ e 5 configurações diferentes para o complexo QRS e para a onda T. Segundo as análises estatísticas, houve diferenças significativas na duração, amplitude e morfologia de algumas ondas, intervalos e complexos, em relação ao grupo de atividade física, sexo e idade.

Palavras-chave: Eqüinos. Eletrocardiografia. Salto. 


\section{ABSTRACT}

DINIZ, M. P. Electrocardiographic profile of show jumping horses raised in São Paulo. [Perfil eletrocardiográfico de eqüinos de salto criados em São Paulo]. 2006. 134 f. Dissertação (Mestrado em Medicina Veterinária) - Faculdade de Medicina Veterinária e Zootecnia, Universidade de São Paulo, São Paulo, 2006.

This study aimed to evaluate the electrocardiographic profiles of horses practicing show jumping in São Paulo as well as whether these parameters are affected by kind of physical activity performed by the animal (competitions below $1.20 \mathrm{~m}$ jumps or above $1.20 \mathrm{~m})$, the age level or gender. A hundred show jumping horses were used, being 61 males, and 39 females. Their ages ranged from 4 to 19 years. Heart rate ranged from 18.50 beats per minute (bpm) to $89.45 \mathrm{bpm}$, with an average of $40.2077 \pm 13.3321$, the most frequent rhythm was sinusal with $56 \%$, followed by sinus tachycardia $23 \%$, sinus arrhythmia $20 \%$ and sinus bradycardia $1 \%$. The alterations found were: wandering pacemaker $25 \%$, second-degree atrioventricular block (BAV $2^{\circ}$ ) $9 \%$, first-degree BAV $7 \%$, ventricular premature complexes $2 \%$ and sinoatrial block / sinus arrest as well as premature atrial complexes $1 \%$. The electrical axis at the frontal plane in $87 \%$ of the cases was between 0 and $+90^{\circ}$. The average cardiac score was $94.9 \pm 16.1$ milliseconds. In relationship to the bipolar lead II, $P$ wave with $0.1100 \pm 0.0242$ seconds, $P-R$ interval of $0.3140 \pm 0.0744$ seconds, QRS complex of $0.0908 \pm 0.0250$ seconds, QT interval of $0.4908 \pm 0.0536$ seconds and T wave with $0.1130 \pm 0.0330$ seconds were obtained. In the amplitude, also at the bipolar lead II a single-peaked P wave was obtained in $35 \%$ of the cases with an average of $0.2671 \pm 0.0747$ millivoltz, biphasic $P$ wave in $11 \%$ of horses with an average of $0.3136 \pm 0.1098 \mathrm{mV}$ and bifid $\mathrm{P}$ wave in $54 \%$ of the animals, being the 
latter divided into portions 1 and 2 (P1 and P2). P1 got an average of $0.1352 \pm 0.0492 \mathrm{mV}$ and P2 got an average of $0.2259 \pm 0.0502 \mathrm{mV}$. R wave and $\mathrm{T}$ wave were present in $100 \%$ of the horses, getting an average of $1.0220 \pm 0.5028 \mathrm{mV}$ and $0.4425 \pm 0.2042 \mathrm{mV}$ respectively. In relationship to the morphology, considering all the analyzed leads, 11 different configurations for $\mathrm{P}$ wave, and 5 different configurations for $\mathrm{T}$ wave were observed. According to the statistical investigation, there were significant differences in duration, amplitude and morphology of some waves, intervals and complexes in relationship to the physical activity group, sex and age.

Key words: Horse. Electrocardiography. Show jumping. 


\section{LISTA DE FIGURAS}

Figura 1 - Imagem do aparelho de eletrocardiografia portátil FUNBEC (ECG-4) com 6 canais, 3 sensibilidades e velocidades de $25 \mathrm{~mm} / \mathrm{s}$ e $50 \mathrm{~mm} / \mathrm{s}$.

Figura 2 - Imagem do posicionamento dos eletrodos nos membros anteriores próximos às articulações úmero-radio-ulnares e nos membros posteriores próximos às articulações fêmoro-tíbiopatelares, São Paulo - SP - 2006.

Figura 3 - Imagem do posicionamento do eletrodo amarelo no membro anterior próximo à articulação úmero-radio-ulnar, São Paulo - SP $-2006$

Figura 4 - Imagem do posicionamento do eletrodo verde no membro posterior próximo à articulação fêmoro-tíbio-patelar, São Paulo $\mathrm{SP}-2006$.

Figura 5 - Eletrocardiograma de eqüino macho da raça $\mathrm{BH}$ com 10 anos, apresentando marcapasso migratório na derivação bipolar II.........

Figura 6 - Eletrocardiograma de eqüino fêmea da raça BH com 5 anos, apresentando marcapasso migratório na derivação bipolar II e taquicardia sinusal.

Figura 7 - Eletrocardiograma de eqüino macho da raça $\mathrm{BH}$ com 6 anos, apresentando marcapasso migratório na derivação bipolar I e taquicardia sinusal.

Figura 8 - Eletrocardiograma de eqüino macho da raça $\mathrm{BH}$ com 9 anos, apresentando marcapasso migratório na derivação bipolar II

Figura 9 - Eletrocardiograma de eqüino fêmea da raça Anglo-árabe com 9 anos, apresentando arritmia sinusal na derivação bipolar II.

Figura 10 - Eletrocardiograma de eqüino macho da raça Anglo-árabe com 5 anos, apresentando arritmia sinusal na derivação bipolar II

Figura 11 - Eletrocardiograma de eqüino macho da raça Hanoverano com 10 anos, apresentando contração ventricular prematura na derivação bipolar II. 
Figura 12 - Eletrocardiograma de eqüino fêmea da raça Zangerchaid com 8 anos, apresentando contração ventricular prematura na derivação unipolar aumentada aVF.

Figura 13 - Eletrocardiograma de eqüino fêmea da raça Anglo-árabe com 5 anos, apresentando bloqueio sinoatrial / "sinus arrest" na derivação bipolar I.

Figura 14 - Eletrocardiograma de eqüino macho da raça Anglo-árabe com 5 anos, apresentando bradicardia sinusal na derivação bipolar III.....

Figura 15 - Eletrocardiograma de eqüino macho da raça $\mathrm{BH}$ com 6 anos, apresentando taquicardia sinusal na derivação bipolar II.

Figura 16 - Eletrocardiograma de eqüino fêmea da raça Sela Francesa com 10 anos, apresentando bloqueio átrio-ventricular de $2^{\circ}$ grau na derivação unipolar aumentada aVR.

Figura 17 - Eletrocardiograma de eqüino fêmea da raça $\mathrm{BH}$ com 9 anos, apresentando bloqueio átrio-ventricular de $2^{\circ}$ grau na derivação unipolar aumentada aVL

Figura 18 - Eletrocardiograma de eqüino macho da raça $\mathrm{BH}$ com 7 anos, apresentando onda $\mathrm{P}$ única e positiva (+), complexo QRS e T bifásica $(-+)$ na derivação bipolar III

Figura 19 - Eletrocardiograma de eqüino macho da raça $\mathrm{BH}$ com 9 anos, apresentando onda $P$ única e negativa (-), complexo QRS com ondas $R$ e $S$ e onda $T$ negativa (-) na derivação unipolar aumentada aVL

Figura 20 - Eletrocardiograma de eqüino macho da raça $\mathrm{BH}$ com 7 anos, apresentando onda $\mathrm{P}$ bífida e positiva $(++)$, complexo QRS com ondas QR e onda T bífida e negativa (- -) na derivação bipolar I....

Figura 21 - Eletrocardiograma de eqüino macho da raça Hosteiner com 11 anos, apresentando onda P bífida e positiva (++), complexo QRS com ondas QR e T bifásica (- +) na derivação unipolar aumentada aVR

Figura 22 - Eletrocardiograma de eqüino fêmea da raça $\mathrm{BH}$ com 9 anos, apresentando onda $P$ bífida e positiva (++), onda $R$ e onda $T$ negativa (-) na derivação unipolar aumentada aVL 
Figura 23 - Eletrocardiograma de eqüino macho da raça $\mathrm{BH}$ com 8 anos, apresentando onda P bífida e negativa (- -), complexo QRS com morfologia QS e onda T bifásica (+ -) na derivação unipolar aumentada aVR.

Figura 24 - Eletrocardiograma de eqüino macho da raça $\mathrm{BH}$ com 7 anos, apresentando onda P bífida e negativa (- -), complexo QRS com ondas $R$ e $S$ e onda $T$ positiva $(+)$ na derivação unipolar aumentada aVR.

Figura 25 - Eletrocardiograma de eqüino fêmea da raça Anglo-árabe com 9 anos, apresentando onda P bifásica $(-+)$, complexo QRS com ondas $\mathrm{R}$ e $\mathrm{S}$ e onda T positiva (+) na derivação bipolar III.

Figura 26 - Eletrocardiograma de eqüino fêmea da raça $\mathrm{BH}$ com 12 anos, apresentando onda P bifásica (- +), complexo QRS com ondas $Q$ e R e onda $T$ bífida e negativa (- -) na derivação bipolar II.

Figura 27 - Eletrocardiograma de eqüino macho SRD com 17 anos, apresentando onda $\mathrm{P}$ bifásica (- +), complexo QRS com ondas $\mathrm{R}$ e S e onda T negativa (-) na derivação unipolar aumentada aVR...

Figura 28 - Eletrocardiograma de eqüino fêmea da raça $\mathrm{BH}$ com 7 anos, apresentando onda $P$ bifásica com segunda porção (P2) bífida $(-,++)$, complexo QRS e onda T bifásica $(-+)$ na derivação bipolar III.

Figura 29 - Eletrocardiograma de eqüino macho da raça $\mathrm{BH}$ com 7 anos, apresentando onda $P$ bifásica com primeira porção $(P 1)$ bífida $(++,-)$, onda $R$ e onda $T$ negativa (-) na derivação unipolar aumentada aVL

Figura 30 - Eletrocardiograma de eqüino fêmea da raça BH com 8 anos, apresentando onda $P$ bifásica com primeira porção $(P 1)$ bífida e negativa $(--,+)$, onda $R$ e onda $T$ bifásica $(-+)$ na derivação bipolar I

Figura 31 - Eletrocardiograma de eqüino fêmea da raça BH com 6 anos, apresentando onda $P$ bifásica com segunda porção (P2) bífida e negativa (+, - -), complexo QRS somente onda $R$ e onda $T$ negativa (-) na derivação unipolar aumentada aVL

Figura 32 - Eletrocardiograma de eqüino macho da raça $\mathrm{BH}$ com 6 anos, apresentando onda $P$ trífida e positiva $(+++)$, complexo QRS com ondas $\mathrm{R}$ e $\mathrm{S}$ e onda $\mathrm{T}$ positiva (+) na derivação bipolar III 


\section{LISTA DE QUADROS}

Quadro 1 - Valores de amplitude para as onda $Q, R$ e $S$, nos eqüinos de salto e eqüinos das raças $\mathrm{PSI}$ e de trote.....

Quadro 2 - Representação morfológica da onda P na derivação bipolar II dos eqüinos de salto e dos eqüinos mestiços 


\section{LISTA DE TABELAS}

Tabela 1 - Valores médios, desvio padrão, valor mínimo, valor máximo, mediana e moda da freqüência cardíaca (bpm) segundo eletrocardiograma de 100 eqüinos de salto, criados em São Paulo - SP - 2006

Tabela 2 - Valores médios, desvio padrão, valor mínimo, valor máximo, mediana e moda da freqüência cardíaca (bpm) do eletrocardiograma de 100 eqüinos de salto criados na cidade de São Paulo, agrupados segundo atividade física- SP 2006 .

Tabela 3 - Valores médios, desvio padrão, valor mínimo, valor máximo, mediana e moda da freqüência cardíaca (bpm) do eletrocardiograma de 100 eqüinos de salto criados na cidade de São Paulo, agrupados por sexo - SP 2006 .

Tabela 4 - Valores médios, desvio padrão, valor mínimo, valor máximo, mediana e moda da freqüência cardíaca (bpm) do eletrocardiograma de 100 eqüinos de salto criados na cidade de São Paulo, agrupados segundo faixa etária-SP2006.

Tabela 5 - Freqüência e porcentagem dos ritmos cardíacos obtidos pelo eletrocardiograma de 100 eqüinos de salto criados na cidade de São Paulo $S P-2006$.

Tabela 6 - Freqüência e porcentagem dos ritmos cardíacos obtidos pelo eletrocardiograma de 100 eqüinos de salto criados na cidade de São Paulo, agrupados segundo atividade física - SP - 2006.

Tabela 7 - Freqüência e porcentagem dos ritmos cardíacos obtidos pelo eletrocardiograma de 100 eqüinos de salto criados na cidade de São Paulo, agrupados por sexo - SP - 2006 ......

Tabela 8 - Freqüência e porcentagem dos ritmos cardíacos obtidos pelo eletrocardiograma de 100 eqüinos de salto criados na cidade de São Paulo, agrupados segundo faixa etária - SP - 2006.

Tabela 9 - Porcentagem das alterações do ritmo cardíaco encontradas no eletrocardiograma de 100 eqüinos de salto criados na cidade de São PauloSP - 2006.

Tabela 10 - Freqüência e porcentagem das alterações do ritmo cardíaco encontradas no eletrocardiograma de 100 eqüinos de salto criados na cidade de São Paulo, agrupados segundo atividade física - SP -2006. 
Tabela 11 - Freqüência e porcentagem das alterações do ritmo cardíaco encontradas no eletrocardiograma de 100 eqüinos de salto criados na cidade de São Paulo, agrupados segundo atividade física - SP - 2006

Tabela 12 - Freqüência e porcentagem das alterações do ritmo cardíaco encontradas no eletrocardiograma de 100 eqüinos de salto, criados na cidade de São Paulo, agrupados por sexo - SP - 2006 .

Tabela 13 - Freqüência e porcentagem das alterações do ritmo cardíaco encontradas no eletrocardiograma de 100 eqüinos de salto, criados na cidade de São Paulo, agrupados segundo faixa etária - SP - 2006.

Tabela 14 - Freqüência e porcentagem da distribuição do eixo cardíaco frontal do eletrocardiograma de 100 eqüinos de salto criados na cidade de São PauloSP - 2006 .

Tabela 15 - Freqüência e porcentagem da distribuição do eixo cardíaco frontal obtido pelo eletrocardiograma de 100 eqüinos de salto criados na cidade de São Paulo, agrupados segundo atividade física - SP- 2006.

Tabela 16 - Freqüência e porcentagem da distribuição do eixo cardíaco frontal obtido pelo eletrocardiograma de 100 eqüinos de salto criados na cidade de São Paulo, agrupados por sexo - SP- 2006 .

Tabela 17 - Freqüência e porcentagem da distribuição do eixo cardíaco frontal obtido pelo eletrocardiograma de 100 eqüinos de salto criados na cidade de São Paulo, agrupados segundo faixa etária - SP - 2006.

Tabela 18 - Valores médios, desvio padrão, valor mínimo, valor máximo, mediana e moda, do score cardíaco obtido pelo eletrocardiograma de 100 eqüinos de salto criados na cidade de São Paulo - SP - 2006.

Tabela 19 - Valores médios, desvio padrão, valor mínimo, valor máximo, mediana e moda do score cardíaco obtido pelo eletrocardiograma de 100 eqüinos de salto criados na cidade de São Paulo, agrupados segundo atividade física - SP 2006 .

Tabela 20 - Valores médios, desvio padrão, valor mínimo, valor máximo, mediana e moda do score cardíaco obtido pelo eletrocardiograma de 100 eqüinos de salto criados na cidade de São Paulo, agrupados por sexo - SP 2006 .

Tabela 21 - Valores médios, desvio padrão, valor mínimo, valor máximo, mediana e moda do score cardíaco obtido pelo eletrocardiograma de 100 eqüinos de salto criados na cidade de São Paulo, agrupados segundo faixa etária - SP 2006 . 
Tabela 22 - Freqüência relativa, valores médios, desvio padrão, valor mínimo, valor máximo, mediana e moda, da duração da onda $\mathrm{P}$ em segundos nas derivações bipolares I, II e III e nas derivações unipolares aVR, aVL e aVF, obtido pelo eletrocardiograma de 100 eqüinos de salto criados na cidade de São Paulo - SP - 2006

Tabela 23 - Freqüência relativa, valores médios, desvio padrão, valor mínimo, valor máximo, mediana e moda, da duração do intervalo P-R em segundos nas derivações bipolares I, II e III e nas derivações unipolares aVR, aVL e aVF, obtido pelo eletrocardiograma de 100 eqüinos de salto criados na cidade de São Paulo - SP - 2006

Tabela 24 - Freqüência relativa, valores médios, desvio padrão, valor mínimo, valor máximo, mediana e moda, da duração do complexo QRS em segundos nas derivações bipolares I, II e III e nas derivações unipolares aVR, aVL e aVF, obtido pelo eletrocardiograma de 100 eqüinos de salto criados na cidade de São Paulo - SP - 2006

Tabela 25 - Freqüência relativa, valores médios, desvio padrão, valor mínimo, valor máximo, mediana e moda, da duração da onda $Q$ em segundos nas derivações bipolares I, II e III e nas derivações unipolares aVR, aVL e aVF, obtido pelo eletrocardiograma de 100 eqüinos de salto criados na cidade de São Paulo - SP - 2006.

Tabela 26 - Freqüência relativa, valores médios, desvio padrão, valor mínimo, valor máximo, mediana e moda, da duração da onda $\mathrm{R}$ em segundos nas derivações bipolares I, II e III e nas derivações unipolares aVR, aVL e aVF, obtido pelo eletrocardiograma de 100 eqüinos de salto criados na cidade de São Paulo - SP - 2006

Tabela 27 - Freqüência relativa, valores médios, desvio padrão, valor mínimo, valor máximo, mediana e moda, da duração da onda $S$ em segundos nas derivações bipolares I, II e III e nas derivações unipolares aVR, aVL e aVF, obtido pelo eletrocardiograma de 100 eqüinos de salto criados na cidade de São Paulo - SP - 2006

Tabela 28 - Valores médios, desvio padrão, valor mínimo, valor máximo, mediana e moda, da duração do intervalo QT em segundos nas derivações bipolares I, II e III e nas derivações unipolares aVR, aVL e aVF, obtido pelo eletrocardiograma de 100 eqüinos de salto criados na cidade de São Paulo - SP 2006.

Tabela 29 - Freqüência relativa, valores médios, desvio padrão, valor mínimo, valor máximo, mediana e moda, da duração da onda $T$ em segundos nas derivações bipolares I, II e III e nas derivações unipolares aVR, aVL e aVF, obtido pelo eletrocardiograma de 100 eqüinos de salto criados na cidade de São Paulo - SP - 2006 
Tabela 30 - Freqüência relativa, valores médios, desvio padrão, valor mínimo, valor máximo, mediana e moda, da amplitude da onda $\mathrm{P}$ única em milivolts nas derivações bipolares I, II e III e nas derivações unipolares aVR, aVL e aVF, obtido pelo eletrocardiograma de 100 eqüinos de salto criados na cidade de São Paulo - SP - 2006

Tabela 31 - Freqüência relativa, valores médios, desvio padrão, valor mínimo, valor máximo, mediana e moda, da amplitude da onda $\mathrm{P}$ bifásica em milivolts nas derivações bipolares I, II e III e nas derivações unipolares aVR, aVL e aVF, obtido pelo eletrocardiograma de 100 eqüinos de salto criados na cidade de São Paulo- SP - 2006.

Tabela 32 - Freqüência relativa, valores médios, desvio padrão, valor mínimo, valor máximo, mediana e moda, da amplitude da primeira porção da onda $\mathrm{P}$ bífida (P1) em milivolts nas derivações bipolares I, II e III e nas derivações unipolares aVR, aVL e aVF, obtido pelo eletrocardiograma de 100 eqüinos de salto criados na cidade de São Paulo - SP - 2006.

Tabela 33 - Freqüência relativa, valores médios, desvio padrão, valor mínimo, valor máximo, mediana e moda, da amplitude da segunda porção da onda $\mathrm{P}$ bífida (P2) em milivolts nas derivações bipolares I, II e III e nas derivações unipolares aVR, aVL e aVF, obtido pelo eletrocardiograma de 100 eqüinos de salto criados na cidade de São Paulo - SP - 2006.

Tabela 34 - Freqüência relativa, valores médios, desvio padrão, valor mínimo, valor máximo, mediana e moda, da amplitude da onda $Q$ em milivolts nas derivações bipolares I, II e III e nas derivações unipolares aVR, aVL e aVF, obtido pelo eletrocardiograma de 100 eqüinos de salto criados na cidade de São Paulo - SP - 2006

Tabela 35 - Freqüência relativa, valores médios, desvio padrão, valor mínimo, valor máximo, mediana e moda, da amplitude da onda $\mathrm{R}$ em milivolts nas derivações bipolares I, II e III e nas derivações unipolares aVR, aVL e aVF, obtido pelo eletrocardiograma de 100 eqüinos de salto criados na cidade de São Paulo - SP - 2006.

Tabela 36 - Freqüência relativa, valores médios, desvio padrão, valor mínimo, valor máximo, mediana e moda, da amplitude da onda $S$ em milivolts nas derivações bipolares I, II e III e nas derivações unipolares aVR, aVL e aVF, obtido pelo eletrocardiograma de 100 eqüinos de salto criados na cidade de São Paulo- SP - 2006

Tabela 37 - Freqüência relativa, valores médios, desvio padrão, valor mínimo, valor máximo, mediana e moda, da amplitude da onda $T$ em milivolts nas derivações bipolares I, II e III e nas derivações unipolares aVR, aVL e aVF, obtido pelo eletrocardiograma de 100 eqüinos de salto criados na cidade de São Paulo- SP - 2006. 
Tabela 38 - Porcentagem da representação morfológica da onda $P$ nas derivações bipolares I, II e III e, unipolares aVR, aVL e aVF, obtido pelo eletrocardiograma de 100 eqüinos de salto criados na cidade de São Paulo$S P-2006$.

Tabela 39 - Porcentagem da representação morfológica do complexo QRS nas derivações bipolares I, II e III e derivações unipolares aVR, aVL e aVF, obtido pelo eletrocardiograma de 100 eqüinos de salto criados na cidade de São Paulo$S P-2006$.

Tabela 40 - Porcentagem da representação morfológica da onda $T$ nas derivações unipolares aVR, aVL e aVF, obtido pelo eletrocardiograma de 100 eqüinos de salto criados na cidade de São Paulo - SP - 2006.

Tabela 41 - Valores médios, desvio padrão, valor mínimo, valor máximo, mediana e moda, da duração do intervalo QT em segundos na derivação bipolar I, obtidos pelo eletrocardiograma de 100 eqüinos de salto criados na cidade de São Paulo, agrupados segundo atividade física - SP - 2006

Tabela 42 - Valores médios, desvio padrão, valor mínimo, valor máximo, mediana e moda, da duração do intervalo QT em segundos na derivação bipolar III, obtidos pelo eletrocardiograma de 100 eqüinos de salto criados na cidade de São Paulo, agrupados segundo atividade física - SP -2006 .

Tabela 43 - Valores médios, desvio padrão, valor mínimo, valor máximo, mediana e moda, da duração do intervalo QT em segundos na derivação unipolar aVF, obtidos pelo eletrocardiograma de 100 eqüinos de salto criados na cidade de São Paulo, agrupados segundo atividade física - SP - 2006.

Tabela 44 - Freqüência relativa, média, desvio padrão, valor mínimo, valor máximo, mediana e moda, da amplitude em milivolts da primeira porção da onda $P$ bífida (P1) na derivação bipolar I, obtidos pelo eletrocardiograma de 100 eqüinos de salto criados na cidade de São Paulo, agrupados segundo atividade física - SP - 2006 .

Tabela 45 - Freqüência relativa, média, desvio padrão, valor mínimo, valor máximo, mediana e moda, da amplitude em milivolts da primeira porção da onda $P$ bífida (P1) na derivação unipolar aVL, obtidos pelo eletrocardiograma de 100 eqüinos de salto criados na cidade de São Paulo, agrupados segundo atividade física - SP - 2006 .

Tabela 46 - Valores médios, desvio padrão, valor mínimo, valor máximo, mediana e moda, da amplitude em milivolts da onda $\mathrm{T}$ na derivação bipolar I, obtidos pelo eletrocardiograma de 100 eqüinos de salto criados na cidade de São Paulo, agrupados segundo atividade física - SP - 2006

Tabela 47 - Freqüência e porcentagem da representação morfológica do complexo QRS na derivação unipolar II, obtido pelo eletrocardiograma de 100 eqüinos de salto criados na cidade de São Paulo, agrupados segundo atividade física SP - 2006 
Tabela 48 - Valores médios, desvio padrão, valor mínimo, valor máximo, mediana e moda, da duração do intervalo P-R em segundos na derivação unipolar aVR, obtidos pelo eletrocardiograma de 100 eqüinos de salto criados na cidade de São Paulo, agrupados por sexo - SP - 2006 .

Tabela 49 - Freqüência relativa, média, desvio padrão, valor mínimo, valor máximo, mediana e moda, da duração da onda $\mathrm{S}$ em segundos na derivação bipolar I, obtidos pelo eletrocardiograma de 100 eqüinos de salto criados na cidade de São Paulo, agrupados por sexo - SP - 2006.

Tabela 50 - Valores médios, desvio padrão, valor mínimo, valor máximo, mediana e moda, da duração da onda $T$ em segundos na derivação bipolar II, obtidos pelo eletrocardiograma de 100 eqüinos de salto criados na cidade de São Paulo, agrupados por sexo - SP - 2006 .

Tabela 51 - Freqüência relativa, média, desvio padrão, valor mínimo, valor máximo, mediana e moda, da amplitude em milivolts da onda $P$ única na derivação unipolar aVL, obtido pelo eletrocardiograma de 100 eqüinos de salto criados na cidade de São Paulo, agrupados por sexo - SP - 2006.

Tabela 52 - Freqüência relativa, média, desvio padrão, valor mínimo, valor máximo, mediana e moda, da amplitude em milivolts da onda $P$ única na derivação unipolar aVF, obtido pelo eletrocardiograma de 100 eqüinos de salto criados na cidade de São Paulo, agrupados por sexo - SP - 2006.

Tabela 53 - Freqüência relativa, média, desvio padrão, valor mínimo, valor máximo, mediana e moda, da amplitude em milivolts da segunda porção da onda $P$ bífida (P2) na derivação bipolar III, obtido pelo eletrocardiograma de 100 eqüinos de salto criados na cidade de São Paulo, agrupados por sexo - SP 2006.

Tabela 54 - Freqüência relativa, média, desvio padrão, valor mínimo, valor máximo, mediana e moda, da amplitude em milivolts da onda $Q$ na derivação bipolar I, obtido pelo eletrocardiograma de 100 eqüinos de salto criados na cidade de São Paulo, agrupados por sexo - SP - 2006.

Tabela 55 - Valores médios, desvio padrão, valor mínimo, valor máximo, mediana e moda, da amplitude em milivolts da onda $T$ na derivação bipolar II, obtido pelo eletrocardiograma de 100 eqüinos de salto criados na cidade de São Paulo, agrupados por sexo - SP - 2006 .

Tabela 56 - Valores médios, desvio padrão, valor mínimo, valor máximo, mediana e moda, da amplitude em milivolts da onda $T$ na derivação unipolar aVF, obtido pelo eletrocardiograma de 100 eqüinos de salto criados na cidade de São Paulo, agrupados por sexo - SP - 2006 .

Tabela 57 - Freqüência e porcentagem da representação morfológica da onda $T$ na derivação unipolar II, obtido pelo eletrocardiograma de 100 eqüinos de salto criados na cidade de São Paulo, agrupados por sexo - SP - 2006. 
Tabela 58 - Valores médios, desvio padrão, valor mínimo, valor máximo, mediana e moda, da duração do complexo QRS em segundos na derivação unipolar aVL, obtido pelo eletrocardiograma de 100 eqüinos de salto criados na cidade de São Paulo, agrupados segundo faixa etária - SP - 2006.

Tabela 59 - Freqüência relativa, média, desvio padrão, valor mínimo, valor máximo, mediana e moda, da duração da onda $\mathrm{R}$ em segundos na derivação bipolar $\mathrm{I}$, obtido pelo eletrocardiograma de 100 eqüinos de salto criados na cidade de São Paulo, agrupados segundo faixa etária - SP - 2006

Tabela 60 - Freqüência relativa, média, desvio padrão, valor mínimo, valor máximo, mediana e moda, da amplitude em milivolts da onda R na derivação bipolar III, obtido pelo eletrocardiograma de 100 eqüinos de salto criados na cidade de São Paulo, agrupados segundo faixa etária - SP - 2006

Tabela 61 - Freqüência relativa, média, desvio padrão, valor mínimo, valor máximo, mediana e moda, da amplitude em milivolts da onda $\mathrm{R}$ na derivação unipolar aVR, obtido pelo eletrocardiograma de 100 eqüinos de salto criados na cidade de São Paulo, agrupados segundo faixa etária - SP - 2006.

Tabela 62 - Freqüência relativa, média, desvio padrão, valor mínimo, valor máximo, mediana e moda, da amplitude em milivolts da onda $\mathrm{R}$ na derivação unipolar aVF, obtido pelo eletrocardiograma de 100 eqüinos de salto criados na cidade de São Paulo, agrupados segundo faixa etária - SP - 2006.

Tabela 63 - Freqüência relativa, média, desvio padrão, valor mínimo, valor máximo, mediana e moda, da amplitude em milivolts da onda $S$ na derivação unipolar aVL, obtido pelo eletrocardiograma de 100 eqüinos de salto criados na cidade de São Paulo, agrupados segundo faixa etária - SP - 2006 


\section{LISTA DE APÊNDICE}

APÊNDICE A - Dados individuais de grupo de atividade física, raça, idade (anos), peso $(\mathrm{kg})$, sexo, freqüência cardíaca $(\mathrm{bpm})$, ritmo cardíaco, eixo cardíaco no plano frontal, score cardíaco (seg) e alterações cardíacas obtido pelo eletrocardiograma de 100 eqüinos de salto criados na cidade de São Paulo- SP - 2006.

APÊNDICE B - Dados individuais de grupo de atividade física, duração em segundos da onda $\mathrm{P}$, intervalo P-R, complexo QRS, intervalo QT e onda T; amplitude em milivolts da onda $\mathrm{P}$ única, onda $\mathrm{P}$ bifásica, primeira porção da onda $\mathrm{P}$ bífida (P1), segunda porção da onda P bífida (P2), complexo QRS e onda T, na derivação bipolar I, obtido pelo eletrocardiograma de 100 eqüinos de salto criados na cidade de São Paulo - SP - 2006

APÊNDICE C -

Dados individuais de grupo de atividade física, duração em segundos da onda P, intervalo P-R, complexo QRS, intervalo QT e onda T; amplitude em milivolts da onda $P$ única, onda $P$ bifásica, primeira porção da onda $P$ bífida (P1), segunda porção da onda P bífida (P2), complexo QRS e onda T, na derivação bipolar II, obtido pelo eletrocardiograma de 100 eqüinos de salto criados na cidade de São Paulo - SP - 2006

APÊNDICE D -

Dados individuais de grupo de atividade física, duração em segundos da onda P, intervalo P-R, complexo QRS, intervalo QT e onda T; amplitude em milivolts da onda $P$ única, onda $P$ bifásica, primeira porção da onda $P$ bífida (P1), segunda porção da onda P bífida (P2), complexo QRS e onda $T$, na derivação bipolar III, obtido pelo eletrocardiograma de 100 eqüinos de salto criados na cidade de São Paulo - SP - 2006

APÊNDICE E -

Dados individuais de grupo de atividade física, duração em segundos da onda $\mathrm{P}$, intervalo $\mathrm{P}-\mathrm{R}$, complexo QRS, intervalo QT e onda T; amplitude em milivolts da onda $P$ única, onda $P$ bifásica, primeira porção da onda $P$ bífida (P1), segunda porção da onda P bífida (P2), complexo QRS e onda T, na derivação unipolar aVR, obtido pelo eletrocardiograma de 100 eqüinos de salto criados na cidade de São Paulo - SP - 2006

APÊNDICE F - Dados individuais de grupo de atividade física, duração em segundos da onda P, intervalo P-R, complexo QRS, intervalo QT e onda T; amplitude em milivolts da onda $P$ única, onda $P$ bifásica, primeira porção da onda $P$ bífida (P1), segunda porção da onda P bífida (P2), complexo QRS e onda T, na derivação unipolar aVL, obtido pelo eletrocardiograma de 100 eqüinos de salto criados na cidade de São Paulo - SP - 2006

APÊNDICE G - Dados individuais de grupo de atividade física, duração em segundos da onda P, intervalo P-R, complexo QRS, intervalo QT e onda T; amplitude em milivolts da onda $\mathrm{P}$ única, onda $\mathrm{P}$ bifásica, primeira porção da onda $\mathrm{P}$ bífida (P1), segunda porção da onda P bífida (P2), complexo QRS e onda T, na derivação unipolar aVF, obtido pelo eletrocardiograma de 100 eqüinos de salto criados na cidade de São Paulo - SP - 2006. 
APÊNDICE H - Dados individuais de grupo de atividade física e representação morfológica da onda P, nas derivações bipolares I, II e III e unipolares aVR, aVL e aVF, obtido pelo eletrocardiograma de 100 eqüinos de salto criados na cidade de São Paulo - SP - 2006 .

APÊNDICE I- Dados individuais de grupo de atividade física e representação morfológica do complexo QRS, nas derivações bipolares I, II e III e unipolares aVR, aVL e aVF, obtido pelo eletrocardiograma de 100 eqüinos de salto criados na cidade de São Paulo - SP - 2006

APÊNDICE J - Dados individuais de grupo de atividade física e representação morfológica da onda T, nas derivações bipolares I, II e III e unipolares aVR, aVL e aVF, obtido pelo eletrocardiograma de 100 eqüinos de salto criados na cidade de São Paulo - SP - 2006. 


\section{LISTA DE ABREVIATURAS E SIGLAS}

\begin{tabular}{|c|c|}
\hline APC & Complexo atrial prematuro \\
\hline AS & Arritmia sinusal \\
\hline aVF & Derivação unipolar aumentada aVF \\
\hline $\mathrm{aVL}$ & Derivação unipolar aumentada aVL \\
\hline aVR & Derivação unipolar aumentada aVR \\
\hline $\mathrm{BAV} 1^{\circ}$ & Bloqueio atrioventricular de $1^{\circ} \mathrm{grau}$ \\
\hline $\mathrm{BAV} 2^{\circ}$ & Bloqueio atrioventricular de $2^{\circ}$ grau \\
\hline $\mathrm{BH}$ & Raça Brasileiro de Hipismo \\
\hline bpm & Batimentos por minuto \\
\hline BRAD & Bradicardia sinusal \\
\hline D I & Derivação bipolar I \\
\hline D II & Derivação bipolar II \\
\hline D III & Derivação bipolar III \\
\hline ECG & Eletrocardiograma \\
\hline $\mathrm{F}$ & Fêmea \\
\hline $\mathrm{FC}$ & Freqüência cardíaca \\
\hline $\mathrm{Kg}$ & Quilograma \\
\hline $\mathrm{Km}$ & Quilômetro \\
\hline M & Macho \\
\hline M & Metros \\
\hline MM & Marcapasso migratório \\
\hline $\mathrm{mm} / \mathrm{s}$ & Milímetros por segundo \\
\hline mseg & Milisegundos \\
\hline $\mathrm{mV}$ & Milivolts \\
\hline$P$ bifás. & Onda P bifásica \\
\hline P1 & Primeira porção da onda $\mathrm{P}$ bífida \\
\hline $\mathrm{P} 2$ & Segunda porção da onda P bífida \\
\hline PSI & Raça Puro Sangue Inglês \\
\hline QR & Complexo QRS com ausência de onda S \\
\hline QRS & Complexo QRS \\
\hline QS & Complexo QRS com ausência de onda $\mathrm{R}$ \\
\hline $\mathrm{R}$ & Onda R \\
\hline RS & Complexo QRS com ausência de onda $Q$ \\
\hline Seg & Segundos \\
\hline SN & Ritmo sinusal \\
\hline SRD & Animal sem raça definida \\
\hline TS & Taquicardia sinusal \\
\hline VPC & Complexo ventricular prematuro \\
\hline
\end{tabular}




\section{LISTA DE SÍMBOLOS}

$\begin{array}{ll}\% & \text { Porcentagem } \\ \circ & \text { Graus } \\ \pm & \text { Mais ou menos } \\ \leq & \text { Menor ou igual } \\ = & \text { Igual } \\ + & \text { Mais ou positivo } \\ - & \text { Menos ou negativo } \\ \mathrm{X}^{2} & \text { Qui quadrado }\end{array}$




\section{SUMÁRIO}

1 INTRODUÇÃO

2 REVISÃO DE LITERATURA …........................................................ 32

$2.1 \quad$ RITMO E FREQÜÊNCIA CARDÍACA …….................................... 32

2.2 FORMAÇÃO, MORFOLOGIA, AMPLITUDE E DURAÇÃO DAS ONDAS, INTERVALOS E COMPLEXOS...................................................... 35

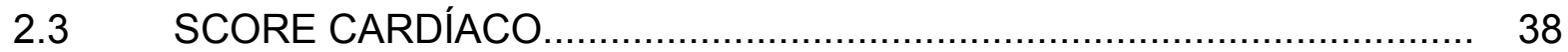

$2.4 \quad$ EIXO ELÉTRICO NO PLANO FRONTAL...................................... 40

3 MATERIAL E MÉTODOS ............................................................. 43

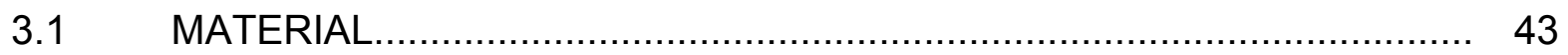

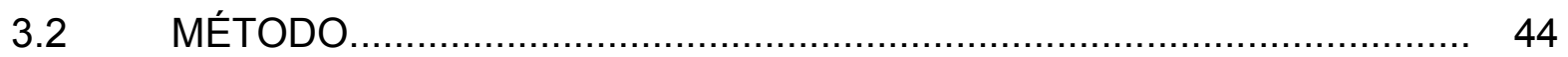

3.3 ANÁLISE ESTATÍSTICA........................................................... 48

$4 \quad$ RESULTADOS ................................................................. 49

4.1 FREQÜÊNCIA CARDÍACA ........................................................ 49

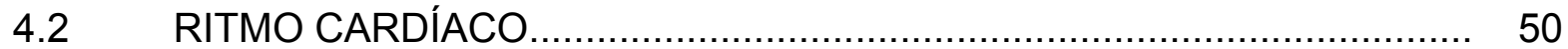

4.3 EIXO ELÉTRICO NO PLANO FRONTAL.......................................... 59

4.4 MENSURAÇÃO E MORFOLOGIA DAS ONDAS, INTERVALOS E

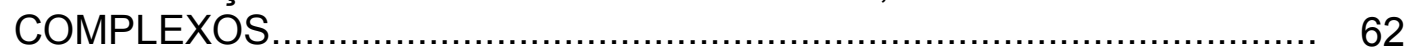

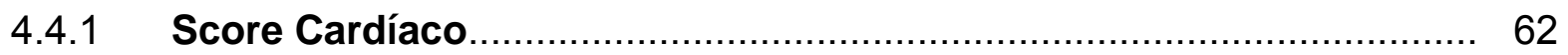

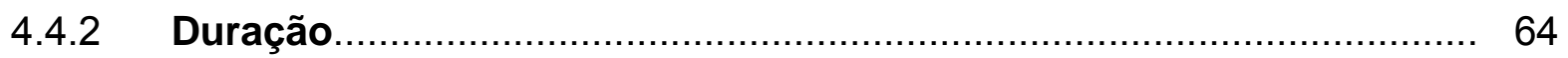

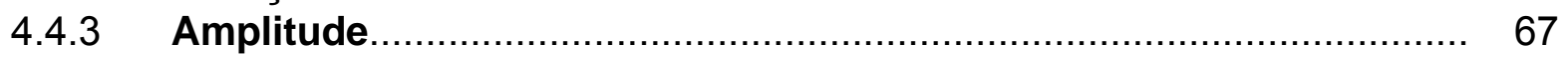

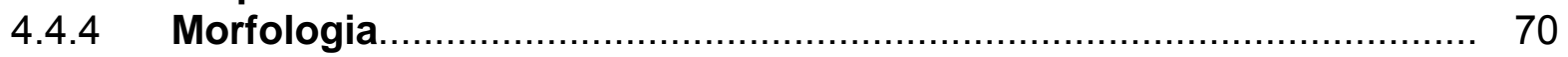

4.4.5 Análise Estatística das Variáveis: Atividade Física, Sexo e Idade...... 78

4.4.5.1 Variável Atividade Física................................................................ 78

4.4.5.2 Variável Sexo......................................................................... 82

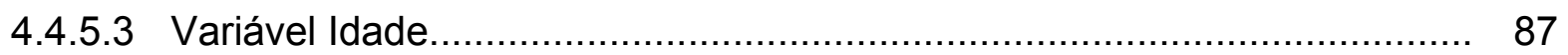

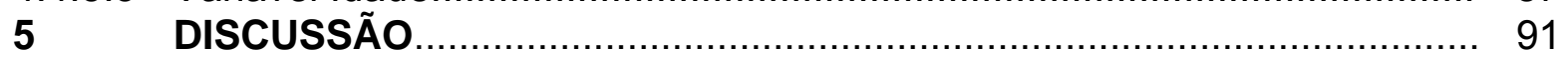

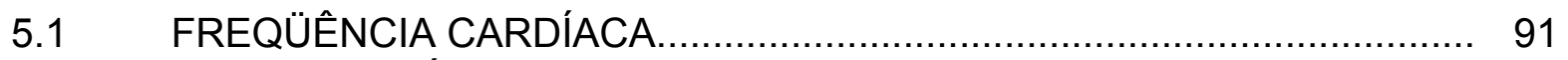

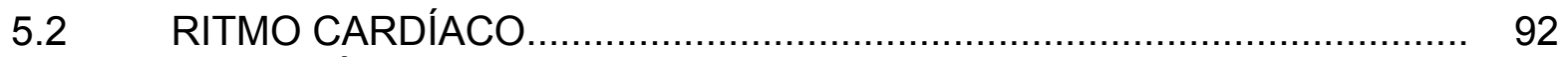

5.3 EIXO ELÉTRICO NO PLANO FRONTAL........................................... 94

5.4 MENSURAÇÃO E MORFOLOGIA DAS ONDAS, INTERVALOS E

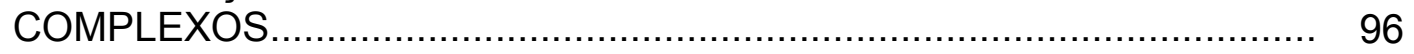

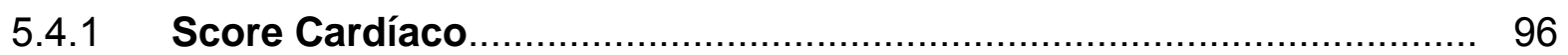

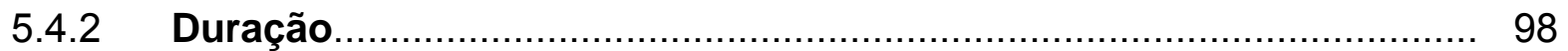

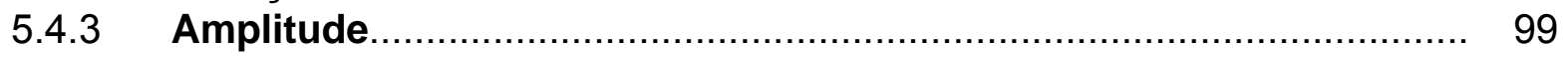

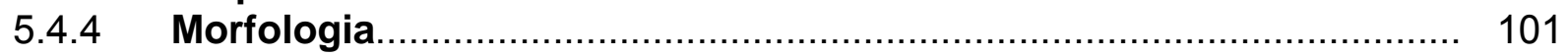

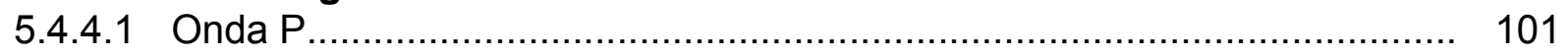

5.4.4.2 Complexo QRS ........................................................................ 103

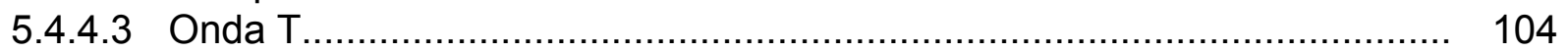

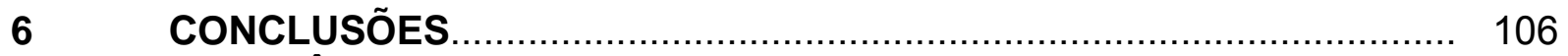

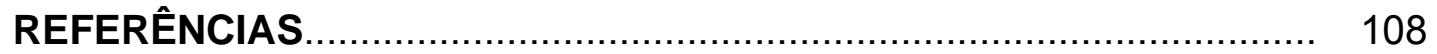

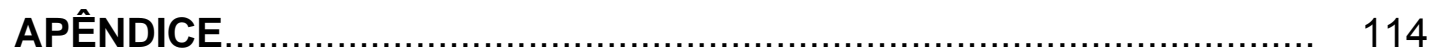




\section{INTRODUÇÃO}

O cavalo desde seu ancestral mais antigo conhecido como Eohippus, que possuía tamanho de uma raposa e quatro e três dedos respectivamente nas mãos e nos pés, sofreu grandes adaptações devido a muitos fatores inerentes à natureza, e ainda, foi obrigado a desenvolver sua velocidade para sobreviver aos ataques de outras espécies predadoras, chegando ao cavalo de hoje.

Indícios históricos confirmam que a domesticação do cavalo teve início há cinco mil anos, sendo o cavalo utilizado para transporte e trabalhos primitivos. Quando o homem descobriu a possibilidade de montá-lo, sua utilização foi decisiva para deslocamentos, caça e lutas entre povos. Até a Idade Média, a posse e o uso do cavalo eram exclusivos da aristocracia dos cavaleiros, que o empregava em guerras, em jogos e na ostentação pessoal. Além de seu emprego militar, o cavalo foi utilizado como animal de sela e de carga, para movimentação de mecanismos destinados a moer, bater os grãos ou elevar a água. Assim, o cavalo desenvolveu grande aptidão para as mais diversas atividades, tendo grande importância para as civilizações, até ser gradativamente substituído por meios mecânicos, sendo utilizados para os esportes hípicos que tiveram grande expansão a partir de então.

O Hipismo Clássico surgiu na Inglaterra, na segunda metade do século XIX, inspirado nas famosas caçadas à raposa e nas corridas em campos abertos que apresentavam obstáculos naturais. Tentou-se criar um tipo de prova que lembrasse às caçadas, mas que pudesse ser realizada em recintos menores, com obstáculos 
artificiais fixos e móveis, semelhantes àqueles naturais normalmente encontrados (cercas, muros e riachos) que o cavalo deve transpor. Assim, surgiu um esporte tido por muito tempo como de elite, mas que atualmente encontra-se bastante difundido.

O Hipismo é dividido em categorias de acordo com a idade dos cavaleiros e amazonas, variando então a altura e a largura dos obstáculos. Cada vez mais cavalo e cavaleiro devem encontrar a mais perfeita harmonia entre si, para superarem as dificuldades dos obstáculos e percursos atuais. Para isso, busca-se um eqüino com força, leveza e coragem, mas acima de tudo com aptidões físicas voltadas para o esporte.

No Brasil, o primeiro resultado expressivo do hipismo, ocorreu em 1952, nas Olimpíadas de Helsinky, com o quarto lugar do tenente coronel Eloy Menezes. Este feito foi igualado em 2000 pelo cavaleiro André Johanpeter, nas Olimpíadas de Sidney.

As medalhas de bronze conquistadas nas Olimpíadas de Sidney e Atlanta e as recentes vitórias do cavaleiro Rodrigo Pessoa, tricampeão mundial e atual campeão olímpico em Atenas 2004, marcaram definitivamente o Brasil como potência neste esporte e ajudaram a difundir o esporte, que a cada dia ganha mais adeptos.

O Brasil apresenta um futuro promissor não só pela qualidade de nossos cavaleiros, mas também pela qualidade de nossas montarias, dentre estas, vale citar o cavalo da raça Brasileiro de Hipismo $(\mathrm{BH})$, uma raça brasileira criada especialmente para esportes hípicos e que tem obtido expressivos resultados mundiais. Aproximadamente vinte raças foram utilizadas na formação do cavalo $\mathrm{BH}$, sendo as principais: animais Puro Sangue Inglês, Hanoverana, Westfalen, Holsteiner e Trakehner, além de animais sem raça definida. Apesar de ter 22 anos de seleção controlada pelo Registro Genealógico, a raça $\mathrm{BH}$ encontra-se ainda em formação, 
possibilitando a implantação de programas de melhoramento genético e necessitando de maiores estudos (DIAS et al., 2000).

No hipismo clássico, como em outros esportes hípicos, necessita-se de um eqüino de alto desempenho para suportar não só o esforço físico que o salto exige, bem como todas as tarefas de adestramento que são necessárias na execução de uma prova. O cavaleiro deve ter pleno domínio sobre as forças do cavalo e completa exploração das mesmas. Para isso, o adestramento é fundamental, restabelecendo o equilíbrio do animal, comprometido pelo peso do cavaleiro, capacitando o animal a dispor sua massa em todas as direções e sentidos, seu governo em todas as andaduras e velocidades e ainda, o equilíbrio e o domínio do cavalo pré e pós-salto (o cálculo e a execução do gesto de salto correto). Sendo assim, o cavalo deve apresentar seu sistema músculo-esquelético, respiratório e cardiovascular íntegros do ponto de vista anatômico e funcional em virtude do esforço que terão de realizar.

A cardiologia dentro da Medicina Veterinária vem assumindo grande importância no universo da medicina esportiva, não só pela detecção das alterações cardíacas, suas origens e tratamentos adequados, mas também, por estabelecer prognósticos tanto na vida atlética como na sobrevida, racionalizando a campanha atlética ou a atividade a que se destina este animal.

Esta especialidade pode ainda atuar na medicina esportiva desde o inicio da vida desses atletas, buscando identificar alterações neonatais e avaliando continuamente à resposta cardiovascular e sua evolução frente à atividade física durante todo o crescimento destes animais, na tentativa de predizer o futuro atlético de cada eqüino, otimizando assim, os investimentos em cada animal. A cardiologia deveria também ser 
utilizada no exame de compra de eqüinos atletas, visando orientar o comprador em casos de alterações pré-existentes, minimizando possíveis prejuízos.

Segundo Robertson (1992), em comparação com outras espécies domésticas, os eqüinos saudáveis têm uma alta incidência de arritmias cardíacas. Reporta-se que mais de $25 \%$ dos eqüinos sem sinais clínicos de doença cardíaca apresentam algum tipo de arritmia (MCGUIRK; MUIR, 1985). Várias destas são fisiológicas e podem ser abolidas com exercício ou excitação, porém outras podem vir acompanhadas de baixo desempenho atlético (MITTEN, 1996). Dentro das causas cardiovasculares que levam a baixa performance física, as arritmias são as mais freqüentes (REEF, 1992). Varias destas podem ser reconhecidas pela auscultação, porém só podem ser realmente confirmadas pelo exame eletrocardiográfico (BELGRAVE, 1990).

O primeiro registro eletrocardiográfico de um eqüino normal foi feito em 1910. No ano seguinte, foi publicado o primeiro caso de arritmia diagnosticada pelo Eletrocardiograma (ECG), que se tratava de um animal com fibrilação atrial. Em 1913, Nörr introduziu o eletrocardiograma na rotina clínica de eqüinos. Posteriormente, vários estudos foram e têm sido realizados na tentativa de elucidar a eletrocardiografia em eqüinos (HILWIG, 1977; LANNEK; RUTQUIST, 1951a).

A cardiologia eqüina tem se desenvolvido muito com os avanços da medicina esportiva eqüina, mas o uso do ECG ainda desperta dúvidas, pois a orientação, amplitude e duração das ondas do ECG dependem de vários fatores, incluindo idade do animal, raça, sexo, derivação examinada, tamanho das câmaras cardíacas, condicionamento físico e até mesmo da fase de ventilação (REEF, 1992).

Os padrões atuais da eletrocardiografia em eqüinos nem sempre são adequados aos animais pesquisados, devido aos fatores que podem influenciar os traçados. Estes 
padrões são determinados em animais normalmente atletas, mas não considera o tipo de atividade física exercida pelo eqüino e nem as condições ambientais e de alimentação a que este é submetido.

Tendo os cavalos de hipismo sofrido grandes adaptações orgânicas e sendo o sistema cardiovascular essencial para todas as funções vitais, talvez este também se comporte de forma diferente nestes atletas. Devemos também considerar que mesmo dentro do hipismo clássico, o esforço físico desenvolvido por um eqüino que salta obstáculos de 1,00 metro é diferente daquele que salta obstáculos de 1,50 metros. Então a utilização do ECG poderia mostrar se há diferença entre estas populações, não só em relação às afecções mais freqüentes diagnosticáveis pelo ECG, mas também qual será o perfil eletrocardiográfico destes animais e quais são as variantes que podem influenciar estes traçados. 


\section{REVISÃO DE LITERATURA}

\subsection{RITMO E FREQÜÊNCIA CARDÍACA}

Estudo retrospectivo realizado por Lannek e Rutquist (1951a), descreve que Nörr (1924) realizando eletrocardiograma em 100 eqüinos, observou alterações de condução atrioventricular em $60 \%$ dos casos, sendo o bloqueio atrioventricular (BAV) de $2^{\circ}$ grau o achado mais freqüente, e ainda, $15 \%$ dos eqüinos apresentaram extrassístoles e $6 \%$ apresentaram arritmia sinusal.

Dukes e Batt ${ }^{1}$ (1941 apud GLAZIER; DUKES, 1963a) reportam a ocorrência de batimentos ventriculares prematuros em eqüino, considerando esta arritmia de ocorrência rara nesta espécie, como já havia referido anteriormente Nöor ${ }^{2}$ (1924, apud LANNEK; RUTQUIST, 1951a; GLAZIER; DUKES, 1963a).

Nicholson $^{3}$ (1953 apud GLAZIER, 1958) foi o primeiro autor a descrever o marcapasso migratório em eqüinos como uma alteração fisiológica. Em 1958, Glazier analisando eletrocardiogramas associa a ocorrência de marcapasso migratório à arritmia sinusal pré-exercício e considera a arritmia sinusal pós-exercício como anormal para a espécie.

Glazier e Dukes (1963b) publicam um caso de bloqueio sinoatrial parcial em um eqüino de corrida, relatando que o intervalo P-R do bloqueio pode ser pouco menor que dois intervalos P-R curtos, principalmente em animais com arritmia sinusal.

\footnotetext{
${ }^{1}$ DUKES, H. H.; BATT, H. American Journal of Physiology, v.133, p.269, 1941.

${ }^{2}$ NÖOR, .Berl. tierärztl. Wschr.,v. 40, p.404, 1924.

${ }^{3}$ NICHOLSON, J. A. Irish Vet. Journal, v.7, p.122, 1953.
} 
Em 1969, Smetzer et al. confirmam a influência vagal nos bloqueios atrioventriculares de $1^{\circ}$ e $2^{\circ}$ graus, através do bloqueio anestésico do nervo vago esquerdo em um eqüino com alto grau de bloqueio atrioventricular de $2^{\circ}$ grau.

Hilwig (1977), utilizando sistema ápice-base realiza eletrocardiogramas em animais sadios e com arritmias, observando uma freqüência cardíaca de 22 a 45 batimentos por minuto (bpm) em repouso e freqüências de 35 a 60 bpm durante o exame. Aproximadamente $30 \%$ dos eqüinos normais apresentavam marcapasso migratório em repouso, mas este desaparecia durante o exercício e o bloqueio atrioventricular de $2^{\circ}$ grau esteve presente em $18 \%$ dos animais em repouso.

Em estudo realizado por Raekallio (1992), utilizando a monitoração por holter em nove eqüinos clinicamente sadios, observou-se que todos os animais apresentaram períodos de arritmia sinusal, e ainda, três apresentaram bradicardia sinusal transitória, três apresentaram períodos de taquicardia sinusal e três tiveram BAV de $2^{\circ}$ grau, sendo, aparentemente, causados por variação no sistema nervoso autônomo. Em outro estudo também utilizando holter em cinco eqüinos, verificou-se que todos os animais apresentaram arritmia sinusal, taquicardia sinusal e bloqueio atrioventricular de $2^{\circ}$ grau e um animal desenvolveu ritmo de escape ventricular (SCHEFFER; ROBBEN; SLOET VAN OLDRUITENBORGH-OOSTERBAAN, 1995).

Fernandes (1994) avalia parâmetros eletrocardiográficos de eqüinos em provas de enduro. A freqüência cardíaca média antes da prova, encontrada pelo autor em eqüinos da raça Árabe foi de 39,3 bpm, diferente dos animais da raça Mangalarga e Mestiços, nos quais os valores foram respectivamente 49 e $51 \mathrm{bpm}$.

Em estudo retrospectivo da Universidade da Pensilvânia (EUA), 348 eqüinos foram avaliados com finalidade diagnóstica, pois apresentavam queda de desempenho 
físico. Em 246 eqüinos (73,5\%) diagnosticou-se a causa para a queda de performance, sendo a afecção mais freqüente a obstrução dinâmica das vias respiratórias durante o exercício e a segunda causa mais freqüente arritmias importantes como complexos atriais e ventriculares prematuros e taquicardia ventricular (MARTIN; REEF; PARENTE, 2000).

Avaliando parâmetros eletrocardiográficos de eqüinos Puro Sangue Inglês, com idades variadas, os autores observaram ritmo sinusal normal em $100 \%$ dos potros de até um ano e freqüência cardíaca de $62,29 \mathrm{bpm}$, este ritmo foi ainda presente em $94 \%$ dos potros de sobreano, sendo observado também arritmia sinusal (2\%), taquicardia sinusal (4\%) e freqüência cardíaca média de 49,960 bpm (FERNANDES et al., 2004).

Em 1978, Rose e Davis, observaram a mesma incidência de BAV de $1^{\circ}$ e $2^{\circ} \mathrm{grau}$ em grupos de eqüinos atendidos na rotina e eqüinos com queda de desempenho físico. Em todos os casos o BAV de $2^{\circ}$ grau pode ser abolido com o uso de sulfato de atropina e depois retornavam quando a freqüência cardíaca voltava ao normal, confirmando que esta condição sofre ampla influência do tônus vagal. Este resultado foi também confirmado por King, Evans e Rose (1994), que não encontraram associação entre o BAV de $2^{\circ}$ grau e os índices cardiorespiratórios e metabólicos medidos no exame em esteira de exercício, contrariando Steel (1963), que encontrou evidências histológicas de miocardite em seis eqüinos com $\mathrm{BAV}$ de $1^{\circ}$ e $2^{\circ}$ graus.

Fregin (1982), analisando eletrocardiogramas de 40 eqüinos Puro Sangue Inglês e 40 eqüinos de trote observou diferenças significativas de amplitude e duração, em função da idade, sexo e raça, reforçando a necessidade de existir um padrão para cada raça. Os animais $\mathrm{PSI}$ apresentaram $15 \%$ de bloqueio atrioventricular de $2^{\circ}$ grau e aproximadamente $30 \%$ das duas raças apresentavam marcapasso migratório. 


\subsection{FORMAÇÃO, MORFOLOGIA, AMPLITUDE E DURAÇÃO DAS ONDAS, INTERVALOS E COMPLEXOS}

Lannek e Rutquist (1951b) publicaram trabalho com 212 eqüinos de diferentes raças e idades. Em relação aos parâmetros eletrocardiográficos de amplitude e duração, não foram encontradas diferenças estatísticas entre os grupos quanto à idade e o sexo, mas houve diferença significativa entre as raças, principalmente entre animais de sangue quente e sangue frio.

Em 1958, Glazier descreve alguns valores eletrocardiográficos de amplitude e duração para eqüinos. Dentre estes parâmetros temos: o intervalo P-R variando de 0,20 a 0,42 seg., o complexo QRS de 0,08 a 0,17 seg. e o intervalo QT de 0,46 a 0,62seg. Posteriormente, Glazier e Dukes (1964), em estudo com dezoito eqüinos com bloqueio atrioventricular de $1^{\circ} \mathrm{grau}$, encontram variação de 0,44 a 0,56 seg. e definem o BAV de $1^{\circ}$ grau em eqüinos como intervalos $P-R$ acima de $0,42 \mathrm{seg}$.

White e Rhode (1974) relacionaram alterações eletrocardiográficas às doenças com manifestações clínicas em eqüinos. Aumento de amplitude do complexo QRS foi encontrado em casos de hipertrofia cardíaca e diminuição na amplitude de QRS foi observada em animais com pleurites crônicas, efusão pericárdica, hérnia diafragmática e hipoproteínemia. Complementando estas observações, Hilwig (1977), relata que podem ocorrer alterações eletrocardiografias como mudanças na amplitude e formato das ondas $\mathrm{P}$ e $\mathrm{T}$, mudanças abruptas de polaridade da onda $\mathrm{T}$ e desvios de segmento ST após o exercício ou excitação.

Em estudo realizado com diferentes sistemas de derivação, foram avaliados 24 eqüinos da raça Andaluz. Segundo o sistema clássico com os eletrodos posicionados 
nos membros e derivação bipolar II, foi observado em $34,78 \%$ dos casos a onda P bífida, em $60,86 \%$ a onda $\mathrm{P}$ única e em $4,34 \%$ dos animais a onda $\mathrm{P}$ bifásica. $\mathrm{A}$ conformação da onda T mais freqüente foi a bifásica $(56,16 \%)$, seguida de morfologia positiva $(29,16 \%)$ e negativa (12,5\%). Quanto à amplitude, a onda P bífida apresentou um valor médio de $0,091 \mathrm{mV}$ para $\mathrm{P} 1$ e $0,180 \mathrm{mV}$ para $\mathrm{P} 2$ e ainda $0,207 \mathrm{mV}$ para $\mathrm{P}$ única (AYALA et al, 1994).

A morfologia, duração e amplitudes das ondas, intervalos e segmentos podem sofrer influências quanto à idade, raça e sexo, segundo estudo realizado com 150 eqüinos da raça Mangalarga, no qual se observou influência dos fatores etários na duração das ondas P e T (VINCENZI; LARSSON; FERNANDES, 2000b).

Segundo Steel (1963), a onda T deve ser interpretada no ECG com cautela, pois seu formato é extremamente lábil. Kroneman ${ }^{4}$ (1965 apud HOLMES; REZAKHANI, 1975) reporta que um curto período de exercício levou a onda T a ficar positiva por 1 a 1,5 minutos e que seria possível provocar esta mesma resposta apenas submetendo o animal ao susto ou barulho, concluindo que este efeito teria ação nervosa.

Alguns autores descrevem mudanças persistentes na onda $T$, associadas com altas freqüências cardíacas em eqüinos, como indício de baixa performance física.

Rose e Davis (1978), observaram alterações de onda T em quatro ou mais derivações em aproximadamente $47,3 \%$ dos eqüinos com história de queda de desempenho atlético em corridas, contra $5,6 \%$ nos eqüinos do grupo de rotina, este estudo foi confirmado por Stewart et al. (1983), que verificou ainda uma incidência significativamente maior nos animais com baixa performance de bloqueios

\footnotetext{
${ }^{4}$ KRONEMAN, J. The electrocardiogram of trained horse. Thesis, State Univ. of Utrecht, 1965.
} 
atrioventriculares de $2^{\circ}$ grau em relação aos eqüinos de rotina. Os autores ressaltam ainda, a relação entre stress e sobrecarga de treinamentos com alterações de onda $\mathrm{T}$.

Em estudo realizado por Persson e Forssberg ${ }^{5}$ (1987 apud KING; EVANS; ROSE, 1994) não foram encontradas diferenças significativas nos índices cardiorespiratórios de animais normais quando comparados a eqüinos com alterações na onda T. Em 1991, Evans relata que as alterações em ondas T no eletrocardiograma de eqüinos em repouso são uma resposta normal aos treinamentos, estas alterações poderiam desaparecer com a diminuição dos treinamentos e ressurgir com a volta da atividade física excessiva. King; Evans e Rose em 1994, também não observam diferenças significativas entre os índices cardiorespiratórios dos animais com BAV e com alterações em onda $\mathrm{T}$, indicando que alguns achados eletrocardiográficos considerados anormais podem ter pouco efeito sobre a capacidade física do animal.

Sheard (1998) observa que o número médio de alterações de onda T e a amplitude média da onda $\mathrm{T}$ aumentam com a progressão do treinamento físico, concluindo assim, que as alterações de onda T poderiam ser uma resposta fisiológica normal ao treinamento.

\footnotetext{
${ }^{5}$ PERSSON, S. G. B.; FORSSBERG, P. In: Equine exercise physiology 2. Davis: ICEEP Publications, p. $770,1987$.
} 


\subsection{SCORE CARDÍACO}

A teoria do score cardíaco foi resultante de descrições de Steel ${ }^{6}$ (1957 apud STEWART, 1981) e de posteriores estudos relacionando este score cardíaco à performance atlética e ao peso cardíaco. Assim, o score cardíaco foi definido como a média aritmética do intervalo QRS em cada uma das derivações bipolares I, II e III.

A relação entre o score cardíaco e a performance em corridas foi inicialmente estudadas por Steel ${ }^{6}$ (1957 apud STEWART, 1981), posteriormente várias pesquisas comprovaram a alta correlação entre o score cardíaco e o peso cardíaco e também comprovaram correlação entre o score cardíaco e a performance em corridas (STEEL ${ }^{7}$, 1967 apud STEWART, 1981; STEEL; STEWART, 1974). Stewart e Steel ${ }^{8}$ (1970 apud STEWART, 1981), ainda observaram diferença significativa entre o score cardíaco médio de machos e fêmeas, analisando eletrocardiogramas de 306 cavalos Puro Sangue Inglês, onde os machos apresentaram score de 111,1mseg. com desvio padrão de 0,66mseg e as fêmeas tiveram 106,9mseg. e um desvio padrão de 0,71mseg.

Em 1974, Steel e Sterwart descrevem alto score cardíaco em eqüinos vencedores de corridas na Austrália, todos os vencedores exceto um tinham score entre 120 e 136 mseg, levando a conclusão de que em esportes que tem grande demanda do sistema cardiovascular, os indivíduos que possuem alto score cardíaco apresentam melhor desempenho. Assim, o score cardíaco seria um indicador da capacidade inata do animal e de sua potencialidade.

\footnotetext{
${ }^{6}$ STEEL, J. D. Med. J. Aust., v.1, p. 78, 1957.

${ }^{7}$ STEEL, J. D. Vict. Vet. Proc., v. 25, p.84, 1967.

${ }^{8}$ STEWART, G. A.; STEEL, J. D. Proc. Am. Ass. Equine Practnr., p. 363, 1970.
} 
Estes conceitos foram também confirmados em outros esportes. Rose e Davis (1978), observaram que o score cardíaco de 10 eqüinos olímpicos de evento de três dias era de 121,0 mseg. e desvio padrão de 0,80 mseg., enquanto os animais com baixa performance apresentavam 114,0 mseg. e desvio padrão de 1,0 mseg. Rose, Ilkiw e Hodgdon (1979), estudando o eletrocardiograma de eqüinos em provas de enduro de 100 km, observaram poucas alterações eletrocardiográficas significantes, porém, os animais mais velozes obtiveram um score cardíaco significantemente superior aos cavalos menos velozes. Este fato foi atribuído segundo os autores ao tipo de exercício, onde a velocidade é relativamente menor. Em outro estudo conduzido por Illera e Illera (1987), também em eqüinos de enduro, o score cardíaco médio do time vencedor foi de 111,3 mseg. contra 106,6 mseg. do time em ultima colocação. Segundo os autores, o score cardíaco seria de grande utilidade para avaliar principalmente animais com pouca condição física (animais com score menor que 100 mseg.) para o esporte, mas este não deve ser utilizado sozinho para avaliar a aptidão de um animal para determinado esporte.

Rose, Backhouse e Ilkiw (1980) avaliaram o eletrocardiograma de 22 eqüinos que participavam de provas de três dias e observaram um aumento significativo de derivações contendo alterações em ondas $\mathrm{T}$, em cada animal após o evento. O score cardíaco destes eqüinos foi de $120 \mathrm{mseg}$., sendo portanto muito superior aos eqüinos Puro Sangue Inglês, o que poderia indicar a necessidade de alto score cardíaco para este tipo de exercício. No mesmo ano, Nielsen e Vibe-Petersen, avaliaram 230 eqüinos de trote e puderam observar que o score cardíaco aumenta com a idade e o treinamento e ainda, há uma alta correlação entre o score cardíaco alto e um menor tempo em corrida de 1 quilômetro e também há diferença entre o score cardíaco de 
machos e fêmeas. Como em pesquisas anteriores os autores relacionam o score cardíaco à combinação de fatores como a hereditariedade, a idade, o crescimento e a intensidade de treinamento físico.

Esta teoria não foi confirmada por outros autores, como Leadon et al. (1991), que pesquisaram as relações entre o score cardíaco e os achados ecocardiográficos em eqüinos Puro Sangue Inglês de um ano e relacionaram estes achados com a performance em corridas destes animais com dois e três anos. Segundo os autores, estas mensurações não foram preditivas do futuro atlético destes animais.

A diferença na duração do QRS entre raças, foi observada por Vincenzi, Larsson e Fernandes (2000b), avaliando a duração do complexo QRS em eqüinos Mangalarga, estes apresentavam valores menores do que os descritos para animais PSI, o que já havia sido relatado por outros autores em relação a eqüinos de esporte e outras raças (LANNEK; RUTQUIST, 1951b).

\subsection{EIXO ELÉTRICO NO PLANO FRONTAL}

O eixo elétrico do músculo cardíaco foi definido por Lewis $^{9}$ (1949 apud HOLMES; ALPS, 1967) como: "a linha ao longo da qual as grandes forças eletromotivas se desenvolvem num determinado instante de tempo, enquanto o músculo esta iniciando ou se recuperando do processo excitatório". Estas forças podem ser chamadas de vetores, desde que tenham magnitude e direção. O estudo dos vetores e de suas resultantes é chamado de vetocardiografia. Em pequenos animais a vetocardiografia é bastante utilizada na identificação de aumento das câmaras cardíacas e distúrbios de

\footnotetext{
${ }^{9}$ LEWIS, T. Electrocardiography and clinical disorders of the heart beat. Shaw and Sons, London. 1949.
} 
condução interventricular (EDWARDS, 1987), já em eqüinos esta área tem sido pouco explorada pelos pesquisadores.

Em 1967, Holmes e Alps, realizarem estudo com 377 eqüinos adultos das Forças Armadas e verificaram que $61 \%$ dos animais apresentavam eixo elétrico no plano frontal para o complexo QRS, variando de 0 a $+89^{\circ}$ graus. Esta variação também foi encontrada por Fregin (1982), que estudando cavalos de corrida observou $86 \%$ dos casos o eixo entre 0 e $+90^{\circ}$, sendo a amplitude de variação de -64 a $+102^{\circ}$ e ressaltou ainda a importância de se obter parâmetros específicos para as diferentes raças. O que pode ser confirmado em trabalho apresentado por Vincenzi et al (2000a) com eqüinos da raça Mangalarga, onde se pode observar que $100 \%$ dos animais apresentaram eixo de $0 \mathrm{a}+120^{\circ}$, sendo a maioria $(94,7 \%)$ com eixo entre 0 e $+90^{\circ}$.

Em trabalho realizado por Hanak (1981), utilizando 60 potros da raça Puro Sangue Inglês, pode-se observar que potros de 5 a 7 meses apresentavam eixo elétrico médio no plano frontal em torno de $3,1^{\circ}$ e com 12 meses estes apresentavam eixo de $40,72^{\circ}$. Aconteceram mudanças significativas também no período de 13 a15 meses, havendo rotação do eixo elétrico cardíaco para a direita e caudoventralmente. Neste mesmo período observa-se um aumento na magnitude do vetor ventricular, o que o autor atribuiu a alta taxa de crescimento deste período, mudando assim o tamanho e a posição do coração no tórax, estas mudanças no vetor são atribuídas em grande parte a chamada hipertrofia de crescimento do ventrículo esquerdo. A partir desta idade o eixo tendeu a se estabilizar nestes animais.

Em outro estudo, também relacionando o eixo elétrico no plano frontal com o crescimento, realizado por Ayala et al. (1998) em eqüinos da raça Andaluz, pode-se concluir que potros de 1 e 2 meses apresentam valores de eixo negativo variando de 
$-45^{\circ}$ e $-24^{\circ}$ respectivamente. A partir desta idade os animais foram apresentando eixos positivos ou tendendo a positivos. Este resultado foi corroborado por Fernandes et al. (2004) com eqüinos Puro Sangue Inglês, que observou em $53,5 \%$ dos potros de até um ano o eixo variando de +1 a $+120^{\circ}$ e $44 \%$ entre 0 e $-119^{\circ}$. Nos potros de sobreano em $83,4 \%$ dos animais o eixo variou entre $+1 \mathrm{e}+90^{\circ}$. 


\section{MATERIAL E MÉTODO}

\subsection{MATERIAL}

Foram utilizados 100 (cem) eqüinos de hipismo clássico praticantes da modalidade de salto, representados por 61 (sessenta e um) machos e 39 (trinta e nove) fêmeas. Com idades entre 4 (quatro) e 19 (dezenove) anos.

As raças analisadas foram: Anglo-árabe, Brasileira de Hipismo, Hanoverano, Holsteiner, Sela Francesa, Sela Holandesa, Sela Belga, Zangerchaid, Westfalen, Odemburgo e animais sem raça definida (SRD).

Os eqüinos foram agrupados em duas classes, de acordo com a capacidade atlética, sendo o grupo 1 composto por 56 (cinqüenta e seis) animais que saltam até 1,20 metros e o grupo 2 composto por 44 (quarenta e quatro) animais que saltam acima de 1,20 metros.

Os traçados eletrocardiográficos foram realizados nos eqüinos alojados na Sociedade Hípica Paulista e Clube Hípico de Santo Amaro, no período de março de 2003 a outubro de 2004 .

Os exames foram realizados nas próprias cocheiras dos animais, sendo utilizado tapetes de borracha no piso, com intuito de minimizar possíveis interferências nos traçados. Foi utilizado um aparelho de eletrocardiografia portátil FUNBEC (ECG-4), composto por 6 canais, 3 sensibilidades e velocidades de $25 \mathrm{~mm} / \mathrm{s}$ e $50 \mathrm{~mm} / \mathrm{s}$ (Figura 1). 


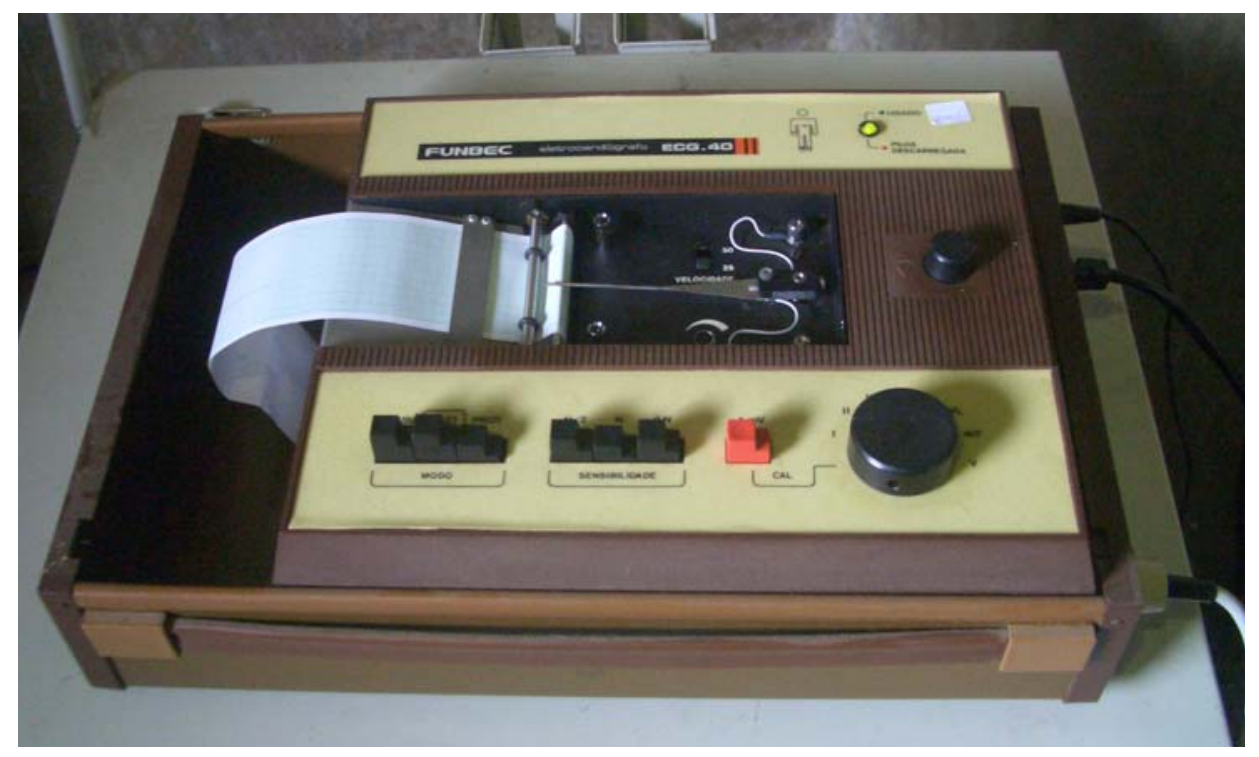

Figura 1 - Imagem do aparelho de eletrocardiografia portátil FUNBEC (ECG-4), com 6 canais, 3 sensibilidades e velocidades de $25 \mathrm{~mm} / \mathrm{s}$ e $50 \mathrm{~mm} / \mathrm{s}$

\subsection{MÉTODO}

Os eqüinos foram identificados por fichas individuais, onde foram descritos todos os dados pertinentes à pesquisa.

Após exames clínicos e cardiovasculares, de inspeção, avaliação das mucosas, auscultação cardíaca e pulmonar, aferição de freqüência cardíaca e pulmonar, avaliação do turgor cutâneo e tempo de preenchimento capilar, foram realizados os exames eletrocardiográficos. Os registros foram feitos com os animais em posição ortostática, sem qualquer tranqüilização. O aparelho foi selecionado para que o papel estivesse numa velocidade de $25 \mathrm{~mm} / \mathrm{s}$ e uma sensibilidade de $1 \mathrm{~cm}=\mathrm{mV}$. Foram registradas a derivações bipolares I, II e III, derivações unipolares amplificadas (aVR, $\mathrm{aVF}, \mathrm{aVL})$. 
Os eletrodos foram colocados sobre a pele, nos membros torácicos e pélvicos, para a análise das derivações bipolares e unipolares amplificadas, segundo Patteson (1996). Os eletrodos de cor amarela e vermelha ficaram posicionados nos membros anteriores esquerdo e direito, respectivamente, próximos às articulações úmero-radioulnares. Os eletrodos de cor verde e preta foram posicionados nos membros posteriores esquerdo e direito, respectivamente, próximos às articulações fêmoro-tíbiopatelares. Durante todo o exame, os membros foram posicionados de forma perpendicular ao dorso do animal e paralelos entre si (Figuras 2 , 3 e 4).

Os eletrodos foram conectados à pele do animal por meio de condutores metálicos (clipes tipo jacaré), após a colocação de um algodão embebido em álcool.

A freqüência cardíaca e o ritmo cardíaco foram determinados na derivação DII, em velocidade de $25 \mathrm{~mm} / \mathrm{s}$. A amplitude das ondas foi mensurada em milivoltz $(\mathrm{mV})$ nas derivações bipolares I, II e III, e nas derivações unipolares aumentadas aVR, aVL e aVF, verificando-se a amplitude das ondas $\mathrm{P}$ positivas, negativas e bifásicas, do complexo QRS, das ondas $Q, R$ e $S$ e das ondas T positivas, negativas e bifásicas.

A duração das ondas e complexos foi calculada em segundos (seg.), nas derivações bipolares I, II e III, e nas derivações unipolares aumentadas aVR, aVL e aVF, avaliando-se a duração da onda $P$, intervalo $P-R$, complexo $Q R S$, intervalo $Q-T$ e onda $\mathrm{T}$.

As morfologias da onda $\mathrm{P}$, complexo QRS, segmento ST e onda $T$, foram observadas nas derivações bipolares I, II, e III e nas derivações unipolares aumentadas aVR, aVL e aVF. 


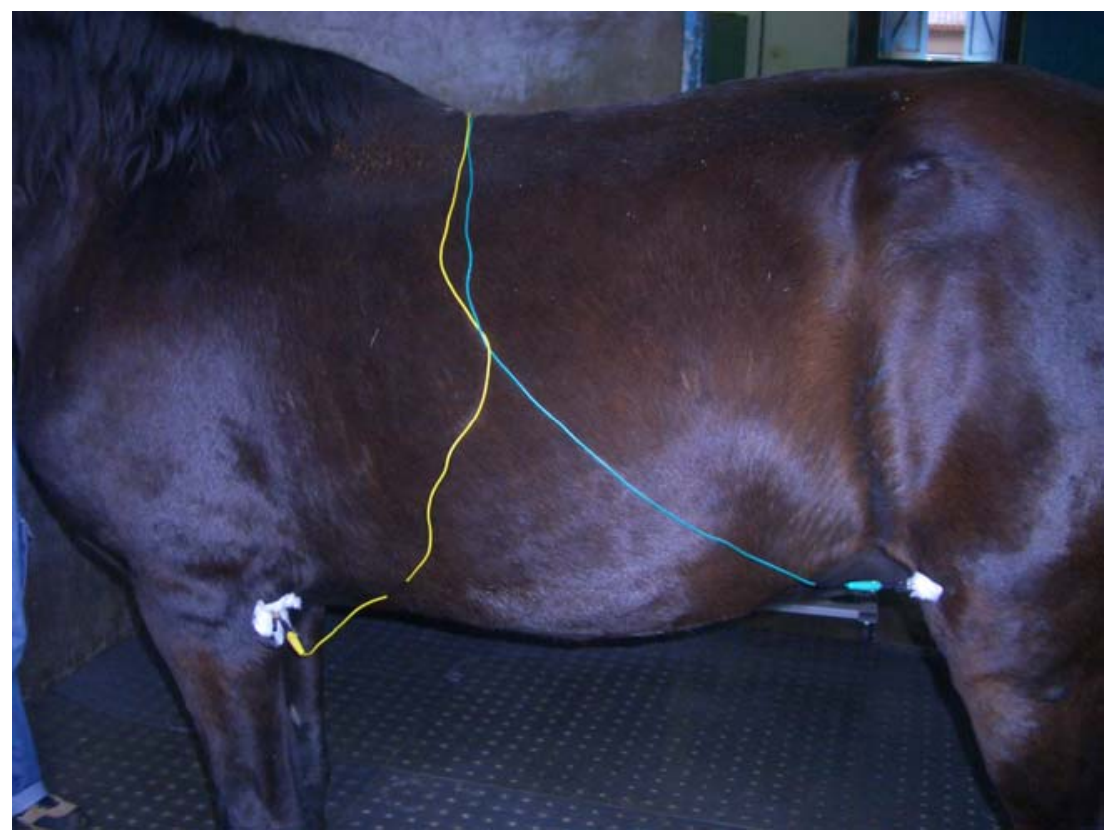

Figura 2 - Imagem do posicionamento dos eletrodos nos membros anteriores próximos às articulações úmero-radio-ulnares e nos membros posteriores próximos às articulações fêmoro-tíbio-patelares, São Paulo - SP - 2006

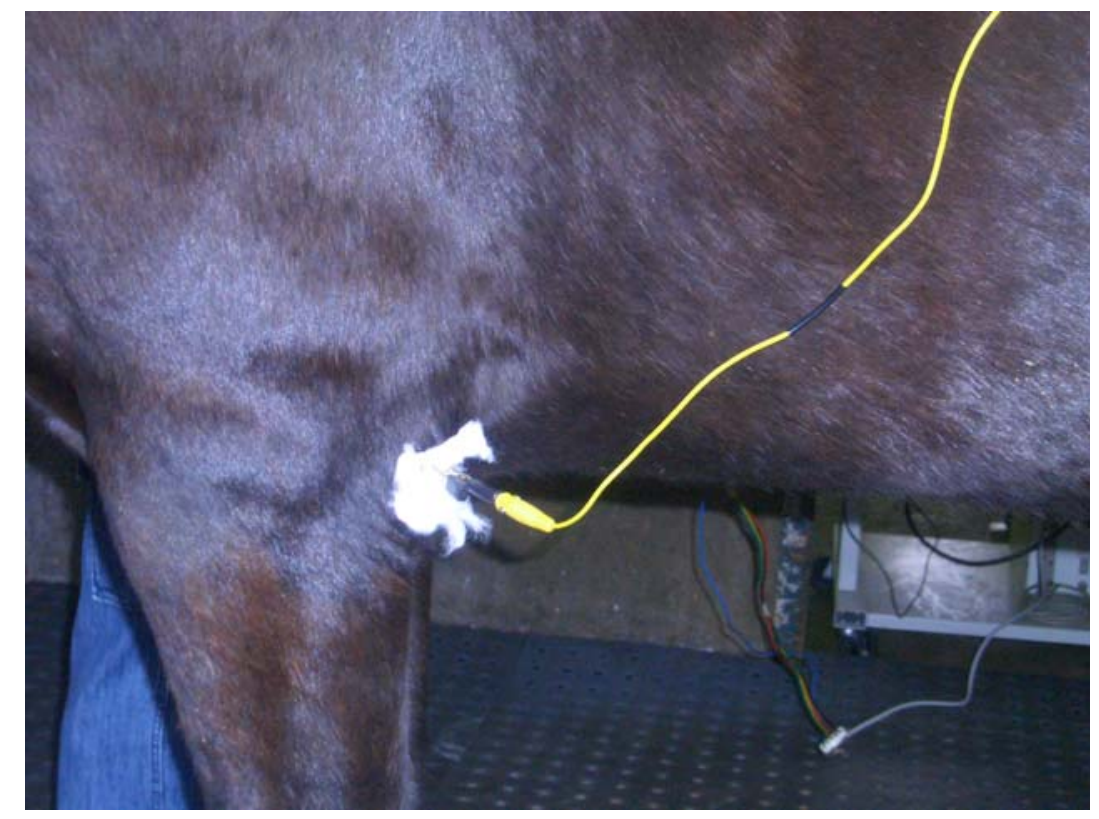

Figura 3 - Imagem do posicionamento do eletrodo amarelo no membro anterior próximo à articulação úmero-radio-ulnar, São Paulo - SP - 2006 


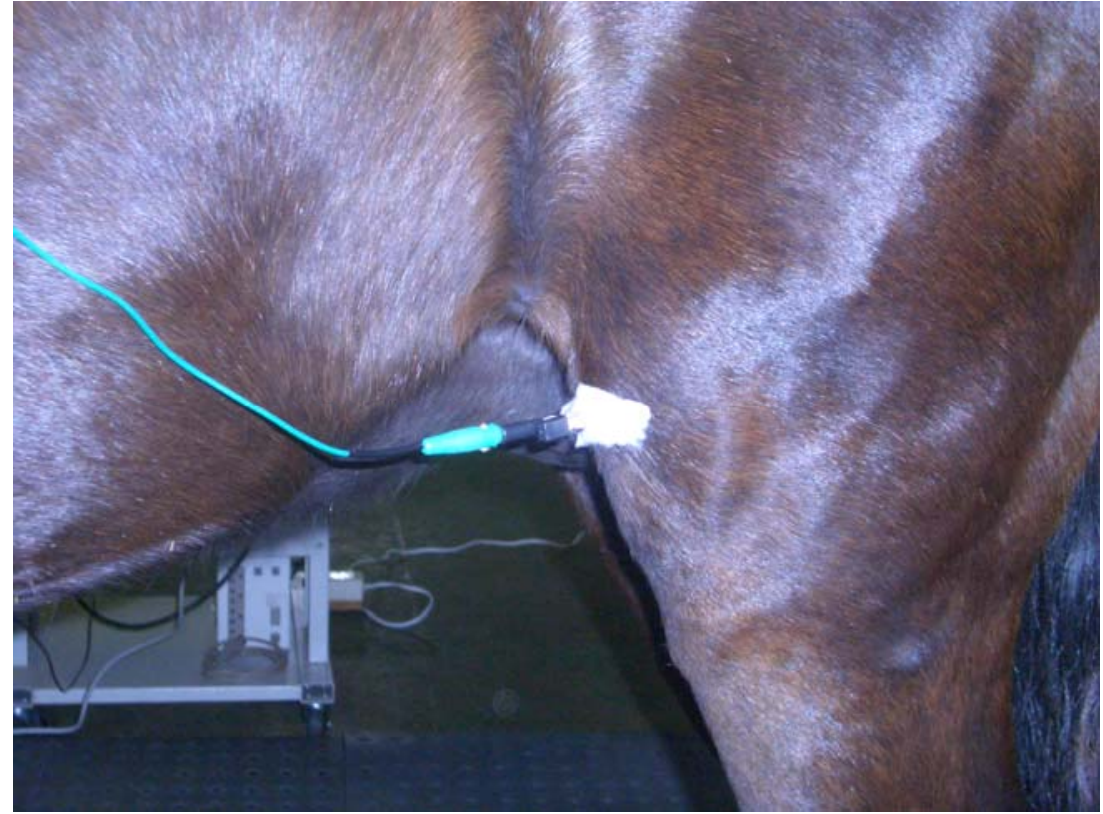

Figura 4 - Imagem do posicionamento do eletrodo verde no membro posterior próximo à articulação fêmoro-tíbio-patelar, São Paulo - SP - 2006 


\subsection{ANÁLISE ESTATÍSTICA}

Calcularam-se as seguintes medidas de tendência central: média, desvio padrão, amplitude de variação, mediana, moda e coeficiente de variação, para as variáveis numéricas de amplitude e duração das ondas, complexos e intervalos e ainda, freqüência cardíaca e score cardíaco.

Os cálculos foram feitos através do programa estatístico Epi info ${ }^{1}$. Realizou-se o teste ANOVA (ou t para amostras independentes) para comparação entre grupos das variáveis numéricas complementados pelo teste de Tukey, e pelo teste Qui-quadrado para as variáveis qualitativas, considerando-se o nível de significância de $5 \%(p \leq 0,05)$. Também avaliou-se as influências relacionadas aos fatores de capacidade atlética, sexuais e etários.

\footnotetext{
${ }^{1}$ Epi Info Software, versão 3.3.2, 2004.
} 


\section{RESULTADOS}

\subsection{FREQÜÊNCIA CARDÍACA}

Os valores médios, desvio padrão, valor mínimo, valor máximo, mediana e moda da freqüência cardíaca estão dispostos em quatro tabelas a seguir (Tabelas 1 a 4). Não houve diferença estatística nesta variável quanto ao grupo de atividade física, faixa etária e idade. Os dados individuais estão apresentados no apêndice A.

Tabela 1 - Valores médios, desvio padrão, valor mínimo, valor máximo, mediana e moda da freqüência cardíaca (bpm) segundo eletrocardiograma de 100 eqüinos de salto, na cidade de São Paulo - SP - 2006

\begin{tabular}{lc}
\hline Freqüência Cardíaca & $\mathbf{N}=\mathbf{1 0 0}$ \\
\hline Média & 40,2077 \\
Desvio Padrão & 13,3321 \\
Valor mínimo & 18,5000 \\
Valor máximo & 89,4500 \\
Mediana & 36,5800 \\
Moda & 33,0000 \\
\hline
\end{tabular}

Tabela 2 - Valores médios, desvio padrão, valor mínimo, valor máximo, mediana e moda da freqüência cardíaca (bpm) do eletrocardiograma de 100 eqüinos de salto criados na cidade de São Paulo, agrupados segundo atividade física - SP - 2006

\begin{tabular}{lcc}
\hline & \multicolumn{2}{c}{ Grupo de Atividade Física } \\
\cline { 2 - 3 } Freqüência Cardíaca & $\begin{array}{c}\text { Grupo 1 } \\
\text { (N=56) }\end{array}$ & $\begin{array}{c}\text { Grupo 2 } \\
\text { (N=44) }\end{array}$ \\
\hline Média & 38,6081 & 42,2434 \\
Desvio Padrão & 14,0672 & 12,1877 \\
Valor mínimo & 18,5000 & 26.3100 \\
Valor máximo & 89,4500 & 83,3300 \\
Mediana & 34,5000 & 40,5200 \\
Moda & 33,0000 & 27,0000 \\
\hline
\end{tabular}

Nota: Grupo 1 (eqüinos que saltam até 1,20m), grupo 2 (eqüinos que saltam acima de 1,20m). Não houve diferença estatística entre os grupos 1 e $2(t=1,3593$ e $p=0,1772)$. 
Tabela 3 - Valores médios, desvio padrão, valor mínimo, valor máximo, mediana e moda da freqüência cardíaca (bpm) do eletrocardiograma de 100 eqüinos de salto criados na cidade de São Paulo, agrupados por sexo - SP - 2006

\begin{tabular}{lcc}
\hline \multirow{2}{*}{ Freqüência Cardíaca } & \multicolumn{2}{c}{ Sexo } \\
\cline { 2 - 3 } & $\begin{array}{c}\text { Machos } \\
\mathbf{( N = 6 1 )}\end{array}$ & $\begin{array}{c}\text { Fêmeas } \\
\mathbf{( N = 3 9 )}\end{array}$ \\
\hline Média & 39,3835 & 41,4967 \\
Desvio Padrão & 13,4350 & 13,2392 \\
Valor mínimo & 18,5000 & 25,0900 \\
Valor máximo & 83,3300 & 89,4500 \\
Mediana & 36,4600 & 38,5000 \\
Moda & 33,0000 & 35,0000 \\
\hline
\end{tabular}

Nota: Não houve diferença estatística entre os grupos segundo sexo $(t=0,7715$ e $p=0,4423)$.

Tabela 4 - Valores médios, desvio padrão, valor mínimo, valor máximo, mediana e moda da freqüência cardíaca (bpm) do eletrocardiograma de 100 eqüinos de salto criados na cidade de São Paulo, agrupados segundo faixa etária - SP - 2006

\begin{tabular}{lccc}
\hline \multirow{2}{*}{ Freqüência cardíaca } & \multicolumn{3}{c}{ Idade } \\
\cline { 2 - 4 } & $\begin{array}{c}\mathbf{4} \text { a } \mathbf{8} \text { anos } \\
\mathbf{( N = 3 3 )}\end{array}$ & $\begin{array}{c}\mathbf{9} \text { a 13 anos } \\
\mathbf{( N = 5 3 )}\end{array}$ & $\begin{array}{c}\mathbf{1 4} \text { a 19 anos } \\
\mathbf{( N = 1 4 )}\end{array}$ \\
\hline Média & 41,4950 & 39,2968 & 40,6214 \\
Desvio padrão & 16,2112 & 11,2373 & 13,9214 \\
Valor mínimo & 18,5000 & 25,0000 & 30,0000 \\
Valor máximo & 89,4500 & 72,0500 & 75,3000 \\
Mediana & 37,5000 & 36,5800 & 34,1150 \\
Moda & 41,0000 & 35,0000 & 30,0000 \\
\hline Nota: Não houve diferença estatística entre os grupos por faixa etária $(\mathrm{F}=0,2801$ e $\mathrm{p}=0,7563)$.
\end{tabular}

Nota: Não houve diferença estatística entre os grupos por faixa etária $(F=0,2801$ e $p=0,7563)$.

\subsection{RITMO CARDÍACO}

Os resultados dos ritmos encontrados nos cem eqüinos encontram-se dispostos na tabela 5. Não houve diferença estatística entre os grupos segundo atividade física, sexo ou faixa etária, os resultados estão dispostos nas tabelas 6,7 e 8 , respectivamente. 
Os resultados individuais de ritmo obtidos pelo eletrocardiograma dos cem eqüinos encontram-se no apêndice $A$.

As alterações de ritmo cardíaco encontradas nos cem animais estão apresentadas na tabela 9 e as alterações de ritmo cardíaco segundo grupo de atividade física, sexo e idade encontram-se nas tabelas 10,11,12 e 13. Não houve diferença estatística entre nenhum dos grupos estudados.

As figuras 5 a 17 apresentam trechos de eletrocardiogramas ilustrando os ritmos e alterações encontradas nos eqüinos do presente estudo.

Tabela 5 - Freqüência e porcentagem dos ritmos cardíacos obtidos pelo eletrocardiograma de 100 eqüinos de salto criados na cidade de São Paulo - SP - 2006

\begin{tabular}{lcc}
\hline Ritmo cardíaco & $\begin{array}{c}\text { Freqüência } \\
(\mathbf{N})\end{array}$ & $\begin{array}{c}\text { Porcentagem } \\
(\%)\end{array}$ \\
\hline Sinusal normal & 56 & 56,0 \\
Taquicardia sinusal & 23 & 23,0 \\
Arritmia sinusal & 20 & 20,0 \\
Bradicardia sinusal & 1 & 1,0 \\
\hline Total & 100 & 100,0 \\
\hline
\end{tabular}

Tabela 6 - Freqüência e porcentagem dos ritmos cardíacos obtidos pelo eletrocardiograma de 100 eqüinos de salto criados na cidade de São Paulo, agrupados segundo atividade física - SP - 2006

\begin{tabular}{lccc}
\hline \multirow{2}{*}{ Ritmo cardíaco } & \multicolumn{3}{c}{ Grupo de Atividade Física } \\
\cline { 2 - 4 } & $\begin{array}{c}\text { Freqüência } \\
(\mathbf{N})\end{array}$ & $\begin{array}{c}\text { Grupo 1 } \\
\text { (\%) }\end{array}$ & $\begin{array}{c}\text { Grupo 2 } \\
\text { (\%) }\end{array}$ \\
\hline Sinusal normal & 56 & 59,0 & 41,0 \\
Arritmia sinusal & 20 & 60,0 & 40,0 \\
Taquicardia sinusal & 23 & 43,0 & 57,0 \\
Bradicardia sinusal & 1 & 100,0 & - \\
\hline Total & 100 & 56,0 & 44,0 \\
\hline
\end{tabular}

Nota: Não houve diferença estatística entre os grupos 1 e $2\left(x^{2}=2,5741, p=0,4621\right.$, graus de liberdade=3). 
Tabela 7 - Freqüência e porcentagem dos ritmos cardíacos obtidos pelo eletrocardiograma de 100 eqüinos de salto criados na cidade de São Paulo, agrupados por sexo $\mathrm{SP}-2006$

\begin{tabular}{lccc}
\hline \multirow{2}{*}{ Ritmo cardíaco } & \multicolumn{3}{c}{ Sexo } \\
\cline { 2 - 4 } & $\begin{array}{c}\text { Freqüência } \\
(\mathbf{N})\end{array}$ & $\begin{array}{c}\text { Fêmeas } \\
(\%)\end{array}$ & $\begin{array}{c}\text { Machos } \\
\text { (\%) }\end{array}$ \\
\hline Sinusal normal & 56 & 34,0 & 66,0 \\
Arritmia sinusal & 20 & 50,0 & 50,0 \\
Taquicardia sinusal & 23 & 43,0 & 57,0 \\
Bradicardia sinusal & 1 & - & 100,0 \\
\hline Total & 100 & 39,0 & 61,0 \\
\hline
\end{tabular}

Nota: Não houve diferença estatística entre os grupos segundo sexo $\left(x^{2}=2,4559, p=0,4833\right.$, graus de liberdade $=3$ )

Tabela 8 - Freqüência e porcentagem dos ritmos cardíacos, obtidos pelo eletrocardiograma de 100 eqüinos de salto criados na cidade de São Paulo, agrupados segundo faixa etária $-\mathrm{SP}-2006$

\begin{tabular}{|c|c|c|c|c|c|c|c|c|}
\hline \multirow{3}{*}{ Ritmo cardíaco } & \multicolumn{4}{|c|}{ IDADE } & \multirow{2}{*}{\multicolumn{2}{|c|}{14 a 19 anos }} & \multirow{2}{*}{\multicolumn{2}{|c|}{ TOTAL }} \\
\hline & \multicolumn{2}{|c|}{4 a 8 anos } & \multicolumn{2}{|c|}{9 a 13 anos } & & & & \\
\hline & $\mathbf{N}$ & $\%$ & $\mathbf{N}$ & $\%$ & $\mathbf{N}$ & $\%$ & $\mathbf{N}$ & $\%$ \\
\hline Sinusal normal & 16 & 28,5 & 30 & 53,5 & 10 & 18,0 & 56 & 100,0 \\
\hline Arritmia sinusal & 7 & 35,0 & 12 & 60,0 & 1 & 5,0 & 20 & 100,0 \\
\hline Taquicardia sinusal & 9 & 39,1 & 11 & 47,9 & 3 & 13,0 & 23 & 100,0 \\
\hline Bradicardia sinusal & 1 & 100,0 & - & - & - & - & 1 & 100,0 \\
\hline Total & 33 & 33,0 & 53 & 53,0 & 14 & 14,0 & 100 & 100,0 \\
\hline
\end{tabular}

Tabela 9 - Porcentagem das alterações do ritmo cardíaco encontradas no eletrocardiograma de 100 eqüinos de salto criados na cidade de São Paulo- SP - 2006

\begin{tabular}{lc}
\hline Alterações do ritmo cardíaco & Porcentagem (\%) \\
\hline Marcapasso migratório & 22,0 \\
Bloqueio atrioventricular de $1^{\circ} \mathrm{grau}$ & 3,0 \\
Bloqueio atrioventricular de $2^{\circ} \mathrm{grau}$ & 4,0 \\
Bloqueio atrioventricular de $1^{\circ} \mathrm{e} 2^{\circ} \mathrm{grau}$ & 3,0 \\
Marcapasso migratório e bloqueio atrioventricular de $2^{\circ} \mathrm{grau}$ & 1,0 \\
Marcapasso migratório e bloqueio atrioventricular de $1^{\circ} \mathrm{e} 2^{\circ} \mathrm{grau}$ & 1,0 \\
Marcapasso migratório e "sinus arrest" & 1,0 \\
Contração atrial prematura & 1,0 \\
Contração ventricular prematura & 2,0 \\
Sem alterações & 62,0 \\
\hline Total & 100,0 \\
\hline
\end{tabular}


Tabela 10 - Freqüência e porcentagem das alterações do ritmo cardíaco encontradas no eletrocardiograma de 100 eqüinos de salto criados na cidade de São Paulo, agrupados segundo atividade física - SP - 2006

\begin{tabular}{|c|c|c|c|c|c|c|}
\hline \multirow{3}{*}{ Alterações do ritmo cardíaco } & \multicolumn{6}{|c|}{ Grupo de Atividade Física } \\
\hline & \multicolumn{2}{|c|}{$\begin{array}{l}\text { Grupo } 1 \\
(\mathrm{~N}=56)\end{array}$} & \multicolumn{2}{|c|}{$\begin{array}{c}\text { Grupo } 2 \\
(\mathrm{~N}=44)\end{array}$} & \multicolumn{2}{|c|}{$\begin{array}{c}\text { Total } \\
(\mathrm{N}=100)\end{array}$} \\
\hline & $\mathbf{N}^{\mathbf{0}}$ & $\%$ & $\mathrm{~N}^{\circ}$ & $\%$ & $\mathbf{N}^{\mathbf{0}}$ & $\%$ \\
\hline Marcapasso migratório & 17 & 30,36 & 8 & $\overline{18,18}$ & 25 & 25,00 \\
\hline Bloqueio atrioventricular de $2^{\circ} \mathrm{grau}$ & 6 & 10,71 & 3 & 6,82 & 9 & 9,00 \\
\hline Bloqueio atrioventricular de $1^{\circ} \mathrm{grau}$ & 3 & 5,36 & 4 & 9,09 & 7 & 7,00 \\
\hline Bloqueio sinoatrial/"sinus arrest" & 1 & 1,79 & - & - & 1 & 1,00 \\
\hline Contração atrial prematura & 1 & 1,79 & _ & - & 1 & 1,00 \\
\hline Contração ventricular prematura & - & - & 2 & 4,55 & 2 & 2,00 \\
\hline
\end{tabular}

Tabela 11 - Freqüência e porcentagem das alterações do ritmo cardíaco encontradas no eletrocardiograma de 100 eqüinos de salto criados na cidade de São Paulo agrupados segundo atividade física - SP -2006

\begin{tabular}{|c|c|c|c|}
\hline \multirow[b]{2}{*}{ Alterações do ritmo cardíaco } & \multicolumn{3}{|c|}{ Grupo de Atividade Física } \\
\hline & $\begin{array}{l}\text { Freqüência } \\
\text { (N) }\end{array}$ & $\begin{array}{c}\text { Grupo } 1 \\
(\%)\end{array}$ & $\begin{array}{c}\text { Grupo } 2 \\
(\%)\end{array}$ \\
\hline Marcapasso migratório & 22 & 63,6 & 36,4 \\
\hline Bloqueio AV de $1^{\circ} \mathrm{grau}$ & 3 & 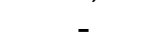 & 100,0 \\
\hline Bloqueio AV de $2^{\circ}$ grau & 4 & 50,0 & 50,0 \\
\hline Bloqueio $\mathrm{AV}$ de $1^{\circ}$ e $2^{\circ} \mathrm{grau}$ & 3 & 66,7 & 33,3 \\
\hline Marcapasso migratório e bloqueio $\mathrm{AV}$ de $1^{\circ}$ e $2^{\circ} \mathrm{grau}$ & 1 & 100,0 & - \\
\hline Marcapasso migratório e bloqueio AV de $2^{\circ}$ grau & 1 & 100,0 & - \\
\hline Marcapasso migratório e "sinus arrest" & 1 & 100,0 & - \\
\hline Contração atrial prematura & 1 & 100,0 & - \\
\hline Contração ventricular prematura & 2 & - & 100,0 \\
\hline Sem alterações & 62 & 54,8 & 45,2 \\
\hline Total & 100 & 56,0 & 44,0 \\
\hline
\end{tabular}

Nota: Não houve diferença estatística entre os grupos 1 e $2\left(x^{2}=10,2581, p=0,3300\right.$, graus de liberdade= 9). 
Tabela 12 - Freqüência e porcentagem das alterações do ritmo cardíaco encontradas no eletrocardiograma de 100 eqüinos de salto criados na cidade de São Paulo, agrupados por sexo - SP - 2006

\begin{tabular}{lccc}
\hline \multirow{2}{*}{ Alterações do ritmo cardíaco } & \multicolumn{3}{c}{ SEXO } \\
\cline { 2 - 4 } & $\begin{array}{c}\text { Freqüência } \\
(\mathbf{N})\end{array}$ & $\begin{array}{c}\text { Machos } \\
\text { (\%) }\end{array}$ & $\begin{array}{c}\text { Fêmeas } \\
\text { (\%) }\end{array}$ \\
\hline Marcapasso migratório & 22 & 59,1 & 40,9 \\
Bloqueio AV de $1^{\circ}$ grau & 3 & 66,7 & 33,3 \\
Bloqueio AV de $2^{\circ}$ grau & 4 & 25,0 & 75,0 \\
Bloqueio AV $1^{\circ}$ e $2^{\circ}$ grau & 3 & 33,3 & 66,7 \\
Marcapasso migratório e bloqueio AV de $1^{\circ}$ e $2^{\circ}$ grau & 1 & 100,0 & - \\
Marcapasso migratório e bloqueio AV de $2^{\circ}$ grau & 1 & - & 100,0 \\
Marcapasso migratório e "sinus arrest" & 1 & - & 100,0 \\
Contração atrial prematura & 1 & 100,0 & - \\
Contração ventricular prematura & 2 & 50,0 & 50,0 \\
Sem alterações & 62 & 66,1 & 33,9 \\
\hline Total & 100 & 61,0 & 39,0 \\
\hline
\end{tabular}

Nota: Não houve diferença estatística entre os grupos segundo sexo $\left(x^{2}=8,4127, p=0,4931\right.$, graus de liberdade $=9$ ).

Tabela 13 - Freqüência e porcentagem das alterações do ritmo cardíaco encontradas no eletrocardiograma de 100 eqüinos de salto criados na cidade de São Paulo agrupados segundo faixa etária - SP - 2006

\begin{tabular}{|c|c|c|c|c|}
\hline \multirow[b]{2}{*}{ Alterações do ritmo cardíaco } & \multicolumn{4}{|c|}{ IDADE } \\
\hline & $\begin{array}{l}\text { Freq. } \\
\text { (N) }\end{array}$ & $\begin{array}{c}4 \text { a } 8 \\
\text { anos } \\
(\%)\end{array}$ & $\begin{array}{c}9 \text { a } 13 \\
\text { anos } \\
(\%)\end{array}$ & $\begin{array}{c}14 \text { a } 19 \\
\text { anos } \\
(\%)\end{array}$ \\
\hline Marcapasso migratório & 22 & 27,3 & 59,1 & 13,6 \\
\hline Bloqueio AV de $1^{\circ} \mathrm{grau}$ & 3 & 33,3 & 33,3 & 33,3 \\
\hline Bloqueio $\mathrm{AV}$ de $2^{\circ} \mathrm{grau}$ & 4 & 25,0 & 75,0 & - \\
\hline Bloqueio $\mathrm{AV}$ de $1^{\circ}$ e $2^{\circ} \mathrm{grau}$ & 3 & 33,3 & 66,7 & - \\
\hline Marcapasso migrat. e bloqueio $\mathrm{AV}$ de $2^{\circ}$ grau & 1 & - & 100,0 & - \\
\hline Marcapasso migrat. e bloqueio $\mathrm{AV}$ de $1^{\circ}$ e $2^{\circ} \mathrm{grau}$ & 1 & - & 100,0 & - \\
\hline Marcapasso migratório e "sinus arrest" & 1 & 100,0 & - & - \\
\hline Contração atrial prematura & 1 & - & - & 100,0 \\
\hline Contração ventricular prematura & 2 & 50,0 & 50,0 & - \\
\hline Sem alterações & 62 & 35,5 & 50,0 & 14,5 \\
\hline Total & 100 & 33,0 & 53,0 & 14,0 \\
\hline
\end{tabular}




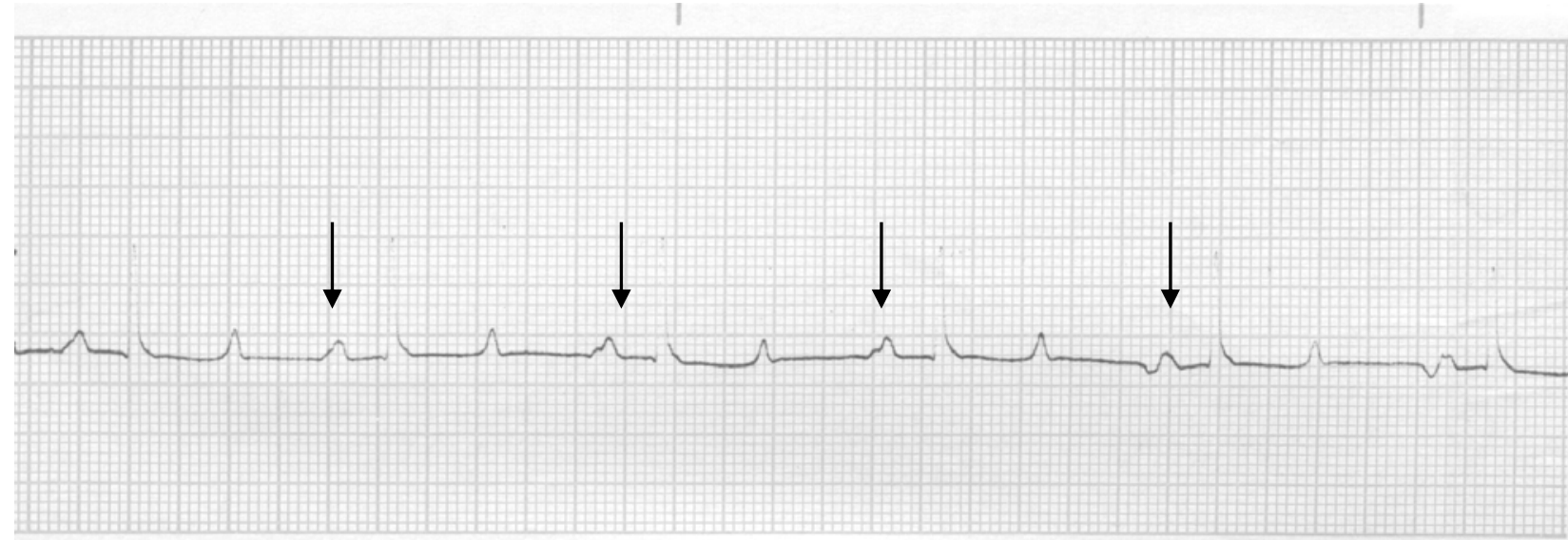

Figura 5 - Eletrocardiograma de eqüino macho da raça $\mathrm{BH}$ com 10 anos, apresentando marcapasso migratório na derivação bipolar II

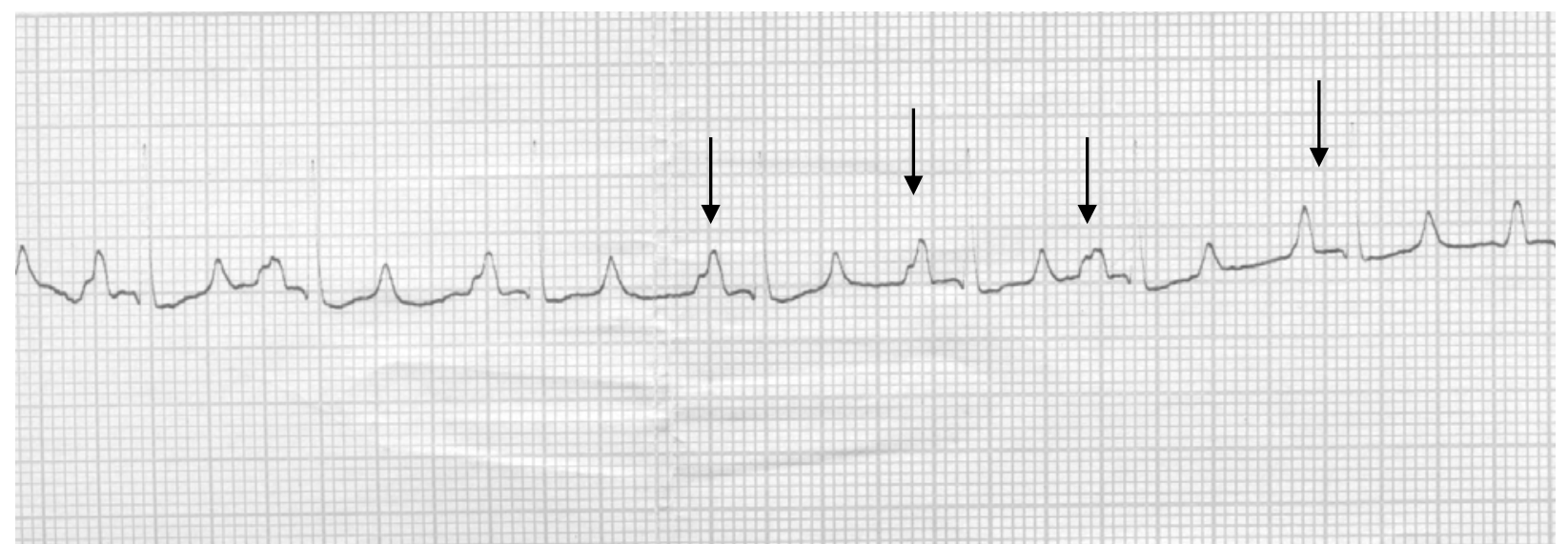

Figura 6 - Eletrocardiograma de eqüino fêmea da raça $\mathrm{BH}$ com 5 anos, apresentando marcapasso migratório na derivação bipolar II e taquicardia sinusal ( $F C=83,33 b p m)$

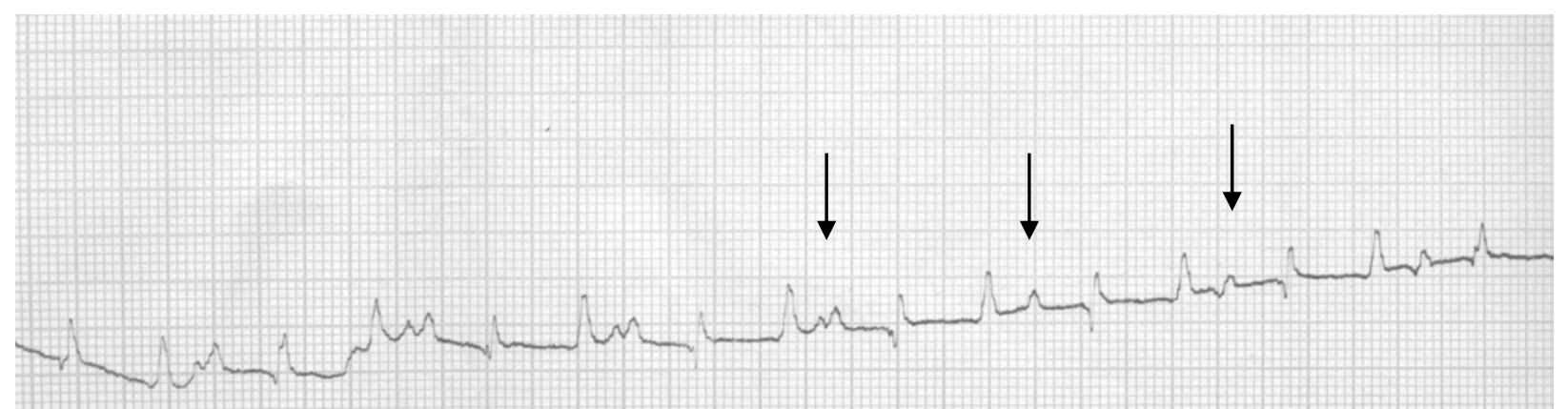

Figura 7 - Eletrocardiograma de eqüino macho da raça $\mathrm{BH}$ com 6 anos, apresentando marcapasso migratório na derivação bipolar I e taquicardia sinusal ( $F C=57,69 b p m)$ 


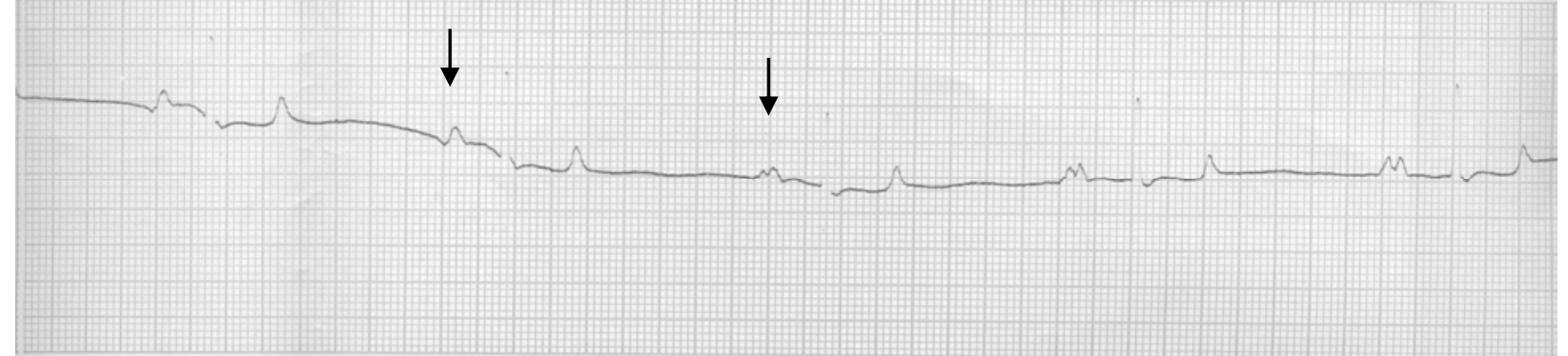

Figura 8 - Eletrocardiograma de eqüino macho da raça $\mathrm{BH}$ com 9 anos, apresentando marcapasso migratório na derivação bipolar II

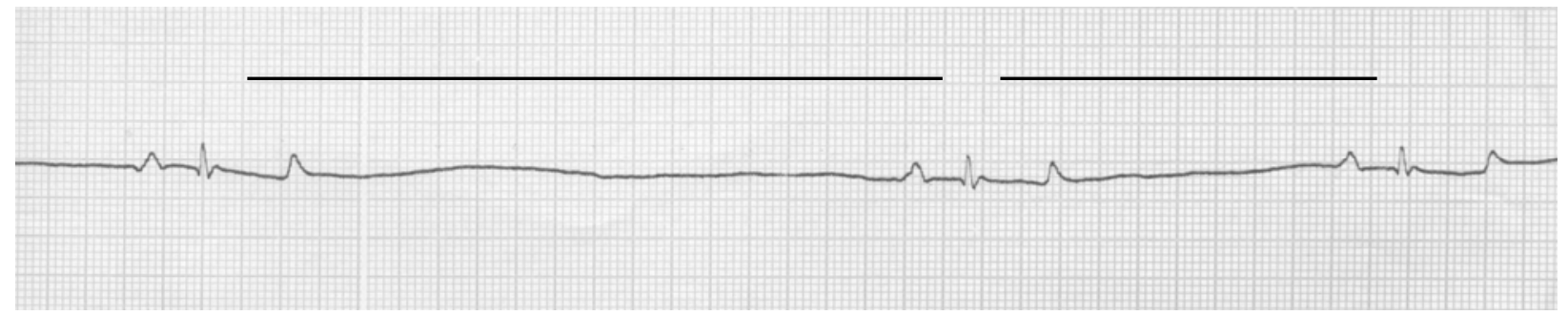

Figura 9 - Eletrocardiograma de eqüino fêmea da raça Anglo-árabe com 9 anos, apresentando arritmia sinusal na derivação bipolar II

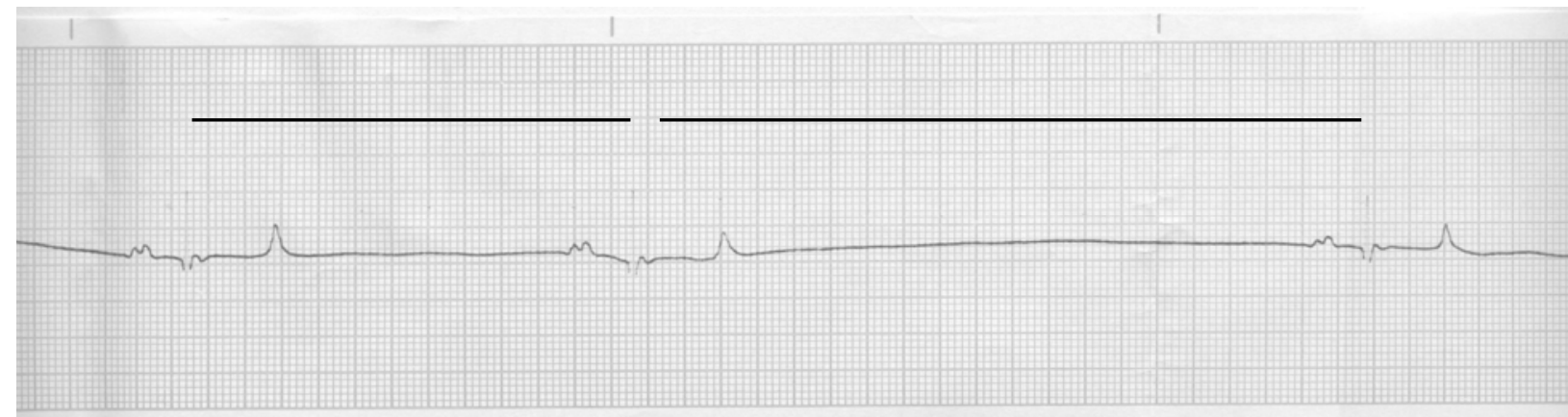

Figura 10 - Eletrocardiograma de eqüino macho da raça Anglo-árabe com 5 anos, apresentando arritmia sinusal na derivação bipolar II 


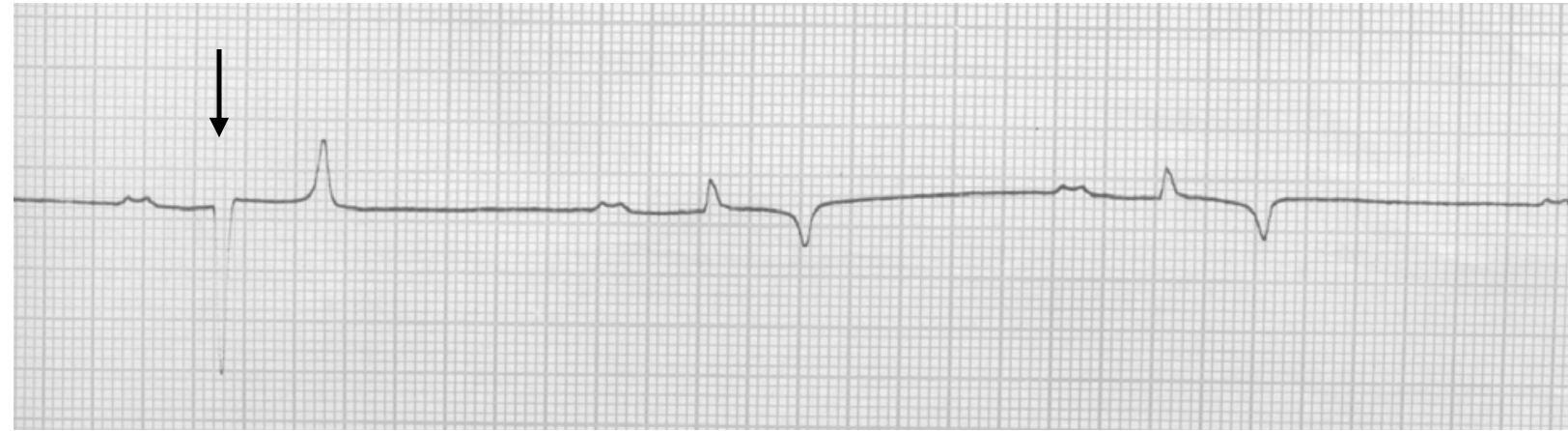

Figura 11 - Eletrocardiograma de eqüino macho da raça Hanoverano com 10 anos, apresentando contração ventricular prematura na derivação bipolar II

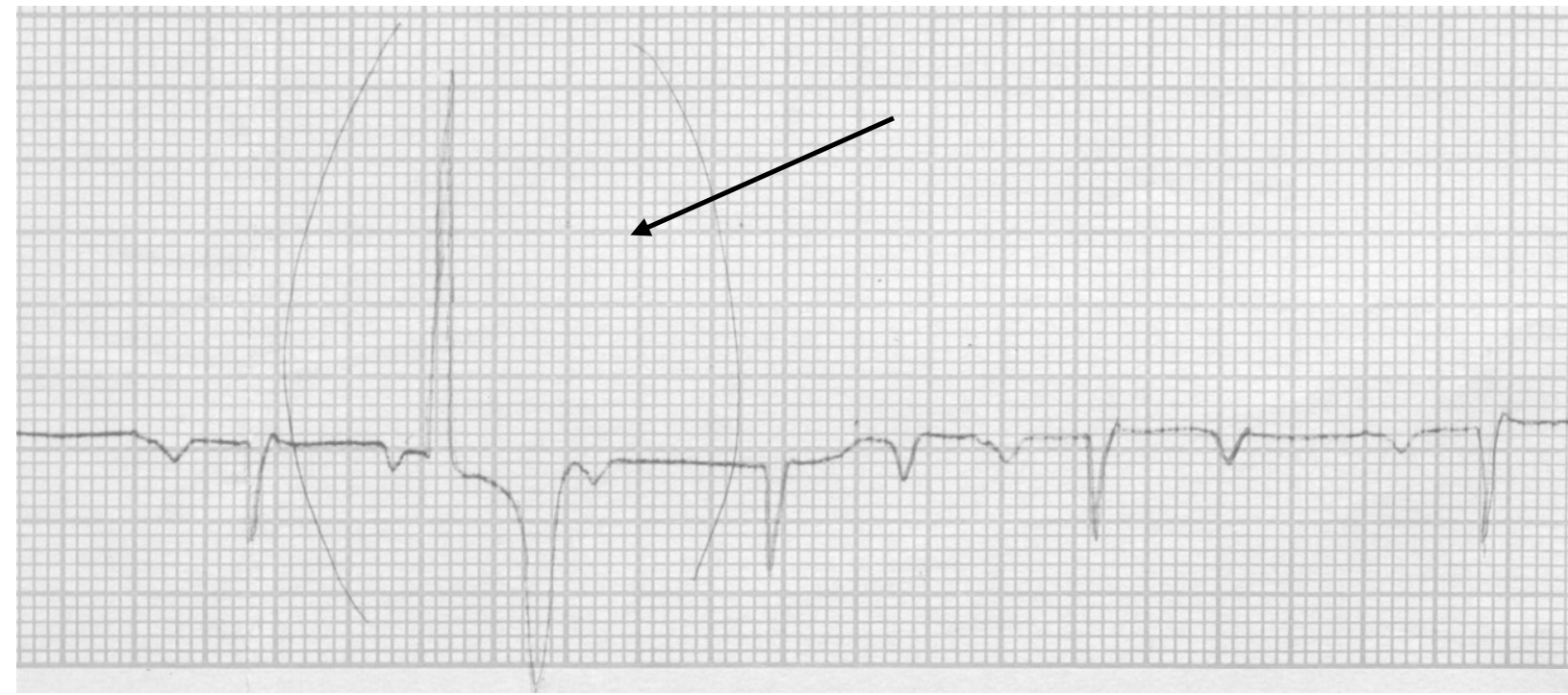

Figura 12 - Eletrocardiograma de eqüino fêmea da raça Zangerchaid com 8 anos, apresentando contração ventricular prematura na derivação unipolar aumentada aVF

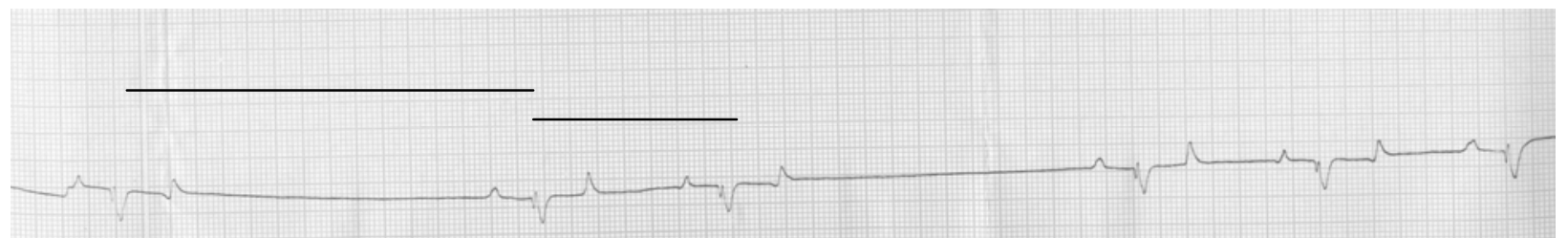

Figura 13 - Eletrocardiograma de eqüino fêmea da raça Anglo-árabe com 5 anos, apresentando bloqueio sinoatrial / "sinus arrest" na derivação bipolar I 


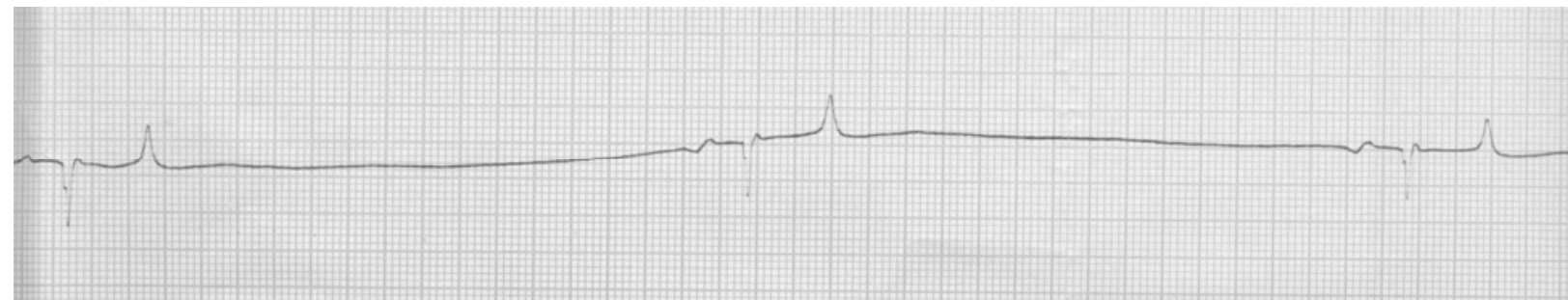

Figura 14 - Eletrocardiograma eqüino macho da raça Anglo-árabe com 5 anos, apresentando bradicardia sinusal na derivação bipolar III (FC=16,7bpm)

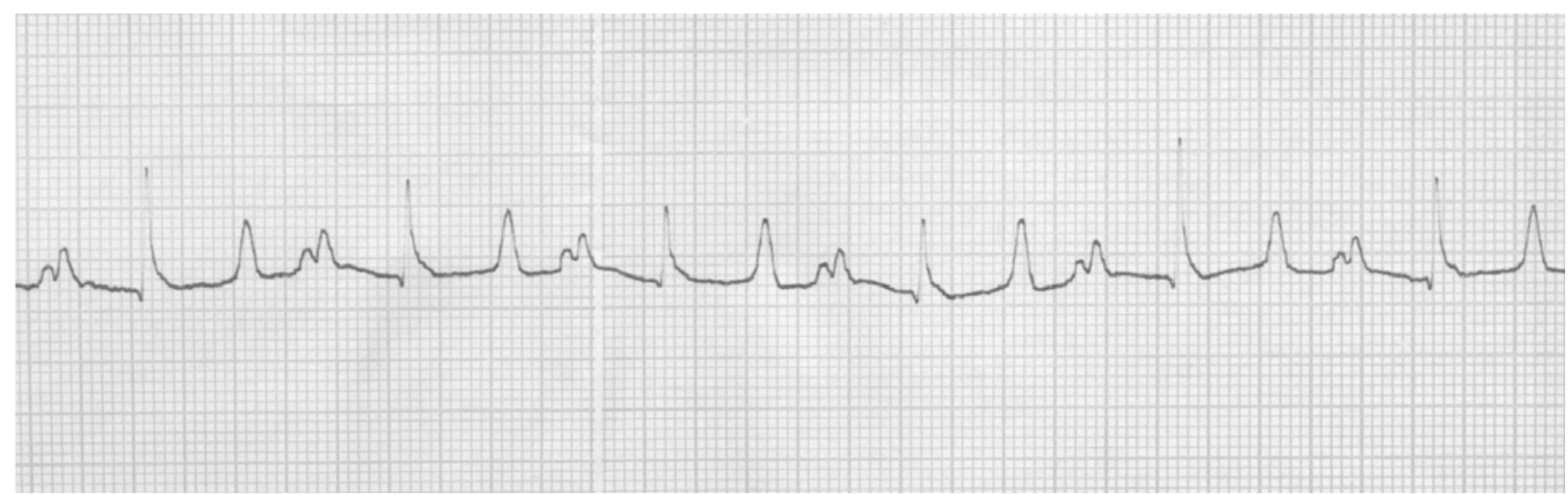

Figura 15 - Eletrocardiograma de eqüino macho da raça $\mathrm{BH}$ com 6 anos, apresentando taquicardia sinusal na derivação bipolar II (FC=60bpm)

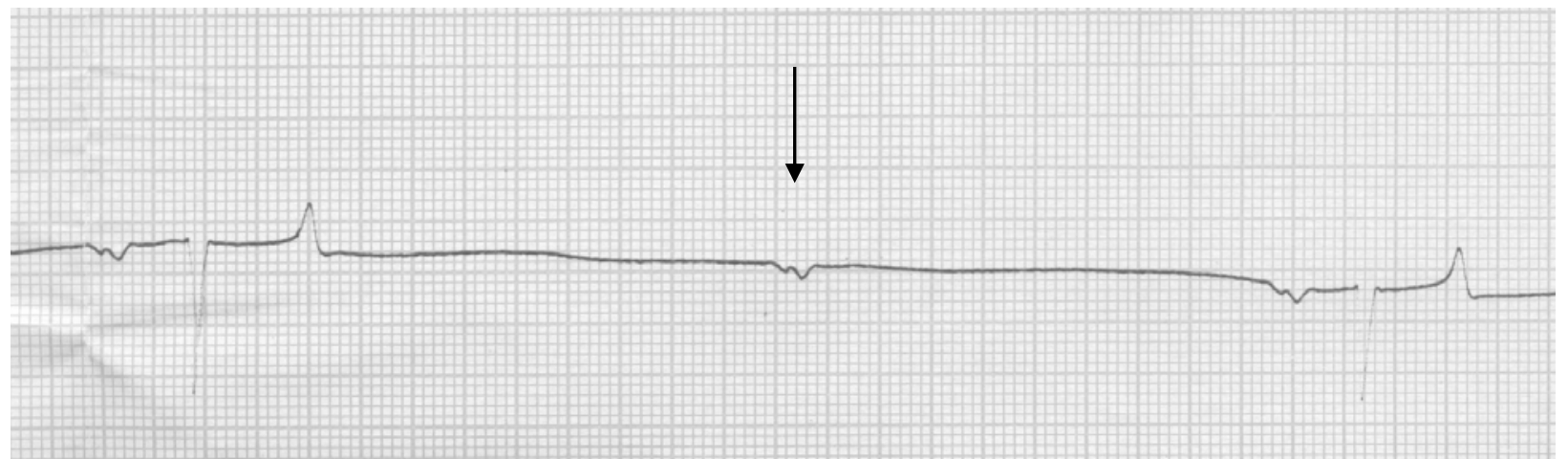

Figura 16 - Eletrocardiograma de eqüino fêmea da raça Sela Francesa com 10 anos, apresentando bloqueio átrio-ventricular de $2^{\circ}$ grau na derivação unipolar aumentada aVR 


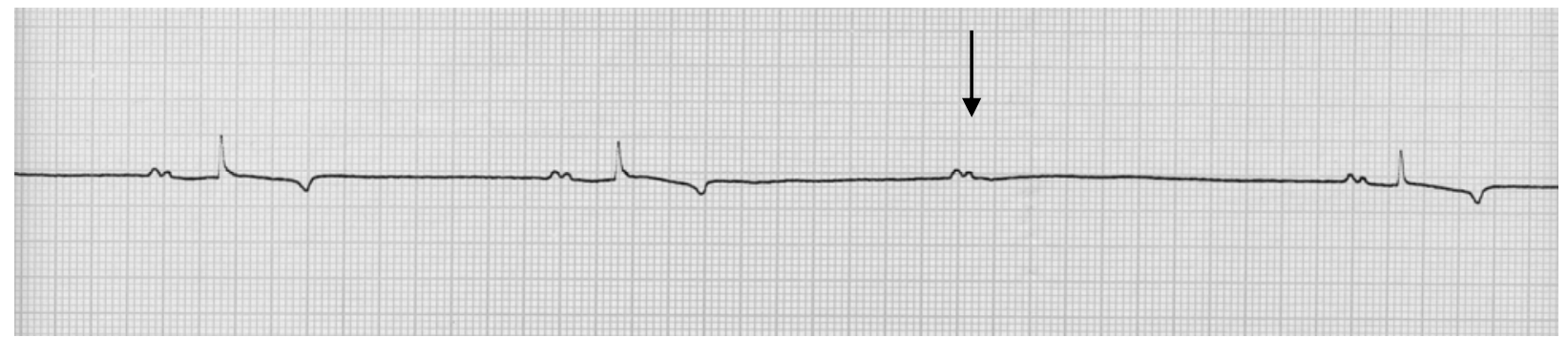

Figura 17 - Eletrocardiograma de eqüino fêmea da raça $\mathrm{BH}$ com 9 anos, apresentando bloqueio átrio-ventricular de $2^{\circ}$ grau na derivação unipolar aumentada aVL

\subsection{EIXO ELÉTRICO NO PLANO FRONTAL}

Os resultados do eixo elétrico no plano frontal dos cem eqüinos encontram-se na tabela 14 , sendo que $87 \%$ dos animais apresentaram eixo cardíaco entre 0 e $+90^{\circ}$ graus.

Não houve diferença estatística nos grupos de atividade física, sexo e idade. Os resultados de freqüência e porcentagem do eixo elétrico no plano frontal estão dispostos nas tabelas 15, 16 e 17 e os dados individuais estão apresentados no apêndice $A$. 
Tabela 14 - Freqüência e porcentagem da distribuição do eixo elétrico no plano frontal do eletrocardiograma de 100 eqüinos de salto criados na cidade de São Paulo- SP $-2006$

\begin{tabular}{lcc}
\hline Eixo & $\begin{array}{c}\text { Freqüência } \\
(\mathbf{N})\end{array}$ & $\begin{array}{c}\text { Porcentagem } \\
(\%)\end{array}$ \\
\hline$\left(0 \mathrm{a}+30^{\circ}\right)$ & 17 & 17,0 \\
$\left(+30^{\circ}\right)$ & 2 & 2,0 \\
$\left(+30 \mathrm{a}+60^{\circ}\right)$ & 29 & 29,0 \\
$\left(+60^{\circ}\right)$ & 1 & 1,0 \\
$\left(+60 \mathrm{a}+90^{\circ}\right)$ & 37 & 37,0 \\
$\left(+90^{\circ}\right)$ & 1 & 1,0 \\
$\left(+90 \mathrm{a}+120^{\circ}\right)$ & 1 & 1,0 \\
$\left(+120 \mathrm{a}+150^{\circ}\right)$ & 3 & 3,0 \\
$\left(+150 \mathrm{a}+180^{\circ}\right)$ & 1 & 1,0 \\
$\left(0 \mathrm{a}-30^{\circ}\right)$ & 4 & 4,0 \\
$\left(-30 \mathrm{a}-60^{\circ}\right)$ & 1 & 1,0 \\
$\left(-60 \mathrm{a}-90^{\circ}\right)$ & 1 & 1,0 \\
$\left(-120 \mathrm{a}-150^{\circ}\right)$ & 2 & 2,0 \\
\hline Total & 100 & 100,0 \\
\hline
\end{tabular}

Tabela 15 - Freqüência e porcentagem da distribuição do eixo elétrico no plano frontal obtidos pelo eletrocardiograma de 100 eqüinos de salto criados na cidade de São Paulo, agrupados segundo atividade física - SP- 2006

\begin{tabular}{lccc}
\hline \multirow{2}{*}{ Eixo } & \multicolumn{3}{c}{ Grupo de Atividade Física } \\
\cline { 2 - 4 } & $\begin{array}{c}\text { Freqüência } \\
(\mathbf{N})\end{array}$ & $\begin{array}{c}\text { Grupo 1 } \\
(\%)\end{array}$ & $\begin{array}{c}\text { Grupo 2 } \\
(\%)\end{array}$ \\
\hline$\left(0 \mathrm{a}+30^{\circ}\right)$ & 17 & 58,8 & 41,2 \\
$\left(+30^{\circ}\right)$ & 2 & 50,0 & 50,0 \\
$\left(+30 \mathrm{a}+60^{\circ}\right)$ & 29 & 48,3 & 51,7 \\
$\left(+60^{\circ}\right)$ & 1 & - & 100,0 \\
$\left(+60 \mathrm{a}+90^{\circ}\right)$ & 37 & 62,2 & 37,8 \\
$\left(+90^{\circ}\right)$ & 1 & - & 100,0 \\
$\left(+90 \mathrm{a}+120^{\circ}\right)$ & 1 & 100,0 & - \\
$\left(+120 \mathrm{a}+150^{\circ}\right)$ & 3 & 66,7 & 33,3 \\
$\left(+150^{\circ} \mathrm{a}+180^{\circ}\right)$ & 1 & - & 100,0 \\
$\left(0 \mathrm{a}-30^{\circ}\right)$ & 4 & 75,0 & 25,0 \\
$\left(-30 \mathrm{a}-60^{\circ}\right)$ & 1 & 100,0 & - \\
$\left(-60 \mathrm{a}-90^{\circ}\right)$ & 1 & - & 100,0 \\
$\left(-120 \mathrm{a}-150^{\circ}\right)$ & 2 & 50,0 & 50,0 \\
\hline Total & 100 & 57,0 & 43,0 \\
\hline
\end{tabular}

Nota: Não houve diferença estatística entre os grupos 1 e $2\left(x^{2}=8,7727, p=0,7222\right.$, graus de liberdade=12). 
Tabela 16 - Freqüência e porcentagem da distribuição do eixo elétrico no plano frontal, obtidos pelo eletrocardiograma de 100 eqüinos de salto criados na cidade de São Paulo, agrupados por sexo - SP- 2006

\begin{tabular}{lccc}
\hline \multirow{2}{*}{ Eixo } & \multicolumn{3}{c}{ SEXO } \\
\cline { 2 - 4 } & $\begin{array}{c}\text { Freqüência } \\
(\mathbf{N})\end{array}$ & $\begin{array}{c}\text { Fêmeas } \\
(\%)\end{array}$ & $\begin{array}{c}\text { Machos } \\
(\%)\end{array}$ \\
\hline$\left(0 \mathrm{a}+30^{\circ}\right)$ & 17 & 17,6 & 82,4 \\
$\left(+30^{\circ}\right)$ & 2 & - & 100,0 \\
$\left(+30 \mathrm{a}+60^{\circ}\right)$ & 29 & 37,9 & 62,1 \\
$\left(+60^{\circ}\right)$ & 1 & - & 100,0 \\
$\left(+60 \mathrm{a}+90^{\circ}\right)$ & 37 & 37,8 & 62,2 \\
$\left(+90^{\circ}\right)$ & 1 & 100,0 & - \\
$\left(+90 \mathrm{a}+120^{\circ}\right)$ & 1 & 100,0 & - \\
$\left(+120 \mathrm{a}+150^{\circ}\right)$ & 3 & 100,0 & - \\
$\left(+150 \mathrm{a}+180^{\circ}\right)$ & 1 & 100,0 & - \\
$\left(0 \mathrm{a}-30^{\circ}\right)$ & 4 & 75,0 & - \\
$\left(-30 \mathrm{a}-60^{\circ}\right)$ & 1 & 100,0 & 100,0 \\
$\left(-60 \mathrm{a}-90^{\circ}\right)$ & 1 & - & 50,0 \\
$\left(-120 \mathrm{a}-150^{\circ}\right)$ & 2 & 50,0 & 61,0 \\
\hline Total & 100 & 39,0 & - \\
\hline Nota: Nă houve
\end{tabular}

Nota: Não houve diferença estatística entre os grupos segundo sexo $\left(x^{2}=19,0800, p=0,0866\right.$, graus de liberdade $=12$ ).

Tabela 17 - Freqüência e porcentagem da distribuição do eixo elétrico no plano frontal, obtidos pelo eletrocardiograma de 100 eqüinos de salto criados na cidade de São Paulo, agrupados segundo faixa etária - SP - 2006

\begin{tabular}{lcccc}
\hline \multirow{2}{*}{ Eixo } & \multicolumn{4}{c}{ IDADE } \\
\cline { 2 - 5 } & $\begin{array}{c}\text { Freqüência } \\
(\mathbf{N})\end{array}$ & $\begin{array}{c}\mathbf{4} \text { a } \mathbf{8} \text { anos } \\
(\%)\end{array}$ & $\begin{array}{c}\mathbf{9} \text { a 13 anos } \\
(\%)\end{array}$ & $\begin{array}{c}\mathbf{1 4} \mathbf{a} \mathbf{1 9} \text { anos } \\
(\%)\end{array}$ \\
\hline$\left(0 \mathrm{a}+30^{\circ}\right)$ & 17 & 29,4 & 52,9 & 17,6 \\
$\left(+30^{\circ}\right)$ & 2 & 50,0 & 50,0 & - \\
$\left(+30 \mathrm{a}+60^{\circ}\right)$ & 29 & 34,5 & 58,6 & 6,9 \\
$\left(+60^{\circ}\right)$ & 1 & 100,0 & - & - \\
$\left(+60 \mathrm{a}+90^{\circ}\right)$ & 37 & 32,4 & 51,4 & 16,2 \\
$\left(+90^{\circ}\right)$ & 1 & - & 100,0 & - \\
$\left(+90 \mathrm{a}+120^{\circ}\right)$ & 1 & 100,0 & - & - \\
$\left(+120 \mathrm{a}+150^{\circ}\right)$ & 3 & 33,3 & 33,3 & 33,3 \\
$\left(+150^{\circ} \mathrm{a}+180^{\circ}\right)$ & 1 & - & - & 100,0 \\
$\left(0 \mathrm{a}-30^{\circ}\right)$ & 4 & 25,0 & 75,0 & - \\
$\left(-30 \mathrm{a}-60^{\circ}\right)$ & 1 & - & 100,0 & - \\
$\left(-60 \mathrm{a}-90^{\circ}\right)$ & 1 & 100,0 & - & - \\
$\left(-120 \mathrm{a}-150^{\circ}\right)$ & 2 & - & 50,0 & 50,0 \\
\hline Total & 100 & 33,0 & 53,0 & 14,0 \\
\hline
\end{tabular}

Nota: Não houve diferença estatística entre os grupos segundo a faixa etária $\left(x^{2}=23,0798\right.$, $p=0,6284$, graus de liberdade $=26$ ). 


\subsection{MENSURAÇÃO E MORFOLOGIA DAS ONDAS, INTERVALOS E COMPLEXOS}

Com o objetivo de facilitar a apresentação dos resultados optou-se por dividir o item mensuração dos complexos em duração, amplitude, morfologia e por fim os resultados que apresentaram diferenças estatísticas nos grupos de atividade física, sexo e idade.

Os dados individuais de duração e amplitude das ondas e complexos, nas derivações bipolares I, II e III e unipolares aVR, aVL e aVF, encontram-se nos apêndices B,C,D,E,F e G.

\subsubsection{Score Cardíaco}

Os valores médios, desvio padrão e demais dados estatísticos do score cardíaco dos cem animais encontram-se na tabela 18.

O escore cardíaco, que representa a média aritmética das derivações bipolares I, II e III, não apresentou diferença estatística em relação aos grupos de atividade física, sexo e idade. Os resultados encontram-se nas tabelas 19, 20 e 21.

Os resultados individuais de score cardíaco para os cem eqüinos encontram-se no apêndice $A$. 
Tabela 18 - Valores médios, desvio padrão, valor mínimo, valor máximo, mediana e moda, do score cardíaco em milisegundos obtido pelo eletrocardiograma de 100 eqüinos de salto criados na cidade de São Paulo - SP - 2006

\begin{tabular}{lc}
\hline Score cardíaco & $\mathbf{N}=\mathbf{1 0 0}$ \\
\hline Média & 94,9 \\
Desvio Padrão & 16,1 \\
Valor mínimo & 60,0 \\
Valor máximo & 126,7 \\
Mediana & 100,0 \\
Moda & 106,7 \\
\hline
\end{tabular}

Tabela 19 - Valores médios, desvio padrão, valor mínimo, valor máximo, mediana e moda do score cardíaco em milisegundos, obtido pelo eletrocardiograma de 100 eqüinos de salto criados na cidade de São Paulo, agrupados segundo atividade física $S P-2006$

\begin{tabular}{lcc}
\hline \multirow{2}{*}{ Score cardíaco } & \multicolumn{2}{c}{ Grupo de Atividade Física } \\
\cline { 2 - 3 } & $\begin{array}{c}\text { Grupo 1 } \\
\mathbf{( N = 5 6 )}\end{array}$ & $\begin{array}{c}\text { Grupo 2 } \\
\mathbf{( N = 4 4 )}\end{array}$ \\
\hline Média & 96,0 & 93,6 \\
Desvio Padrão & 15,8 & 16,6 \\
Valor mínimo & 60,0 & 60,0 \\
Valor máximo & 120,0 & 126,7 \\
Mediana & 100,0 & 93,3 \\
Moda & 106,7 & 106,7 \\
\hline Nota: Não houve diferença significativa entre os grupos 1 e 2 $(\mathrm{t}=0,7115$ e $\mathrm{p}=0,4785)$.
\end{tabular}

Nota: Não houve diferença significativa entre os grupos 1 e 2 ( $t=0,7115$ e $p=0,4785)$.

Tabela 20 - Valores médios, desvio padrão, valor mínimo, valor máximo, mediana e moda do score cardíaco em milisegundos obtido pelo eletrocardiograma de 100 eqüinos de salto criados na cidade de São Paulo, agrupados por sexo - SP - 2006

\begin{tabular}{lcc}
\hline Score cardíaco & \multicolumn{2}{c}{ SEXO } \\
\cline { 2 - 3 } & $\begin{array}{c}\text { Fêmeas } \\
(\mathbf{N}=\mathbf{3 9})\end{array}$ & $\begin{array}{c}\text { Machos } \\
(\mathbf{N}=61)\end{array}$ \\
\hline Média & 94,4 & 95,3 \\
Desvio Padrão & 16,2 & 16,3 \\
Valor mínimo & 60,0 & 60,0 \\
Valor máximo & 120,0 & 126,7 \\
Mediana & 100,0 & 100,0 \\
Moda & 106,7 & 106,7 \\
\hline
\end{tabular}

Nota: Não houve diferença significativa entre os grupos segundo sexo $(t=0,2837$ e $p=0,7773)$. 
Tabela 21 - Valores médios, desvio padrão, valor mínimo, valor máximo, mediana e moda do score cardíaco em milisegundos obtido pelo eletrocardiograma de 100 eqüinos de salto criados na cidade de São Paulo, agrupados segundo faixa etária - SP 2006

\begin{tabular}{lccc}
\hline Score cardíaco & \multicolumn{3}{c}{ IDADE } \\
\cline { 2 - 4 } & $\begin{array}{c}\mathbf{4} \text { a 8 anos } \\
(\mathbf{N}=\mathbf{3 3})\end{array}$ & $\begin{array}{c}\mathbf{9} \text { a 13 anos } \\
\mathbf{( N = 5 3 )}\end{array}$ & $\begin{array}{c}\mathbf{1 4} \text { a 19 anos } \\
(\mathbf{N}=\mathbf{1 4})\end{array}$ \\
\hline Média & 94,8 & 95,5 & 93,3 \\
Desvio Padrão & 18,0 & 15,9 & 13,1 \\
Valor mínimo & 60,0 & 66,7 & 60,0 \\
Valor máximo & 126,7 & 120,0 & 106,7 \\
Mediana & 100,0 & 100,0 & 96,7 \\
Moda & 106,7 & 106,7 & 100,0 \\
\hline
\end{tabular}

Nota: Não houve diferença significativa entre os grupos segundo faixa etária $(F=0,0995$ e $\mathrm{p}=0,9054)$.

\subsubsection{Duração}

Os dados referentes à duração em segundos das ondas, intervalos e complexos estão dispostos em oito tabelas. As tabelas 22 a 29 apresentam freqüência relativa, média, desvio padrão, valor mínimo, valor máximo, mediana e moda das variáveis de duração da onda $P$, intervalo $P-R$, complexo $Q R S$, onda $Q$, onda $R$, onda $S$, intervalo QT e onda T, respectivamente, nas derivações bipolares I, II e III e nas derivações unipolares aVR, aVL e aVF. 
Tabela 22 - Freqüência relativa, valores médios, desvio padrão, valor mínimo, valor máximo, mediana e moda, da duração da onda $\mathrm{P}$ em segundos nas derivações bipolares I, II e III e nas derivações unipolares aVR, aVL e aVF, obtido pelo eletrocardiograma de 100 eqüinos de salto criados na cidade de São Paulo - SP $-2006$

\begin{tabular}{lrrrrrr}
\hline & \multicolumn{3}{c}{ Derivações bipolares } & \multicolumn{3}{c}{ Derivações unipolares } \\
\cline { 2 - 7 } Duração da onda P & $\mathbf{I}$ & II & III & aVR & aVL & aVF \\
\hline Freqüência relativa & 100 & 100 & 100 & 100 & 100 & 100 \\
Média & 0,1079 & 0,1216 & 0,1100 & 0,1186 & 0,1090 & 0,1136 \\
Desvio padrão & 0,0238 & 0,0260 & 0,0242 & 0,0215 & 0,0275 & 0,0222 \\
Valor mínimo & 0,0400 & 0,0400 & 0,0800 & 0,0600 & 0,0400 & 0,0800 \\
Valor máximo & 0,1600 & 0,1600 & 0,1600 & 0,1600 & 0,1600 & 0,1600 \\
Mediana & 0,1200 & 0,1200 & 0,1200 & 0,1200 & 0,1200 & 0,1200 \\
Moda & 0,1200 & 0,1200 & 0,1200 & 0,1200 & 0,1200 & 0,1200 \\
\hline
\end{tabular}

Tabela 23 - Freqüência relativa, valores médios, desvio padrão, valor mínimo, valor máximo, mediana e moda, da duração do intervalo $P-R$ em segundos nas derivações bipolares I, II e III e nas derivações unipolares aVR, aVL e aVF, obtido pelo eletrocardiograma de 100 eqüinos de salto criados na cidade de São Paulo - SP $-2006$

\begin{tabular}{lrrrrrr}
\hline & \multicolumn{3}{c}{ Derivações bipolares } & \multicolumn{3}{c}{ Derivações unipolares } \\
\cline { 2 - 7 } Duração intervalo P-R & $\mathbf{I}$ & $\mathbf{I}$ & III & aVR & aVL & aVF \\
\hline Freqüência relativa & 100 & 100 & 100 & 100 & 100 & 100 \\
Média & 0,3146 & 0,3140 & 0,3072 & 0,3230 & 0,3242 & 0,3094 \\
Desvio padrão & 0,0710 & 0,0744 & 0,0660 & 0,0625 & 0,0709 & 0,0641 \\
Valor mínimo & 0,1600 & 0,1600 & 0,1600 & 0,2000 & 0,2000 & 0,2000 \\
Valor máximo & 0,5200 & 0,5200 & 0,5200 & 0,5200 & 0,5200 & 0,5200 \\
Mediana & 0,3200 & 0,3200 & 0,2800 & 0,3200 & 0,3200 & 0,3000 \\
Moda & 0,2800 & 0,2800 & 0,2800 & 0,3200 & 0,2800 & 0,2800 \\
\hline
\end{tabular}

Tabela 24 - Freqüência relativa, valores médios, desvio padrão, valor mínimo, valor máximo, mediana e moda, da duração do complexo QRS em segundos nas derivações bipolares I, II e III e nas derivações unipolares aVR, aVL e aVF, obtido pelo eletrocardiograma de 100 eqüinos de salto criados na cidade de São Paulo - SP $-2006$

\begin{tabular}{lrrrrrr}
\hline & \multicolumn{3}{c}{ Derivações bipolares } & \multicolumn{3}{c}{ Derivações unipolares } \\
\cline { 2 - 7 } Duração QRS & $\mathbf{I}$ & II & III & aVR & aVL & aVF \\
\hline Freqüência relativa & 100 & 100 & 100 & 100 & 100 & 100 \\
Média & 0,1050 & 0,0908 & 0,0890 & 0,0870 & 0,0920 & 0,0842 \\
Desvio padrão & 0,0269 & 0,0250 & 0,0225 & 0,0232 & 0,0271 & 0,0213 \\
Valor mínimo & 0,0400 & 0,0400 & 0,0400 & 0,0400 & 0,0400 & 0,0400 \\
Valor máximo & 0,1600 & 0,1600 & 0,1200 & 0,1600 & 0,1600 & 0,1200 \\
Mediana & 0,1200 & 0,0800 & 0,0800 & 0,0800 & 0,0800 & 0,0800 \\
Moda & 0,1200 & 0,0800 & 0,0800 & 0,0800 & 0,0800 & 0,0800 \\
\hline
\end{tabular}


Tabela 25 - Freqüência relativa, valores médios, desvio padrão, valor mínimo, valor máximo, mediana e moda, da duração da onda $Q$ em segundos nas derivações bipolares I, II e III e nas derivações unipolares aVR, aVL e aVF, obtido pelo eletrocardiograma de 100 eqüinos de salto criados na cidade de São Paulo - SP $-2006$

\begin{tabular}{lrrrrrr}
\hline & \multicolumn{3}{c}{ Derivações bipolares } & \multicolumn{3}{c}{ Derivações unipolares } \\
\cline { 2 - 7 } Duração onda Q & I & II & III & aVR & aVL & aVF \\
\hline Freqüência relativa & 58 & 65 & 42 & 7 & 40 & 52 \\
Média & 0,0262 & 0,0260 & 0,0340 & 0,0457 & 0,0330 & 0,0273 \\
Desvio padrão & 0,0101 & 0,0110 & 0,0204 & 0,0190 & 0,0107 & 0,0105 \\
Valor mínimo & 0,0200 & 0,0200 & 0,0200 & 0,0200 & 0,0200 & 0,0200 \\
Valor máximo & 0,0600 & 0,0800 & 0,1000 & 0,0800 & 0,0600 & 0,0600 \\
Mediana & 0,0200 & 0,0200 & 0,0200 & 0,0400 & 0,0400 & 0,0200 \\
Moda & 0,0200 & 0,0200 & 0,0200 & 0,0400 & 0,0400 & 0,0200 \\
\hline
\end{tabular}

Tabela 26 - Freqüência relativa, valores médios, desvio padrão, valor mínimo, valor máximo, mediana e moda, da duração da onda $\mathrm{R}$ em segundos nas derivações bipolares I, II e III e nas derivações unipolares aVR, aVL e aVF, obtido pelo eletrocardiograma de 100 eqüinos de salto criados na cidade de São Paulo - SP $-2006$

\begin{tabular}{lrrrrrr}
\hline & \multicolumn{3}{c}{ Derivações bipolares } & \multicolumn{3}{c}{ Derivações unipolares } \\
\cline { 2 - 7 } Duração onda R & $\mathbf{I}$ & $\mathbf{I}$ & III & aVR & aVL & aVF \\
\hline Freqüência relativa & 96 & 100 & 96 & 70 & 90 & 97 \\
Média & 0,0616 & 0,0582 & 0,0497 & 0,0313 & 0,0527 & 0,0534 \\
Desvio padrão & 0,0242 & 0,0233 & 0,0240 & 0,0194 & 0,0225 & 0,0197 \\
Valor mínimo & 0,0200 & 0,0200 & 0,0200 & 0,0200 & 0,0200 & 0,0200 \\
Valor máximo & 0,1400 & 0,1200 & 0,1200 & 0,1200 & 0,1000 & 0,1200 \\
Mediana & 0,0600 & 0,0600 & 0,0400 & 0,0200 & 0,0400 & 0,0400 \\
Moda & 0,0400 & 0,0400 & 0,0400 & 0,0200 & 0,0400 & 0,0400 \\
\hline
\end{tabular}

Tabela 27 - Freqüência relativa, valores médios, desvio padrão, valor mínimo, valor máximo, mediana e moda, da duração da onda $S$ em segundos nas derivações bipolares I, II e III e nas derivações unipolares aVR, aVL e aVF, obtido pelo eletrocardiograma de 100 eqüinos de salto criados na cidade de São Paulo - SP $-2006$

\begin{tabular}{lrrrrrr}
\hline & \multicolumn{3}{c}{ Derivações bipolares } & \multicolumn{3}{c}{ Derivações unipolares } \\
\cline { 2 - 7 } Duração onda S & I & II & III & aVR & aVL & aVF \\
\hline Freqüência relativa & 56 & 41 & 52 & 62 & 50 & 44 \\
Média & 0,0488 & 0,0359 & 0,0469 & 0,0650 & 0,0456 & 0,0368 \\
Desvio padrão & 0,0201 & 0,0143 & 0,0142 & 0,0218 & 0,0218 & 0,0129 \\
Valor mínimo & 0,0200 & 0,0200 & 0,0200 & 0,0200 & 0,0200 & 0,0200 \\
Valor máximo & 0,0800 & 0,0800 & 0,0800 & 0,1400 & 0,1200 & 0,0800 \\
Mediana & 0,0400 & 0,0400 & 0,0400 & 0,0600 & 0,0400 & 0,0400 \\
Moda & 0,0400 & 0,0400 & 0,0400 & 0,0600 & 0,0400 & 0,0400 \\
\hline
\end{tabular}


Tabela 28 - Valores médios, desvio padrão, valor mínimo, valor máximo, mediana e moda, da duração do intervalo QT em segundos nas derivações bipolares I, II e III e nas derivações unipolares aVR, aVL e aVF, obtido pelo eletrocardiograma de 100 eqüinos de salto criados na cidade de São Paulo - SP - 2006

\begin{tabular}{lrrrrrr}
\hline & \multicolumn{3}{c}{ Derivações bipolares } & \multicolumn{3}{c}{ Derivações unipolares } \\
\cline { 2 - 7 } Duração QT & I & II & III & aVR & aVL & aVF \\
\hline Média & 0,4737 & 0,4908 & 0,4796 & 0,4812 & 0,4784 & 0,4952 \\
Desvio padrão & 0,0521 & 0,0536 & 0,0567 & 0,0481 & 0,0548 & 0,0571 \\
Valor mínimo & 0,3200 & 0,3200 & 0,3200 & 0,3200 & 0,3200 & 0,3200 \\
Valor máximo & 0,6000 & 0,6000 & 0,5600 & 0,5600 & 0,5600 & 0,6000 \\
Mediana & 0,4800 & 0,4800 & 0,4800 & 0,4800 & 0,4800 & 0,5200 \\
Moda & 0,4800 & 0,4800 & 0,5200 & 0,4800 & 0,5200 & 0,5200 \\
\hline
\end{tabular}

Tabela 29 - Freqüência relativa, valores médios, desvio padrão, valor mínimo, valor máximo, mediana e moda, da duração da onda $T$ em segundos nas derivações bipolares I, II e III e nas derivações unipolares aVR, aVL e aVF, obtido pelo eletrocardiograma de 100 eqüinos de salto criados na cidade de São Paulo - SP $-2006$

\begin{tabular}{lrrrrrr}
\hline & \multicolumn{3}{c}{ Derivações bipolares } & \multicolumn{3}{c}{ Derivações unipolares } \\
\cline { 2 - 7 } Duração onda T & I & II & III & aVR & aVL & aVF \\
\hline Freqüência relativa & 100 & 100 & 100 & 100 & 100 & 100 \\
Média & 0,1112 & 0,1130 & 0,1118 & 0,1126 & 0,1052 & 0,1096 \\
Desvio padrão & 0,0308 & 0,0330 & 0,0236 & 0,0363 & 0,0242 & 0,0269 \\
Valor mínimo & 0,0400 & 0,0400 & 0,0800 & 0,0400 & 0,0400 & 0,0400 \\
Valor máximo & 0,1600 & 0,2000 & 0,1600 & 0,3200 & 0,1600 & 0,2000 \\
Mediana & 0,1200 & 0,1200 & 0,1200 & 0,1200 & 0,1200 & 0,1200 \\
Moda & 0,1200 & 0,1200 & 0,1200 & 0,1200 & 0,1200 & 0,1200 \\
\hline
\end{tabular}

\subsubsection{Amplitude}

Os dados referentes à amplitude em milivolts das ondas e complexos estão dispostos em oito tabelas. As tabelas 30 a 37 apresentam freqüência relativa, média, desvio padrão, valor mínimo, valor máximo, mediana e moda das variáveis de amplitude da onda $P$ única, onda $P$ bifásica, primeira porção da onda $P$ bífida $(P 1)$, segunda porção da onda $P$ bífida (P2), onda $Q$, onda $R$, onda $S$ e onda $T$, respectivamente, nas derivações bipolares I, II e III e nas derivações unipolares aVR, aVL e aVF. 
Tabela 30 - Freqüência relativa, valores médios, desvio padrão, valor mínimo, valor máximo, mediana e moda, da amplitude da onda $\mathrm{P}$ única em milivolts nas derivações bipolares I, II e III e nas derivações unipolares aVR, aVL e aVF, obtido pelo eletrocardiograma de 100 eqüinos de salto criados na cidade de São Paulo - SP $-2006$

\begin{tabular}{lrrrrrr}
\hline & \multicolumn{3}{c}{ Derivações bipolares } & \multicolumn{3}{c}{ Derivações unipolares } \\
\cline { 2 - 7 } Amplitude P única & I & II & III & aVR & aVL & aVF \\
\hline Freqüência relativa & 26 & 35 & 42 & 22 & 30 & 43 \\
Média & 0,1519 & 0,2671 & 0,1750 & 0,1818 & 0,1250 & 0,2198 \\
Desvio padrão & 0,0818 & 0,0747 & 0,0767 & 0,0608 & 0,0666 & 0,0952 \\
Valor mínimo & 0,0500 & 0,1000 & 0,1000 & 0,1000 & 0,0500 & 0,1000 \\
Valor máximo & 0,3000 & 0,5000 & 0,5000 & 0,3000 & 0,3000 & 0,6000 \\
Mediana & 0,1250 & 0,3000 & 0,2000 & 0,2000 & 0,1000 & 0,2000 \\
Moda & 0,1000 & 0,3000 & 0,2000 & 0,2000 & 0,1000 & 0,2000 \\
\hline
\end{tabular}

Tabela 31 - Freqüência relativa, valores médios, desvio padrão, valor mínimo, valor máximo, mediana e moda, da amplitude da onda $P$ bifásica em milivolts nas derivações bipolares I, II e III e nas derivações unipolares aVR, aVL e aVF, obtido pelo eletrocardiograma de 100 eqüinos de salto criados na cidade de São Paulo- SP $-2006$

\begin{tabular}{lrrrrrr}
\hline & \multicolumn{3}{c}{ Derivações bipolares } & \multicolumn{3}{c}{ Derivações unipolares } \\
\cline { 2 - 7 } Amplitude P bifásica & $\mathbf{I}$ & II & III & aVR & aVL & aVF \\
\hline Freqüência relativa & 11 & 11 & 14 & 10 & 13 & 13 \\
Média & 0,2455 & 0,3136 & 0,2464 & 0,3000 & 0,2115 & 0,2538 \\
Desvio padrão & 0,0688 & 0,1098 & 0,0843 & 0,0816 & 0,0682 & 0,0967 \\
Valor mínimo & 0,1500 & 0,2000 & 0,2000 & 0,2000 & 0,1500 & 0,2000 \\
Valor máximo & 0,3500 & 0,6000 & 0,5000 & 0,4000 & 0,4000 & 0,5000 \\
Mediana & 0,2500 & 0,3000 & 0,2000 & 0,3000 & 0,2000 & 0,2000 \\
Moda & 0,3000 & 0,3000 & 0,2000 & 0,3000 & 0,2000 & 0,2000 \\
\hline
\end{tabular}

Tabela 32 - Freqüência relativa, valores médios, desvio padrão, valor mínimo, valor máximo, mediana e moda, da amplitude da primeira porção da onda $P$ bífida (P1) em milivolts nas derivações bipolares I, II e III e nas derivações unipolares aVR, aVL e aVF, obtido pelo eletrocardiograma de 100 eqüinos de salto criados na cidade de São Paulo - SP - 2006

\begin{tabular}{lrrrrrr}
\hline & \multicolumn{3}{c}{ Derivações bipolares } & \multicolumn{3}{c}{ Derivações unipolares } \\
\cline { 2 - 7 } Amplitude de P bífida (P1) & I & II & III & aVR & aVL & aVF \\
\hline Freqüência relativa & 63 & 54 & 43 & 68 & 57 & 44 \\
Média & 0,1206 & 0,1352 & 0,1093 & 0,1235 & 0,0947 & 0,1080 \\
Desvio padrão & 0,0521 & 0,0492 & 0,0397 & 0,0485 & 0,0469 & 0,0263 \\
Valor mínimo & 0,0500 & 0,1000 & 0,0500 & 0,0500 & 0,0500 & 0,0500 \\
Valor máximo & 0,2000 & 0,2500 & 0,2500 & 0,2500 & 0,2000 & 0,2000 \\
Mediana & 0,1000 & 0,1000 & 0,1000 & 0,1000 & 0,1000 & 0,1000 \\
Moda & 0,1000 & 0,1000 & 0,1000 & 0,1000 & 0,1000 & 0,1000 \\
\hline
\end{tabular}


Tabela 33 - Freqüência relativa, valores médios, desvio padrão, valor mínimo, valor máximo, mediana e moda, da amplitude da segunda porção da onda P bífida (P2) em milivolts nas derivações bipolares I, II e III e nas derivações unipolares aVR, aVL e aVF, obtido pelo eletrocardiograma de 100 eqüinos de salto criados na cidade de São Paulo - SP - 2006

\begin{tabular}{lrrrrrr}
\hline & \multicolumn{3}{c}{ Derivações bipolares } & \multicolumn{3}{c}{ Derivações unipolares } \\
\cline { 2 - 7 } Amplitude de P bífida (P2) & I & II & III & aVR & aVL & aVF \\
\hline Freqüência relativa & 63 & 54 & 43 & 68 & 57 & 44 \\
Média & 0,1373 & 0,2259 & 0,1593 & 0,1860 & 0,1044 & 0,1841 \\
Desvio padrão & 0,0707 & 0,0502 & 0,0548 & 0,0604 & 0,0520 & 0,0479 \\
Valor mínimo & 0,0500 & 0,1000 & 0,1000 & 0,1000 & 0,0500 & 0,0500 \\
Valor máximo & 0,3000 & 0,3000 & 0,3000 & 0,3000 & 0,2000 & 0,3000 \\
Mediana & 0,1000 & 0,2000 & 0,1500 & 0,2000 & 0,1000 & 0,2000 \\
Moda & 0,1000 & 0,2000 & 0,2000 & 0,2000 & 0,1000 & 0,2000 \\
\hline
\end{tabular}

Tabela 34 - Freqüência relativa, valores médios, desvio padrão, valor mínimo, valor máximo, mediana e moda, da amplitude da onda $Q$ em milivolts nas derivações bipolares I, II e III e nas derivações unipolares aVR, aVL e aVF, obtido pelo eletrocardiograma de 100 eqüinos de salto criados na cidade de São Paulo - SP $-2006$

\begin{tabular}{lrrrrrr}
\hline & \multicolumn{3}{c}{ Derivações bipolares } & \multicolumn{3}{c}{ Derivações unipolares } \\
\cline { 2 - 7 } Amplitude da onda Q & $\mathbf{I}$ & II & III & aVR & aVL & aVF \\
\hline Freqüência relativa & 58 & 65 & 42 & 7 & 40 & 52 \\
Média & 0,1716 & 0,1923 & 0,2250 & 0,7429 & 0,2675 & 0,1298 \\
Desvio padrão & 0,2462 & 0,3115 & 0,1865 & 0,3735 & 0,2263 & 0,0812 \\
Valor mínimo & 0,0500 & 0,0500 & 0,0500 & 0,1000 & 0,0500 & 0,0500 \\
Valor máximo & 1,4000 & 2,4000 & 0,8000 & 1,3000 & 1,0000 & 0,5000 \\
Mediana & 0,1000 & 0,1000 & 0,1750 & 0,8000 & 0,2000 & 0,1000 \\
Moda & 0,1000 & 0,1000 & 0,1000 & 0,9000 & 0,1000 & 0,1000 \\
\hline
\end{tabular}

Tabela 35 - Freqüência relativa, valores médios, desvio padrão, valor mínimo, valor máximo, mediana e moda, da amplitude da onda $\mathrm{R}$ em milivolts nas derivações bipolares I, II e III e nas derivações unipolares aVR, aVL e aVF, obtido pelo eletrocardiograma de 100 eqüinos de salto criados na cidade de São Paulo - SP $-2006$

\begin{tabular}{lrrrrrr}
\hline & \multicolumn{3}{c}{ Derivações bipolares } & \multicolumn{3}{c}{ Derivações unipolares } \\
\cline { 2 - 7 } Amplitude onda R & I & II & III & aVR & aVL & aVF \\
\hline Freqüência relativa & 96 & 100 & 96 & 70 & 90 & 97 \\
Média & 0,6688 & 1,0220 & 0,6469 & 0,1929 & 0,3550 & 0,8299 \\
Desvio padrão & 0,3438 & 0,5028 & 0,4081 & 0,2878 & 0,2073 & 0,4239 \\
Valor mínimo & 0,1000 & 0,1000 & 0,0500 & 0,0500 & 0,1000 & 0,0500 \\
Valor máximo & 1,6000 & 2,8000 & 2,1000 & 2,2000 & 1,0000 & 2,1000 \\
Mediana & 0,6000 & 1,0000 & 0,6000 & 0,1000 & 0,3000 & 0,8000 \\
Moda & 0,4000 & 1,0000 & 0,8000 & 0,1000 & 0,1000 & 0,8000 \\
\hline
\end{tabular}


Tabela 36 - Freqüência relativa, valores médios, desvio padrão, valor mínimo, valor máximo, mediana e moda, da amplitude da onda $S$ em milivolts nas derivações bipolares I, II e III e nas derivações unipolares aVR, aVL e aVF, obtido pelo eletrocardiograma de 100 eqüinos de salto criados na cidade de São Paulo- SP $-2006$

\begin{tabular}{lrrrrrr}
\hline & \multicolumn{3}{c}{ Derivações bipolares } & \multicolumn{3}{c}{ Derivações unipolares } \\
\cline { 2 - 7 } Amplitude onda S & I & II & III & aVR & aVL & aVF \\
\hline Freqüência relativa & 56 & 41 & 52 & 62 & 50 & 44 \\
Média & 0,1482 & 0,1256 & 0,2865 & 0,8823 & 0,2590 & 0,1659 \\
Desvio padrão & 0,1324 & 0,0603 & 0,1727 & 0,4737 & 0,3005 & 0,0854 \\
Valor mínimo & 0,0500 & 0,0500 & 0,1000 & 0,1000 & 0,0500 & 0,1000 \\
Valor máximo & 0,9000 & 0,3000 & 0,7000 & 2,3000 & 1,7000 & 0,4000 \\
Mediana & 0,1000 & 0,1000 & 0,2000 & 0,9000 & 0,1000 & 0,1000 \\
Moda & 0,1000 & 0,1000 & 0,2000 & 1,0000 & 0,1000 & 0,1000 \\
\hline
\end{tabular}

Tabela 37 - Freqüência relativa, valores médios, desvio padrão, valor mínimo, valor máximo, mediana e moda, da amplitude da onda T em milivolts nas derivações bipolares I, II e III e nas derivações unipolares aVR, aVL e aVF, obtido pelo eletrocardiograma de 100 eqüinos de salto criados na cidade de São Paulo- SP $-2006$

\begin{tabular}{lrrrrrr}
\hline & \multicolumn{3}{c}{ Derivações bipolares } & \multicolumn{3}{c}{ Derivações unipolares } \\
\cline { 2 - 7 } Amplitude onda T & I & II & III & aVR & aVL & aVF \\
\hline Freqüência relativa & 100 & 100 & 100 & 100 & 100 & 100 \\
Média & 0,3530 & 0,4425 & 0,4190 & 0,3525 & 0,3300 & 0,3860 \\
Desvio padrão & 0,1792 & 0,2042 & 0,1695 & 0,1837 & 0,1575 & 0,1622 \\
Valor mínimo & 0,1000 & 0,1000 & 0,2000 & 0,0500 & 0,1000 & 0,1000 \\
Mediana & 0,3000 & 0,4000 & 0,4000 & 0,3000 & 0,3000 & 0,3500 \\
Valor máximo & 0,8000 & 1,1000 & 1,0000 & 0,8000 & 0,8000 & 0,8000 \\
Moda & 0,2000 & 0,4000 & 0,4000 & 0,2000 & 0,3000 & 0,3000 \\
\hline
\end{tabular}

\subsubsection{Morfologia}

A análise morfológica das ondas e complexos está apresentada em três tabelas. As tabelas 38, 39 e 40 descrevem a representação morfológica em porcentagem da onda P, complexo QRS e onda T, respectivamente.

As diferentes morfologias apresentadas pela onda $\mathrm{P}$, complexo QRS e onda T encontram-se dispostas nas figuras 18 a 32, a seguir. 
No presente trabalho a onda $P$ apresentou-se de 11 formas distintas nas derivações bipolares e unipolares aumentadas. A morfologia bífida possibilitou a divisão da onda P em duas porções distintas, a primeira chamada de P1 e a segunda chamada de P2.

Quanto à morfologia do complexo QRS, obteve-se 5 formas diferentes de morfologia. A primeira com a presença das ondas $Q, R$ e $S(Q R S)$, a segunda com a ausência da onda $S(Q R)$, a terceira com a ausência da onda $Q(R S)$, a quarta sem a presença da onda $\mathrm{R}$ formando o complexo $\mathrm{QS}$ e por fim a presença da onda $\mathrm{R}$ sem a presença das ondas Q e S.

A onda T também apresentou 5 formatos distintos, estando positiva e única $(+)$, negativa e única (-), bifásica com a primeira porção negativa e a segunda porção positiva $(-+)$, bifásica com a primeira porção positiva e a segunda porção negativa (+ -) e por fim bífida e negativa (- -).

Segundo a descrição de alguns autores, existem alterações de onda T que podem estar associadas à queda de performance física ou falta de condicionamento físico. Estas alterações incluiriam onda T positiva ou bifásica na derivação bipolar I e onda T negativa na derivação unipolar aumentada aVR (ROSE; BACKHOUSE; ILKIIW, 1980; STEEL, 1963; STEWART et al., 1983). Seguindo estes parâmetros aproximadamente $44 \%$ dos eqüinos apresentaram alterações de onda T na derivação I e $33 \%$ na derivação aVR, e ainda, segundo atividade física, $41,1 \%$ dos animais do grupo 1 e 47,7\% dos eqüinos do grupo 2 apresentaram alterações de onda $T$ na derivação DI; e na derivação aVR, houve $32,1 \%$ de alterações no grupo 1 contra 34,0\% de alterações de onda T no grupo 2. 
Em relação a variável sexo, observou-se maior proporção de alterações em onda $T$ nas fêmeas do que nos machos, na derivação DI as fêmeas tiveram $48,8 \%$ de alterações e os machos, 40,9\%. Na derivação aVR, as fêmeas apresentaram $43,6 \%$ de ondas T negativas e os machos $26,2 \%$ de alterações.

Quanto à faixa etária, o grupo com idade de 14 a 19 anos apresentou maiores proporções de alterações em onda T nas duas derivações analisadas (DI e aVR), correspondendo a $64,29 \%$ e $35,7 \%$, em cada derivação respectivamente. O grupo com idade entre 9 e 13 anos apresentou 45,28\% de alterações em DI e 30,2\% em aVR e o grupo com idade entre 4 e 8 anos obteve 33,4\% de alterações na derivação DI e 36,4\% na derivação aVR.

Os dados individuais com as representações morfológicas das ondas $\mathrm{P}$ e T e complexo QRS, encontram-se nos apêndices $\mathrm{H}$, I e J.

Tabela 38 - Porcentagem da representação morfológica da onda $\mathrm{P}$ nas derivações bipolares I, II e III e, unipolares aVR, aVL e aVF, obtido pelo eletrocardiograma de 100 eqüinos de salto criados na cidade de São Paulo-SP - 2006

\begin{tabular}{lcccccc}
\hline \multirow{2}{*}{ Morfologia onda $\mathbf{P}$} & \multicolumn{3}{c}{ Derivações bipolares } & \multicolumn{3}{c}{ Derivações unipolares } \\
\cline { 2 - 7 } & $\begin{array}{c}\mathbf{P}(\mathbf{D I}) \\
(\%)\end{array}$ & $\begin{array}{r}\mathbf{P}(\mathbf{D I I}) \\
(\%)\end{array}$ & $\begin{array}{c}\mathbf{P}(\mathbf{D I I I}) \\
(\%)\end{array}$ & $\mathbf{P}(\mathbf{a V R})$ & $\mathbf{P}(\mathbf{a V L})$ & $\mathbf{P}(\mathbf{a V F})$ \\
$(\mathbf{\%})$ & $(\%)$ & $(\%)$ \\
\hline$(+)$ & 26,0 & 36,0 & 39,0 & - & 11,0 & 40,0 \\
$(++)$ & 61,0 & 53,0 & 36,0 & - & 35,0 & 44,0 \\
$(+-)$ & 1,0 & - & 1,0 & 9,0 & 7,0 & 1,0 \\
$(-+)$ & 7,0 & 10,0 & 8,0 & - & 2,0 & 11,0 \\
$(-)$ & - & - & 4,0 & 22,0 & 19,0 & 3,0 \\
$(--)$ & 2,0 & - & 6,0 & 68,0 & 22,0 & - \\
$(--,+)$ & 1,0 & - & - & - & - & - \\
$(-,++)$ & 2,0 & 1,0 & 5,0 & - & - & 1,0 \\
$(+++)$ & - & - & 1,0 & - & - & - \\
$(++,-)$ & - & - & - & 1,0 & 3,0 & - \\
$(+,--)$ & - & - & - & - & 1,0 & - \\
\hline Total & 100,0 & 100,0 & 100,0 & 100,0 & 100,0 & 100,0 \\
\hline
\end{tabular}

Nota: (+) onda $\mathrm{P}$ única positiva, (++) onda $\mathrm{P}$ bífida e positiva, (+ -) onda $\mathrm{P}$ bifásica com primeira porção (P1) positiva e segunda porção (P2) negativa, $(-+)$ onda $P$ bifásica com P1 negativa e P2 positiva, (-) onda $\mathrm{P}$ única e negativa, (- -) onda $\mathrm{P}$ bífida e negativa, $(--,+)$ onda $\mathrm{P}$ bifásica com $\mathrm{P} 1$ bífida e negativa $\mathrm{e}$ $\mathrm{P} 2$ positiva, $(-,++)$ onda $\mathrm{P}$ bifásica com $\mathrm{P} 1$ negativa e $\mathrm{P} 2$ bífida e positiva, $(+++)$ onda $\mathrm{P}$ trífida e positiva, $(++,-)$ onda $\mathrm{P}$ bifásica com P1 bífida e positiva e P2 negativa e (+, - -) onda P bifásica com P1 positiva e $\mathrm{P} 2$ bifida e negativa. 
Tabela 39 - Porcentagem da representação morfológica do complexo QRS nas derivações bipolares I, II e III e derivações unipolares aVR, aVL e aVF, obtido pelo eletrocardiograma de 100 eqüinos de salto criados na cidade de São Paulo- SP $-2006$

\begin{tabular}{lcccccc}
\hline \multirow{2}{*}{ Morfologia QRS } & \multicolumn{3}{c}{ Derivações bipolares } & \multicolumn{3}{c}{ Derivações unipolares } \\
\cline { 2 - 7 } & $\begin{array}{c}\text { D I } \\
\mathbf{( \% )}\end{array}$ & $\begin{array}{c}\text { D II } \\
\mathbf{( \% )}\end{array}$ & $\begin{array}{c}\text { D III } \\
\mathbf{( \% )}\end{array}$ & $\begin{array}{c}\text { aVR } \\
\mathbf{( \% )}\end{array}$ & $\begin{array}{c}\text { aVL } \\
\mathbf{( \% )}\end{array}$ & $\begin{array}{c}\text { aVF } \\
\text { (\%) }\end{array}$ \\
\hline QRS & 33,0 & 27,0 & 16,0 & - & 19,0 & 17,0 \\
QR & 25,0 & 38,0 & 26,0 & 7,0 & 21,0 & 35,0 \\
RS & 23,0 & 14,0 & 36,0 & 62,0 & 31,0 & 27,0 \\
QS & 4,0 & - & 4,0 & 30,0 & 10,0 & 3,0 \\
R & 15,0 & 21,0 & 18,0 & 1,0 & 19,0 & 18,0 \\
\hline Total & 100,0 & 100,0 & 100,0 & 100,0 & 100,0 & 100,0 \\
\hline
\end{tabular}

Tabela 40 - Porcentagem da representação morfológica da onda $T$ nas derivações unipolares aVR, aVL e aVF, obtido pelo eletrocardiograma de 100 eqüinos de salto criados na cidade de São Paulo - SP - 2006

\begin{tabular}{lcccccc}
\hline \multirow{2}{*}{ Morfologia T } & \multicolumn{3}{c}{ Derivações bipolares } & \multicolumn{3}{c}{ Derivações unipolares } \\
\cline { 2 - 7 } & T(DI) & T (DII) & T(DIII) & T(aVR) & T(aVL) & T(aVF) \\
& $(\%)$ & $(\%)$ & $(\%)$ & $(\%)$ & $(\%)$ & $(\%)$ \\
\hline$(+)$ & 22,0 & 58,0 & 79,0 & 21,0 & 10,0 & 70,0 \\
$(-)$ & 52,0 & 7,0 & 5,0 & 33,0 & 76,0 & 7,0 \\
$(-+)$ & 20,0 & 33,0 & 12,0 & 4,0 & 8,0 & 21,0 \\
$(+-)$ & 2,0 & 2,0 & 4,0 & 42,0 & 4,0 & 2,0 \\
$(--)$ & 4,0 & - & - & - & 2,0 & - \\
\hline Total & 100,0 & 100,0 & 100,0 & 100,0 & 100,0 & 100,0 \\
\hline
\end{tabular}

Nota: (+) onda T única e positiva, (-) onda T única e negativa, (- +) onda T bifásica, sendo a primeira porção negativa e a segunda porção positiva, (+ -) onda T bifásica, sendo a primeira porção positiva e a segunda porção negativa e (- -) onda T bífida e negativa. 


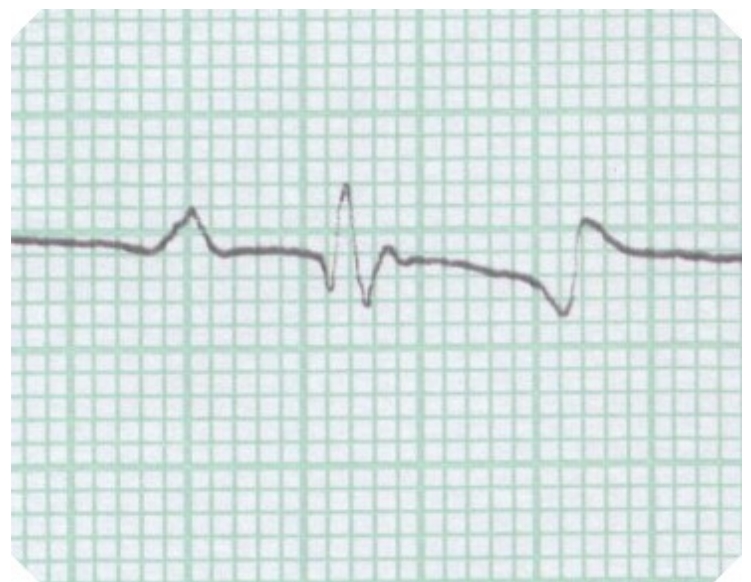

Figura 18 -

Eletrocardiograma

de

eqüino macho da raça $\mathrm{BH}$

com 7 anos, apresentando onda $P$ única e positiva $(+)$, complexo QRS e T bifásica $(-+)$ na derivação bipolar III

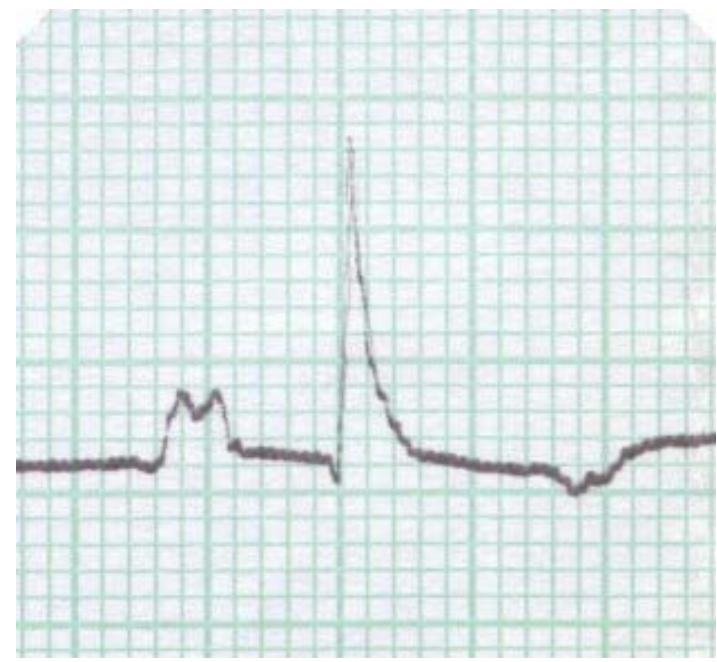

Figura 20 -

Eletrocardiograma de eqüino macho da raça $\mathrm{BH}$ com 7 anos, apresentando onda $\mathrm{P}$ bífida e positiva (++), complexo QRS com ondas QR e onda T bífida e negativa (- -$)$ na derivação bipolar I

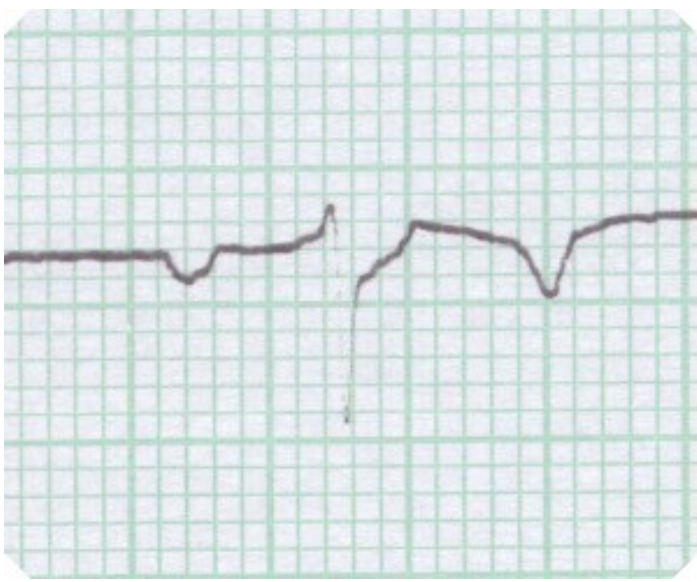

Figura 19 - Eletrocardiograma de eqüino macho da raça $\mathrm{BH}$ com 9 anos, apresentando onda $P$ única e negativa (-), complexo QRS com ondas $\mathrm{R}$ e $\mathrm{S}$ e onda $\mathrm{T}$ negativa (-) na derivação unipolar aumentada aVL

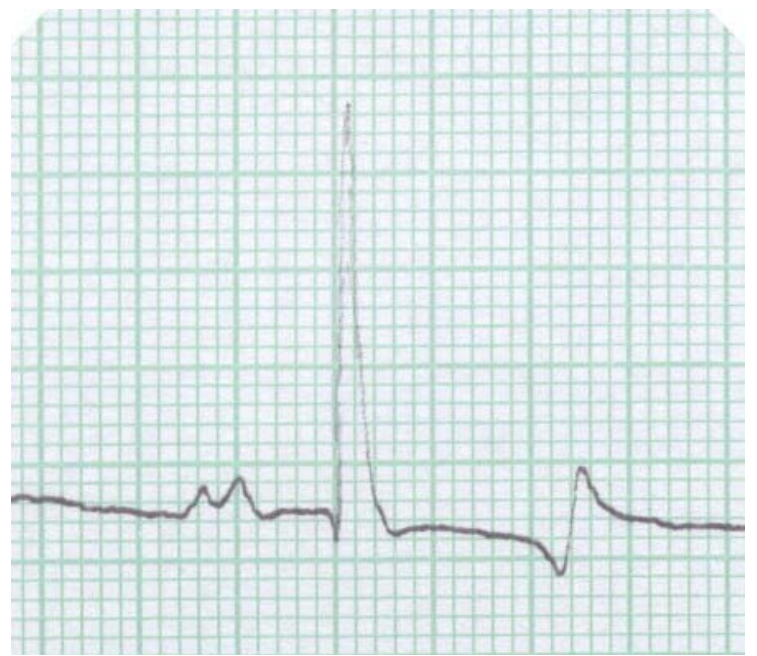

Figura 21 - Eletrocardiograma de eqüino macho da raça Hosteiner com 11 anos, apresentando onda $\mathrm{P}$ bífida e positiva $(++)$, complexo QRS com ondas QR e T bifásica $(-+)$ na derivação unipolar aumentada $\mathrm{aVR}$ 


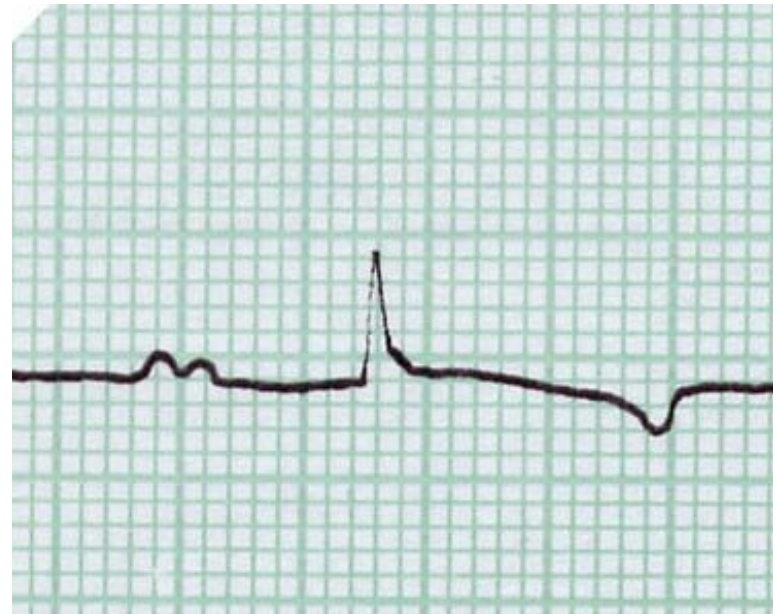

Figura $22-$

Eletrocardiograma de eqüino fêmea da raça $\mathrm{BH}$ com 9 anos, apresentando onda $P$ bífida e positiva $(++)$, onda $R$ e onda $T$ negativa (-) na derivação unipolar aumentada aVL

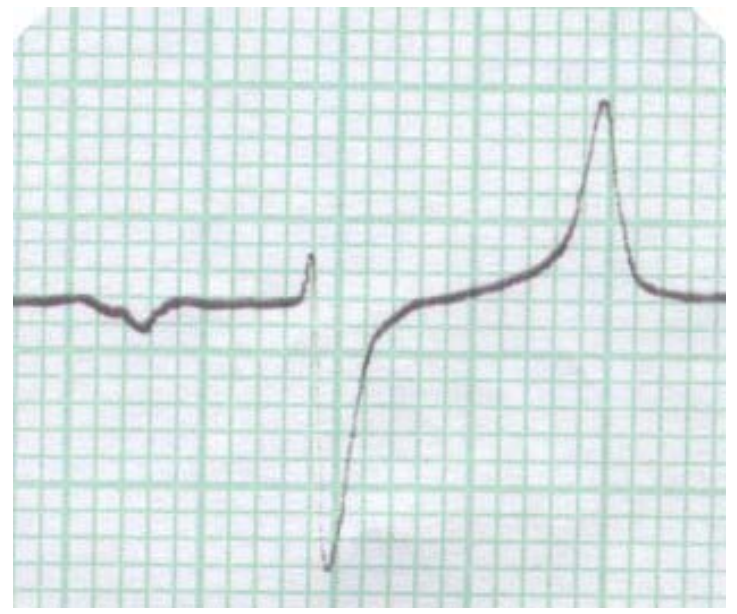

Figura 24 - Eletrocardiograma de eqüino macho da raça $\mathrm{BH}$ com 7 anos, apresentando onda $\mathrm{P}$ bífida e negativa (- -), complexo QRS com ondas $\mathrm{R}$ e $\mathrm{S}$ e onda $\mathrm{T}$ positiva $(+)$ na derivação unipolar aumentada aVR

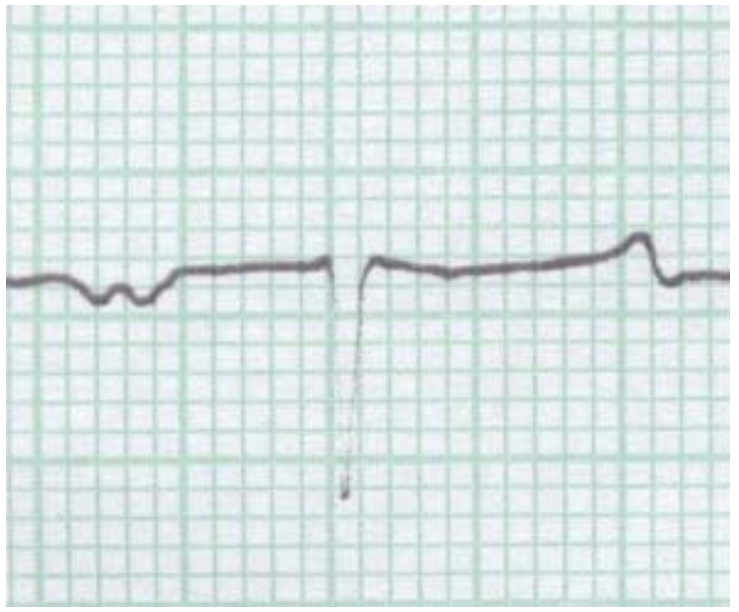

Figura 23 - Eletrocardiograma de eqüino macho da raça $\mathrm{BH}$ com 8 anos, apresentando onda $\mathrm{P}$ bífida e negativa (- -) complexo QRS com morfologia QS e onda T bifásica (+ -) na derivação unipolar aumentada aVR

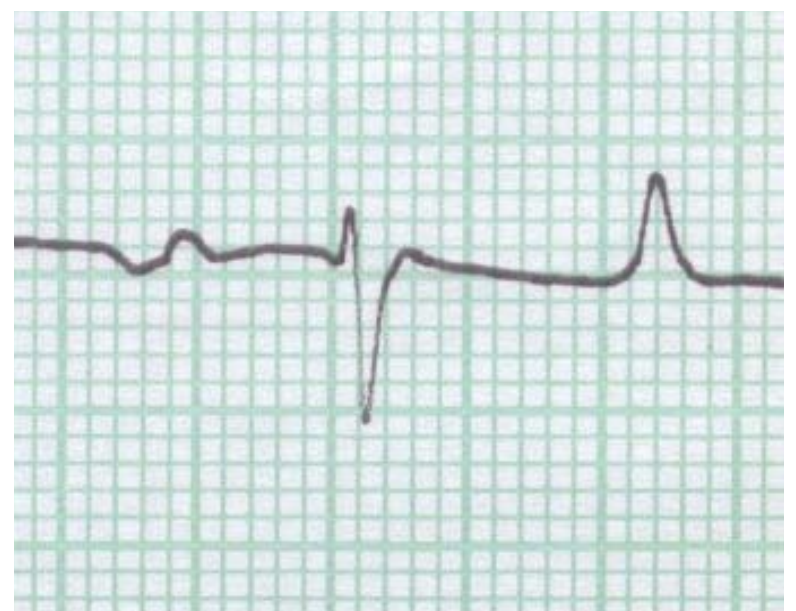

Figura 25 - Eletrocardiograma de eqüino fêmea da raça Anglo-árabe com 9 anos, apresentando onda $P$ bifásica $(-+)$, complexo QRS com ondas $R$ e $S$ e onda $T$ positiva (+) na derivação bipolar III 


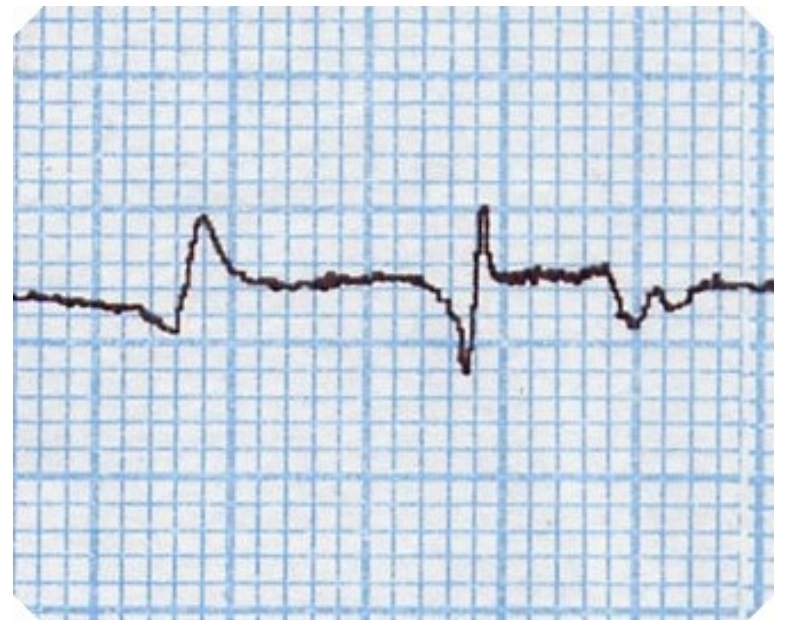

Figura 26 - Eletrocardiograma de eqüino fêmea da raça $\mathrm{BH}$ com 12 anos, apresentando onda $\mathrm{P}$ bifásica $(-+)$, complexo QRS com ondas $Q$ e $R$ e onda $T$ bífida e negativa (- -$)$ na derivação bipolar II

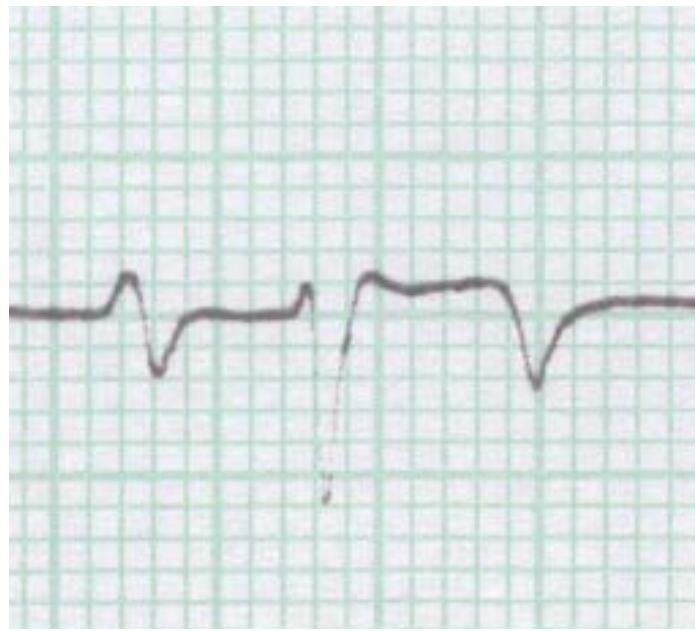

Figura 27 - Eletrocardiograma de eqüino macho SRD com 17 anos, apresentando onda $\mathrm{P}$ bifásica $(-\quad+)$, complexo QRS com ondas $\mathrm{R}$ e $\mathrm{S}$ e onda $\mathrm{T}$ negativa (-) na derivação unipolar aumentada aVR

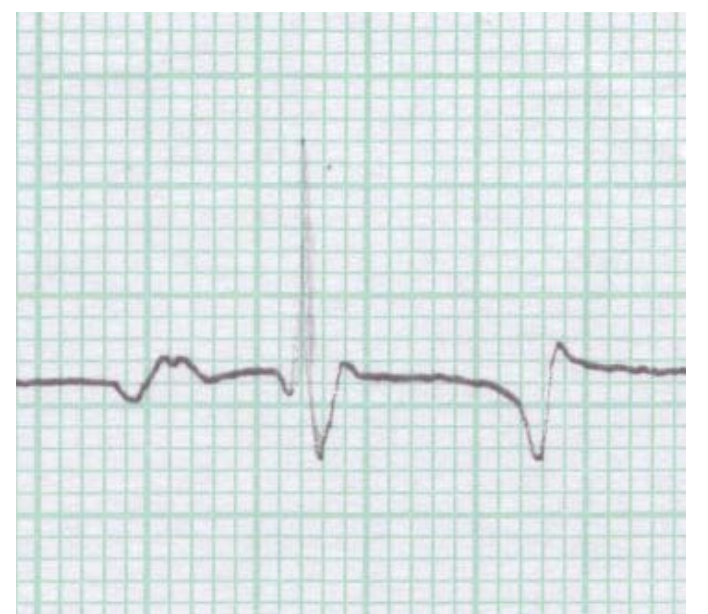

Figura 28 - Eletrocardiograma de eqüino fêmea da raça $\mathrm{BH}$ com 7 anos, apresentando onda $P$ bifásica com segunda porção (P2) bífida $(-,++)$, complexo QRS e onda T bifásica $(-+)$ na derivação bipolar III

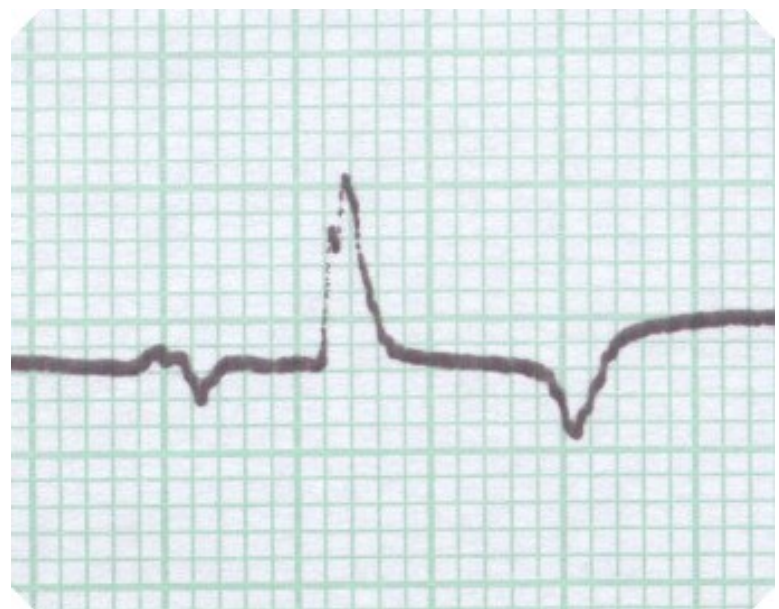

Figura 29 - Eletrocardiograma de eqüino macho da raça $\mathrm{BH}$ com 7 anos, apresentando onda $P$ bifásica com primeira porção (P1) bífida (++, -), onda $\mathrm{R}$ fenestrada e onda $T$ negativa (-) na derivação unipolar aumentada $\mathrm{aVL}$ 


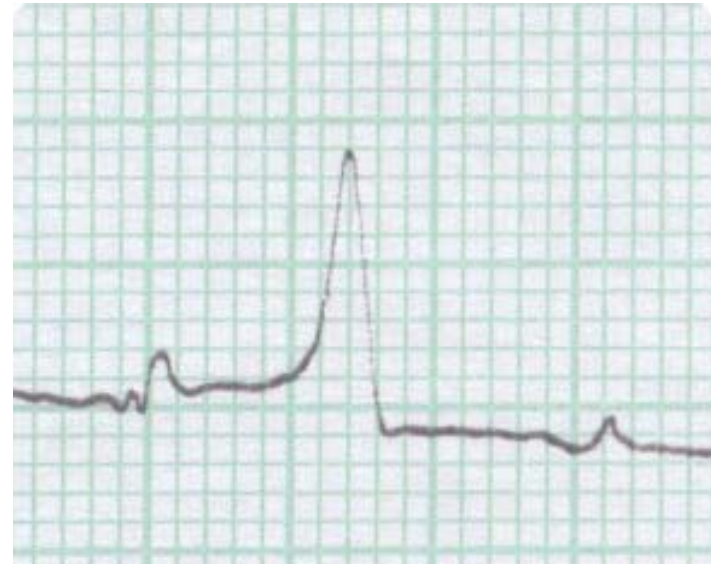

Figura 30 - Eletrocardiograma de eqüino fêmea da raça $\mathrm{BH}$ com 8 anos, apresentando onda $\mathrm{P}$ bifásica com primeira porção $(\mathrm{P} 1)$ bífida e negativa $(--,+)$, onda $\mathrm{R} e$ onda $T$ bifásica $(-+)$ na derivação bipolar I

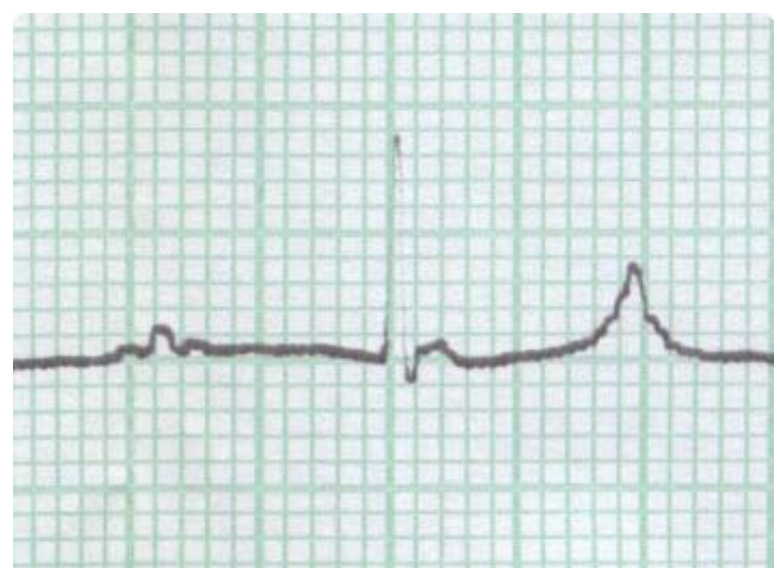

Figura 32 - Eletrocardiograma de eqüino macho da raça $\mathrm{BH}$ com 6 anos, apresentando onda $P$ trífida $\mathrm{e}$ positiva $(+++)$, complexo QRS com ondas $R$ e $S$ e onda $T$ positiva (+) na derivação bipolar III

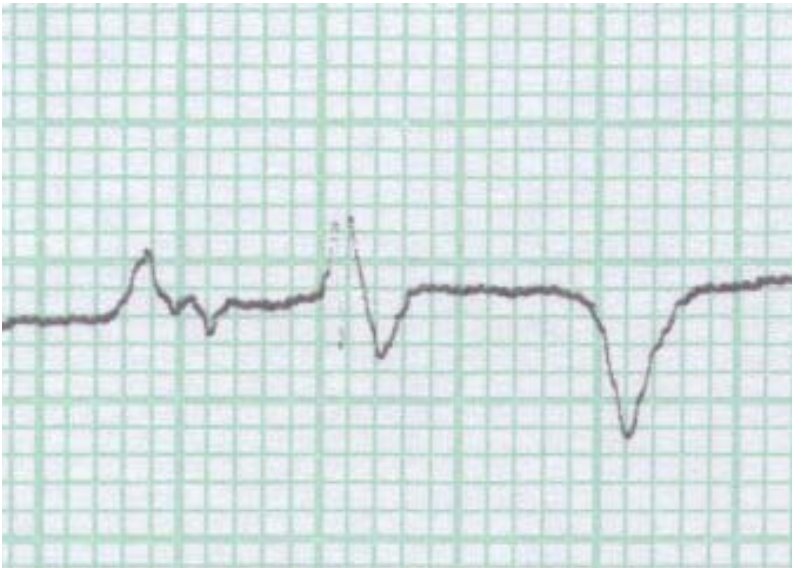

Figura 31 - Eletrocardiograma de eqüino fêmea da raça $\mathrm{BH}$ com 6 anos, apresentando onda $\mathrm{P}$ bifásica com segunda porção (P2) bífida e negativa (+, - -), complexo QRS, com ondas $R$ fenestrada e $S$ e onda $T$ negativa (-) na derivação unipolar aumentada aVL 


\subsubsection{Análise Estatística pelas Variáveis: Atividade Física, Sexo e Idade.}

Para organização da análise estatística deste trabalho, optou-se por apresentar somente os resultados com diferenças significantes, divididos nas três variáveis abaixo.

\subsubsection{Variável Atividade Física}

Quanto ao grupo de atividade física, houve diferença significativa na duração do intervalo QT nas derivações bipolares I e III (Tabela 41 e 42, respectivamente) e na derivação unipolar aVF (Tabela 43). Em relação à amplitude, apresentou diferença significativa: a amplitude da primeira porção da onda $P$ bífida (P1) na derivação bipolar I (Tabela 44) e na derivação unipolar aVL (Tabela 45), e também, a amplitude da onda T na derivação bipolar I (Tabela 46).

O complexo QRS apresentou diferença significativa quanto a sua morfologia na derivação bipolar II. Nas demais análises estatísticas não houve diferença significativa entre os grupos segundo atividade física (Tabela 47). 
Tabela 41 - Valores médios, desvio padrão, valor mínimo, valor máximo, mediana e moda, da duração do intervalo QT em segundos na derivação bipolar I, obtidos pelo eletrocardiograma de 100 eqüinos de salto criados na cidade de São Paulo agrupados segundo atividade física - SP -2006

\begin{tabular}{lcc}
\hline & \multicolumn{2}{c}{ Grupo de Atividade Física } \\
\cline { 2 - 3 } Duração do intervalo QT (DI) & $\begin{array}{c}\text { Grupo 1 } \\
(\mathbf{N = 5 6 )}\end{array}$ & $\begin{array}{c}\text { Grupo 2 } \\
(\mathbf{N}=44)\end{array}$ \\
\hline Média & $0,4829^{\mathrm{a}}$ & $0,4620^{\mathrm{b}}$ \\
Desvio Padrão & 0,0533 & 0,0487 \\
Valor mínimo & 0,3200 & 0,3600 \\
Valor máximo & 0,4800 & 0,4800 \\
Mediana & 0,6000 & 0,5600 \\
Moda & 0,4800 & 0,4800 \\
\hline
\end{tabular}

Nota: As letras (ab) não coincidentes indicam diferença significativa entre os grupos 1 e 2 $(t=2,0124$ e $p=0,0469)$.

Tabela 42 - Valores médios, desvio padrão, valor mínimo, valor máximo, mediana e moda, da duração do intervalo QT em segundos na derivação bipolar III, , obtidos pelo eletrocardiograma de 100 eqüinos de salto criados na cidade de São Paulo agrupados segundo atividade física - SP - 2006

\begin{tabular}{|c|c|c|}
\hline \multirow{2}{*}{ Duração do intervalo QT (DIII) } & \multicolumn{2}{|c|}{ Grupo de Atividade Física } \\
\hline & $\begin{array}{c}\text { Grupo } 1 \\
(\mathrm{~N}=56)\end{array}$ & $\begin{array}{c}\text { Grupo } 2 \\
(\mathrm{~N}=44)\end{array}$ \\
\hline Média & $0,4907^{a}$ & $0,4655^{b}$ \\
\hline Desvio Padrão & 0,0531 & 0,0586 \\
\hline Valor mínimo & 0,3200 & 0,3200 \\
\hline Valor máximo & 0,5600 & 0,5600 \\
\hline Mediana & 0,5200 & 0,4800 \\
\hline Moda & 0,5200 & 0,4400 \\
\hline \multicolumn{3}{|c|}{$\begin{array}{l}\text { Nota: As letras (ab) não coincidentes indicam diferença significativa entre os grupos } 1 \text { e } 2 \\
(t=2,2562 \text { e } p=0,0263) \text {. }\end{array}$} \\
\hline \multirow[t]{2}{*}{ Tabela 43 - } & $\begin{array}{l}\text { o, valor } m \\
\text { em segun } \\
\text { eqüinos } c \\
\text { física - SP }\end{array}$ & $\begin{array}{l}\text { mediana e moda, } \\
\text { ipolar aVF, obtidos } \\
\text { dade de São Paulo, }\end{array}$ \\
\hline & \multicolumn{2}{|c|}{ Grupo de Atividade Física } \\
\hline Duração do intervalo QT (aVF) & $\begin{array}{c}\text { Grupo } 1 \\
(\mathrm{~N}=56)\end{array}$ & $\begin{array}{c}\text { Grupo } 2 \\
(\mathrm{~N}=44)\end{array}$ \\
\hline & $0,5086^{a}$ & $0,4782^{b}$ \\
\hline Desvio Padrão & 0,0594 & 0,0495 \\
\hline Valor mínimo & 0,3200 & 0,3600 \\
\hline Valor máximo & 0,6000 & 0,5600 \\
\hline & 0,5200 & 0,4800 \\
\hline Moda & 0,5200 & 0,4800 \\
\hline
\end{tabular}

Nota: As letras (ab) não coincidentes indicam diferença significativa entre os grupos 1 e 2 $(t=2,7276$ e $p=0,0076)$. 
Tabela 44 - Freqüência relativa, média, desvio padrão, valor mínimo, valor máximo, mediana e moda, da amplitude em milivolts da primeira porção da onda P bífida (P1) na derivação bipolar I, obtidos pelo eletrocardiograma de 100 eqüinos de salto criados na cidade de São Paulo, agrupados segundo atividade física - SP 2006

\begin{tabular}{lcc}
\hline Amplitude em mV de P1 (DI) & \multicolumn{2}{c}{ Grupo de Atividade Física } \\
\cline { 2 - 3 } & $\begin{array}{c}\text { Grupo 1 } \\
(\mathbf{N = 5 6 )}\end{array}$ & $\begin{array}{c}\text { Grupo 2 } \\
\text { (N=44) }\end{array}$ \\
\hline Freqüência relativa & 33 & 30 \\
Média & $0,1348^{\mathrm{a}}$ & $0,1050^{\mathrm{b}}$ \\
Desvio Padrão & 0,0508 & 0,0497 \\
Valor mínimo & 0,0500 & 0,0500 \\
Valor máximo & 0,2000 & 0,2000 \\
Mediana & 0,1000 & 0,1000 \\
Moda & 0,1000 & 0,1000 \\
\hline
\end{tabular}

Nota: As letras (ab) não coincidentes indicam diferença significativa entre os grupos 1 e 2 $(t=2,3536$ e $p=0,0218)$.

Tabela 45 - Freqüência relativa, média, desvio padrão, valor mínimo, valor máximo, mediana e moda, da amplitude em milivolts da primeira porção da onda P bífida (P1) na derivação unipolar aVL, obtidos pelo eletrocardiograma de 100 eqüinos de salto criados na cidade de São Paulo, agrupados segundo atividade física - SP 2006

\begin{tabular}{lcc}
\hline & \multicolumn{2}{c}{ Grupo de Atividade Física } \\
\cline { 2 - 3 } Amplitude em mV de P1 (aVL) & $\begin{array}{c}\text { Grupo 1 } \\
(\mathbf{N}=\mathbf{5 6})\end{array}$ & $\begin{array}{c}\text { Grupo 2 } \\
(\mathbf{N}=\mathbf{4 4})\end{array}$ \\
\hline Freqüência relativa & 29 & 28 \\
Média & $0,1069^{\mathrm{a}}$ & $0,0821^{\mathrm{b}}$ \\
Desvio Padrão & 0,0477 & 0,0435 \\
Valor mínimo & 0,0500 & 0,0500 \\
Valor máximo & 0,2000 & 0,2000 \\
Mediana & 0,1000 & 0,0500 \\
Moda & 0,1000 & 0,0500 \\
\hline Nota: As letras (ab) não coincidentes indicam diferença significativa entre os grupos 1 e 2 \\
(t=2,0460 e p=0,0456).
\end{tabular}


Tabela 46 - Valores médios, desvio padrão, valor mínimo, valor máximo, mediana e moda, da amplitude em milivolts da onda $\mathrm{T}$ na derivação bipolar I, obtidos pelo eletrocardiograma de 100 eqüinos de salto criados na cidade de São Paulo agrupados segundo atividade física - SP - 2006

\begin{tabular}{lcc}
\hline & \multicolumn{2}{c}{ Grupo de Atividade Física } \\
\cline { 2 - 3 } Amplitude em mV de T (DI) & $\begin{array}{c}\text { Grupo 1 } \\
(\mathbf{N = 5 6 )}\end{array}$ & $\begin{array}{c}\text { Grupo 2 } \\
\text { (N=44) }\end{array}$ \\
\hline Média & $0,3884^{\mathrm{a}}$ & $0,3080^{\mathrm{b}}$ \\
Desvio Padrão & 0,1940 & 0,1486 \\
Valor mínimo & 0,1000 & 0,1000 \\
Valor máximo & 0,8000 & 0,7000 \\
Mediana & 0,3000 & 0,3000 \\
Moda & 0,2000 & 0,2000 \\
\hline Nota: As letras (ab) não coincidentes indicam diferença significativa entre os grupos 1 e 2 \\
(t=2,2747 e p=0,0251).
\end{tabular}

Tabela 47 - Freqüência e porcentagem da representação morfológica do complexo QRS na derivação unipolar II, obtido pelo eletrocardiograma de 100 eqüinos de salto criados na cidade de São Paulo, agrupados segundo atividade física - SP - 2006

\begin{tabular}{lccc}
\hline \multirow{2}{*}{ Morfologia do complexo QRS em DII } & \multicolumn{3}{c}{ Grupo de Atividade Física } \\
\cline { 2 - 4 } & $\begin{array}{c}\text { Freqüência } \\
(\mathrm{N})\end{array}$ & $\begin{array}{c}\text { Grupo 1 } \\
(\%)\end{array}$ & $\begin{array}{c}\text { Grupo 2 } \\
\text { (\%) }\end{array}$ \\
\hline QRS & 27 & 63,0 & 37,0 \\
QR & 38 & 47,4 & 52,6 \\
R & 21 & 81,0 & 19,0 \\
RS & 14 & 28,6 & 71,4 \\
\hline Total & 100 & 56,0 & 44,0 \\
\hline
\end{tabular}

Nota: Houve diferença significativa entre os grupos 1 e 2, quanto a distribuição das diferentes representações morfológicas do complexo QRS $\left(x^{2}=11,2613\right.$, graus de liberdade $=3$ e $\mathrm{p}=0,0104$ ). 


\subsubsection{Variável Sexo}

As análises estatísticas que apresentaram diferenças significativas estão distribuídas em dez tabelas. Quanto à duração as variáveis foram: intervalo P-R na derivação unipolar aVR (Tabela 48), onda S na derivação bipolar I (Tabela 49), e onda T na derivação bipolar II (Tabela 50). Em relação à amplitude as variáveis foram: onda P única nas derivações unipolares aVL e aVF (Tabelas 51 e 52, respectivamente), segunda porção da onda P bífida (P2) na derivação bipolar III (Tabela 53), onda Q na derivação bipolar I (Tabela 54) e onda T nas derivações bipolar II e unipolar aVF (Tabelas 55 e 56, respectivamente). A onda $\mathrm{T}$ também apresentou diferença significativa na sua morfologia em relação ao sexo na derivação bipolar II (Tabela 57).

Tabela 48 - Valores médios, desvio padrão, valor mínimo, valor máximo, mediana e moda, da duração do intervalo P-R em segundos na derivação unipolar aVR, obtidos pelo eletrocardiograma de 100 eqüinos de salto criados na cidade de São Paulo, agrupados por sexo - SP -2006

\begin{tabular}{lcc}
\hline & \multicolumn{2}{c}{ SEXO } \\
\cline { 2 - 3 } Duração do intervalo P-R em aVR & $\begin{array}{c}\text { Fêmeas } \\
(\mathbf{N}=39)\end{array}$ & $\begin{array}{c}\text { Machos } \\
(\mathbf{N}=61)\end{array}$ \\
\hline Média & $0,3077^{\mathrm{a}}$ & $0,3328^{\mathrm{b}}$ \\
Desvio Padrão & 0,0574 & 0,0641 \\
Valor mínimo & 0,2000 & 0,2400 \\
Valor máximo & 0,4800 & 0,5200 \\
Mediana & 0,2800 & 0,3200 \\
Moda & 0,2800 & 0,3200 \\
\hline
\end{tabular}

Nota: As letras $(a b)$ não coincidentes indicam diferença significativa entre os grupos segundo sexo $(t=1,9874$ e $p=0,0497)$. 
Tabela 49 - Freqüência relativa, média, desvio padrão, valor mínimo, valor máximo, mediana e moda, da duração da onda S em segundos na derivação bipolar I, obtidos pelo eletrocardiograma de 100 eqüinos de salto criados na cidade de São Paulo, agrupados por sexo - SP -2006

\begin{tabular}{lcc}
\hline & \multicolumn{2}{c}{ SEXO } \\
\cline { 2 - 3 } Duração da onda S em DI & $\begin{array}{c}\text { Fêmeas } \\
(\mathbf{N = 3 9 )}\end{array}$ & $\begin{array}{c}\text { Machos } \\
(\mathbf{N}=61)\end{array}$ \\
\hline Freqüência relativa & 21 & 35 \\
Média & $0,0410^{\mathrm{a}}$ & $0,0534^{\mathrm{b}}$ \\
Desvio Padrão & 0,0161 & 0,0210 \\
Valor mínimo & 0,0200 & 0,0200 \\
Valor máximo & 0,0800 & 0,0800 \\
Mediana & 0,0400 & 0,0600 \\
Moda & 0,0400 & 0,0400 \\
\hline
\end{tabular}

Nota: As letras (ab) não coincidentes indicam diferença significativa entre os grupos segundo $\operatorname{sexo}(t=2,3387$ e $p=0,0231)$.

Tabela 50 - Valores médios, desvio padrão, valor mínimo, valor máximo, mediana e moda, da duração da onda T em segundos na derivação bipolar II, obtidos pelo eletrocardiograma de 100 eqüinos de salto criados na cidade de São Paulo, agrupados por sexo - SP - 2006

\begin{tabular}{lcc}
\hline & \multicolumn{2}{c}{ SEXO } \\
\cline { 2 - 3 } Duração da onda T em DII & $\begin{array}{c}\text { Fêmeas } \\
(\mathbf{N}=\mathbf{3 9})\end{array}$ & $\begin{array}{c}\text { Machos } \\
(\mathbf{N}=61)\end{array}$ \\
\hline Média & $0,1026^{\mathrm{a}}$ & $0,1197^{\mathrm{b}}$ \\
Desvio Padrão & 0,0328 & 0,0315 \\
Valor mínimo & 0,0400 & 0,0600 \\
Valor máximo & 0,2000 & 0,2000 \\
Mediana & 0,0800 & 0,1200 \\
Moda & 0,0800 & 0,1200 \\
\hline
\end{tabular}

Nota: As letras $(a b)$ não coincidentes indicam diferença significativa entre os grupos segundo $\operatorname{sexo}(t=2,6052$ e $p=0,0106)$. 
Tabela 51 - Freqüência relativa, média, desvio padrão, valor mínimo, valor máximo, mediana e moda, da amplitude em milivolts da onda $\mathrm{P}$ única na derivação unipolar aVL, obtido pelo eletrocardiograma de 100 eqüinos de salto criados na cidade de São Paulo, agrupados por sexo - SP - 2006

\begin{tabular}{lcc}
\hline & \multicolumn{2}{c}{ SEXO } \\
\cline { 2 - 3 } Amplitude de onda P única em aVL & $\begin{array}{c}\text { Fêmeas } \\
(\mathbf{N}=\mathbf{3 9})\end{array}$ & $\begin{array}{c}\text { Machos } \\
(\mathbf{N}=\mathbf{6 1})\end{array}$ \\
\hline Freqüência relativa & 16 & 14 \\
Média & $0,1531^{\mathrm{a}}$ & $0,0929^{\mathrm{b}}$ \\
Desvio padrão & 0,0806 & 0,0182 \\
Valor mínimo & 0,1000 & 0,0500 \\
Valor máximo & 0,3000 & 0,1000 \\
Mediana & 0,1000 & 0,1000 \\
Moda & 0,1000 & 0,1000 \\
\hline
\end{tabular}

Nota: As letras (ab) não coincidentes indicam diferença significativa entre os grupos segundo $\operatorname{sexo}(t=2,7335$ e $p=0,0107)$.

Tabela 52 - Freqüência relativa, média, desvio padrão, valor mínimo, valor máximo, mediana e moda, da amplitude em milivolts da onda $\mathrm{P}$ única na derivação unipolar aVF, obtido pelo eletrocardiograma de 100 eqüinos de salto criados na cidade de São Paulo, agrupados por sexo - SP - 2006

\begin{tabular}{lcc}
\hline & \multicolumn{2}{c}{ SEXO } \\
\cline { 2 - 3 } Amplitude da onda P única em aVF & $\begin{array}{c}\text { Fêmeas } \\
(\mathbf{N}=\mathbf{3 9})\end{array}$ & $\begin{array}{c}\text { Machos } \\
\mathbf{( N = 6 1 )}\end{array}$ \\
\hline Freqüência relativa & 14 & 29 \\
Média & $0,2821^{\mathrm{a}}$ & $0,1897^{\mathrm{b}}$ \\
Desvio padrão & 0,1265 & 0,0573 \\
Valor mínimo & 0,1000 & 0,1000 \\
Valor máximo & 0,6000 & 0,3000 \\
Mediana & 0,2500 & 0,2000 \\
Moda & 0,2000 & 0,2000 \\
\hline
\end{tabular}

Nota: As letras (ab) não coincidentes indicam diferença significativa entre os grupos segundo $\operatorname{sexo}(t=3,3227$ e $p=0,0019)$. 
Tabela 53 - Freqüência relativa, média, desvio padrão, valor mínimo, valor máximo, mediana e moda, da amplitude em milivolts da segunda porção da onda P bífida (P2) na derivação bipolar III, obtido pelo eletrocardiograma de 100 eqüinos de salto criados na cidade de São Paulo, agrupados por sexo - SP - 2006

\begin{tabular}{lcc}
\hline & \multicolumn{2}{c}{ SEXO } \\
\cline { 2 - 3 } Amplitude da onda P2 em DIII & $\begin{array}{c}\text { Fêmeas } \\
(\mathbf{N}=\mathbf{3 9})\end{array}$ & $\begin{array}{c}\text { Machos } \\
(\mathbf{N}=\mathbf{6 1})\end{array}$ \\
\hline Freqüência relativa & 19 & 24 \\
Média & $0,1895^{\mathrm{a}}$ & $0,1354^{\mathrm{b}}$ \\
Desvio Padrão & 0,0542 & 0,0429 \\
Valor mínimo & 0,1000 & 0,1000 \\
Valor máximo & 0,3000 & 0,2000 \\
Mediana & 0,2000 & 0,1000 \\
Moda & 0,2000 & 0,2000 \\
\hline
\end{tabular}

Nota: As letras (ab) não coincidentes indicam diferença significativa entre os grupos segundo $\operatorname{sexo}(t=3,6515$ e $p=0,0007)$.

Tabela 54 - Freqüência relativa, média, desvio padrão, valor mínimo, valor máximo, mediana e moda, da amplitude em milivolts da onda $Q$ na derivação bipolar I, obtido pelo eletrocardiograma de 100 eqüinos de salto criados na cidade de São Paulo, agrupados por sexo - SP - 2006

\begin{tabular}{lcc}
\hline Amplitude da onda Q em DI & \multicolumn{2}{c}{ SEXO } \\
\cline { 2 - 3 } & $\begin{array}{c}\text { Fêmeas } \\
(\mathbf{N}=\mathbf{3 9 )}\end{array}$ & $\begin{array}{c}\text { Machos } \\
(\mathbf{N}=61)\end{array}$ \\
\hline Freqüência relativa & 22 & 36 \\
Média & $0,2795^{\mathrm{a}}$ & $0,1056^{\mathrm{b}}$ \\
Desvio Padrão & 0,3766 & 0,0427 \\
Valor mínimo & 0,0500 & 0,0500 \\
Valor máximo & 1,4000 & 0,2000 \\
Mediana & 0,1000 & 0,1000 \\
Moda & 0,1000 & 0,1000 \\
\hline
\end{tabular}

Nota: As letras (ab) não coincidentes indicam diferença significativa entre os grupos segundo $\operatorname{sexo}(t=2,7585$ e $p=0,0078)$. 
Tabela 55 - Valores médios, desvio padrão, valor mínimo, valor máximo, mediana e moda, da amplitude em milivolts da onda $\mathrm{T}$ na derivação bipolar II, obtido pelo eletrocardiograma de 100 eqüinos de salto criados na cidade de São Paulo, agrupados por sexo - SP - 2006

\begin{tabular}{lcc}
\hline & \multicolumn{2}{c}{ SEXO } \\
\cline { 2 - 3 } Amplitude da onda T em DII & $\begin{array}{c}\text { Fêmeas } \\
(\mathbf{N}=\mathbf{3 9 )}\end{array}$ & $\begin{array}{c}\text { Machos } \\
(\mathbf{N}=61)\end{array}$ \\
\hline Média & $0,3756^{\mathrm{a}}$ & $0,4852^{\mathrm{b}}$ \\
Desvio padrão & 0,1926 & 0,2013 \\
Valor mínimo & 0,1000 & 0,1000 \\
Valor máximo & 0,9000 & 1,1000 \\
Mediana & 0,3000 & 0,4000 \\
Moda & 0,3000 & 0,4000 \\
\hline
\end{tabular}

Nota: As letras (ab) não coincidentes indicam diferença significativa entre os grupos segundo $\operatorname{sexo}(t=2,7003$ e $p=0,0082)$.

Tabela 56 - Valores médios, desvio padrão, valor mínimo, valor máximo, mediana e moda, da amplitude em milivolts da onda $T$ na derivação unipolar aVF, obtido pelo eletrocardiograma de 100 eqüinos de salto criados na cidade de São Paulo, agrupados por sexo - SP -2006

\begin{tabular}{lcc}
\hline Amplitude da onda T em aVF & \multicolumn{2}{c}{ SEXO } \\
\cline { 2 - 3 } & $\begin{array}{c}\text { Fêmeas } \\
(\mathbf{N}=\mathbf{3 9 )}\end{array}$ & $\begin{array}{c}\text { Machos } \\
(\mathbf{N}=\mathbf{6 1})\end{array}$ \\
\hline Média & $0,3462^{\mathrm{a}}$ & $0,4115^{\mathrm{b}}$ \\
Desvio padrão & 0,1462 & 0,1679 \\
Valor mínimo & 0,1000 & 0,1000 \\
Valor máximo & 0,7000 & 0,8000 \\
Mediana & 0,3000 & 0,4000 \\
Moda & 0,3000 & 0,3000 \\
\hline
\end{tabular}

Nota: As letras $(\mathrm{ab})$ não coincidentes indicam diferença significativa entre os grupos segundo $\operatorname{sexo}(t=1,9932$ e $p=0,0490)$. 
Tabela 57 - Freqüência e porcentagem da representação morfológica da onda $T$ na derivação unipolar II, obtido pelo eletrocardiograma de 100 eqüinos de salto criados na cidade de São Paulo, agrupados por sexo - SP - 2006

\begin{tabular}{lccc}
\hline \multirow{2}{*}{ Morfologia da onda T(DII) } & \multicolumn{3}{c}{ SEXO } \\
\cline { 2 - 4 } & $\begin{array}{c}\text { Freqüência } \\
(\mathbf{N})\end{array}$ & $\begin{array}{c}\text { Fêmeas } \\
(\%)\end{array}$ & $\begin{array}{c}\text { Machos } \\
(\%)\end{array}$ \\
\hline$(+)$ & 58 & 50,0 & 50,0 \\
$(-)$ & 7 & 14,3 & 85,7 \\
$(-+)$ & 33 & 27,3 & 72,7 \\
$(+-)$ & 2 & - & 100,0 \\
\hline Total & 100 & 39,0 & 61,0 \\
\hline
\end{tabular}

Nota: (+) onda T única e positiva, (-) onda T única e negativa, (- +) onda T bifásica, sendo a primeira porção negativa e a segunda porção positiva, (+ -) onda T bifásica, sendo a primeira porção positiva e a segunda porção negativa.

Houve diferença significativa entre os grupos segundo sexo, quanto a distribuição das diferentes representações morfológicas da onda $T\left(x^{2}=7,9336\right.$, graus de liberdade $=3$ e $p=0,0474)$.

\subsubsection{Variável Idade}

Apresentaram diferença estatística em duração as variáveis: complexo QRS na derivação unipolar aVL (Tabela 58) e onda R na derivação bipolar I (Tabela 59). Em relação à amplitude houve diferença estatística na onda $\mathrm{R}$ nas derivações bipolar III e unipolares aumentadas (aVR e aVF), representadas nas tabelas 60, 61 e 62, respectivamente e, por fim, houve diferença estatística na amplitude da onda $S$ na derivação aVL (Tabela 63). Nas demais variáveis não houveram diferenças significativas. 
Tabela 58 - Valores médios, desvio padrão, valor mínimo, valor máximo, mediana e moda, da duração do complexo QRS em segundos na derivação unipolar aVL, obtido pelo eletrocardiograma de 100 eqüinos de salto criados na cidade de São Paulo, agrupados segundo faixa etária - SP - 2006

\begin{tabular}{lccc}
\hline Duração de QRS em aVL & \multicolumn{3}{c}{ IDADE } \\
\cline { 2 - 4 } & $\begin{array}{c}\mathbf{4} \text { a } \mathbf{8} \text { anos } \\
(\mathbf{N}=\mathbf{3 3})\end{array}$ & $\begin{array}{c}\mathbf{9} \text { a 13 anos } \\
(\mathbf{N}=53)\end{array}$ & $\begin{array}{c}\mathbf{1 4} \text { a 19 anos } \\
(\mathbf{N}=\mathbf{1 4})\end{array}$ \\
\hline Média & $0,0830^{\mathrm{a}}$ & $0,0981^{\mathrm{b}}$ & $0,0900^{\mathrm{ab}}$ \\
Desvio padrão & 0,0270 & 0,0272 & 0,0218 \\
Valor mínimo & 0,0400 & 0,0400 & 0,0400 \\
Valor máximo & 0,1400 & 0,1600 & 0,1200 \\
Mediana & 0,0800 & 0,1000 & 0,0800 \\
Moda & 0,0800 & 0,1200 & 0,0800 \\
\hline
\end{tabular}

Nota: As letras (ab) não coincidentes indicam diferença significativa entre os grupos segundo faixa etária $(F=3,3410$ e $p=0,0395)$.

Tabela 59 - Freqüência relativa, média, desvio padrão, valor mínimo, valor máximo, mediana e moda, da duração da onda $\mathrm{R}$ em segundos na derivação bipolar I, obtido pelo eletrocardiograma de 100 eqüinos de salto criados na cidade de São Paulo agrupados segundo faixa etária - SP - 2006

\begin{tabular}{lccc}
\hline \multirow{2}{*}{ Duração da onda R em DI } & \multicolumn{3}{c}{ IDADE } \\
\cline { 2 - 4 } & $\begin{array}{c}\mathbf{4} \mathbf{a} \mathbf{8} \text { anos } \\
\mathbf{( N = 3 3 )}\end{array}$ & $\begin{array}{c}\mathbf{9} \text { a 13 anos } \\
\mathbf{( N = 5 3 )}\end{array}$ & $\begin{array}{c}\mathbf{1 4} \text { a 19 anos } \\
\mathbf{( N = 1 4 )}\end{array}$ \\
\hline Freqüência relativa & 31 & 52 & 13 \\
Média & $0,0710^{\mathrm{a}}$ & $0,0575^{\mathrm{b}}$ & $0,0554^{\mathrm{ab}}$ \\
Desvio padrão & 0,0178 & 0,0265 & 0,0233 \\
Valor mínimo & 0,0400 & 0,0200 & 0,0200 \\
Valor máximo & 0,1200 & 0,1400 & 0,1000 \\
Mediana & 0,0800 & 0,0450 & 0,0400 \\
Moda & 0,0800 & 0,0400 & 0,0400 \\
\hline
\end{tabular}

Nota: As letras (ab) não coincidentes indicam diferença significativa entre os grupos segundo faixa etária $(F=3,6796$ e $p=0,0290)$. 
Tabela 60 - Freqüência relativa, média, desvio padrão, valor mínimo, valor máximo, mediana e moda, da amplitude em milivolts da onda R na derivação bipolar III, obtido pelo eletrocardiograma de 100 eqüinos de salto criados na cidade de São Paulo, agrupados segundo faixa etária - SP - 2006

\begin{tabular}{lccc}
\hline Amplitude da onda R em DIII & \multicolumn{3}{c}{ IDADE } \\
\cline { 2 - 4 } & $\begin{array}{c}\mathbf{4} \text { a } \mathbf{8} \text { anos } \\
(\mathbf{N}=\mathbf{3 3})\end{array}$ & $\begin{array}{c}\mathbf{9} \text { a 13 anos } \\
(\mathbf{N}=53)\end{array}$ & $\begin{array}{c}\mathbf{1 4} \text { a 19 anos } \\
(\mathbf{N}=\mathbf{1 4})\end{array}$ \\
\hline Freqüência relativa & 32 & 50 & 14 \\
Média & $0,5859^{\mathrm{a}}$ & $0,6130^{\mathrm{a}}$ & $0,9071^{\mathrm{b}}$ \\
Desvio padrão & 0,3300 & 0,3578 & 0,6232 \\
Valor mínimo & 0,1000 & 0,0500 & 0,1000 \\
Valor máximo & 1,1000 & 1,5000 & 2,1000 \\
Mediana & 0,6000 & 0,6000 & 0,8500 \\
Moda & 0,8000 & 0,5000 & 0,1000 \\
\hline
\end{tabular}

Nota: As letras (ab) não coincidentes indicam diferença significativa entre os grupos segundo faixa etária $(F=3,5574$ e $p=0,0325)$.

Tabela 61 - Freqüência relativa, média, desvio padrão, valor mínimo, valor máximo, mediana e moda, da amplitude em milivolts da onda $\mathrm{R}$ na derivação unipolar aVR, obtido pelo eletrocardiograma de 100 eqüinos de salto criados na cidade de São Paulo, agrupados segundo faixa etária - SP - 2006

\begin{tabular}{lccc}
\hline Amplitude da onda R em aVR & \multicolumn{3}{c}{ IDADE } \\
\cline { 2 - 4 } & $\begin{array}{c}\mathbf{4} \text { a } \mathbf{~ a n o s} \\
\mathbf{( N = 3 3 )}\end{array}$ & $\begin{array}{c}\mathbf{9} \text { a 13 anos } \\
(\mathbf{N}=53)\end{array}$ & $\begin{array}{c}\mathbf{1 4} \text { a 19 anos } \\
(\mathbf{N}=\mathbf{1 4})\end{array}$ \\
\hline Freqüência relativa & 21 & 38 & 11 \\
Média & $0,1595^{\mathrm{a}}$ & $0,1408^{\mathrm{a}}$ & $0,4364^{\mathrm{b}}$ \\
Desvio padrão & 0,1261 & 0,1026 & 0,6504 \\
Valor mínimo & 0,0500 & 0,0500 & 0,0500 \\
Valor máximo & 0,6000 & 0,5000 & 2,2000 \\
Mediana & 0,1000 & 0,1000 & 0,1000 \\
Moda & 0,1000 & 0,1000 & 0,1000 \\
\hline
\end{tabular}

Nota: As letras $(a b)$ não coincidentes indicam diferença significativa entre os grupos segundo faixa etária $(F=5,2823$ e $p=0,0074)$. 
Tabela 62 - Freqüência relativa, média, desvio padrão, valor mínimo, valor máximo, mediana e moda, da amplitude em milivolts da onda $\mathrm{R}$ na derivação unipolar aVF, obtido pelo eletrocardiograma de 100 eqüinos de salto criados na cidade de São Paulo, agrupados segundo faixa etária - SP - 2006

\begin{tabular}{lccc}
\hline Amplitude da onda R em aVF & \multicolumn{3}{c}{ IDADE } \\
\cline { 2 - 4 } & $\begin{array}{c}\mathbf{4} \text { a } \mathbf{8} \text { anos } \\
\mathbf{( N = 3 3 )}\end{array}$ & $\begin{array}{c}\mathbf{9} \text { a 13 anos } \\
\mathbf{( N = 5 3 )}\end{array}$ & $\begin{array}{c}\mathbf{1 4} \text { a 19 anos } \\
(\mathbf{N}=\mathbf{1 4})\end{array}$ \\
\hline Freqüência relativa & 32 & 52 & 13 \\
Média & $0,7750^{\mathrm{a}}$ & $0,7885^{\mathrm{a}}$ & $1,1308^{\mathrm{b}}$ \\
Desvio padrão & 0,3844 & 0,3985 & 0,5170 \\
Valor mínimo & 0,1000 & 0,0500 & 0,4000 \\
Valor máximo & 1,5000 & 2,1000 & 2,0000 \\
Mediana & 0,8000 & 0,8000 & 1,1000 \\
Moda & 0,8000 & 0,8000 & 1,6000 \\
\hline
\end{tabular}

Nota: As letras $(a b)$ não coincidentes indicam diferença significativa entre os grupos segundo faixa etária $(F=4,0312$ e $p=0,0209)$.

Tabela 63 - Freqüência relativa, média, desvio padrão, valor mínimo, valor máximo, mediana e moda, da amplitude em milivolts da onda S na derivação unipolar aVL, obtido pelo eletrocardiograma de 100 eqüinos de salto criados na cidade de São Paulo, agrupados segundo faixa etária - SP - 2006

\begin{tabular}{lccc}
\hline Amplitude da onda S em aVL & \multicolumn{3}{c}{ IDADE } \\
\cline { 2 - 4 } & $\begin{array}{c}\mathbf{4} \text { a } \mathbf{8} \text { anos } \\
\mathbf{( N = 3 3 )}\end{array}$ & $\begin{array}{c}\mathbf{9} \text { a 13 anos } \\
\mathbf{( N = 5 3 )}\end{array}$ & $\begin{array}{c}\mathbf{1 4} \text { a 19 anos } \\
(\mathbf{N}=\mathbf{1 4})\end{array}$ \\
\hline Freqüência relativa & 13 & 29 & 8 \\
Média & $0,2115^{\mathrm{a}}$ & $0,2034^{\mathrm{a}}$ & $0,5375^{\mathrm{b}}$ \\
Desvio padrão & 0,1557 & 0,1982 & 0,5724 \\
Valor mínimo & 0,0500 & 0,0500 & 0,1000 \\
Valor máximo & 0,5000 & 0,8000 & 1,7000 \\
Mediana & 0,1000 & 0,1000 & 0,2750 \\
Moda & 0,1000 & 0,1000 & 0,1000 \\
\hline
\end{tabular}

Nota: As letras (ab) não coincidentes indicam diferença significativa entre os grupos segundo faixa etária $(F=4,7156$ e $p=0,0136)$. 


\section{DISCUSSÃO}

\subsection{FREQÜÊNCIA CARDÍACA}

A freqüência cardíaca média dos 100 eqüinos no presente trabalho foi de 40,2077bpm e desvio padrão de 13,3321, o que se encontra dentro da faixa de normalidade descrita por outros autores, como Fregin (1992) e Bertone (1999) de 26 a 50bpm.e Hilwig (1977) de 22 a 50bpm,

A freqüência cardíaca média no presente estudo, apresenta-se pouco mais elevada do que a média encontrada por pesquisadores em outros esportes como Michima (2003) em cavalos de enduro da raça Árabe e mestiços de Árabe, que

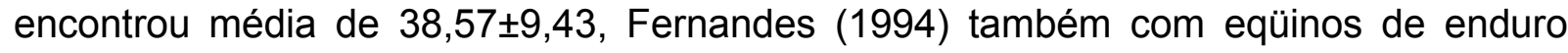
encontrou média de 39,3bpm para os eqüinos Árabes, 49bpm em Mangalargas e $51 \mathrm{bpm}$ para animais mestiços e Fregin (1982) com eqüinos de corrida que obteve média de 35,46bpm.

Não houve diferença significativa entre os grupos segundo atividade física, sexo ou idade. O que concorda com os resultados de Vincenzi (1995) que trabalhando com eqüinos Mangalarga não observou diferenças quanto ao sexo e difere dos resultados obtidos por Fernandes et al. (2004) com eqüinos Puro Sangue Inglês onde a freqüência cardíaca diminuiu com a idade, havendo diferença entre potros até 1 ano e os animais de sobreanos, mas não houve diferença entre os eqüinos de sobreanos e as éguas prenhes. Como no presente trabalho os animais tinham acima de 4 anos, ou seja adultos, talvez seja essa a explicação para não haver diferença entre os grupos 
segundo faixa etária nesta variável, já que nessa faixa etária os eqüinos já atingiram quase que o máximo de desenvolvimento corpóreo e também cardiovascular.

\subsection{RITMO CARDÍACO}

O ritmo mais freqüentemente encontrado nos eqüinos estudados foi o sinusal (56\%), seguido de taquicardia sinusal (23\%), arritmia sinusal $(20 \%)$ e bradicardia sinusal (1\%). Estes resultados concordam parcialmente com os de Fernandes et al. (2004), que encontrou em eqüinos Puro Sangue Inglês o ritmo sinusal em $94 \%$ dos sobreanos e $70 \%$ das éguas prenhes; encontrou ainda, $2 \%$ de arritmia sinusal e $4 \%$ de taquicardia sinusal nos animais de sobreanos, e $30 \%$ de taquicardia sinusal nas éguas

prenhes e, discordam dos resultados de Ayala et al. (1994) com eqüinos da raça Andaluz onde o ritmo mais freqüente foi a arritmia sinusal com $54,16 \%$ dos casos e em segundo o ritmo sinusal com $37,5 \%$.

Quanto às alterações de ritmo encontradas, observou-se marcapasso migratório $(25 \%)$, BAV $2^{\circ}(9 \%)$, BAV $1^{\circ}(7 \%)$, contração ventricular prematura $(2 \%)$, bloqueio sinoatrial / "sinus arrest" (1\%), contração atrial prematura (1\%). A maioria dos autores consultados, concordam que o marcapasso migratório e os bloqueios atrioventriculares de $1^{\circ}$ e $2^{\circ}$ graus, são arritmias fisiológicas em eqüinos, sendo algumas influenciadas pelo alto tônus vagal e que desaparecem com o exercício (GLAZIER, 1958; HILWIG, 1977; MITTEN, 1996; REIMER, 1992). No entanto, existem autores que descrevem o BAV $2^{\circ}$ como motivo de queda de performance atlética. Steel (1963) encontrou indícios histológicos de miocardite em seis eqüinos com BAV de $1^{\circ}$ ou $2^{\circ}$ e concluiu baseado em eletrocardiogramas seriados de eqüinos com BAV que este achado não deve ser 
considerado normal em eqüinos. Porém, estudos realizados por King, Evans e Rose (1994) e Stewart et al. (1983) não encontraram diferenças cardiorespiratórias, metabólicas e na incidência de BAV entre eqüinos de corrida normais e os com baixa performance.

Raekallio (1992) utilizando monitoração por Holter em 9 eqüinos saudáveis, observou que todos os animais apresentaram períodos de arritmia sinusal e 3 apresentaram BAV de $2^{\circ}$,o que foi posteriormente confirmado por Scheffer, Robben e Sloet Van Oldruitenborgh (1995) também com monitoração por Holter. Porém, segundo Fregin (1982) e Hilwig (1977), o BAV $2^{\circ}$ pode estar presente em 15 a $18 \%$ dos eqüinos em repouso, enquanto o marcapasso migratório pode estar presente em aproximadamente $30 \%$ dos eqüinos, o que difere parcialmente destes estudos, pois se encontrou uma proporção de BAV de $2^{\circ}$ de metade da porcentagem descrita pelo autor.

As contrações atriais e ventriculares prematuras geralmente são indícios de doenças miocárdicas. Estas alterações podem estar associadas às doenças miocárdicas, doenças sistêmicas não cardíacas, desequilíbrios metabólicos e eletrolíticos e hipóxia. A contração atrial prematura pode ainda predispor ao desenvolvimento de fibrilação atrial (REIMER, 1992). Porém, segundo Mitten (1996) as contrações atriais prematuras podem ocorrer em eqüinos em repouso sem estar associada à intolerância ao exercício, estas poderiam ainda diminuir ou desaparecer durante o exercício. Já, o complexo ventricular prematuro segundo o autor é indicativo de doença miocárdica, mesmo sem sinais clínicos de doenças cardiovasculares e deve ser considerado significante se aumenta de freqüência durante o exercício ou apresenta-se multiforme (MITTEN, 1996). O dano miocárdico segundo Fregin (1992) é significante quando as contrações são freqüentes, de focos diferentes, quando são 
induzidas pelo esforço ou acompanhadas de sinais clínicos. No presente trabalho, os eqüinos que apresentaram estas alterações não tinham qualquer queixa de queda de desempenho atlético por parte de seus proprietários, porém, existem estudos que verificaram alta prevalência de arritmias cardíacas (contrações ventriculares e supraventriculares prematuras) induzidas pelo exercício em animais saudáveis Ryan, Marr e McGladdery (2005).

\subsection{EIXO ELÉTRICO NO PLANO FRONTAL}

O eixo elétrico no plano frontal em eqüinos tem sido ainda pouco explorado o que dificulta sua aplicação clínica, devendo sempre estar associado a outros dados clínicos.

No presente trabalho o eixo de $87 \%$ dos animais se apresentou entre 0 e $+90^{\circ}$, o que se encontra de acordo com os trabalhos realizados Fregin (1982) onde $86 \%$ dos animais tiveram eixo nesta mesma faixa e com os trabalhos de Holmes e Alps (1967), com 377 eqüinos atletas de provas de três dias, onde $61 \%$ dos animais tiveram eixo de $0 \mathrm{a}+89^{\circ}$. Neste mesmo trabalho $14,6 \%$ dos animais tiveram desvio de eixo à direita e $24,4 \%$ tiveram desvios à esquerda, enquanto que em nossa amostra apenas $7 \%$ apresentaram desvio de eixo à direita contra $6 \%$ que tiveram desvios à esquerda.

Não foram observadas diferenças estatísticas quanto ao sexo, seguindo os mesmos resultados de Fernandes et al. (2004) com cavalos Puro Sangue Inglês, porém contrariando os resultados de Vincenzi et al. (2000a) em eqüinos Mangalarga que observou diferenças no eixo cardíaco das fêmeas adultas em relação aos machos adultos e jovens. 
Não houve diferenças estatísticas quanto à idade, assim como no trabalho realizado por Vincenzi et al. (2000a) que utilizou eqüinos de 11 meses a 3 anos e acima de 4 anos, talvez porque no presente estudos todos os animais já eram adultos acima de 4 anos e segundo autores as maiores mudanças de eixo ocorrem até os 15 meses de vida do eqüino (AYALA et al., 1998; HANAK, 1981).

Quanto à atividade física, não houve diferenças estatísticas entre os animais que saltam abaixo de 1,20 metros e os que saltam acima de 1,20 metros no presente trabalho, não foram encontrados trabalhos na literatura confrontando esforço físico com o eixo elétrico frontal. Segundo Holmes (1976), a alta intensidade de treinamentos físicos tende a induzir hipertrofia do ventrículo esquerdo, e ainda, lesões valvulares e fatores extra-cardíacos que acarretem em distúrbios de fluxo sangüíneo poderiam levar a dilatação das câmaras cardíacas. O efeito sistêmico na circulação é dependente da velocidade com a qual as mudanças ocorrem. Se o desenvolvimento é lento, podem ocorrer compensações mantendo normal a eficiência da circulação. O coração eqüino possui considerável habilidade em promover estas compensações. O aumento de uma câmara cardíaca pode ser seguido de uma resposta similar na câmara oposta. Assim, o vetor cardíaco pode não sofrer grandes modificações nas alterações miocardiais. 


\subsection{MENSURAÇÃO E MORFOLOGIA DAS ONDAS, INTERVALOS E COMPLEXOS}

\subsubsection{Score Cardíaco}

O score cardíaco como índice de potencial de performance atlética foi bastante estudado por Steel (1963) e Steel e Stewart (1974) em cavalos de corrida. Rose, Ilkiw Hodgdon (1979) também observaram relação significante entre o alto score cardíaco e a performance de eqüinos em provas de enduro, o que também foi confirmado por Illera e Illera (1987) no mesmo esporte. Posteriormente Rose, Backhouse e llkiw (1980), também observaram os mesmos resultados em cavalos Puro Sangue Inglês que competiam em eventos de três dias, sendo encontrado um score médio de 120 milisegundos, levando os autores a concluir a necessidade de se ter alto score cardíaco para se competir com sucesso neste tipo de prova.

O score cardíaco médio encontrado nos eqüinos de salto foi de $94,9 \mathrm{mseg} \pm 16,1$, que é bastante inferior aos índices descritos acima para cavalos de evento de três dias, encontrados por Rose, Backhouse e Ilkiw (1980); encontra-se também abaixo dos resultados de Nielsen e Vibe-Petersen (1980) em cavalos de trote com mais de 5 anos (105mseg.) e Illera e Illera (1987) em eqüinos de enduro que observaram score menor que 100mseg nos animais com pior condicionamento físico.

O score cardíaco também foi testado em eqüinos de trote por Nielsen e VibePetersen (1980), que concluíram: o score cardíaco aumenta com a idade até 3ou 4 anos, havendo pouco acréscimo a partir de 5 anos. Os autores correlacionam o score cardíaco ao peso do coração e este seria determinado por uma combinação hereditariedade, idade, crescimento e treinamento. Assim, o score cardíaco seria um 
indicador simples e aplicável do potencial de corrida para cavalos de trote. Em nosso trabalho não se observou diferença estatística segundo a faixa etária, talvez porque os animais estudados estavam acima de quatro anos, faixa etária próxima da que o autor descreve como tendo pouca alteração no score cardíaco.

O score cardíaco segundo Steel ${ }^{1}$ (1967 apud STEWART,1981) pode variar entre machos e fêmeas, em estudo realizado com 306 eqüinos, a média do score cardíacos das fêmeas foi de 106,9 mseg. contra 111,1 mseg dos machos, esta diferença foi altamente significante. No presente estudo não houve diferença significativa entre machos e fêmeas apesar dos machos apresentarem score pouco maiores (95,3mseg.) do que as fêmeas (94,4mseg.).

Esta teoria também teve suas críticas, e segundo Leadon et al. (1991), em estudo com eqüinos PSI acompanhados por 3 a 4 anos, confrontando os dados eletrocardiográficos e ecocardiográficos com subseqüente performance em corridas, os autores puderam concluir não haver relação entre o score cardíaco e os parâmetros ecocardiográficos com subseqüente performance.

As análises estatísticas dos resultados encontrados neste trabalho não mostraram diferença estatisticamente significante para score cardíaco segundo os dois grupos de atividade física, talvez esta medida não se aplique ao tipo de exercício que as provas de salto promovem, ou porque o tipo de condicionamento físico realizado pelo grupo 1 e 2 seja basicamente o mesmo, independente da altura que os animais saltam nas provas.

\footnotetext{
${ }^{1}$ STEEL, J. D. Vict. Vet. Proc., v.25, p.84, 1967.
} 


\subsubsection{Duração}

Um dos primeiros trabalhos em que se definem parâmetros eletrocardiográficos, foi publicado por Glazier (1958), neste, o autor define o intervalo PR de 0,20-0,42seg., o complexo QRS de 0,08-0,17seg. e o intervalo QT de 0,46-0,62seg. Os resultados deste trabalho na derivação DII, encontram-se de acordo com os parâmetros do autor acima, duração da onda P (0,1216seg.), intervalo PR (0,3140seg.), complexo QRS (0,0908seg.), intervalo QT (0,4908seg.) e onda T (0,1130seg.), porém diferem dos trabalhos realizados por Fregin (1982) em cavalos de corrida, onde a onda $\mathrm{P}(0,14 \mathrm{seg})$, intervalo PR (0,33 seg), complexo QRS $(0,13 \mathrm{seg})$ e intervalo QT $(0,51 \mathrm{seg})$ tiveram uma duração média maior do que nos eqüinos de salto.

Os resultados dos eqüinos de salto se aproximam dos resultados obtidos por Ayala et al. (1995) em cavalos da raça Andaluz, onde os autores encontraram os seguintes parâmetros de duração: onda P 0,105seg., intervalo PR 0,258seg., complexo QRS 0,095seg., onda T 0,126seg. e intervalo QT 0,465seg. Entretanto as durações medias são maiores (exceto para a duração do complexo QRS) do que as obtidas por Vincenzi, Larsson e Fernandes (2000b) com eqüinos adultos da raça Mangalarga, onde a duração de $P$ foi de 0,07 seg., intervalo PR 0,26seg., complexo QRS 0,97seg, intervalo QT 0,39seg. e onda T 0,08seg.

Quanto a variável sexo, houve diferença estatística na duração das ondas S em DI e T em DIl e ainda no intervalo PR na derivação unipolar aumentada aVR, estes dados divergem de Vincenzi, Larsson e Fernandes (2000b) em estudo realizado com eqüinos da raça Mangalarga, onde não foram observadas diferenças estatísticas em 
relação ao fator sexual quanto à duração da onda $\mathrm{P}$, complexo $\mathrm{QRS}$, onda $T$ e intervalo PR e QT.

Os resultados das análises estatísticas para a variável idade, mostraram diferenças significativas na duração do complexo QRS em aVL e na duração da onda $R$ em DI, o que difere do trabalho realizado por Fernandes et al. (2004), onde houve diferenças estatísticas na duração de P, do intervalo PR e do intervalo QT, dos animais de sobreano em relação aos potros.

Em relação à atividade física desempenhada, houve diferenças estatísticas quanto à duração do intervalo QT nas derivações DI, DIII e aVF. O intervalo QT representa o período de tempo entre o início da despolarização ventricular até sua completa repolarização. Este intervalo varia inversamente à freqüência cardíaca (EDWARDS, 1987). Esta talvez seja a explicação para o ocorrido, já que a média do intervalo QT no grupo 1 foi maior que no grupo 2 nas derivações citadas e, a freqüência cardíaca média do grupo 1 foi menor que a do grupo 2.

\subsubsection{Amplitude}

A diminuição da amplitude do complexo QRS segundo White e Rhode (1974), pode estar associada a pleurites crônicas, efusões pericárdicas, pericardites, anemia e hipoproteínemia. A depressão do segmento ST quando excede $0,3 \mathrm{mV}$ nas derivações bipolares, podem estar associadas à doença abdominal aguda incluindo peritonite e obstrução intestinal com comprometimento vascular, podem ainda estar associadas a condições de anestesia e em casos bem marcados a choque. A onda T quando se encontra maior que $1,4 \mathrm{mV}$ nas derivações bipolares pode estar associada a miocardite 
ou intoxicações por potássio. Não foram observadas depressões no segmento ST nos eqüinos de salto com esta amplitude e ondas $T$ com amplitudes superiores aos valores citados.

As amplitudes médias apresentadas pelos cem eqüinos de salto estudados, foram: onda $\mathrm{Q} 0,1923 \mathrm{mV}$, onda $\mathrm{R} 1,0220 \mathrm{mV}$, onda S $0,1256 \mathrm{mV}$ e onda $\mathrm{T} 0,4425 \mathrm{mV}$, estes resultados apresentam-se superiores aos resultados obtidos por Ayala et al. (1998) com eqüinos adultos da raça Andaluz. A onda $Q$ na derivação bipolar II teve média de $0,11 \mathrm{mV}$, a onda $\mathrm{R}$ teve média de $0,54 \mathrm{mV}$ e a onda $S$ teve média de $0,09 \mathrm{mV}$. e são também superiores aos resultados obtidos por Vincenzi, Larsson e Fernandes (2000b), onde a onda $P$ teve $0,16 \mathrm{mV}$., onda $Q 0,08 \mathrm{mV}$, onda $R \quad 0,58 \mathrm{mV}$ e onda $S$ $0,09 \mathrm{mV}$.

O quadro abaixo apresenta os dados dos eqüinos de salto e de eqüinos da raça PSI e trote estudadas por Fregin (1982). Os cavalos de salto por nós avaliados, apresentaram maior amplitude de onda $Q$ que os demais e apresentaram valores de amplitude de onda $\mathrm{R}$ maiores que os eqüinos de trote e menores que os eqüinos $\mathrm{PSI}$ e onda $\mathrm{S}$ com amplitude menor que as duas raças (Quadro 1).

\begin{tabular}{|lcccccc|}
\hline Amplitude & \multicolumn{2}{c}{ Onda Q } & \multicolumn{2}{c|}{ Onda R } & \multicolumn{2}{c|}{ Onda S } \\
\hline & Freqüência & Média & Freqüência & Média & Freqüência & Média \\
Salto & $65 \%$ & 0,19 & $100 \%$ & 1,02 & $41 \%$ & 0,13 \\
PSI & $90 \%$ & 0,12 & $100 \%$ & 1,13 & $55 \%$ & 0,15 \\
Trote & $97,5 \%$ & 0,16 & $100 \%$ & 0,73 & $42,5 \%$ & 0,17 \\
\hline
\end{tabular}

Fonte dos dados brutos: Fregin (1982).

Quadro 1 - Valores de amplitude para as onda $Q, R$ e $S$, nos eqüinos de salto e eqüinos das raças $\mathrm{PSI}$ e trote. 
Em relação à amplitude média das ondas, houve diferenças estatísticas significativas segundo a variável sexo, nas amplitudes da onda $\mathrm{P}$ única nas derivações unipolares aumentadas aVL e aVF, segunda porção da onda P (P2) em DIII, onda Q em DI e onda T em DII e aVF. Estes dados diferem dos resultados obtidos por Ayala et al. (1998) e Vincenzi, Larsson e Fernandes (2000b) onde não foram observadas diferenças estatísticas em relação ao fator sexual quanto à amplitude das ondas $P, Q, R, S$ e T.

Quanto à faixa etária, houve diferenças estatísticas entre os grupos, na onda $\mathrm{R}$ nas derivações DIII, aVR e aVF e onda $S$ em aVL. A onda $R$ apresentou tendência ao crescimento de acordo com a idade, o que não foi observado por Fernandes et al. (2004) que não encontraram diferenças estatísticas em relação às amplitudes entre os diferentes grupos etários de eqüinos da raça PSI.

Os grupos divididos segundo a atividade física, também apresentaram diferenças estatísticas na amplitude da primeira porção da onda $P(P 1)$ na derivação DI e aVL e na amplitude da onda T em DI.

\subsubsection{Morfologia}

\subsubsection{Onda P}

A onda $\mathrm{P}$ em eqüinos apresenta morfologia geralmente variável, o que dificulta sua padronização, pois pode sofrer influências de raça, idade e sexo (ILLERA; HAMLIN; ILLERA, 1987).

A morfologia da onda $\mathrm{P}$ na derivação bipolar II apresentou 4 formas distintas, das 11 formas encontradas quando consideradas todas as derivações estudadas. Sendo a 
mais freqüentemente encontrada a onda $\mathrm{P}$ bífida e positiva $(++)$ com $53 \%$, seguida da $\mathrm{P}$ única e positiva $(+)$ com $36 \%$, onda $P$ bifásica $(-+)$ com $10 \%$ e onda $P$ trifásica $(-++)$ com $1 \%$. Estes resultados concordam parcialmente com o estudo realizado por Muylle e Oyaert (1975) que analisaram a ativação do marcapasso atrial em 21 cavalos, com a utilização de um eletrodo bipolar suturado ao átrio via pericardiotomia e puderam observar que em 17 dos 21 animais a configuração da onda $P$ foi semelhante à do ECG para a mesma derivação, sendo em sua maioria bífida e positiva $(++)$ e ocasionalmente trifásica $(-++)$.

Os resultados da análise da onda $\mathrm{P}$ diferem dos resultados de Ayala et al. (1994), com eqüinos da raça Andaluz, onde $34,78 \%$ dos animais apresentaram onda P bífida e positiva (++), 60,86\% tiveram onda $P$ única e positiva (+) e $4,34 \%$ onda $P$ bifásica (- +) na derivação DII.

Illera, Hamlin e Illera (1987) realizaram estudo com 100 eqüinos mestiços das raças PSI, Hanoverano e Árabe, com intuito de analisar as diferentes morfologias da onda P, classificando-as em 6 tipos, 3 destes tipos aparecem na derivação bipolar II e apresentam porcentagem diferentes dos eqüinos de salto do presente estudo (Quadro 2). 


\begin{tabular}{|lcc|}
\hline & \multicolumn{2}{c|}{ Derivação bipolar II (\%) } \\
\hline $\mathbf{P}$ & Salto & Mestiços \\
\hline$(+)$ & $36,00 \%$ & $57,58 \%$ \\
$(++)$ & $53,00 \%$ & $39,39 \%$ \\
$(-+)$ & $10,00 \%$ & $0,00 \%$ \\
Outras & $1,00 \%$ & $0,00 \%$ \\
\hline
\end{tabular}

Fonte dos dados brutos: Illera; Hamlin; Illera (1987).

Quadro 2 - Representação morfológica da onda P na derivação bipolar II dos eqüinos de salto e dos eqüinos mestiços.

\subsubsection{Complexo QRS}

No presente trabalho encontrou-se 5 tipos morfológicos para o complexo QRS. A morfologia mais freqüente na derivação DII foi do tipo QR (ou seja, sem a presença da onda S) com 38\%, seguido do tipo QRS (com a presença das ondas $Q, R$ e $S$ ) com $27 \%$, morfologia R (ausência da onda Q e S) com $21 \%$, morfologia RS (com a ausência da onda Q) com 14\% sendo que a morfologia QS (com ausência de R) não foi observada na derivação DII no presente estudo. Estes resultados diferem dos obtidos por Ayala et al. (1994), em estudo com eqüinos da raça Andaluz, onde a morfologia mais freqüente foi a QRS $(58,3 \%)$, seguida da morfologia $Q R(12,5 \%)$ e somente onda R $(29,2 \%)$ na derivação DII. Não houve as morfologias RS e QS nesta derivação.

Os resultados diferem parcialmente, dos resultados obtidos por Illera, Illera e Hamlin (1987) com 100 eqüinos mestiços das raças PSI, Hanoverano e Árabe. Assim como nos eqüinos de salto, as morfologias mais freqüentes nestes animais foram a $Q R$ porém, em uma proporção muito mais elevada $(64,29 \%)$ dos casos, seguida da morfologia QRS com valor próximo aos eqüinos de salto $(24,49 \%)$, havendo grande diferença na proporção dos animais que apresentaram somente a onda $R$, que nos 
eqüinos mestiços foi de $2,04 \%$ contra $21,00 \%$ nos animais de salto, a morfologia $R S$ apresentou proporções próximas às dos animais de salto $(9,18 \%)$.

Houve diferença estatística quanto a morfologia do complexo QRS na derivação DII, relacionada à atividade física, assim, o grupo que salta abaixo de 1,20metros apresentou $81 \%$ dos complexos formados apenas pela onda $\mathrm{R}$ e $63 \%$ dos complexos de formato QRS e o grupo que salta acima de 1,20metros apresentou maior proporção de complexos no formato RS $(71,4 \%)$.

\subsubsection{Onda T}

A interpretação da representação morfológica da onda $\mathrm{T}$ ainda apresenta controvérsias na literatura, alguns autores acreditam que anormalidades de onda T estão dentre os achados eletrocardiográficos que podem estar associadas à queda de performance atlética (STEEL, 1963; STEWART et al., 1983).

Em trabalho realizado por Stewart et al. (1983) comparando eqüinos com baixa performance e eqüinos atendidos na rotina, observa-se alta incidência de anormalidades em ondas $\mathrm{T}$ e bloqueio atrioventricular de $2^{\circ}$ nos animais com queda de performance. Rose, Backhouse e llkiw (1980), observa um aumento significativo no número de derivações apresentando alterações em onda $\mathrm{T}$, quando comparado os traçados antes e depois de 22 eqüinos da raça Puro Sangue Inglês competindo em eventos de três dias, sustentando seu conceito de que a miocardite poderia ser induzida pelo stress físico. Por outro lado, Evans (1991) descreve que as alterações em ondas T são encontradas em altas proporções em eqüinos PSI condicionados e estas podem ser uma resposta fisiológica normal ao treinamento e não estar associada à 
queda de performance. Estes resultados são confirmados por Evans e Polglaze (1994), com eqüinos de trote onde são encontradas as alterações ditas como anormais de onda T em $50 \%$ dos cavalos condicionados e em $60 \%$ dos eqüinos com bons resultados nas corridas. King, Evans e Rose (1994), observam não haver diferença significativa na capacidade física em esteiras de exercício comparando eqüinos normais e com baixa performance atlética e alterações de onda T. No presente estudo $44 \%$ dos animais apresentaram alterações de onda $T$ (caracterizada por onda $T$ positiva ou bifásica) na derivação DI e 33 \% na derivação unipolar aumentada aVR (presença de onda T negativa).

Quanto à morfologia da onda T na derivação II, observou-se onda T positiva em $58 \%$ dos animais, seguido de onda $\mathrm{T}$ bifásica $(-+)$ com $33 \%$, onda $\mathrm{T}$ negativa $(-)$ com $7 \%$ e onda T bifásica (+ -) com $2 \%$. Estes resultados são semelhantes aos resultados obtidos por Vincenzi, Larsson e Fernandes (2000b) em eqüinos da raça Mangalarga, onde se obteve $56 \%$ de ondas T positivas, $37 \%$ de ondas T negativas e $7 \%$ de ondas T bifásicas, na derivação DII.

Em relação a variável sexo, houve diferença estatística entre as morfologias das ondas $\mathrm{T}$ apresentadas por machos e fêmeas na derivação DII. Os machos apresentaram maior proporção de ondas T negativas $(85,7 \%)$ e ondas $T$ bifásicas $(72,7 \%)$ que as fêmeas. Não se encontrou dados na literatura sobre diferenças morfológicas de onda T entre machos e fêmeas. 


\section{CONCLUSÕES}

Os resultados deste trabalho, nos permitem concluir que os eqüinos de salto apresentam uma freqüência cardíaca média de 40,2077bpm com desvio padrão de 13,3321 e o ritmo cardíaco mais freqüente é o sinusal, seguido de taquicardia sinusal, arritmia sinusal e bradicardia sinusal. Variáveis estas, que não sofrem influência de capacidade atlética, faixa etária e sexo.

As variações fisiológicas mais frequentemente observadas são: o marcapasso migratório, o bloqueio atrioventricular de $2^{\circ}$ grau e o bloqueio atrioventricular de $1^{\circ}$ grau. As variações não fisiológicas encontradas nos eqüinos de salto foram as contrações ventriculares prematuras, as contrações atriais prematuras e o bloqueio sinoatrial / "sinus arrest", que não são influenciadas por capacidade atlética, idade e sexo.

O eixo elétrico no plano frontal neste grupo de eqüinos, assim como na maioria das populações eqüinas estudadas, apresenta-se em sua maioria entre 0 e $+90^{\circ}$.

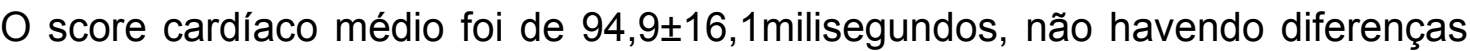
estatísticas quanto à capacidade atlética, idade ou sexo.

A duração do intervalo QT nas derivações bipolares I e III a na derivação unipolar aumentada aVF; amplitude da primeira porção da onda P bífida (P1) nas derivações bipolar I e unipolar aumentada aVL e na onda T na derivação bipolar I, sofreram influência de capacidade atlética dos animais.

A duração do intervalo P-R na derivação unipolar aumentada aVR, duração da onda S na derivação bipolar I, amplitude da onda $T$ nas derivações II e aVF, a amplitude da onda $\mathrm{P}$ única em aVL e aVF, a amplitude da segunda porção da onda $\mathrm{P}$ 
bífida (P2) na derivação III e a amplitude da onda $Q$ na derivação I, e a duração da onda T em D II sofreram influência da variável sexo.

A faixa etária influiu na amplitude da onda R em D III, aVR e aVF e da onda S em aVL, bem como na duração do complexo QRS em aVL e na onda R em DI.

A morfologia da onda $\mathrm{P}$ em eqüinos de salto apresentou-se bastante variável, com 11 formatos distintos, porém não apresentando influências quanto a desempenho, sexo e idade. Já o complexo QRS e a onda T apresentaram 5 tipos diferentes de conformação cada um e, ambos sofreram influências na derivação DII, sendo o complexo QRS influenciado pela capacidade atlética e a onda T pelo sexo. 


\section{REFERÊNCIAS}

AYALA, I.; MONTES, A.; BENEDITO, J. L.; CASTILLO, C.; HERNÁNDEZ, J.; GUTIERREZ, C.; GARCIA-PARTIDA, P. Modifications of the form and amplitude of the electrocardiographic QRS complex during growth in the Spanish-Bred horse. Journal of the American Veterinary Medical Association, v. 45, p. 309-317, 1998.

AYALA, I.; MONTES, A.; BERNAL, L. J.; SANDOVAL, J. A. Electrocardiographic values in Spanish-bred horses in different ages. Australian Veterinary Journal, v. 72, n.6, p.225-6, 1995.

AYALA, I.; MONTES, A. M.; FERNANDEZ del PALACIO, M. J.; GUTIÉRREZ PANIZO, C. Aportaciones al estudio electrocardiográfico del caballo. An. Vet.(MURCIA), v. 9, n. 10, p. 25-35, 1994.

BELGRAVE, J. O. S. A case of atrial fibrillation with congestive heart failure. Equine Veterinary Education, v. 2, n. 1, p. 2-4, 1990.

BERTONE, J. J. Practical approach to cardiac evaluation in the field. AAEP Proceedings, v. 45, p. 266-270, 1999.

DIAS, I. M. G.; BERGMANN, J. A. G.; REZENDE, A. C. C.; CASTRO, G. H. F. Formação e estrutura populacional do eqüino Brasileiro de Hipismo. Arquivo Brasileiro de Medicina Veterinária e Zootecnia, v. 52, n. 6, p. 647-654, 2000.

EDWARDS, N. J. Bolton's handbook of canine and feline electrocardiography. 2. ed. Philadelphia: W. B. Saunders Company, 1987. 381 p.

EVANS, D. L. T-waves in the equine electrocardiogram: effects of training and implications for race performance. Equine Exercise Physiology, v. 3, p. 475-481, 1991.

EVANS, D. L.; POLGLAZE, K. E. Relationships between electrocardiographic findings, racing performance and training in Standardbred horses. Australian Veterinary Journal, v. 71, n. 11, p. 375-378, 1994. 
FERNANDES, W. R. Alterações dos parâmetros do eletrocardiograma e da crase sangüínea em eqüinos das raças Árabe e Mangalarga, bem como de Mestiços, submetidos à prova de enduro. 1994. $21 \mathrm{f}$. Tese (Doutorado em Medicina Veterinária) - Faculdade de Medicina Veterinária e Zootecnia, Universidade de São Paulo, São Paulo, 1994.

FERNANDES, W. R.; LARSSON, M. H. M. A.; ALVES, A. L. G.; FANTONI, D. T.; BELLI, C. B. Características eletrocardiográficas em eqüinos clinicamente normais da raça Puro Sangue Inglês. Arquivo Brasileiro de Medicina Veterinária e Zootecnia, v. 56, n. 2, p.143-149, 2004.

FREGIN, G. F. Medical evaluation of the cardiovascular system. The Veterinary Clinics of North America: Equine Practice, v. 8, p. 329-346, n. 2, 1992.

FREGIN, G. F. The equine electrocardiogram with standardized body and limb positions. Cornell Veterinary, v. 72, n. 3, p. 304-324, 1982.

GLAZIER, D. B. Electrocardiography in Veterinary Medicine. The Irish Veterinary Journal, v. 12, p. 230-252, 1958.

GLAZIER, D. B.; DUKES, H. H. Atrioventricular heart block - some case reports. The Irish Veterinary Journal, v. 18, n. 12, p. 221-228, 1964.

GLAZIER, D. B.; DUKES, H. H. Partial sino-atrial heart block in the horse. The Irish Veterinary Journal, v. 17, n. 3, p .233-235, $1963 \mathrm{~b}$.

GLAZIER, D. B.; DUKES, H. H. Premature beats of the ventricle in a horse. The Irish Veterinary Journal, v. 17, n. 3, p. 41-44, 1963a.

HANAK, J. Angle of the electrical cardiac axis and magnitude of the ventricular vector in Thoroughbred foals. Acta Veterinaria, v. 50, p. 207-212, 1981.

HILWIG, R. W. Cardiac arrhythmias in the horse. Journal of the American Veterinary Medical Association, v. 170, n. 2, p. 153-163, 1977.

HOLMES, J. R. Spatial vector changes during ventricular depolarization using a semiorthogonal lead system - a study of 190 cases. Equine Veterinary Journal, v. 8, n.1, p. 1-16, 1976. 
HOLMES, J. R.; ALPS, B. J. Studies into equine electrocardiography and vectorcardiography II. Cardiac vector distributions in apparently healthy horses.

Canadian Journal Compendium Medical Veterinary Science, v. 31, p.150-155, 1975.

HOLMES, J. R.; REZAKHANI, A. Observations on the T wave of the equine electrocardiogram. Equine Veterinary Journal, v. 7, n. 2, p. 55-62, 1975.

ILLERA, J. C.; ILLERA, M. Electrocardiography and heart score of horses competing in an endurance ride. Australian Veterinary Journal, v. 64, n. 3, p. 88-89, 1987.

ILLERA, J. C.; ILLERA, M.; HAMLIN, R. L. Unipolar thoracic electrocardiography that induces QRS complexes of relative uniformity from male horses. The American Journal of Veterinary Research, v. 48, n. 12, p. 1700-1702, 1987.

ILLERA, J. C.; HAMLIN, R. L.; ILLERA, M. Unipolar thoracic electrocardiograms in which $P$ waves of relative uniformity occur in male horses. The American Journal of Veterinary Research, v. 48, n. 12, p. 1700-1702, 1987.

KING, C. M.; EVANS, D. L.; ROSE, R. J. Significance for exercise capacity of some electrocardiographic findings in racehorses. Australian Veterinary Journal, v. 71, n. 7, p. 200-202, 1994.

LANNEK, N.; RUTQUIST, L. Electrocardiography in horses: a historical review. Nordisk Veterinaer Medicin, v. 3, p. 435-447, 1951 a.

LANNEK, N.; RUTQUIST, L. Normal Area of Variation for the Electrocardiogram of Horses. Nordisk Veterinaer Medicin, v. 3, p. 1094-1117, 1951b

LEADON, D.; MCALLISTER, H.; MULLINS, E.; OSBORNE, M. Electrocardiographic and echocardiographic measurements and their relationships in Thoroughbred yearlings to subsequent performance. In: PERSSON, S. G. B. Equine exercise physiology. 3. ed. Davis: ICEEP Publications, 1991. p. 22.

MARTIN, B. B.; REEF, V. B.; PARENTE, E. J. Causes of Poor Performance of horses during training, racing, or showing: 348 cases (1992-1996). Journal of the American Veterinary Medical Association, v. 216, n. 4, p. 554-558, 2000. 
MCGUIRK, S. M.; MUIR, W. W. Diagnosis and treatment of cardiac arrhythmias.

Veterinary Clinics of North America: Equine Practice, v 1, p. 353-369, n. 2, 1985.

MICHIMA, L. E. S. Avaliação de dimensões e índices cardíacos obtidos por ecocardiografia de eqüinos de enduro criados no estado de São Paulo. 2003. 71 f. Dissertação (Mestrado em Medicina Veterinária) - Faculdade de Medicina Veterinária e Zootecnia, Universidade de São Paulo, São Paulo, 2003.

MITTEN, L. A. Cardiovascular causes of exercise intolerance. The Veterinary Clinics of North America: Equine Practice, v. 12, n. 3, p. 473-494, 1996.

MUYLLE, E.; OYAERT, W. Atrial activation pathways and the $P$ wave in the horse. Zentralblatt für Veterinärmedizin Rheihe A, v. 22, p. 474-484, 1975.

NIELSEN, K.; VIBE-PETERSEN, G. Relationship between QRS-duration (heart score) and racing performance in trotters. Equine Veterinary Journal, v. 12, n. 2, p. 81-84, 1980.

PATTESON, M. W. Equine cardiology . Oxford: Blackwell Science, 1996. 254 p.

RAEKALLIO, M. Long term ECG recording with holter monitoring in clinically healthy horses. Acta Veterinaria Scandinavica, v. 33, n. 1, p. 71-75, 1992.

REEF, V. B. Cardiovascular problems associated with poor performance. In:

ROBINSON, N. E. Current therapy in equine medicine 3. London: Saunders, 1992. p. 381-410.

REIMER, J. M. Cardiac arrhythmias. In: ROBINSON, N. E. Current therapy in equine medicine 3. London: Saunders, 1992. p. 382-393.

ROBERTSON, S. A. Electrocardiography for the equine practioner. Vet. Annual., v. 32, p. 192-200, 1992.

ROSE, R. J.; BACKHOUSE, J. W.; ILKIW, J. E. Electrocardiography and haematology of horses competing in a three-day event. Australian Veterinary Journal, v. 56, p. 318 $320,1980$. 
ROSE, R. J.; DAVIS, P. E. The use of electrocardiography in the diagnosis of poor racing performance in the horse. Australian Veterinary Journal, v. 54, p. 51-56, 1978.

ROSE, R. J.; ILKIW, J. E.; HODGDON, D. Electrocardiography, heart score and haematology of horses competing in an endurance ride. Australian Veterinary Journal, v. 55 , p. $247-250,1979$.

RYAN, N.; MARR, C. M.; McGLADDERY, A. J. Survey of cardiac arrhythmias during submaximal and maximal exercise in Thoroughbred racehorses. Equine Veterinary Journal, v. 37, n. 3, p. 265-268, 2005.

SCHEFFER, C. J. W.; ROBBEN, J. H.; SLOET VAN OLDRUITENBORGHOOSTERBAAN, M. M. Continuous monitoring of ECG in horses at rest and during exercise. The Veterinary Record, v. 137, p. 371-374, 1995.

SHEARD, P. W. P. Cardiovascular System. In: COLAHAN, P. T. Equine medicine and surgery. 5. ed. St Louis: Mosby, 1998. v. 1, p. 295-438.

SMETZER, D. L.; SENTA, T.; SMITH, C. R.; CROMER, D. B. High-grade seconddegree atrioventricular block in a horse. The American Journal of Veterinary Research, v. 30, n. 3, p. 337-343, 1969.

SPEIRS, V. C. Exame clínico de eqüinos. Porto Alegre: Artes Médicas, 1997. 365 p.

STEEL, J. D. Studies on the electrocardiogram of the racehorse. Sydney: Australian Medical Publishing Co., 1963.

STEEL, J. D.; HALL, M. C.; STEWART, G. A. Cardiac monitoring during exercise tests in the horse. Australian Veterinary Journal, v. 52, n. 1, p. 6-10, 1976.

STEEL, J. D.; STEWART, G. A. Electrocardiography of the horse and potential performance ability. Journal of the South African Veterinary Association, v. 45, n. 4, p. 263-268, 1974.

STEWART, G. A. The heart score theory in the racehorse. Australian Veterinary Journal, v. 57, n. 9, p. 422-428, 1981. 
STEWART, J. H.; ROSE, R. J.; DAVIS, P. E.; HOFFMAN, K. A comparison of electrocardiographic findings in racehorses presented either for routine examination or poor racing performance. In: SNOW, D. H. Equine exercise physiology. Cambridge: Granta Editions, 1983. p. 135-143.

VIBE-PETERSEN, G.; NIELSEN, K. Electrocardiography in the horse. Nordisk Veterinaer Medicin, v. 32, p. 105-121, 1980.

VINCENZI, R. C. Determinação dos parâmetros eletrocardiográficos de eqüinos da raça Mangalarga, criados no Estado de São Paulo. 1995. 73 f. Dissertação (Mestrado em Medicina Veterinária) - Faculdade de Medicina Veterinária e Zootecnia, Universidade de São Paulo, São Paulo, 1995.

VINCENZI, R. C.; LARSSON, M. H. M. A.; FERNANDES, W. R. Parâmetros eletrocardiográficos em eqüinos clinicamente normais da raça Mangalarga. Parte II: Eixo elétrico médio no plano frontal. Revista Brasileira de Medicina Veterinária, v. 22, n. 3, p. 111-112, 2000a.

VINCENZI, R. C.; LARSSON, M. H. M. A.; FERNANDES, W. R. Parâmetros eletrocardiográficos em eqüinos clinicamente normais da raça Mangalarga. Parte III: Amplitude e duração dos complexos e intervalos. Revista brasileira de Medicina Veterinária, v. 22, n. 5, p. 194-198, 2000b.

WHITE II, N. A.; RHODE, E. A. Correlation of electrocardiographic findings to clinical disease in the horse. Journal of the American Veterinary Medical Association, v. 164, p. 46-56, 1974. 
Apêndices 
APÊNDICE A - Dados individuais de grupo de atividade física, raça, idade (anos), peso (kg), sexo, freqüência cardíaca (bpm), ritmo cardíaco, eixo cardíaco no plano frontal, score cardíaco (seg) e alterações cardíacas obtido pelo eletrocardiograma de 100 eqüinos de salto criados na cidade de São Paulo- SP - 2006.

(continua)

\begin{tabular}{|c|c|c|c|c|c|c|c|c|c|c|}
\hline $\mathrm{N}$ & Grupo & Raça & Idade & Peso & Sexo & $\mathrm{FC}$ & Ritmo & Eixo & Score & Alterações \\
\hline 1 & 1 & $\mathrm{BH}$ & 9 & 500 & $\mathrm{~F}$ & 29,20 & SN & $\left(-30 a-60^{\circ}\right)$ & 0,1067 & \\
\hline 2 & 1 & $\mathrm{BH}$ & 6 & 500 & $F$ & 30,60 & SN & $\left(0\right.$ a $\left.30^{\circ}\right)$ & 0,0667 & \\
\hline 3 & 1 & SRD & 16 & 420 & $\mathrm{M}$ & 40,10 & SN & $\left(60\right.$ a $\left.90^{\circ}\right)$ & 0,1000 & MM \\
\hline 4 & 1 & $\mathrm{BH}$ & 10 & 530 & $\mathrm{~F}$ & 34,10 & SN & $\left(60\right.$ a $\left.90^{\circ}\right)$ & 0,1200 & $\mathrm{BAV} 1^{\circ}$ e $2^{\circ}$ \\
\hline 5 & 1 & Hosteiner & 11 & 530 & $\mathrm{M}$ & 28,95 & AS & $\left(0\right.$ a $\left.30^{\circ}\right)$ & 0,1200 & $\mathrm{BAV} 1^{\circ}$ e $2^{\circ}, \mathrm{MM}$ \\
\hline 6 & 1 & $\mathrm{BH}$ & 16 & 486 & $\mathrm{M}$ & 39,60 & SN & $\left(0\right.$ a $\left.30^{\circ}\right)$ & 0,1000 & \\
\hline 7 & 1 & Sela Francesa & 12 & 513 & $\mathrm{M}$ & 25,80 & SN & $\left(0 a-30^{\circ}\right)$ & 0,1067 & \\
\hline 8 & 1 & SRD & 15 & 436 & $\mathrm{M}$ & 30,60 & SN & $\left(0\right.$ a $\left.30^{\circ}\right)$ & 0,0867 & MM \\
\hline 9 & 1 & $\mathrm{BH}$ & 6 & 500 & $\mathrm{~F}$ & 41,70 & SN & $\left(30\right.$ a $\left.60^{\circ}\right)$ & 0,0867 & \\
\hline 10 & 1 & $\mathrm{BH}$ & 7 & 513 & $\mathrm{M}$ & 33,10 & SN & $\left(30^{\circ}\right)$ & 0,1000 & \\
\hline 11 & 1 & $\mathrm{BH}$ & 16 & 486 & $\mathrm{~F}$ & 32,60 & SN & $\left(-120 \mathrm{a}-150^{\circ}\right)$ & 0,1000 & \\
\hline 12 & 1 & $\mathrm{BH}$ & 8 & 486 & $\mathrm{~F}$ & 31,50 & AS & $\left(0 \mathrm{a}-30^{\circ}\right)$ & 0,1000 & $\mathrm{BAV} 1^{\circ}$ e $2^{\circ}$ \\
\hline 13 & 1 & Anglo Árabe & 15 & 500 & $\mathrm{~F}$ & 64,50 & TS & $\left(30\right.$ a $\left.60^{\circ}\right)$ & 0,1000 & \\
\hline 14 & 1 & Anglo Árabe & 16 & 413 & $\mathrm{~F}$ & 34,90 & SN & $\left(120\right.$ a $\left.150^{\circ}\right)$ & 0,1067 & \\
\hline 15 & 1 & Sela Francesa & 10 & 595 & $\mathrm{~F}$ & 31,30 & AS & $\left(30\right.$ a $\left.60^{\circ}\right)$ & 0,0933 & BAV $2^{\circ}$ \\
\hline 16 & 1 & $\mathrm{BH}$ & 10 & 500 & $\mathrm{~F}$ & 48,20 & TS & $\left(60\right.$ a $\left.90^{\circ}\right)$ & 0,1000 & MM \\
\hline 17 & 1 & SRD & 17 & 500 & $\mathrm{M}$ & 75,30 & TS & $\left(60\right.$ a $\left.90^{\circ}\right)$ & 0,1067 & \\
\hline 18 & 1 & $\mathrm{BH}$ & 6 & 476 & $\mathrm{M}$ & 32,10 & AS & $\left(60\right.$ a $\left.90^{\circ}\right)$ & 0,1200 & MM \\
\hline 19 & 1 & $\mathrm{BH}$ & 7 & 595 & $\mathrm{~F}$ & 38,70 & AS & $\left(60\right.$ a $\left.90^{\circ}\right)$ & 0,1200 & \\
\hline 20 & 1 & $\mathrm{BH}$ & 8 & 538 & $\mathrm{M}$ & 37,55 & SN & $\left(30\right.$ a $\left.60^{\circ}\right)$ & 0,0867 & \\
\hline 21 & 1 & $\mathrm{BH}$ & 10 & 475 & $\mathrm{M}$ & 29,40 & SN & $\left(0\right.$ a $\left.30^{\circ}\right)$ & 0,1067 & \\
\hline 22 & 1 & $\mathrm{BH}$ & 9 & 513 & $\mathrm{M}$ & 69,45 & TS & $\left(60\right.$ a $\left.90^{\circ}\right)$ & 0,1000 & \\
\hline 23 & 1 & Anglo Árabe & 7 & 540 & $\mathrm{M}$ & 32,70 & AS & $\left(60\right.$ a $\left.90^{\circ}\right)$ & 0,1067 & \\
\hline 24 & 1 & $\mathrm{BH}$ & 5 & 500 & $\mathrm{~F}$ & 43,05 & AS & $\left(60\right.$ a $\left.90^{\circ}\right)$ & 0,0933 & BAV $2^{\circ}$ \\
\hline 25 & 1 & $\mathrm{BH}$ & 12 & 490 & $\mathrm{~F}$ & 57,75 & TS & $\left(60\right.$ a $\left.90^{\circ}\right)$ & 0,1067 & MM \\
\hline 26 & 1 & $\mathrm{BH}$ & 5 & 440 & $\mathrm{~F}$ & 89,45 & TS & $\left(60\right.$ a $\left.90^{\circ}\right)$ & 0,0800 & MM \\
\hline 27 & 1 & $\mathrm{BH}$ & 12 & 440 & $\mathrm{~F}$ & 42,20 & AS & $\left(30\right.$ a $\left.60^{\circ}\right)$ & 0,1000 & MM \\
\hline 28 & 1 & $\mathrm{BH}$ & 16 & 585 & $\mathrm{M}$ & 31,05 & AS & $\left(60\right.$ a $\left.90^{\circ}\right)$ & 0,0800 & APC \\
\hline 29 & 1 & $\mathrm{BH}$ & 7 & 500 & $\mathrm{~F}$ & 59,50 & TS & $\left(60\right.$ a $\left.90^{\circ}\right)$ & 0,0667 & \\
\hline 30 & 1 & Hosteiner & 9 & 600 & $M$ & 72,05 & TS & $\left(60\right.$ a $\left.90^{\circ}\right)$ & 0,0667 & \\
\hline 31 & 1 & Sela Francesa & 11 & 513 & $\mathrm{M}$ & 25,00 & SN & $\left(30\right.$ a $\left.60^{\circ}\right)$ & 0,1067 & \\
\hline 32 & 1 & $\mathrm{BH}$ & 5 & 500 & $\mathrm{~F}$ & 36,15 & SN & $\left(90\right.$ a $\left.120^{\circ}\right)$ & 0,0733 & \\
\hline 33 & 1 & $\mathrm{BH}$ & 12 & 570 & $\mathrm{M}$ & 29,55 & SN & $\left(60\right.$ a $\left.90^{\circ}\right)$ & 0,1067 & MM \\
\hline 34 & 1 & Sela Francesa & 8 & 575 & $\mathrm{M}$ & 33,33 & SN & $\left(60\right.$ a $\left.90^{\circ}\right)$ & 0,1067 & \\
\hline 35 & 1 & $\mathrm{BH}$ & 9 & 470 & $\mathrm{~F}$ & 28,30 & SN & $\left(30\right.$ a $\left.60^{\circ}\right)$ & 0,0800 & $\mathrm{MM}, \mathrm{BAV} 2^{\circ}$ \\
\hline 36 & 1 & SRD & 11 & 513 & $\mathrm{~F}$ & 40,54 & SN & $\left(30\right.$ a $\left.60^{\circ}\right)$ & 0,0933 & $\mathrm{MM}$ \\
\hline 37 & 1 & $\mathrm{BH}$ & 11 & 486 & $\mathrm{M}$ & 39,39 & SN & $\left(60\right.$ a $\left.90^{\circ}\right)$ & 0,1133 & \\
\hline 38 & 1 & $\mathrm{BH}$ & 6 & 540 & $\mathrm{M}$ & 59,90 & TS & $\left(60\right.$ a $\left.90^{\circ}\right)$ & 0,1000 & MM \\
\hline 39 & 1 & $\mathrm{BH}$ & 6 & 486 & $M$ & 24,82 & SN & $\left(30\right.$ a $\left.60^{\circ}\right)$ & 0,0600 & \\
\hline 40 & 1 & $\mathrm{BH}$ & 8 & 486 & $\mathrm{M}$ & 26,31 & SN & $\left(0\right.$ a $\left.30^{\circ}\right)$ & 0,1000 & \\
\hline 41 & 1 & $\mathrm{BH}$ & 5 & 500 & $\mathrm{M}$ & 25,96 & AS & $\left(30\right.$ a $\left.60^{\circ}\right)$ & 0,0600 & \\
\hline 42 & 1 & $\mathrm{BH}$ & 13 & 520 & $\mathrm{~F}$ & 35,71 & SN & $\left(60\right.$ a $\left.90^{\circ}\right)$ & 0,1067 & \\
\hline 43 & 1 & $\mathrm{BH}$ & 6 & 540 & $F$ & 31,49 & SN & $\left(30\right.$ a $\left.60^{\circ}\right)$ & 0,1067 & \\
\hline 44 & 1 & Anglo Árabe & 9 & 540 & $\mathrm{~F}$ & 25,09 & AS & $\left(0\right.$ a $\left.30^{\circ}\right)$ & 0,1000 & $\mathrm{MM}$ \\
\hline 45 & 1 & $\mathrm{BH}$ & 11 & 520 & $\mathrm{~F}$ & 37,50 & SN & $\left(0 a-30^{\circ}\right)$ & 0,1067 & \\
\hline 46 & 1 & Anglo Árabe & 5 & 545 & $\mathrm{~F}$ & 39,47 & AS & $\left(120\right.$ a $\left.150^{\circ}\right)$ & 0,1067 & MM, "sinus arrest" \\
\hline 47 & 1 & Anglo Árabe & 5 & 486 & $\mathrm{M}$ & 18,50 & BRAD & $\left(0\right.$ a $\left.30^{\circ}\right)$ & 0,1000 & \\
\hline 48 & 1 & Sela Holandesa & 10 & 560 & $\mathrm{M}$ & 36,58 & SN & $\left(30\right.$ a $\left.60^{\circ}\right)$ & 0,0867 & MM \\
\hline 49 & 1 & $\mathrm{BH}$ & 10 & 486 & $M$ & 27,08 & SN & $\left(30\right.$ a $\left.60^{\circ}\right)$ & 0,0667 & \\
\hline 50 & 1 & $\mathrm{BH}$ & 4 & 530 & $\mathrm{M}$ & 46,99 & TS & $\left(60\right.$ a $\left.90^{\circ}\right)$ & 0,0933 & \\
\hline
\end{tabular}


APÊNDICE A - Dados individuais de grupo de atividade física, raça, idade (anos), peso (kg), sexo, freqüência cardíaca (bpm), ritmo cardíaco, eixo cardíaco no plano frontal, score cardíaco (seg) e alterações cardíacas obtido pelo eletrocardiograma de 100 eqüinos de salto criados na cidade de São Paulo - SP - 2006.

\begin{tabular}{|c|c|c|c|c|c|c|c|c|c|c|}
\hline $\mathrm{N}$ & Grupo & Raça & Idade & Peso & Sexo & FC & Ritmo & Eixo & Score & Arritmias \\
\hline 51 & 1 & Anglo Árabe & 10 & 500 & $M$ & 38,46 & SN & $\left(60\right.$ a $\left.90^{\circ}\right)$ & 0,1067 & \\
\hline 52 & 1 & Sela Belga & 19 & 540 & $M$ & 33,33 & SN & $\left(60\right.$ a $\left.90^{\circ}\right)$ & 0,0933 & \\
\hline 53 & 1 & $\mathrm{BH}$ & 14 & 461 & $\mathrm{M}$ & 33,33 & SN & $\left(60\right.$ a $\left.90^{\circ}\right)$ & 0,0800 & MM \\
\hline 54 & 1 & $\mathrm{BH}$ & 6 & 486 & $\mathrm{M}$ & 35,33 & SN & $\left(0\right.$ a $\left.30^{\circ}\right)$ & 0,1067 & \\
\hline 55 & 1 & $\mathrm{BH}$ & 6 & 540 & $\mathrm{M}$ & 37,50 & SN & $\left(30\right.$ a $\left.60^{\circ}\right)$ & 0,0667 & \\
\hline 56 & 1 & $\mathrm{BH}$ & 5 & 580 & M & 29,45 & SN & $\left(0\right.$ a $\left.30^{\circ}\right)$ & 0,1133 & MM \\
\hline 57 & 2 & Sela Holandesa & 12 & 550 & $M$ & 39,00 & SN & $\left(0\right.$ a $\left.30^{\circ}\right)$ & 0,0867 & \\
\hline 58 & 2 & SRD & 11 & 490 & $\mathrm{~F}$ & 27,50 & AS & $\left(60\right.$ a $\left.90^{\circ}\right)$ & 0,1000 & BAV $2^{\circ}$ \\
\hline 59 & 2 & Hanoverano & 10 & 548 & $M$ & 43,00 & SN & $\left(60\right.$ a $\left.90^{\circ}\right)$ & 0,1067 & \\
\hline 60 & 2 & Westfalen & 10 & 470 & $M$ & 41,10 & SN & $\left(30\right.$ a $\left.60^{\circ}\right)$ & 0,0933 & \\
\hline 61 & 2 & $\mathrm{BH}$ & 7 & 486 & $\mathrm{M}$ & 31,25 & SN & $\left(60^{\circ}\right)$ & 0,0733 & BAV $1^{\circ}$ \\
\hline 62 & 2 & $\mathrm{BH}$ & 13 & 620 & $M$ & 26,31 & SN & $\left(30\right.$ a $\left.60^{\circ}\right)$ & 0,0800 & $\operatorname{BAV} 2^{\circ}, \operatorname{BAV} 1^{\circ}$ \\
\hline 63 & 2 & $\mathrm{BH}$ & 12 & 550 & $F$ & 34,70 & AS & $\left(0 \mathrm{a}-30^{\circ}\right)$ & 0,1200 & \\
\hline 64 & 2 & $\mathrm{BH}$ & 15 & 595 & $\mathrm{M}$ & 30,00 & SN & $\left(0\right.$ a $\left.30^{\circ}\right)$ & 0,0933 & $\mathrm{BAV} 1^{\circ}$ \\
\hline 65 & 2 & $\mathrm{BH}$ & 14 & 513 & $\mathrm{~F}$ & 30,00 & SN & $\left(30\right.$ a $\left.60^{\circ}\right)$ & 0,0933 & \\
\hline 66 & 2 & $\mathrm{BH}$ & 10 & 486 & $\mathrm{~F}$ & 40,50 & SN & $\left(60\right.$ a $\left.90^{\circ}\right)$ & 0,1067 & MM \\
\hline 67 & 2 & Sela Francesa & 10 & 595 & $M$ & 41,80 & AS & $\left(0\right.$ a $\left.30^{\circ}\right)$ & 0,1200 & MM \\
\hline 68 & 2 & Sela Francesa & 8 & 520 & $\mathrm{M}$ & 83,33 & TS & $\left(-60\right.$ a $\left.-90^{\circ}\right)$ & 0,0867 & MM \\
\hline 69 & 2 & Sela Francesa & 9 & 471 & $\mathrm{M}$ & 56,80 & TS & $\left(30^{\circ}\right)$ & 0,1000 & \\
\hline 70 & 2 & $\mathrm{BH}$ & 7 & 540 & $M$ & 41,70 & SN & $\left(30\right.$ a $\left.60^{\circ}\right)$ & 0,1267 & \\
\hline 71 & 2 & $\mathrm{BH}$ & 11 & 482 & $\mathrm{M}$ & 51,70 & TS & $\left(30\right.$ a $\left.60^{\circ}\right)$ & 0,0733 & \\
\hline 72 & 2 & Sela Francesa & 11 & 550 & $\mathrm{~F}$ & 68,20 & TS & $\left(30\right.$ a $\left.60^{\circ}\right)$ & 0,0667 & \\
\hline 73 & 2 & Sela Francesa & 10 & 535 & $M$ & 41,70 & SN & $\left(60\right.$ a $\left.90^{\circ}\right)$ & 0,1067 & \\
\hline 74 & 2 & $\mathrm{BH}$ & 7 & 550 & $\mathrm{M}$ & 65,20 & TS & $\left(30\right.$ a $\left.60^{\circ}\right)$ & 0,1067 & \\
\hline 75 & 2 & $\mathrm{BH}$ & 10 & 480 & $\mathrm{M}$ & 51,70 & TS & $\left(30\right.$ a $\left.60^{\circ}\right)$ & 0,1200 & \\
\hline 76 & 2 & $\mathrm{BH}$ & 8 & 500 & $\mathrm{~F}$ & 58,05 & TS & $\left(60\right.$ a $\left.90^{\circ}\right)$ & 0,1133 & MM \\
\hline 77 & 2 & $\mathrm{BH}$ & 6 & 515 & $\mathrm{~F}$ & 38,50 & SN & $\left(30\right.$ a $\left.60^{\circ}\right)$ & 0,1067 & \\
\hline 78 & 2 & Sela Holandesa & 10 & 595 & $\mathrm{M}$ & 40,50 & SN & $\left(30\right.$ a $\left.60^{\circ}\right)$ & 0,0933 & \\
\hline 79 & 2 & $\mathrm{BH}$ & 7 & 567 & $\mathrm{M}$ & 57,69 & TS & $\left(30\right.$ a $\left.60^{\circ}\right)$ & 0,1067 & \\
\hline 80 & 2 & Odemburgo & 16 & 640 & $M$ & 51,72 & TS & $\left(60\right.$ a $\left.90^{\circ}\right)$ & 0,1067 & \\
\hline 81 & 2 & Hanoverano & 10 & 580 & $M$ & 33,00 & AS & $\left(60\right.$ a $\left.90^{\circ}\right)$ & 0,0800 & VPC \\
\hline 82 & 2 & $\mathrm{BH}$ & 7 & 560 & $\mathrm{M}$ & 27,27 & SN & $\left(60\right.$ a $\left.90^{\circ}\right)$ & 0,0933 & \\
\hline 83 & 2 & Hanoverano & 13 & 500 & $\mathrm{M}$ & 29,02 & AS & $\left(60\right.$ a $\left.90^{\circ}\right)$ & 0,0800 & \\
\hline 84 & 2 & SRD & 10 & 550 & $\mathrm{~F}$ & 28,80 & SN & $\left(60\right.$ a $\left.90^{\circ}\right)$ & 0,0800 & $\mathrm{BAV} 1^{\circ}$ \\
\hline 85 & 2 & Sela Holandesa & 12 & 567 & $\mathrm{~F}$ & 35,71 & SN & $\left(90^{\circ}\right)$ & 0,1067 & \\
\hline 86 & 2 & Westfalen & 16 & 540 & $\mathrm{~F}$ & 41,67 & SN & $\left(150\right.$ a $\left.180^{\circ}\right)$ & 0,0600 & \\
\hline 87 & 2 & $\mathrm{BH}$ & 12 & 540 & $M$ & 40,54 & SN & $\left(60\right.$ a $\left.90^{\circ}\right)$ & 0,0800 & \\
\hline 88 & 2 & Sela Holandesa & 12 & 567 & $\mathrm{M}$ & 34,88 & SN & $\left(0\right.$ a $\left.30^{\circ}\right)$ & 0,0867 & $\mathrm{BAV} 2^{\circ}$ \\
\hline 89 & 2 & $\mathrm{BH}$ & 9 & 567 & $\mathrm{M}$ & 49,74 & TS & $\left(60\right.$ a $\left.90^{\circ}\right)$ & 0,1067 & MM \\
\hline 90 & 2 & $\mathrm{BH}$ & 11 & 486 & $M$ & 36,58 & SN & $\left(-120 \mathrm{a}-150^{\circ}\right)$ & 0,0867 & MM \\
\hline 91 & 2 & $\mathrm{BH}$ & 10 & 513 & $\mathrm{~F}$ & 53,31 & TS & $\left(120\right.$ a $\left.150^{\circ}\right)$ & 0,0800 & MM \\
\hline 92 & 2 & Hosteiner & 11 & 595 & $M$ & 36,46 & AS & $\left(30\right.$ a $\left.60^{\circ}\right)$ & 0,0933 & \\
\hline 93 & 2 & Zangerchaid & 8 & 575 & $\mathrm{~F}$ & 51,20 & TS & $\left(60\right.$ a $\left.90^{\circ}\right)$ & 0,0933 & VPC \\
\hline 94 & 2 & $\mathrm{BH}$ & 9 & 486 & $\mathrm{M}$ & 45,31 & AS & $\left(30\right.$ a $\left.60^{\circ}\right)$ & 0,1200 & MM \\
\hline 95 & 2 & $\mathrm{BH}$ & 10 & 513 & $\mathrm{M}$ & 35,71 & SN & $\left(0\right.$ a $\left.30^{\circ}\right)$ & 0,0667 & \\
\hline 96 & 2 & $\mathrm{BH}$ & 9 & 567 & $\mathrm{M}$ & 33,33 & SN & $\left(30\right.$ a $\left.60^{\circ}\right)$ & 0,1067 & \\
\hline 97 & 2 & Hanoverano & 9 & 550 & $\mathrm{~F}$ & 34,59 & AS & $\left(0\right.$ a $\left.30^{\circ}\right)$ & 0,0800 & \\
\hline 98 & 2 & Sela Holandesa & 12 & 540 & $F$ & 49,29 & TS & $\left(30\right.$ a $\left.60^{\circ}\right)$ & 0,0867 & \\
\hline 99 & 2 & $\mathrm{BH}$ & 12 & 560 & $\mathrm{M}$ & 27,50 & SN & $\left(0\right.$ a $\left.30^{\circ}\right)$ & 0,0800 & \\
\hline 100 & 2 & $\mathrm{BH}$ & 9 & 540 & $\mathrm{~F}$ & 42,85 & SN & $\left(60\right.$ a $\left.90^{\circ}\right)$ & 0,0667 & \\
\hline
\end{tabular}

Nota: Raça - BH (Brasileiro de Hipismo), sexo - M (macho) e F (fêmea), ritmo - SN (ritmo sinusal), AS (arritmia sinusal), TS (taquicardia sinusal), alterações - MM (marcapasso migratório), ${ }^{\circ}, \mathrm{BAV} 1^{\circ}$ (bloqueio átrio-ventricular de $1^{\circ}$ grau), BAV $2^{\circ}$ (bloqueio átrio-ventricular de $2^{\circ}$ grau), VPC (contração ventricular prematura). 
APÊNDICE B - Dados individuais de grupo de atividade física, duração em segundos da onda $P$, intervalo $P-R$, complexo QRS, intervalo QT e onda T; amplitude em milivolts da onda $\mathrm{P}$ única, onda $\mathrm{P}$ bifásica, primeira porção da onda $P$ bífida (P1), segunda porção da onda $P$ bífida (P2), complexo QRS e onda T, na derivação bipolar I, obtido pelo eletrocardiograma de 100 eqüinos de salto criados na cidade de São Paulo - SP - 2006.

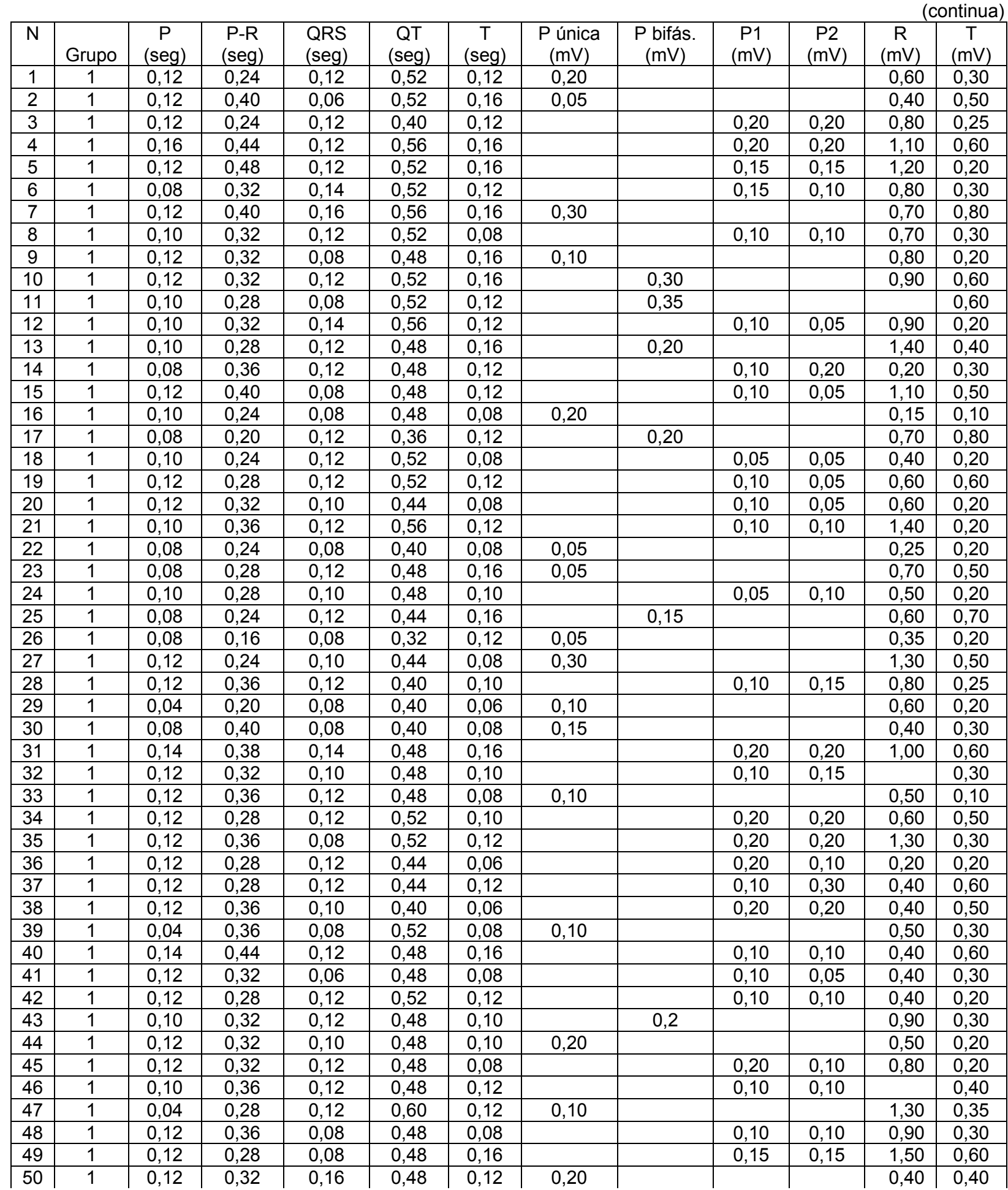


APÊNDICE B - Dados individuais de grupo de atividade física, duração em segundos da onda P, intervalo P-R, complexo QRS, intervalo QT e onda T; amplitude em milivolts da onda $P$ única, onda $P$ bifásica, primeira porção da onda $P$ bífida (P1), segunda porção da onda $P$ bífida (P2), complexo QRS e onda $T$, na derivação bipolar I, obtido pelo eletrocardiograma de 100 eqüinos de salto criados na cidade de São Paulo - SP - 2006.

(conclusão)

\begin{tabular}{|c|c|c|c|c|c|c|c|c|c|c|c|c|}
\hline $\mathrm{N}$ & Grupo & $\begin{array}{c}P \\
\text { (seg) }\end{array}$ & $\begin{array}{c}\text { P-R } \\
\text { (seg) }\end{array}$ & $\begin{array}{l}\text { QRS } \\
\text { (seg) }\end{array}$ & $\begin{array}{c}\text { QT } \\
\text { (seg) }\end{array}$ & $\begin{array}{c}\mathrm{T} \\
(\mathrm{seg})\end{array}$ & $\begin{array}{c}\text { P única } \\
(\mathrm{mV})\end{array}$ & $\begin{array}{c}\text { P bifás. } \\
(\mathrm{mV})\end{array}$ & $\begin{array}{c}\mathrm{P} 1 \\
(\mathrm{mV})\end{array}$ & $\begin{array}{c}\mathrm{P} 2 \\
(\mathrm{mV})\end{array}$ & $\begin{array}{c}\mathrm{R} \\
(\mathrm{mV})\end{array}$ & $\begin{array}{c}\mathrm{T} \\
(\mathrm{mV})\end{array}$ \\
\hline 51 & 1 & 0,12 & 0,32 & 0,12 & 0,44 & 0,16 & & & 0,20 & 0,20 & 0,70 & 0,70 \\
\hline 52 & 1 & 0,12 & 0,36 & 0,12 & 0,52 & 0,12 & & & 0,10 & 0,20 & 0,80 & 0,50 \\
\hline 53 & 1 & 0,12 & 0,28 & 0,12 & 0,52 & 0,16 & & & 0,20 & 0,30 & 0,25 & 0,80 \\
\hline 54 & 1 & 0,12 & 0,28 & 0,12 & 0,52 & 0,08 & & & 0,20 & 0,30 & 1,30 & 0,20 \\
\hline 55 & 1 & 0,12 & 0,28 & 0,08 & 0,52 & 0,12 & & & 0,10 & 0,10 & 1,00 & 0,40 \\
\hline 56 & 1 & 0,08 & 0,28 & 0,10 & 0,52 & 0,16 & 0,20 & & & & 0,70 & 0,70 \\
\hline 57 & 2 & 0,09 & 0,28 & 0,12 & 0,52 & 0,16 & & & 0,15 & 0,15 & 1,20 & 0,40 \\
\hline 58 & 2 & 0,12 & 0,40 & 0,08 & 0,48 & 0,12 & & & 0,15 & 0,15 & 0,50 & 0,20 \\
\hline 59 & 2 & 0,12 & 0,24 & 0,08 & 0,44 & 0,10 & & & 0,10 & 0,10 & 0,45 & 0,25 \\
\hline 60 & 2 & 0,06 & 0,32 & 0,08 & 0,52 & 0,10 & 0,05 & & & & 0,70 & 0,25 \\
\hline 61 & 2 & 0,14 & 0,46 & 0,08 & 0,48 & 0,12 & & & 0,15 & 0,10 & 0,40 & 0,20 \\
\hline 62 & 2 & 0,12 & 0,48 & 0,08 & 0,48 & 0,08 & & & 0,10 & 0,20 & 0,80 & 0,25 \\
\hline 63 & 2 & 0,12 & 0,40 & 0,12 & 0,44 & 0,12 & 0,10 & & & & 0,20 & 0,20 \\
\hline 64 & 2 & 0,12 & 0,48 & 0,12 & 0,52 & 0,12 & & & 0,10 & 0,05 & 0,40 & 0,20 \\
\hline 65 & 2 & 0,16 & 0,32 & 0,08 & 0,53 & 0,12 & & & 0,20 & 0,25 & 1,10 & 0,30 \\
\hline 66 & 2 & 0,12 & 0,24 & 0,12 & 0,48 & 0,12 & & 0,15 & & & 0,50 & 0,30 \\
\hline 67 & 2 & 0,12 & 0,28 & 0,16 & 0,48 & 0,08 & & & 0,05 & 0,10 & 0,80 & 0,30 \\
\hline 68 & 2 & 0,06 & 0,20 & 0,12 & 0,44 & 0,10 & & 0,30 & & & 0,50 & 0,30 \\
\hline 69 & 2 & 0,10 & 0,28 & 0,06 & 0,44 & 0,12 & & & 0,05 & 0,20 & 0,20 & 0,70 \\
\hline 70 & 2 & 0,08 & 0,28 & 0,12 & 0,48 & 0,16 & & & 0,05 & 0,05 & 0,80 & 0,60 \\
\hline 71 & 2 & 0,08 & 0,28 & 0,08 & 0,44 & 0,04 & & & 0,10 & 0,10 & 0,90 & 0,15 \\
\hline 72 & 2 & 0,10 & 0,24 & 0,10 & 0,40 & 0,12 & & & 0,05 & 0,05 & 0,70 & 0,20 \\
\hline 73 & 2 & 0,16 & 0,36 & 0,12 & 0,52 & 0,12 & & & 0,15 & 0,20 & 0,80 & 0,50 \\
\hline 74 & 2 & 0,12 & 0,20 & 0,12 & 0,40 & 0,04 & & & 0,05 & 0,05 & 1,20 & 0,20 \\
\hline 75 & 2 & 0,12 & 0,24 & 0,16 & 0,36 & 0,12 & & 0,30 & & & 0,50 & 0,10 \\
\hline 76 & 2 & 0,10 & 0,24 & 0,16 & 0,44 & 0,10 & & 0,25 & & & 0,80 & 0,20 \\
\hline 77 & 2 & 0,10 & 0,24 & 0,12 & 0,48 & 0,16 & & & 0,05 & 0,05 & 0,70 & 0,50 \\
\hline 78 & 2 & 0,12 & 0,32 & 0,12 & 0,44 & 0,12 & & & 0,10 & 0,05 & 0,60 & 0,15 \\
\hline 79 & 2 & 0,10 & 0,24 & 0,12 & 0,44 & 0,12 & & & 0,20 & 0,20 & 1,20 & 0,10 \\
\hline 80 & 2 & 0,08 & 0,24 & 0,12 & 0,40 & 0,12 & 0,20 & & & & 0,20 & 0,60 \\
\hline 81 & 2 & 0,14 & 0,42 & 0,08 & 0,44 & 0,12 & & & 0,10 & 0,10 & 0,30 & 0,40 \\
\hline 82 & 2 & 0,12 & 0,40 & 0,12 & 0,48 & 0,12 & & & 0,10 & 0,10 & 0,30 & 0,40 \\
\hline 83 & 2 & 0,10 & 0,32 & 0,08 & 0,56 & 0,12 & & & 0,10 & 0,20 & 0,30 & 0,40 \\
\hline 84 & 2 & 0,12 & 0,52 & 0,04 & 0,52 & 0,10 & 0,30 & & & & 0,40 & 0,30 \\
\hline 85 & 2 & 0,12 & 0,32 & 0,08 & 0,48 & 0,12 & & & 0,05 & 0,10 & 0,30 & 0,30 \\
\hline 86 & 2 & 0,12 & 0,28 & 0,08 & 0,48 & 0,08 & 0,25 & & & & 0,20 & 0,40 \\
\hline 87 & 2 & 0,04 & 0,40 & 0,08 & 0,40 & 0,08 & 0,10 & & & & 0,60 & 0,30 \\
\hline 88 & 2 & 0,12 & 0,36 & 0,04 & 0,40 & 0,08 & & & 0,10 & 0,10 & 0,60 & 0,30 \\
\hline 89 & 2 & 0,10 & 0,28 & 0,12 & 0,48 & 0,08 & & & 0,20 & 0,20 & 0,60 & 0,40 \\
\hline 90 & 2 & 0,12 & 0,24 & 0,06 & 0,44 & 0,12 & & & 0,05 & 0,10 & & 0,20 \\
\hline 91 & 2 & 0,08 & 0,40 & 0,08 & 0,44 & 0,08 & 0,20 & & & & 0,20 & 0,20 \\
\hline 92 & 2 & 0,12 & 0,24 & 0,08 & 0,48 & 0,12 & & & 0,10 & 0,20 & 1,60 & 0,40 \\
\hline 93 & 2 & 0,12 & 0,32 & 0,12 & 0,36 & 0,04 & & 0,30 & & & 0,40 & 0,20 \\
\hline 94 & 2 & 0,12 & 0,28 & 0,16 & 0,48 & 0,12 & & & 0,20 & 0,30 & 0,60 & 0,30 \\
\hline 95 & 2 & 0,12 & 0,36 & 0,08 & 0,48 & 0,12 & & & 0,10 & 0,20 & 0,70 & 0,40 \\
\hline 96 & 2 & 0,12 & 0,40 & 0,16 & 0,56 & 0,12 & & & 0,05 & 0,10 & 0,45 & 0,70 \\
\hline 97 & 2 & 0,12 & 0,32 & 0,08 & 0,48 & 0,08 & & & 0,10 & 0,10 & 0,10 & 0,10 \\
\hline 98 & 2 & 0,08 & 0,24 & 0,08 & 0,36 & 0,08 & 0,20 & & & & 1,10 & 0,30 \\
\hline 99 & 2 & 0,08 & 0,28 & 0,08 & 0,48 & 0,08 & 0,10 & & & & 0,60 & 0,20 \\
\hline 100 & 2 & 0,12 & 0,28 & 0,08 & 0,48 & 0,08 & & & 0,10 & 0,10 & 0,60 & 0,20 \\
\hline
\end{tabular}


APÊNDICE C - Dados individuais de grupo de atividade física, duração em segundos da onda $\mathrm{P}$, intervalo $\mathrm{P}-\mathrm{R}$, complexo QRS, intervalo QT e onda T; amplitude em milivolts da onda $P$ única, onda $P$ bifásica, primeira porção da onda $P$ bífida (P1), segunda porção da onda $P$ bífida (P2), complexo QRS e onda T, na derivação bipolar II, obtido pelo eletrocardiograma de 100 eqüinos de salto criados na cidade de São Paulo - SP - 2006.

\begin{tabular}{|c|c|c|c|c|c|c|c|c|c|c|c|c|}
\hline $\mathrm{N}$ & Grupo & $\begin{array}{c}P \\
(\mathrm{seg})\end{array}$ & $\begin{array}{c}\text { P-R } \\
\text { (seg) }\end{array}$ & $\begin{array}{l}\text { QRS } \\
\text { (seg) }\end{array}$ & $\begin{array}{c}\text { QT } \\
\text { (seg) }\end{array}$ & $\begin{array}{c}\mathrm{T} \\
(\mathrm{seg})\end{array}$ & $\begin{array}{c}\text { P única } \\
(\mathrm{mV})\end{array}$ & $\begin{array}{c}\text { P bifás. } \\
(\mathrm{mV})\end{array}$ & $\begin{array}{c}\mathrm{P} 1 \\
(\mathrm{mV})\end{array}$ & $\begin{array}{c}\mathrm{P} 2 \\
(\mathrm{mV})\end{array}$ & $\begin{array}{c}\mathrm{R} \\
(\mathrm{mV})\end{array}$ & $\begin{array}{c}\mathrm{T} \\
(\mathrm{mV})\end{array}$ \\
\hline 1 & 1 & 0,16 & 0,32 & 0,12 & 0,56 & 0,16 & & 0,20 & & & 0,40 & 0,50 \\
\hline 2 & 1 & 0,12 & 0,40 & 0,04 & 0,56 & 0,12 & & & 0,10 & 0,20 & 0,50 & 0,40 \\
\hline 3 & 1 & 0,12 & 0,32 & 0,10 & 0,48 & 0,12 & & & 0,10 & 0,20 & 2,00 & 0,10 \\
\hline 4 & 1 & 0,16 & 0,44 & 0,12 & 0,56 & 0,16 & & & 0,15 & 0,30 & 1,30 & 0,60 \\
\hline 5 & 1 & 0,16 & 0,48 & 0,12 & 0,56 & 0,16 & & & 0,15 & 0,30 & 1,40 & 0,60 \\
\hline 6 & 1 & 0,12 & 0,32 & 0,08 & 0,52 & 0,16 & 0,20 & & & & 0,90 & 0,80 \\
\hline 7 & 1 & 0,16 & 0,40 & 0,08 & 0,52 & 0,12 & & & 0,10 & 0,20 & 1,20 & 0,50 \\
\hline 8 & 1 & 0,12 & 0,28 & 0,06 & 0,52 & 0,16 & & & 0,15 & 0,20 & 0,60 & 0,60 \\
\hline 9 & 1 & 0,12 & 0,32 & 0,08 & 0,52 & 0,12 & & & 0,25 & 0,25 & 1,20 & 0,80 \\
\hline 10 & 1 & 0,16 & 0,36 & 0,10 & 0,52 & 0,12 & & 0,30 & & & 0,60 & 0,40 \\
\hline 11 & 1 & 0,08 & 0,28 & 0,12 & 0,48 & 0,12 & & & 0,10 & 0,30 & 0,10 & 0,70 \\
\hline 12 & 1 & 0,12 & 0,48 & 0,04 & 0,56 & 0,08 & & & 0,15 & 0,25 & 0,40 & 0,20 \\
\hline 13 & 1 & 0,12 & 0,28 & 0,08 & 0,44 & 0,08 & 0,50 & & & & 2,20 & 0,10 \\
\hline 14 & 1 & 0,12 & 0,36 & 0,08 & 0,48 & 0,12 & 0,30 & & & & 0,70 & 0,20 \\
\hline 15 & 1 & 0,14 & 0,40 & 0,12 & 0,52 & 0,12 & & & 0,10 & 0,25 & 1,40 & 0,40 \\
\hline 16 & 1 & 0,14 & 0,24 & 0,10 & 0,48 & 0,06 & & & 0,10 & 0,20 & 1,20 & 0,30 \\
\hline 17 & 1 & 0,12 & 0,20 & 0,10 & 0,32 & 0,06 & & 0,40 & & & 0,90 & 0,20 \\
\hline 18 & 1 & 0,12 & 0,20 & 0,12 & 0,56 & 0,12 & 0,20 & & & & 0,90 & 0,70 \\
\hline 19 & 1 & 0,16 & 0,28 & 0,12 & 0,52 & 0,16 & & & 0,10 & 0,20 & 1,80 & 0,70 \\
\hline 20 & 1 & 0,16 & 0,32 & 0,08 & 0,52 & 0,16 & & & 0,15 & 0,20 & 1,10 & 0,30 \\
\hline 21 & 1 & 0,12 & 0,32 & 0,12 & 0,52 & 0,08 & 0,20 & & & & 0,90 & 0,40 \\
\hline 22 & 1 & 0,08 & 0,20 & 0,10 & 0,44 & 0,08 & 0,30 & & & & 1,50 & 0,20 \\
\hline 23 & 1 & 0,04 & 0,28 & 0,10 & 0,48 & 0,12 & 0,30 & & & & 1,30 & 0,30 \\
\hline 24 & 1 & 0,12 & 0,40 & 0,08 & 0,48 & 0,08 & & & 0,10 & 0,20 & 0,80 & 0,20 \\
\hline 25 & 1 & 0,08 & 0,20 & 0,10 & 0,40 & 0,12 & 0,30 & & & & 0,80 & 0,30 \\
\hline 26 & 1 & 0,08 & 0,16 & 0,08 & 0,36 & 0,08 & 0,40 & & & & 1,20 & 0,30 \\
\hline 27 & 1 & 0,12 & 0,28 & 0,12 & 0,44 & 0,04 & & & 0,15 & 0,30 & 1,50 & 0,30 \\
\hline 28 & 1 & 0,12 & 0,32 & 0,08 & 0,48 & 0,08 & 0,20 & & & & 1,60 & 0,70 \\
\hline 29 & 1 & 0,08 & 0,24 & 0,08 & 0,40 & 0,08 & 0,30 & & & & 0,80 & 0,60 \\
\hline 30 & 1 & 0,08 & 0,20 & 0,04 & 0,36 & 0,12 & 0,20 & & & & 0,60 & 0,70 \\
\hline 31 & 1 & 0,16 & 0,40 & 0,10 & 0,52 & 0,16 & & & 0,10 & 0,10 & 1,80 & 0,80 \\
\hline 32 & 1 & 0,12 & 0,28 & 0,06 & 0,52 & 0,10 & & & 0,10 & 0,20 & 1,20 & 0,40 \\
\hline 33 & 1 & 0,08 & 0,28 & 0,08 & 0,48 & 0,12 & 0,30 & & & & 1,10 & 0,40 \\
\hline 34 & 1 & 0,16 & 0,32 & 0,12 & 0,56 & 0,12 & & & 0,20 & 0,20 & 1,00 & 0,70 \\
\hline 35 & 1 & 0,12 & 0,32 & 0,08 & 0,60 & 0,16 & 0,20 & & & & 1,40 & 0,40 \\
\hline 36 & 1 & 0,16 & 0,28 & 0,08 & 0,48 & 0,10 & & & 0,20 & 0,30 & 0,60 & 0,40 \\
\hline 37 & 1 & 0,12 & 0,24 & 0,12 & 0,48 & 0,12 & 0,30 & & & & 1,40 & 0,50 \\
\hline 38 & 1 & 0,12 & 0,36 & 0,12 & 0,48 & 0,08 & & & 0,20 & 0,30 & 1,00 & 0,60 \\
\hline 39 & 1 & 0,12 & 0,32 & 0,06 & 0,52 & 0,12 & & & 0,10 & 0,20 & 1,00 & 0,60 \\
\hline 40 & 1 & 0,16 & 0,52 & 0,10 & 0,48 & 0,12 & & & 0,10 & 0,20 & 0,40 & 0,40 \\
\hline 41 & 1 & 0,16 & 0,32 & 0,04 & 0,56 & 0,08 & & & 0,20 & 0,20 & 0,80 & 0,30 \\
\hline 42 & 1 & 0,12 & 0,24 & 0,12 & 0,52 & 0,08 & 0,40 & & & & 0,90 & 0,20 \\
\hline 43 & 1 & 0,12 & 0,32 & 0,12 & 0,48 & 0,08 & 0,20 & & & & 1,40 & 0,30 \\
\hline 44 & 1 & 0,10 & 0,28 & 0,10 & 0,56 & 0,08 & 0,25 & & & & 0,30 & 0,30 \\
\hline 45 & 1 & 0,16 & 0,32 & 0,08 & 0,48 & 0,08 & & & 0,10 & 0,20 & 0,30 & 0,20 \\
\hline$\frac{45}{46}$ & $\frac{1}{1}$ & 0,12 & $\begin{array}{l}0,02 \\
0,36\end{array}$ & $\begin{array}{l}0,00 \\
0,12\end{array}$ & $\begin{array}{l}0,40 \\
0,52\end{array}$ & $\begin{array}{l}0,00 \\
0,10\end{array}$ & 0,20 & & & & $\begin{array}{l}0,30 \\
0,30\end{array}$ & 0,30 \\
\hline 47 & 1 & 0,12 & 0,28 & 0,08 & 0,60 & 0,12 & & & 0,10 & 0,20 & 1,00 & 0,40 \\
\hline 48 & 1 & 0,12 & 0,28 & 0,10 & 0,52 & 0,12 & & & 0,10 & 0,20 & 1,50 & 0,40 \\
\hline 49 & 1 & 0,12 & 0,28 & 0,06 & 0,48 & 0,20 & & & 0,10 & 0,20 & 2,00 & 0,60 \\
\hline 50 & 1 & 0,08 & 0,32 & 0,08 & 0,48 & 0,12 & 0,30 & & & & 1,20 & 0,40 \\
\hline
\end{tabular}


APÊNDICE C - Dados individuais de grupo de atividade física, duração em segundos da onda $P$, intervalo $P-R$, complexo QRS, intervalo QT e onda T; amplitude em milivolts da onda $\mathrm{P}$ única, onda $\mathrm{P}$ bifásica, primeira porção da onda $P$ bífida (P1), segunda porção da onda $P$ bífida (P2), complexo QRS e onda T, na derivação bipolar II, obtido pelo eletrocardiograma de 100 eqüinos de salto criados na cidade de São Paulo - SP - 2006.

\begin{tabular}{|c|c|c|c|c|c|c|c|c|c|c|c|c|}
\hline $\mathrm{N}$ & Grupo & $\begin{array}{c}\mathrm{P} \\
\text { (seg) }\end{array}$ & $\begin{array}{c}\text { P-R } \\
\text { (seg) }\end{array}$ & $\begin{array}{l}\text { QRS } \\
\text { (seg) }\end{array}$ & $\begin{array}{c}\text { QT } \\
\text { (seg) }\end{array}$ & $\begin{array}{c}\mathrm{T} \\
\text { (seg) }\end{array}$ & $\begin{array}{c}\text { P única } \\
(\mathrm{mV})\end{array}$ & $\begin{array}{c}P \text { bifás. } \\
(\mathrm{mV})\end{array}$ & $\begin{array}{c}\mathrm{P} 1 \\
\text { (mV) }\end{array}$ & $\begin{array}{c}\text { P2 } \\
(\mathrm{mV})\end{array}$ & $\begin{array}{c}\mathrm{R} \\
(\mathrm{mV})\end{array}$ & $\begin{array}{c}\mathrm{T} \\
(\mathrm{mV})\end{array}$ \\
\hline 51 & 1 & 0,08 & 0,32 & 0,08 & 0,48 & 0,12 & 0,30 & & & & 1,50 & 0,40 \\
\hline 52 & 1 & 0,16 & 0,32 & 0,08 & 0,52 & 0,08 & & & 0,20 & 0,30 & 2,15 & 0,60 \\
\hline 53 & 1 & 0,12 & 0,36 & 0,08 & 0,48 & 0,12 & & & 0,10 & 0,30 & 1,00 & 0,50 \\
\hline 54 & 1 & 0,08 & 0,28 & 0,08 & 0,52 & 0,12 & 0,30 & & & & 1,10 & 0,50 \\
\hline 55 & 1 & 0,12 & 0,28 & 0,12 & 0,48 & 0,12 & 0,30 & & & & 2,00 & 0,80 \\
\hline 56 & 1 & 0,16 & 0,32 & 0,04 & 0,52 & 0,08 & & & 0,10 & 0,20 & 0,70 & 0,40 \\
\hline 57 & 2 & 0,12 & 0,36 & 0,12 & 0,52 & 0,12 & & & 0,20 & 0,20 & 0,60 & 0,60 \\
\hline 58 & 2 & 0,12 & 0,32 & 0,08 & 0,52 & 0,20 & & & 0,20 & 0,25 & 1,20 & 0,90 \\
\hline 59 & 2 & 0,12 & 0,40 & 0,10 & 0,52 & 0,08 & & & 0,20 & 0,20 & 0,90 & 0,30 \\
\hline 60 & 2 & 0,12 & 0,28 & 0,16 & 0,52 & 0,12 & 0,25 & & & & 0,80 & 0,35 \\
\hline 61 & 2 & 0,08 & 0,24 & 0,12 & 0,56 & 0,12 & 0,30 & & & & 0,20 & 0,20 \\
\hline 62 & 2 & 0,14 & 0,44 & 0,06 & 0,48 & 0,12 & & & 0,10 & 0,20 & 1,00 & 0,40 \\
\hline 63 & 2 & 0,12 & 0,44 & 0,08 & 0,56 & 0,08 & 0,20 & & & & 0,40 & 0,35 \\
\hline 64 & 2 & 0,14 & 0,36 & 0,12 & 0,52 & 0,12 & & & 0,10 & 0,15 & 0,70 & 0,50 \\
\hline 65 & 2 & 0,14 & 0,44 & 0,08 & 0,56 & 0,16 & & & 0,10 & 0,20 & 1,30 & 0,40 \\
\hline 66 & 2 & 0,16 & 0,36 & 0,08 & 0,56 & 0,08 & & & 0,10 & 0,20 & 1,40 & 0,30 \\
\hline 67 & 2 & 0,16 & 0,28 & 0,08 & 0,48 & 0,12 & & 0,30 & & & 0,70 & 0,15 \\
\hline 68 & 2 & 0,12 & 0,32 & 0,12 & 0,48 & 0,16 & & & 0,10 & 0,20 & 0,15 & 0,50 \\
\hline 69 & 2 & 0,12 & 0,24 & 0,06 & 0,36 & 0,08 & & 0,60 & & & 0,70 & 0,40 \\
\hline 70 & 2 & 0,12 & 0,28 & 0,12 & 0,48 & 0,16 & & 0,30 & & & 1,00 & 1,10 \\
\hline 71 & 2 & 0,12 & 0,28 & 0,14 & 0,48 & 0,16 & & 0,25 & & & 1,70 & 0,50 \\
\hline 72 & 2 & 0,12 & 0,28 & 0,06 & 0,48 & 0,12 & & & 0,15 & 0,30 & 1,00 & 0,70 \\
\hline 73 & 2 & 0,08 & 0,24 & 0,06 & 0,40 & 0,08 & 0,20 & & & & 0,80 & 0,20 \\
\hline 74 & 2 & 0,16 & 0,40 & 0,08 & 0,52 & 0,12 & & & 0,25 & 0,30 & 2,10 & 0,60 \\
\hline 75 & 2 & 0,12 & 0,20 & 0,12 & 0,48 & 0,16 & & 0,30 & & & 1,40 & 0,70 \\
\hline 76 & 2 & 0,10 & 0,24 & 0,08 & 0,48 & 0,12 & & 0,30 & & & 1,00 & 0,20 \\
\hline 77 & 2 & 0,08 & 0,24 & 0,08 & 0,40 & 0,12 & 0,25 & & & & 0,80 & 0,90 \\
\hline 78 & 2 & 0,08 & 0,20 & 0,12 & 0,48 & 0,20 & 0,10 & & & & 0,70 & 0,50 \\
\hline 79 & 2 & 0,12 & 0,36 & 0,08 & 0,40 & 0,08 & & & 0,10 & 0,15 & 1,60 & 0,20 \\
\hline 80 & 2 & 0,12 & 0,24 & 0,08 & 0,44 & 0,08 & & & 0,20 & 0,30 & 1,10 & 0,30 \\
\hline 81 & 2 & 0,12 & 0,24 & 0,08 & 0,44 & 0,08 & 0,30 & & & & 1,00 & 0,10 \\
\hline 82 & 2 & 0,14 & 0,40 & 0,08 & 0,48 & 0,12 & & & 0,10 & 0,15 & 1,30 & 0,30 \\
\hline 83 & 2 & 0,12 & 0,40 & 0,08 & 0,52 & 0,12 & & & 0,10 & 0,20 & 1,00 & 0,30 \\
\hline 84 & 2 & 0,12 & 0,36 & 0,08 & 0,56 & 0,12 & & & 0,10 & 0,20 & 0,80 & 0,40 \\
\hline 85 & 2 & 0,12 & 0,52 & 0,08 & 0,52 & 0,08 & 0,30 & & & & 0,50 & 0,30 \\
\hline 86 & 2 & 0,12 & 0,28 & 0,12 & 0,48 & 0,08 & & & 0,10 & 0,20 & 0,15 & 0,30 \\
\hline 87 & 2 & 0,12 & 0,32 & 0,04 & 0,44 & 0,12 & & 0,30 & & & 0,80 & 0,60 \\
\hline 88 & 2 & 0,12 & 0,24 & 0,08 & 0,44 & 0,08 & 0,30 & & & & 0,80 & 0,60 \\
\hline 89 & 2 & 0,16 & 0,44 & 0,10 & 0,44 & 0,08 & & & 0,10 & 0,30 & 0,80 & 0,50 \\
\hline 90 & 2 & 0,12 & 0,24 & 0,10 & 0,48 & 0,12 & & & 0,20 & 0,30 & 0,10 & 0,80 \\
\hline 91 & 2 & 0,12 & 0,28 & 0,12 & 0,44 & 0,08 & & & 0,10 & 0,20 & 0,40 & 0,40 \\
\hline 92 & 2 & 0,12 & 0,28 & 0,08 & 0,44 & 0,12 & & & 0,10 & 0,30 & 2,80 & 0,60 \\
\hline 93 & 2 & 0,12 & 0,28 & 0,12 & 0,52 & 0,16 & & & 0,20 & 0,20 & 1,10 & 0,60 \\
\hline 94 & 2 & 0,12 & 0,28 & 0,08 & 0,40 & 0,08 & 0,30 & & & & 1,20 & 0,30 \\
\hline 95 & 2 & 0,16 & 0,40 & 0,12 & 0,48 & 0,12 & & & 0,25 & 0,25 & 0,60 & 0,40 \\
\hline 96 & 2 & 0,12 & 0,36 & 0,04 & 0,48 & 0,16 & & & 0,10 & 0,20 & 0,80 & 0,60 \\
\hline 97 & 2 & 0,12 & 0,36 & 0,08 & 0,56 & 0,12 & 0,20 & & & & 1,00 & 0,40 \\
\hline 98 & 2 & 0,12 & 0,36 & 0,08 & 0,48 & 0,08 & & & 0,10 & 0,20 & 1,05 & 0,20 \\
\hline 99 & 2 & 0,08 & 0,24 & 0,10 & 0,44 & 0,08 & 0,30 & & & & 1,00 & 0,10 \\
\hline 100 & 2 & 0,08 & 0,28 & 0,08 & 0,52 & 0,12 & 0,20 & & & & 0,90 & 0,40 \\
\hline
\end{tabular}


APÊNDICE D - Dados individuais de grupo de atividade física, duração em segundos da onda $P$, intervalo $P-R$, complexo QRS, intervalo QT e onda T; amplitude em milivolts da onda $P$ única, onda $P$ bifásica, primeira porção da onda $P$ bífida (P1), segunda porção da onda $P$ bífida (P2), complexo QRS e onda T, na derivação bipolar III, obtido pelo eletrocardiograma de 100 eqüinos de salto criados na cidade de São Paulo - SP - 2006.

(continua)

\begin{tabular}{|c|c|c|c|c|c|c|c|c|c|c|c|c|}
\hline $\mathrm{N}$ & Grupo & $\begin{array}{c}P \\
(\operatorname{seg})\end{array}$ & $\begin{array}{c}\text { P-R } \\
\text { (seg) }\end{array}$ & $\begin{array}{l}\text { QRS } \\
\text { (seg) }\end{array}$ & $\begin{array}{c}\text { QT } \\
\text { (seg) }\end{array}$ & $\begin{array}{c}\mathrm{T} \\
(\mathrm{seg})\end{array}$ & $\begin{array}{c}\text { P única } \\
(\mathrm{mV})\end{array}$ & $\begin{array}{c}\text { P bifás. } \\
(\mathrm{mV})\end{array}$ & $\begin{array}{c}\mathrm{P} 1 \\
(\mathrm{mV})\end{array}$ & $\begin{array}{c}\mathrm{P} 2 \\
(\mathrm{mV})\end{array}$ & $\begin{array}{c}\mathrm{R} \\
(\mathrm{mV})\end{array}$ & $\begin{array}{c}\mathrm{T} \\
(\mathrm{mV})\end{array}$ \\
\hline 1 & 1 & 0,16 & 0,32 & 0,08 & 0,56 & 0,16 & 0,15 & & & & 0,10 & 0,55 \\
\hline 2 & 1 & 0,12 & 0,40 & 0,10 & 0,52 & 0,12 & & & 0,10 & 0,20 & 0,10 & 0,40 \\
\hline 3 & 1 & 0,12 & 0,28 & 0,08 & 0,44 & 0,12 & & & 0,10 & 0,20 & 1,20 & 0,20 \\
\hline 4 & 1 & 0,08 & 0,44 & 0,12 & 0,56 & 0,16 & 0,20 & & & & 1,30 & 1,00 \\
\hline 5 & 1 & 0,12 & 0,36 & 0,12 & 0,52 & 0,16 & & & 0,05 & 0,15 & 0,20 & 0,50 \\
\hline 6 & 1 & 0,08 & 0,36 & 0,08 & 0,52 & 0,16 & & & 0,10 & 0,10 & 0,10 & 0,40 \\
\hline 7 & 1 & 0,12 & 0,36 & 0,08 & 0,52 & 0,12 & 0,10 & & & & 0,70 & 0,40 \\
\hline 8 & 1 & 0,10 & 0,28 & 0,08 & 0,56 & 0,16 & & & 0,15 & 0,15 & 0,10 & 0,40 \\
\hline 9 & 1 & 0,12 & 0,32 & 0,10 & 0,52 & 0,16 & & & 0,10 & 0,20 & 0,80 & 0,80 \\
\hline 10 & 1 & 0,12 & 0,40 & 0,08 & 0,52 & 0,12 & & & 0,10 & 0,20 & 0,10 & 0,40 \\
\hline 11 & 1 & 0,12 & 0,28 & 0,10 & 0,52 & 0,12 & 0,20 & & & & 0,30 & 0,30 \\
\hline 12 & 1 & 0,12 & 0,48 & 0,12 & 0,56 & 0,12 & & & 0,10 & 0,20 & 0,15 & 0,40 \\
\hline 13 & 1 & 0,10 & 0,28 & 0,10 & 0,48 & 0,12 & 0,50 & & & & 0,80 & 0,40 \\
\hline 14 & 1 & 0,16 & 0,36 & 0,12 & 0,48 & 0,12 & & & 0,20 & 0,30 & 2,10 & 0,40 \\
\hline 15 & 1 & 0,12 & 0,40 & 0,08 & 0,52 & 0,12 & & & 0,10 & 0,30 & 0,30 & 0,60 \\
\hline 16 & 1 & 0,10 & 0,24 & 0,12 & 0,44 & 0,08 & & & 0,10 & 0,20 & 1,00 & 0,20 \\
\hline 17 & 1 & 0,08 & 0,24 & 0,10 & 0,32 & 0,08 & & & 0,25 & 0,15 & 1,30 & 0,30 \\
\hline 18 & 1 & 0,08 & 0,20 & 0,12 & 0,52 & 0,12 & 0,15 & & & & 0,80 & 0,70 \\
\hline 19 & 1 & 0,12 & 0,28 & 0,12 & 0,52 & 0,12 & & 0,20 & & & 1,00 & 0,50 \\
\hline 20 & 1 & 0,12 & 0,32 & 0,08 & 0,48 & 0,12 & 0,20 & & & & 0,60 & 0,30 \\
\hline 21 & 1 & 0,12 & 0,36 & 0,08 & 0,52 & 0,10 & & & 0,15 & 0,10 & & 0,30 \\
\hline 22 & 1 & 0,08 & 0,18 & 0,12 & 0,36 & 0,08 & 0,35 & & & & 1,40 & 0,20 \\
\hline 23 & 1 & 0,08 & 0,28 & 0,10 & 0,48 & 0,08 & 0,20 & & & & 1,00 & 0,30 \\
\hline 24 & 1 & 0,12 & 0,36 & 0,10 & 0,48 & 0,12 & & & 0,10 & 0,20 & 0,40 & 0,50 \\
\hline 25 & 1 & 0,08 & 0,24 & 0,10 & 0,40 & 0,12 & & & 0,10 & 0,20 & 0,60 & 0,40 \\
\hline 26 & 1 & 0,08 & 0,16 & 0,08 & 0,36 & 0,08 & 0,30 & & & & 1,10 & 0,30 \\
\hline 27 & 1 & 0,12 & 0,28 & 0,08 & 0,44 & 0,12 & & & 0,10 & 0,20 & 0,50 & 0,40 \\
\hline 28 & 1 & 0,12 & 0,32 & 0,04 & 0,48 & 0,08 & 0,10 & & & & 0,90 & 0,80 \\
\hline 29 & 1 & 0,08 & 0,24 & 0,04 & 0,40 & 0,08 & 0,20 & & & & 0,30 & 0,70 \\
\hline 30 & 1 & 0,08 & 0,24 & 0,08 & 0,36 & 0,08 & 0,10 & & & & 0,50 & 0,90 \\
\hline 31 & 1 & 0,16 & 0,40 & 0,08 & 0,52 & 0,10 & & & 0,15 & 0,10 & 0,90 & 0,50 \\
\hline 32 & 1 & 0,12 & 0,28 & 0,06 & 0,52 & 0,10 & & & 0,10 & 0,20 & 0,90 & 0,40 \\
\hline 33 & 1 & 0,14 & 0,32 & 0,12 & 0,52 & 0,12 & & 0,30 & & & 0,50 & 0,20 \\
\hline 34 & 1 & 0,08 & 0,36 & 0,08 & 0,52 & 0,12 & 0,10 & & & & 0,80 & 0,60 \\
\hline 35 & 1 & 0,16 & 0,40 & 0,08 & 0,52 & 0,12 & & 0,20 & & & 0,20 & 0,20 \\
\hline 36 & 1 & 0,12 & 0,24 & 0,08 & 0,48 & 0,12 & 0,10 & & & & 0,50 & 0,35 \\
\hline 37 & 1 & 0,08 & 0,24 & 0,10 & 0,44 & 0,08 & & & 0,10 & 0,10 & 1,00 & 0,20 \\
\hline 38 & 1 & 0,12 & 0,36 & 0,08 & 0,48 & 0,12 & & & & & 0,80 & 0,30 \\
\hline 39 & 1 & 0,08 & 0,28 & 0,04 & 0,52 & 0,12 & 0,20 & & & & 0,60 & 0,70 \\
\hline 40 & 1 & 0,12 & 0,40 & 0,08 & 0,52 & 0,12 & & & 0,10 & 0,10 & 0,10 & 0,60 \\
\hline 41 & 1 & 0,16 & 0,28 & 0,08 & 0,56 & 0,12 & & & 0,10 & 0,20 & 0,40 & 0,40 \\
\hline 42 & 1 & 0,08 & 0,28 & 0,08 & 0,52 & 0,08 & 0,20 & & & & 0,40 & 0,20 \\
\hline 43 & 1 & 0,12 & 0,36 & 0,08 & 0,48 & 0,08 & 0,10 & & & & 0,80 & 0,20 \\
\hline 44 & 1 & 0,12 & 0,32 & 0,10 & 0,52 & 0,10 & & 0,25 & & & 0,30 & 0,50 \\
\hline 45 & 1 & 0,10 & 0,24 & 0,12 & 0,48 & 0,08 & 0,10 & & & & 0,10 & 0,40 \\
\hline 46 & 1 & 0,12 & 0,28 & 0,08 & 0,48 & 0,12 & & 0,20 & & & 0,40 & 0,20 \\
\hline 47 & 1 & 0,16 & 0,36 & 0,10 & 0,52 & 0,10 & & 0,20 & & & 0,10 & 0,60 \\
\hline 48 & 1 & 0,12 & 0,36 & 0,08 & 0,52 & 0,12 & & 0,20 & & & 0,80 & 0,40 \\
\hline 49 & 1 & 0,08 & 0,28 & 0,06 & 0,48 & 0,12 & & & 0,10 & 0,10 & 0,50 & 0,40 \\
\hline 50 & 1 & 0,08 & 0,28 & 0,04 & 0,48 & 0,12 & 0,20 & & & & 0,80 & 0,30 \\
\hline
\end{tabular}


APÊNDICE D - Dados individuais de grupo de atividade física, duração em segundos da onda $P$, intervalo $P-R$, complexo QRS, intervalo QT e onda T; amplitude em milivolts da onda $\mathrm{P}$ única, onda $\mathrm{P}$ bifásica, primeira porção da onda $P$ bífida ( $P 1)$, segunda porção da onda $P$ bífida $(P 2)$, complexo $Q R S$ e onda T, na derivação bipolar III, obtido pelo eletrocardiograma de 100 eqüinos de salto criados na cidade de São Paulo - SP - 2006

\begin{tabular}{|c|c|c|c|c|c|c|c|c|c|c|c|c|}
\hline $\mathrm{N}$ & Grupo & $\begin{array}{c}P \\
\text { (seg) }\end{array}$ & $\begin{array}{c}\text { P-R } \\
\text { (seg) }\end{array}$ & $\begin{array}{l}\text { QRS } \\
\text { (seg) }\end{array}$ & $\begin{array}{c}\mathrm{QT} \\
\text { (seg) }\end{array}$ & $\begin{array}{c}\mathrm{T} \\
(\mathrm{seg})\end{array}$ & $\begin{array}{c}\text { P única } \\
\text { (mV) }\end{array}$ & $\begin{array}{c}\text { P bifás. } \\
(\mathrm{mV})\end{array}$ & $\begin{array}{c}\mathrm{P} 1 \\
(\mathrm{mV})\end{array}$ & $\begin{array}{c}\text { P2 } \\
(\mathrm{mV})\end{array}$ & $\begin{array}{c}\mathrm{R} \\
(\mathrm{mV})\end{array}$ & $\begin{array}{c}\mathrm{T} \\
(\mathrm{mV})\end{array}$ \\
\hline 51 & 1 & 0,08 & 0,28 & 0,04 & 0,48 & 0,12 & 0,20 & & & & 0,90 & 0,30 \\
\hline 52 & 1 & 0,12 & 0,32 & 0,12 & 0,52 & 0,08 & & & 0,10 & 0,20 & 1,50 & 0,20 \\
\hline 53 & 1 & 0,16 & 0,40 & 0,08 & 0,48 & 0,12 & & 0,20 & & & 1,00 & 0,30 \\
\hline 54 & 1 & 0,12 & 0,28 & 0,04 & 0,48 & 0,12 & 0,10 & & & & 0,30 & 0,40 \\
\hline 55 & 1 & 0,12 & 0,28 & 0,08 & 0,52 & 0,16 & & & 0,10 & 0,10 & 1,10 & 0,70 \\
\hline 56 & 1 & 0,08 & 0,28 & 0,08 & 0,52 & 0,10 & 0,20 & & & & 0,20 & 0,60 \\
\hline 57 & 2 & 0,12 & 0,32 & 0,12 & 0,52 & 0,08 & 0,10 & & & & 0,05 & 0,50 \\
\hline 58 & 2 & 0,12 & 0,32 & 0,06 & 0,48 & 0,12 & & & 0,05 & 0,10 & 0,70 & 0,50 \\
\hline 59 & 2 & 0,08 & 0,44 & 0,12 & 0,52 & 0,12 & 0,15 & & & & 1,10 & 0,60 \\
\hline 60 & 2 & 0,10 & 0,24 & 0,08 & 0,44 & 0,12 & 0,20 & & & & 0,60 & 0,35 \\
\hline 61 & 2 & 0,10 & 0,24 & 0,08 & 0,52 & 0,12 & 0,20 & & & & 0,40 & 0,30 \\
\hline 62 & 2 & 0,12 & 0,36 & 0,08 & 0,52 & 0,12 & & & 0,10 & 0,15 & 0,50 & 0,30 \\
\hline 63 & 2 & ,12 & 0,36 & 0,08 & 0,52 & 0,08 & 0,10 & & & & 0,30 & 0,60 \\
\hline 64 & 2 & 0,12 & 0,28 & 0,12 & 0,48 & 0,08 & & & 0,10 & 0,20 & 0,30 & 0,20 \\
\hline 65 & 2 & 0,08 & 0,36 & 0,08 & 0,56 & 0,12 & 0,20 & & & & 0,50 & 0,30 \\
\hline 66 & 2 & 0,12 & 0,32 & 0,12 & 0,56 & 0,12 & & & 0,10 & 0,10 & 1,20 & 0,40 \\
\hline 67 & 2 & 0,14 & 0,26 & 0,12 & 0,48 & 0,10 & & & 0,15 & 0,20 & 0,10 & 0,30 \\
\hline 68 & 2 & 0,12 & 0,36 & 0,08 & 0,44 & 0,12 & & & 0,10 & 0,20 & & 0,40 \\
\hline 69 & 2 & 0,12 & 0,32 & 0,08 & 0,36 & 0,12 & & 0,30 & & & 0,50 & 0,50 \\
\hline 70 & 2 & 0,08 & 0,24 & 0,12 & 0,44 & 0,16 & & & 0,15 & 0,20 & 0,30 & 0,60 \\
\hline 71 & 2 & 0,12 & 0,28 & 0,12 & 0,52 & 0,16 & & 0,50 & & & 0,80 & 0,35 \\
\hline 72 & 2 & 0,12 & 0,28 & 0,08 & 0,44 & 0,12 & 0,20 & & & & 0,60 & 0,60 \\
\hline 73 & 2 & 0,08 & 0,28 & 0,04 & 0,36 & 0,08 & 0,20 & & & & 1,10 & 0,30 \\
\hline 74 & 2 & 0,12 & 0,40 & 0,12 & 0,52 & 0,12 & & 0,20 & & & 0,90 & 0,40 \\
\hline 75 & 2 & 0,12 & 0,20 & 0,08 & 0,44 & 0,12 & & 0,30 & & & 0,80 & 0,60 \\
\hline 76 & 2 & 0,12 & 0,24 & 0,12 & 0,48 & 0,12 & & & 0,10 & 0,15 & 0,90 & 0,30 \\
\hline 77 & 2 & 0,10 & 0,24 & 0,10 & 0,32 & 0,08 & & 0,20 & & & 0,30 & 0,20 \\
\hline 78 & 2 & 0,12 & 0,24 & 0,08 & 0,56 & 0,16 & & & 0,10 & 0,15 & 0,50 & 0,30 \\
\hline 79 & 2 & 0,08 & 0,28 & 0,08 & 0,44 & 0,08 & 0,20 & & & & 0,60 & 0,40 \\
\hline 80 & 2 & 0,08 & 0,20 & 0,12 & 0,44 & 0,12 & 0,20 & & & & 1,80 & 0,30 \\
\hline 81 & 2 & 0,08 & 0,24 & 0,12 & 0,40 & 0,12 & 0,15 & & & & 0,70 & 0,40 \\
\hline 82 & 2 & 0,12 & 0,36 & 0,08 & 0,52 & 0,12 & & & 0,05 & 0,10 & 1,00 & 0,30 \\
\hline 83 & 2 & 0,08 & 0,36 & 0,08 & 0,48 & 0,12 & 0,20 & & & & 0,70 & 0,30 \\
\hline 84 & 2 & 0,08 & 0,36 & 0,08 & 0,52 & 0,12 & 0,15 & & & & 0,60 & 0,50 \\
\hline 85 & 2 & 0,16 & 0,52 & 0,12 & 0,52 & 0,08 & & & 0,20 & 0,10 & 0,90 & 0,40 \\
\hline 86 & 2 & 0,12 & 0,32 & 0,12 & 0,44 & 0,12 & 0,15 & & & & 0,80 & 0,60 \\
\hline 87 & 2 & 0,12 & 0,24 & 0,06 & 0,44 & 0,08 & & & 0,10 & 0,10 & 0,80 & 0,50 \\
\hline 88 & 2 & 0,08 & 0,24 & 0,08 & 0,48 & 0,12 & 0,20 & & & & 0,10 & 0,30 \\
\hline 89 & 2 & 0,08 & 0,36 & 0,12 & 0,44 & 0,12 & 0,20 & & & & 0,20 & 0,30 \\
\hline 90 & 2 & 0,16 & 0,32 & 0,10 & 0,44 & 0,12 & & 0,20 & & & 0,30 & 0,30 \\
\hline 91 & 2 & 0,12 & 0,28 & 0,08 & 0,44 & 0,12 & 0,10 & & & & 0,80 & 0,60 \\
\hline 92 & 2 & 0,12 & 0,28 & 0,08 & 0,44 & 0,12 & & & 0,15 & 0,15 & 1,50 & 0,40 \\
\hline 93 & 2 & 0,12 & 0,28 & 0,08 & 0,52 & 0,12 & & & 0,10 & 0,10 & 0,70 & 0,20 \\
\hline 94 & 2 & 0,10 & 0,20 & 0,0 & 0,44 & 0,08 & & & 0,10 & 0,20 & 0,60 & 0,20 \\
\hline 95 & 2 & 0,08 & 0,36 & 0,08 & 0,48 & 0,12 & & & 0,05 & 0,10 & & 0,50 \\
\hline 96 & 2 & 0,12 & 0,32 & 0, & 0,52 & 0,08 & & & 0,05 & 0,10 & 0,50 & 0,50 \\
\hline 97 & 2 & 0,12 & 0,36 & 0,08 & 0,52 & 0,12 & & & 0,10 & 0,10 & & 0,70 \\
\hline 98 & 2 & 0,12 & 0,32 & 0,08 & 0,48 & 0,08 & & & 0,10 & 0,20 & 0,40 & 0,40 \\
\hline 99 & 2 & 0,12 & 0,24 & 0,08 & 0,36 & 0,08 & 0,10 & & & & 0,10 & 0,30 \\
\hline 100 & 2 & 0,08 & 0,32 & 0,08 & 0,36 & 0,08 & 0,20 & & & & 00 & 0 \\
\hline
\end{tabular}


APÊNDICE E - Dados individuais de grupo de atividade física, duração em segundos da onda $\mathrm{P}$, intervalo P-R, complexo QRS, intervalo QT e onda T; amplitude em milivolts da onda $P$ única, onda $P$ bifásica, primeira porção da onda $P$ bífida (P1), segunda porção da onda $P$ bífida (P2), complexo QRS e onda $\mathrm{T}$, na derivação unipolar aVR, obtido pelo eletrocardiograma de 100 eqüinos de salto criados na cidade de São Paulo - SP - 2006.

\begin{tabular}{|c|c|c|c|c|c|c|c|c|c|c|c|c|}
\hline $\mathrm{N}$ & Grupo & $\begin{array}{c}\mathrm{P} \\
\text { (seg) }\end{array}$ & $\begin{array}{c}\text { P-R } \\
\text { (seg) }\end{array}$ & $\begin{array}{l}\text { QRS } \\
\text { (seg) }\end{array}$ & $\begin{array}{c}\text { QT } \\
\text { (seg) }\end{array}$ & $\begin{array}{c}\mathrm{T} \\
(\mathrm{seg})\end{array}$ & $\begin{array}{c}\text { P única } \\
\text { (mV) }\end{array}$ & $\begin{array}{c}P \text { bifás. } \\
(\mathrm{mV})\end{array}$ & $\begin{array}{c}\mathrm{P} 1 \\
(\mathrm{mV})\end{array}$ & $\begin{array}{c}\mathrm{P} 2 \\
(\mathrm{mV})\end{array}$ & $\begin{array}{c}\mathrm{R} \\
(\mathrm{mV})\end{array}$ & $\begin{array}{c}\mathrm{T} \\
(\mathrm{mV})\end{array}$ \\
\hline 1 & 1 & 0,12 & 0,28 & 0,10 & 0,56 & 0,16 & 0,15 & & & & 0,20 & 0,40 \\
\hline 2 & 1 & 0,12 & 0,40 & 0,06 & 0,56 & 0,16 & & & 0,10 & 0,20 & & 0,40 \\
\hline 3 & 1 & 0,12 & 0,28 & 0,10 & 0,44 & 0,12 & & & 0,10 & 0,20 & 0,15 & 0,30 \\
\hline 4 & 1 & 0,16 & 0,40 & 0,10 & 0,52 & 0,16 & & & 0,20 & 0,30 & 0,10 & 0,40 \\
\hline 5 & 1 & 0,12 & 0,48 & 0,08 & 0,48 & 0,12 & & & 0,15 & 0,20 & 0,05 & 0,40 \\
\hline 6 & 1 & 0,12 & 0,40 & 0,06 & 0,52 & 0,16 & & & 0,10 & 0,20 & & 0,80 \\
\hline 7 & 1 & 0,16 & 0,40 & 0,08 & 0,52 & 0,16 & & & 0,10 & 0,30 & 0,20 & 0,60 \\
\hline 8 & 1 & 0,12 & 0,32 & 0,08 & 0,56 & 0,08 & & & 0,10 & 0,20 & 0,10 & 0,20 \\
\hline 9 & 1 & 0,12 & 0,32 & 0,08 & 0,48 & 0,08 & & & 0,10 & 0,10 & & 0,20 \\
\hline 10 & 1 & 0,12 & 0,36 & 0,12 & 0,52 & 0,16 & & & 0,15 & 0,20 & 0,10 & 0,60 \\
\hline 11 & 1 & 0,08 & 0,24 & 0,12 & 0,48 & 0,12 & 0,20 & & & & 2,20 & 0,80 \\
\hline 12 & 1 & 0,12 & 0,40 & 0,08 & 0,52 & 0,12 & & & 0,15 & 0,10 & & 0,30 \\
\hline 13 & 1 & 0,08 & 0,24 & 0,08 & 0,44 & 0,12 & 0,20 & & & & 0,10 & 0,30 \\
\hline 14 & 1 & 0,12 & 0,36 & 0,12 & 0,44 & 0,08 & & 0,20 & & & 0,50 & 0,15 \\
\hline 15 & 1 & 0,12 & 0,32 & 0,08 & 0,52 & 0,16 & & & 0,10 & 0,20 & & 0,50 \\
\hline 16 & 1 & 0,10 & 0,24 & 0,06 & 0,48 & 0,08 & 0,15 & & & & & 0,20 \\
\hline 17 & 1 & 0,12 & 0,24 & 0,10 & 0,36 & 0,12 & & 0,30 & & & 0,10 & 0,30 \\
\hline 18 & 1 & 0,12 & 0,24 & 0,08 & 0,52 & 0,12 & & 0,30 & & & 0,20 & 0,80 \\
\hline 19 & 1 & 0,12 & 0,28 & 0,08 & 0,52 & 0,12 & & & 0,10 & 0,10 & & 0,70 \\
\hline 20 & 1 & 0,12 & 0,36 & 0,06 & 0,48 & 0,12 & & & 0,10 & 0,10 & & 0,25 \\
\hline 21 & 1 & 0,12 & 0,36 & 0,10 & 0,52 & 0,08 & & & 0,10 & 0,20 & 0,05 & 0,30 \\
\hline 22 & 1 & 0,08 & 0,24 & 0,10 & 0,36 & 0,08 & 0,15 & & & & 0,10 & 0,10 \\
\hline 23 & 1 & 0,08 & 0,28 & 0,08 & 0,48 & 0,12 & 0,20 & & & & & 0,30 \\
\hline 24 & 1 & 0,10 & 0,28 & 0,10 & 0,48 & 0,04 & & & 0,05 & 0,10 & 0,20 & 0,20 \\
\hline 25 & 1 & 0,12 & 0,28 & 0,08 & 0,40 & 0,12 & & & 0,10 & 0,20 & 0,20 & 0,40 \\
\hline 26 & 1 & 0,08 & 0,20 & 0,06 & 0,32 & 0,10 & 0,20 & & & & & 0,20 \\
\hline 27 & 1 & 0,12 & 0,28 & 0,08 & 0,44 & 0,08 & & 0,40 & & & 0,30 & 0,50 \\
\hline 28 & 1 & 0,12 & 0,36 & 0,08 & 0,48 & 0,10 & & & 0,10 & 0,20 & & 0,30 \\
\hline 29 & 1 & 0,08 & 0,24 & 0,08 & 0,44 & 0,08 & 0,30 & & & & & 0,20 \\
\hline 30 & 1 & 0,08 & 0,24 & 0,04 & 0,40 & 0,08 & 0,20 & & & & & 0,20 \\
\hline 31 & 1 & 0,14 & 0,38 & 0,08 & 0,52 & 0,16 & & & 0,15 & 0,15 & 0,10 & 0,70 \\
\hline 32 & 1 & 0,12 & 0,32 & 0,06 & 0,48 & 0,12 & & & 0,10 & 0,20 & 0,10 & 0,30 \\
\hline 33 & 1 & 0,12 & 0,36 & 0,08 & 0,52 & 0,12 & & & 0,20 & 0,20 & 0,20 & 0,30 \\
\hline 34 & 1 & 0,12 & 0,36 & 0,12 & 0,52 & 0,10 & & & 0,15 & 0,15 & 0,20 & 0,50 \\
\hline 35 & 1 & 0,12 & 0,36 & 0,10 & 0,56 & 0,12 & & & 0,20 & 0,20 & 0,10 & 0,30 \\
\hline 36 & 1 & 0,12 & 0,32 & 0,08 & 0,48 & 0,12 & & & 0,20 & 0,20 & & 0,30 \\
\hline 37 & 1 & 0,12 & 0,32 & 0,08 & 0,48 & 0,08 & & & 0,10 & 0,30 & 0,10 & 0,20 \\
\hline 38 & 1 & 0,16 & 0,40 & 0,08 & 0,48 & 0,08 & & & 0,20 & 0,30 & 0,10 & 0,50 \\
\hline 39 & 1 & 0,12 & 0,32 & 0,06 & 0,56 & 0,08 & & & 0,10 & 0,10 & & 0,20 \\
\hline 40 & 1 & 0,16 & 0,52 & 0,08 & 0,48 & 0,12 & & & 0,10 & 0,20 & 0,10 & 0,45 \\
\hline 41 & 1 & 0,12 & 0,32 & 0,06 & 0,56 & 0,12 & & & 0,10 & 0,10 & & 0,30 \\
\hline 42 & 1 & 0,12 & 0,28 & 0,10 & 0,52 & 0,12 & & & 0,20 & 0,25 & 0,10 & 0,20 \\
\hline 43 & 1 & 0,12 & 0,36 & 0,10 & 0,52 & 0,12 & & 0,20 & & & 0,10 & 0,30 \\
\hline 44 & 1 & 0,12 & 0,32 & 0,08 & 0,52 & 0,12 & 0,20 & & & & & 0,20 \\
\hline 45 & 1 & 0,16 & 0,32 & 0,08 & 0,44 & 0,08 & & & 0,20 & 0,20 & & 0,10 \\
\hline 46 & 1 & 0,12 & 0,32 & 0,12 & 0,52 & 0,10 & 0,10 & & & & 0,40 & 0,30 \\
\hline 47 & 1 & 0,12 & 0,28 & 0,08 & 0,52 & 0,12 & & & 0,05 & 0,10 & 0,10 & 0,20 \\
\hline 48 & 1 & 0,12 & 0,32 & 0,06 & 0,48 & 0,08 & & & 0,10 & 0,15 & 0,10 & 0,20 \\
\hline 49 & 1 & 0,12 & 0,28 & 0,08 & 0,48 & 0,12 & & & 0,10 & 0,10 & & 0,40 \\
\hline 50 & 1 & 0,08 & 0,28 & 0,08 & 0,52 & 0,12 & 0,30 & & & & & 0,30 \\
\hline
\end{tabular}


APÊNDICE E - Dados individuais de grupo de atividade física, duração em segundos da onda P, intervalo P-R, complexo QRS, intervalo QT e onda T; amplitude em milivolts da onda $\mathrm{P}$ única, onda $\mathrm{P}$ bifásica, primeira porção da onda $\mathrm{P}$ bífida (P1), segunda porção da onda $\mathrm{P}$ bífida (P2), complexo QRS e onda $T$, na derivação unipolar aVR, obtido pelo eletrocardiograma de 100 eqüinos de salto criados na cidade de São Paulo - SP - 2006.

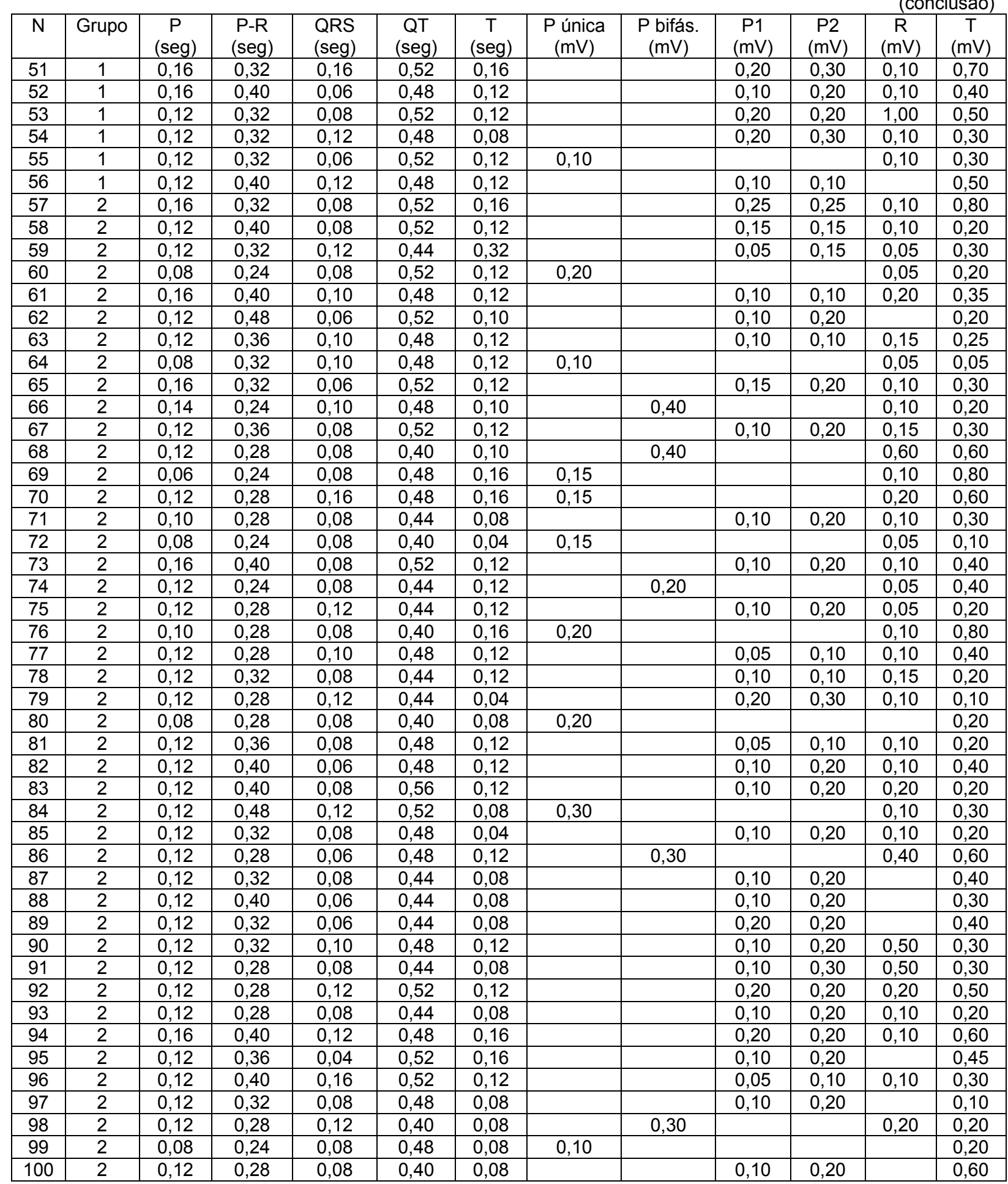


APÊNDICE F - Dados individuais de grupo de atividade física, duração em segundos da onda $P$, intervalo $P-R$, complexo QRS, intervalo QT e onda T; amplitude em milivolts da onda $\mathrm{P}$ única, onda $\mathrm{P}$ bifásica, primeira porção da onda $\mathrm{P}$ bífida (P1), segunda porção da onda $\mathrm{P}$ bífida (P2), complexo $\mathrm{QRS}$ e onda $\mathrm{T}$, na derivação unipolar aVL, obtido pelo eletrocardiograma de 100 eqüinos de salto criados na cidade de São Paulo - SP - 2006

\begin{tabular}{|c|c|c|c|c|c|c|c|c|c|c|c|c|}
\hline $\mathrm{N}$ & Grupo & $\begin{array}{c}P \\
\text { (seg) }\end{array}$ & $\begin{array}{c}\text { P-R } \\
\text { (seg) }\end{array}$ & $\begin{array}{l}\text { QRS } \\
\text { (seg) }\end{array}$ & $\begin{array}{c}\text { QT } \\
\text { (seg) }\end{array}$ & $\begin{array}{c}\mathrm{T} \\
\text { (seg) }\end{array}$ & $\begin{array}{c}\text { P única } \\
(\mathrm{mV})\end{array}$ & $\begin{array}{c}\text { P bifás. } \\
(\mathrm{mV})\end{array}$ & $\begin{array}{c}\mathrm{P} 1 \\
(\mathrm{mV})\end{array}$ & $\begin{array}{c}\mathrm{P} 2 \\
(\mathrm{mV})\end{array}$ & $\begin{array}{c}\mathrm{R} \\
(\mathrm{mV})\end{array}$ & $\begin{array}{c}\mathrm{T} \\
(\mathrm{mV})\end{array}$ \\
\hline 1 & 1 & 0,16 & 0,28 & 0,06 & 0,52 & 0,12 & 0,10 & & & & 0,40 & 0,30 \\
\hline 2 & 1 & 0,08 & 0,36 & 0,08 & 0,52 & 0,12 & 0,10 & & & & 0,40 & 0,30 \\
\hline 3 & 1 & 0,12 & 0,28 & 0,08 & 0,44 & 0,08 & & & 0,05 & 0,05 & & 0,30 \\
\hline 4 & 1 & 0,16 & 0,48 & 0,08 & 0,52 & 0,16 & & 0,20 & & & 0,40 & 0,80 \\
\hline 5 & 1 & 0,16 & 0,52 & 0,08 & 0,56 & 0,08 & & 0,15 & & & 0,60 & 0,20 \\
\hline 6 & 1 & 0,08 & 0,36 & 0,08 & 0,52 & 0,10 & & & 0,05 & 0,05 & 0,60 & 0,20 \\
\hline 7 & 1 & 0,16 & 0,40 & 0,08 & 0,52 & 0,12 & & & 0,10 & 0,15 & 0,30 & 0,50 \\
\hline 8 & 1 & 0,12 & 0,28 & 0,10 & 0,56 & 0,16 & & & 0,05 & 0,05 & 0,50 & 0,20 \\
\hline 9 & 1 & 0,12 & 0,36 & 0,08 & 0,52 & 0,12 & & & 0,10 & 0,10 & 0,50 & 0,50 \\
\hline 10 & 1 & 0,12 & 0,40 & 0,06 & 0,56 & 0,16 & & & 0,15 & 0,20 & 0,60 & 0,60 \\
\hline 11 & 1 & 0,08 & 0,28 & 0,12 & 0,48 & 0,04 & 0,10 & & & & 0,20 & 0,20 \\
\hline 12 & 1 & 0,08 & 0,32 & 0,14 & 0,56 & 0,08 & & & 0,10 & 0,15 & 0,60 & 0,10 \\
\hline 13 & 1 & 0,12 & 0,24 & 0,12 & 0,40 & 0,16 & 0,30 & & & & 0,60 & 0,50 \\
\hline 14 & 1 & 0,08 & 0,28 & 0,10 & 0,44 & 0,08 & 0,30 & & & & 0,10 & 0,20 \\
\hline 15 & 1 & 0,12 & 0,36 & 0,08 & 0,52 & 0,12 & & & 0,10 & 0,20 & 0,50 & 0,50 \\
\hline 16 & 1 & 0,10 & 0,24 & 0,10 & 0,44 & 0,08 & & & 0,05 & 0,10 & & 0,10 \\
\hline 17 & 1 & 0,10 & 0,28 & 0,12 & 0,32 & 0,08 & 0,10 & & & & 0,70 & 0,30 \\
\hline 18 & 1 & 0,12 & 0,24 & 0,12 & 0,52 & 0,08 & & & 0,10 & 0,05 & 0,20 & 0,20 \\
\hline 19 & 1 & 0,08 & 0,28 & 0,12 & 0,52 & 0,12 & 0,20 & & & & 0,40 & 0,30 \\
\hline 20 & 1 & 0,12 & 0,36 & 0,08 & 0,48 & 0,12 & & 0,20 & & & 0,20 & 0,10 \\
\hline 21 & 1 & 0,08 & 0,32 & 0,08 & 0,56 & 0,12 & & & 0,10 & 0,10 & 0,70 & 0,15 \\
\hline 22 & 1 & 0,08 & 0,20 & 0,08 & 0,36 & 0,08 & 0,10 & & & & 0,10 & 0,30 \\
\hline 23 & 1 & 0,08 & 0,28 & 0,04 & 0,48 & 0,08 & 0,10 & & & & 0,30 & 0,30 \\
\hline 24 & 1 & 0,12 & 0,24 & 0,08 & 0,48 & 0,08 & & & 0,05 & 0,05 & 0,10 & 0,20 \\
\hline 25 & 1 & 0,10 & 0,24 & 0,08 & 0,40 & 0,12 & & & 0,05 & 0,05 & 0,30 & 0,40 \\
\hline 26 & 1 & 0,08 & 0,20 & 0,04 & 0,32 & 0,12 & 0,20 & & & & & 0,30 \\
\hline 27 & 1 & 0,12 & 0,28 & 0,10 & 0,44 & 0,12 & 0,30 & & & & 0,60 & 0,30 \\
\hline 28 & 1 & 0,12 & 0,32 & 0,08 & 0,48 & 0,12 & & & 0,10 & 0,10 & 0,15 & 0,50 \\
\hline 29 & 1 & 0,08 & 0,24 & 0,08 & 0,44 & 0,08 & 0,10 & & & & 0,30 & 0,50 \\
\hline 30 & 1 & 0,08 & 0,24 & 0,08 & 0,36 & 0,12 & 0,05 & & & & 0,10 & 0,50 \\
\hline 31 & 1 & 0,14 & 0,40 & 0,16 & 0,52 & 0,12 & & & 0,15 & 0,15 & 0,40 & 0,40 \\
\hline 32 & 1 & 0,06 & 0,26 & 0,04 & 0,48 & 0,12 & 0,10 & & & & & 0,40 \\
\hline 33 & 1 & 0,12 & 0,36 & 0,12 & 0,48 & 0,12 & & & 0,10 & 0,20 & 0,20 & 0,10 \\
\hline 34 & 1 & 0,12 & 0,36 & 0,08 & 0,52 & 0,12 & & & 0,10 & 0,10 & 0,20 & 0,50 \\
\hline 35 & 1 & 0,12 & 0,36 & 0,08 & 0,52 & 0,08 & & & 0,20 & 0,10 & 0,60 & 0,20 \\
\hline 36 & 1 & 0,12 & 0,28 & 0,12 & 0,52 & 0,12 & & & 0,10 & 0,05 & 0,30 & 0,30 \\
\hline 37 & 1 & 0,12 & 0,32 & 0,12 & 0,48 & 0,08 & & & 0,10 & 0,20 & & 0,25 \\
\hline 38 & 1 & 0,16 & 0,44 & 0,08 & 0,44 & 0,12 & & & 0,20 & 0,20 & 0,20 & 0,30 \\
\hline 39 & 1 & 0,08 & 0,28 & 0,06 & 0,52 & 0,12 & 0,10 & & & & 0,10 & 0,50 \\
\hline 40 & 1 & 0,12 & 0,48 & 0,12 & 0,48 & 0,12 & & & 0,10 & 0,10 & 0,40 & 0,60 \\
\hline 41 & 1 & 0,12 & 0,32 & 0,04 & 0,52 & 0,12 & 0,10 & & & & 0,40 & 0,30 \\
\hline 42 & 1 & 0,12 & 0,28 & 0,12 & 0,52 & 0,10 & & & 0,20 & 0,10 & & 0,20 \\
\hline 43 & 1 & 0,12 & 0,36 & 0,08 & 0,52 & 0,12 & 0,10 & & & & 0,10 & 0,10 \\
\hline 44 & 1 & 0,12 & 0,32 & 0,12 & 0,56 & 0,12 & & 0,20 & & & 0,50 & 0,40 \\
\hline 45 & 1 & 0,08 & 0,36 & 0,12 & 0,48 & 0,08 & 0,10 & & & & 0,70 & 0,30 \\
\hline 46 & 1 & 0,08 & 0,36 & 0,12 & 0,48 & 0,10 & & & 0,15 & 0,10 & & 0,20 \\
\hline 47 & 1 & 0,08 & 0,36 & 0,08 & 0,52 & 0,08 & 0,05 & & & & 0,60 & 0,40 \\
\hline 48 & 1 & 0,08 & 0,36 & 0,08 & 0,48 & 0,08 & & & 0,10 & 0,10 & 0,20 & 0,20 \\
\hline 49 & 1 & 0,12 & 0,28 & 0,10 & 0,48 & 0,08 & & & 0,05 & 0,05 & 0,70 & 0,25 \\
\hline 50 & 1 & 0,08 & 0,28 & 0,10 & 0,52 & 0,12 & 0,10 & & & & 0,20 & 0,20 \\
\hline
\end{tabular}


APÊNDICE F - Dados individuais de grupo de atividade física, duração em segundos da onda $P$, intervalo $P-R$, complexo QRS, intervalo QT e onda T; amplitude em milivolts da onda $\mathrm{P}$ única, onda $\mathrm{P}$ bifásica, primeira porção da onda $P$ bífida (P1), segunda porção da onda $P$ bífida (P2), complexo QRS e onda $\mathrm{T}$, na derivação unipolar aVL, obtido pelo eletrocardiograma de 100 eqüinos de salto criados na cidade de São Paulo - SP - 2006.

(conclusão)

\begin{tabular}{|c|c|c|c|c|c|c|c|c|c|c|c|c|}
\hline $\mathrm{N}$ & Grupo & $\begin{array}{c}P \\
\text { (seg) }\end{array}$ & $\begin{array}{l}\text { P-R } \\
\text { (seg) }\end{array}$ & $\begin{array}{l}\text { QRS } \\
\text { (seg) }\end{array}$ & $\begin{array}{c}\text { QT } \\
\text { (seg) }\end{array}$ & $\begin{array}{c}\mathrm{T} \\
\text { (seg) }\end{array}$ & $\begin{array}{c}\text { P única } \\
(\mathrm{mV})\end{array}$ & $\begin{array}{l}P \text { bifás. } \\
(\mathrm{mV})\end{array}$ & $\begin{array}{c}\mathrm{P} 1 \\
(\mathrm{mV})\end{array}$ & $\begin{array}{c}\mathrm{P} 2 \\
(\mathrm{mV})\end{array}$ & $\begin{array}{c}\mathrm{R} \\
(\mathrm{mV})\end{array}$ & $\begin{array}{c}\mathrm{T} \\
(\mathrm{mV})\end{array}$ \\
\hline 51 & 1 & 0,16 & 0,36 & 0,16 & 0,52 & 0,12 & & 0,20 & & & 0,10 & 0,40 \\
\hline 52 & 1 & 0,16 & 0,36 & 0,08 & 0,44 & 0,08 & & & 0,10 & 0,10 & 0,20 & 0,30 \\
\hline 53 & 1 & 0,12 & 0,32 & 0,08 & 0,48 & 0,12 & & & 0,20 & 0,20 & & 0,70 \\
\hline 54 & 1 & 0,12 & 0,32 & 0,08 & 0,48 & 0,12 & & & 0,10 & 0,20 & 0,70 & 0,30 \\
\hline 55 & 1 & 0,12 & 0,32 & 0,06 & 0,48 & 0,12 & 0,10 & & & & 0,20 & 0,50 \\
\hline 56 & 1 & 0,12 & 0,40 & 0,08 & 0,56 & 0,12 & 0,10 & & & & 0,40 & 0,60 \\
\hline 57 & 2 & 0,08 & 0,32 & 0,12 & 0,52 & 0,12 & & & 0,05 & 0,05 & 1,00 & 0,30 \\
\hline 58 & 2 & 0,12 & 0,40 & 0,10 & 0,52 & 0,12 & 0,15 & & & & 0,10 & 0,30 \\
\hline 59 & 2 & 0,16 & 0,36 & 0,12 & 0,44 & 0,12 & & 0,15 & & & 0,10 & 0,80 \\
\hline 60 & 2 & 0,12 & 0,32 & 0,08 & 0,48 & 0,12 & 0,10 & & & & 0,20 & 0,30 \\
\hline 61 & 2 & 0,16 & 0,40 & 0,10 & 0,48 & 0,16 & & & 0,15 & 0,10 & 0,20 & 0,15 \\
\hline 62 & 2 & 0,12 & 0,48 & 0,08 & 0,52 & 0,08 & & & 0,10 & 0,10 & 0,45 & 0,40 \\
\hline 63 & 2 & 0,08 & 0,32 & 0,08 & 0,48 & 0,08 & 0,10 & & & & 0,40 & 0,20 \\
\hline 64 & 2 & 0,08 & 0,36 & 0,10 & 0,52 & 0,12 & & & 0,05 & 0,10 & 0,30 & 0,25 \\
\hline 65 & 2 & 0,12 & 0,32 & 0,08 & 0,52 & 0,08 & & & 0,10 & 0,10 & 0,50 & 0,20 \\
\hline 66 & 2 & 0,12 & 0,48 & 0,12 & 0,48 & 0,12 & & & 0,10 & 0,20 & 0,10 & 0,30 \\
\hline 67 & 2 & 0,08 & 0,36 & 0,14 & 0,44 & 0,08 & & 0,20 & & & 0,60 & 0,20 \\
\hline 68 & 2 & 0,04 & 0,20 & 0,04 & 0,36 & 0,08 & & 0,30 & & & 0,30 & 0,40 \\
\hline 69 & 2 & 0,08 & 0,28 & 0,12 & 0,48 & 0,12 & & & 0,05 & 0,10 & 0,30 & 0,30 \\
\hline 70 & 2 & 0,12 & 0,32 & 0,08 & 0,48 & 0,12 & & & 0,05 & 0,10 & 0,40 & 0,40 \\
\hline 71 & 2 & 0,08 & 0,24 & 0,06 & 0,40 & 0,08 & 0,10 & & & & 0,40 & 0,40 \\
\hline 72 & 2 & 0,08 & 0,24 & 0,06 & 0,36 & 0,08 & & & 0,05 & 0,10 & 0,30 & 0,20 \\
\hline 73 & 2 & 0,16 & 0,36 & 0,08 & 0,52 & 0,08 & & & 0,10 & 0,10 & 0,10 & 0,40 \\
\hline 74 & 2 & 0,08 & 0,20 & 0,08 & 0,44 & 0,08 & & & 0,05 & 0,10 & 0,50 & 0,20 \\
\hline 75 & 2 & 0,08 & 0,28 & 0,12 & 0,48 & 0,12 & & & 0,05 & 0,05 & 0,60 & 0,10 \\
\hline 76 & 2 & 0,08 & 0,28 & 0,08 & 0,36 & 0,10 & & & 0,05 & 0,05 & 0,10 & 0,40 \\
\hline 77 & 2 & 0,16 & 0,28 & 0,12 & 0,52 & 0,12 & & 0,40 & & & 0,35 & 0,50 \\
\hline 78 & 2 & 0,08 & 0,28 & 0,12 & 0,44 & 0,12 & & & 0,05 & 0,10 & 0,40 & 0,30 \\
\hline 79 & 2 & 0,12 & 0,28 & 0,10 & 0,44 & 0,12 & & 0,20 & & & 0,80 & 0,40 \\
\hline 80 & 2 & 0,08 & 0,24 & 0,04 & 0,40 & 0,12 & & & 0,10 & 0,10 & & 0,30 \\
\hline 81 & 2 & 0,12 & 0,36 & 0,10 & 0,52 & 0,12 & & & 0,05 & 0,05 & 0,20 & 0,30 \\
\hline 82 & 2 & 0,08 & 0,36 & 0,12 & 0,52 & 0,12 & 0,10 & & & & 0,20 & 0,30 \\
\hline 83 & 2 & 0,12 & 0,40 & 0,08 & 0,56 & 0,12 & & & 0,10 & 0,05 & 0,10 & 0,30 \\
\hline 84 & 2 & 0,12 & 0,48 & 0,12 & 0,52 & 0,08 & & & 0,20 & 0,20 & 0,40 & 0,30 \\
\hline 85 & 2 & 0,12 & 0,32 & 0,04 & 0,44 & 0,12 & 0,10 & & & & & 0,50 \\
\hline 86 & 2 & 0,08 & 0,24 & 0,08 & 0,48 & 0,08 & 0,10 & & & & 0,10 & 0,40 \\
\hline 87 & 2 & 0,12 & 0,28 & 0,12 & 0,48 & 0,12 & & & 0,05 & 0,05 & 0,30 & 0,20 \\
\hline 88 & 2 & 0,12 & 0,48 & 0,10 & 0,48 & 0,12 & & 0,20 & & & 0,40 & 0,20 \\
\hline 89 & 2 & 0,16 & 0,36 & 0,12 & 0,44 & 0,08 & & & 0,20 & 0,10 & 0,10 & 0,20 \\
\hline 90 & 2 & 0,12 & 0,28 & 0,06 & 0,48 & 0,12 & & & 0,05 & 0,05 & 0,10 & 0,40 \\
\hline 91 & 2 & 0,08 & 0,20 & 0,12 & 0,44 & 0,08 & & 0,20 & & & 0,10 & 0,20 \\
\hline 92 & 2 & 0,12 & 0,28 & 0,08 & 0,52 & 0,08 & 0,10 & & & & 0,40 & 0,30 \\
\hline 93 & 2 & 0,08 & 0,32 & 0,08 & 0,40 & 0,04 & & & 0,05 & 0,05 & 0,20 & 0,10 \\
\hline 94 & 2 & 0,12 & 0,40 & 0,12 & 0,44 & 0,12 & & & 0,10 & 0,10 & 0,20 & 0,60 \\
\hline 95 & 2 & 0,12 & 0,36 & 0,06 & 0,52 & 0,08 & & & 0,10 & 0,20 & 0,40 & 0,40 \\
\hline 96 & 2 & 0,12 & 0,44 & 0,12 & 0,52 & 0,12 & & & 0,05 & 0,05 & 0,50 & 0,80 \\
\hline 97 & 2 & 0,12 & 0,36 & 0,08 & 0,48 & 0,08 & & & 0,10 & 0,10 & 0,70 & 0,20 \\
\hline 98 & 2 & 0,12 & 0,28 & 0,12 & 0,40 & 0,08 & & 0,15 & & & 0,70 & 0,25 \\
\hline 99 & 2 & 0,08 & 0,28 & 0,12 & 0,48 & 0,08 & & & 0,10 & 0,10 & 0,30 & 0,10 \\
\hline 100 & 2 & 0,12 & 0,28 & 0,04 & 0,40 & 0,12 & & & 0,05 & 0,05 & 0,20 & 0,50 \\
\hline
\end{tabular}


APÊNDIE G - Dados individuais de grupo de atividade física, duração em segundos da onda $P$, intervalo $P$-R, complexo QRS, intervalo QT e onda T; amplitude em milivolts da onda $\mathrm{P}$ única, onda $\mathrm{P}$ bifásica, primeira porção da onda P bífida (P1), segunda porção da onda P bífida (P2), complexo QRS e onda T, na derivação unipolar aVF, obtido pelo eletrocardiograma de 100 eqüinos de salto criados na cidade de São Paulo - SP - 2006.

\begin{tabular}{|c|c|c|c|c|c|c|c|c|c|c|c|c|}
\hline $\mathrm{N}$ & Grupo & $\begin{array}{c}P \\
\text { (seg) }\end{array}$ & $\begin{array}{c}\text { P-R } \\
\text { (seg) }\end{array}$ & $\begin{array}{l}\text { QRS } \\
\text { (seg) }\end{array}$ & $\begin{array}{c}\text { QT } \\
\text { (seg) }\end{array}$ & $\begin{array}{c}\mathrm{T} \\
\text { (seg) }\end{array}$ & $\begin{array}{l}\text { P única } \\
(\mathrm{mV})\end{array}$ & $\begin{array}{c}P \text { bifás. } \\
(\mathrm{mV})\end{array}$ & $\begin{array}{c}\mathrm{P} 1 \\
(\mathrm{mV})\end{array}$ & $\begin{array}{c}\mathrm{P} 2 \\
(\mathrm{mV})\end{array}$ & $\begin{array}{c}\mathrm{R} \\
(\mathrm{mV})\end{array}$ & $\begin{array}{c}\mathrm{T} \\
(\mathrm{mV})\end{array}$ \\
\hline 1 & 1 & 0,08 & 0,32 & 0,12 & 0,56 & 0,12 & 0,10 & & & & 0,10 & 0,40 \\
\hline 2 & 1 & 0,12 & 0,40 & 0,06 & 0,56 & 0,08 & & & 0,10 & 0,20 & 0,50 & 0,30 \\
\hline 3 & 1 & 0,12 & 0,24 & 0,10 & 0,48 & 0,12 & & & 0,10 & 0,20 & 1,50 & 0,20 \\
\hline 4 & 1 & 0,16 & 0,44 & 0,12 & 0,56 & 0,12 & & & 0,10 & 0,20 & 1,40 & 0,60 \\
\hline 5 & 1 & 0,12 & 0,48 & 0,12 & 0,60 & 0,12 & & & 0,10 & 0,20 & 0,60 & 0,30 \\
\hline 6 & 1 & 0,12 & 0,32 & 0,08 & 0,56 & 0,16 & & & 0,10 & 0,15 & 0,50 & 0,80 \\
\hline 7 & 1 & 0,12 & 0,36 & 0,08 & 0,56 & 0,12 & 0,20 & & & & 0,90 & 0,30 \\
\hline 8 & 1 & 0,12 & 0,32 & 0,06 & 0,56 & 0,12 & 0,20 & & & & 0,70 & 0,40 \\
\hline 9 & 1 & 0,12 & 0,32 & 0,08 & 0,48 & 0,12 & & & 0,15 & 0,20 & 0,80 & 0,70 \\
\hline 10 & 1 & 0,14 & 0,28 & 0,06 & 0,60 & 0,16 & & 0,20 & & & 0,40 & 0,35 \\
\hline 11 & 1 & 0,12 & 0,28 & 0,08 & 0,52 & 0,12 & 0,20 & & & & & 0,70 \\
\hline 12 & 1 & 0,12 & 0,44 & 0,12 & 0,56 & 0,12 & & & 0,10 & 0,20 & 0,10 & 0,40 \\
\hline 13 & 1 & 0,08 & 0,24 & 0,12 & 0,44 & 0,08 & 0,60 & & & & 1,60 & 0,20 \\
\hline 14 & 1 & 0,12 & 0,32 & 0,08 & 0,48 & 0,16 & 0,40 & & & & 1,30 & 0,30 \\
\hline 15 & 1 & 0,12 & 0,32 & 0,10 & 0,56 & 0,08 & & & 0,10 & 0,30 & 0,80 & 0,30 \\
\hline 16 & 1 & 0,08 & 0,20 & 0,12 & 0,44 & 0,08 & 0,20 & & & & 1,00 & 0,30 \\
\hline 17 & 1 & 0,12 & 0,26 & 0,12 & 0,36 & 0,08 & & 0,30 & & & 1,10 & 0,30 \\
\hline 18 & 1 & 0,12 & 0,24 & 0,08 & 0,56 & 0,12 & 0,15 & & & & 0,90 & 0,60 \\
\hline 19 & 1 & 0,12 & 0,24 & 0,08 & 0,48 & 0,12 & 0,20 & & & & 1,50 & 0,50 \\
\hline 20 & 1 & 0,12 & 0,32 & 0,08 & 0,48 & 0,12 & & & 0,10 & 0,20 & 1,00 & 0,30 \\
\hline 21 & 1 & 0,12 & 0,36 & 0,10 & 0,52 & 0,08 & 0,20 & & & & 0,50 & 0,30 \\
\hline 22 & 1 & 0,08 & 0,24 & 0,08 & 0,44 & 0,08 & 0,30 & & & & 1,40 & 0,15 \\
\hline 23 & 1 & 0,08 & 0,28 & 0,08 & 0,52 & 0,08 & 0,30 & & & & 1,10 & 0,20 \\
\hline 24 & 1 & 0,12 & 0,32 & 0,08 & 0,44 & 0,08 & & & 0,10 & 0,20 & 0,40 & 0,50 \\
\hline 25 & 1 & 0,08 & 0,20 & 0,12 & 0,40 & 0,12 & 0,30 & & & & 0,70 & 0,40 \\
\hline 26 & 1 & 0,12 & 0,20 & 0,08 & 0,32 & 0,10 & 0,40 & & & & 1,30 & 0,20 \\
\hline 27 & 1 & 0,12 & 0,28 & 0,08 & 0,40 & 0,08 & & 0,30 & & & 0,90 & 0,20 \\
\hline 28 & 1 & 0,12 & 0,36 & 0,08 & 0,52 & 0,08 & 0,20 & & & & 1,60 & 0,60 \\
\hline 29 & 1 & 0,08 & 0,28 & 0,08 & 0,44 & 0,12 & 0,30 & & & & 0,70 & 0,60 \\
\hline 30 & 1 & 0,08 & 0,28 & 0,08 & 0,44 & 0,12 & 0,20 & & & & 0,70 & 0,60 \\
\hline 31 & 1 & 0,14 & 0,36 & 0,08 & 0,52 & 0,12 & & & 0,05 & 0,05 & 1,40 & 0,60 \\
\hline 32 & 1 & 0,12 & 0,32 & 0,06 & 0,52 & 0,10 & & & 0,10 & 0,20 & 0,80 & 0,40 \\
\hline 33 & 1 & 0,12 & 0,32 & 0,08 & 0,56 & 0,12 & & & 0,10 & 0,20 & 0,90 & 0,30 \\
\hline 34 & 1 & 0,10 & 0,28 & 0,10 & 0,56 & 0,12 & 0,10 & & & & 0,90 & 0,50 \\
\hline 35 & 1 & 0,12 & 0,32 & 0,08 & 0,60 & 0,12 & & & 0,10 & 0,10 & 0,80 & 0,25 \\
\hline 36 & 1 & 0,12 & 0,28 & 0,08 & 0,52 & 0,12 & & & 0,10 & 0,20 & 0,40 & 0,30 \\
\hline 37 & 1 & 0,12 & 0,32 & 0,12 & 0,44 & 0,04 & 0,10 & & & & 1,10 & 0,10 \\
\hline 38 & 1 & 0,16 & 0,40 & 0,04 & 0,48 & 0,08 & & & 0,10 & 0,20 & 0,80 & 0,50 \\
\hline 39 & 1 & 0,10 & 0,28 & 0,04 & 0,56 & 0,12 & 0,20 & & & & 0,60 & 0,60 \\
\hline 40 & 1 & 0,14 & 0,40 & 0,08 & 0,48 & 0,08 & & & 0,10 & 0,20 & 0,20 & 0,30 \\
\hline 41 & 1 & 0,16 & 0,28 & 0,06 & 0,52 & 0,12 & & & 0,10 & 0,10 & 0,40 & 0,30 \\
\hline 42 & 1 & 0,12 & 0,24 & 0,08 & 0,52 & 0,08 & 0,35 & & & & 0,80 & 0,20 \\
\hline 43 & 1 & 0,12 & 0,36 & 0,08 & 0,52 & 0,12 & & 0,20 & & & 1,30 & 0,40 \\
\hline 44 & 1 & 0,12 & 0,28 & 0,08 & 0,56 & 0,12 & 0,30 & & & & 0,40 & 0,60 \\
\hline 45 & 1 & 0,12 & 0,28 & 0,04 & 0,48 & 0,08 & & & 0,10 & 0,20 & & 0,30 \\
\hline 46 & 1 & 0,12 & 0,32 & 0,08 & 0,52 & 0,12 & & 0,20 & & & 0,30 & 0,25 \\
\hline 47 & 1 & 0,08 & 0,28 & 0,04 & 0,60 & 0,12 & 0,20 & & & & 0,50 & 0,50 \\
\hline 48 & 1 & 0,08 & 0,28 & 0,08 & 0,52 & 0,12 & 0,20 & & & & 1,20 & 0,40 \\
\hline 49 & 1 & 0,12 & 0,28 & 0,04 & 0,48 & 0,20 & & & 0,10 & 0,20 & 1,10 & 0,70 \\
\hline 50 & 1 & 0,08 & 0,28 & 0,06 & 0,52 & 0,08 & 0,20 & & & & 0,80 & 0,20 \\
\hline
\end{tabular}


APÊNDICE G - Dados individuais de grupo de atividade física, duração em segundos da onda $P$, intervalo $P-R$, complexo QRS, intervalo QT e onda T; amplitude em milivolts da onda $\mathrm{P}$ única, onda $\mathrm{P}$ bifásica, primeira porção da onda $P$ bífida (P1), segunda porção da onda $P$ bífida (P2), complexo QRS e onda $\mathrm{T}$, na derivação unipolar aVF, obtido pelo eletrocardiograma de 100 eqüinos de salto criados na cidade de São Paulo - SP - 2006.

(conclusão)

\begin{tabular}{|c|c|c|c|c|c|c|c|c|c|c|c|c|}
\hline & & & & & & & & & & & & \\
\hline $\mathrm{N}$ & Grupo & $\begin{array}{c}P \\
\text { (seg) }\end{array}$ & $\begin{array}{l}\text { P-R } \\
\text { (seg) }\end{array}$ & $\begin{array}{l}\text { QRS } \\
\text { (seg) }\end{array}$ & $\begin{array}{c}\text { QT } \\
\text { (seg) }\end{array}$ & $\begin{array}{c}\mathrm{T} \\
\text { (seg) }\end{array}$ & $\begin{array}{c}\text { P única } \\
(\mathrm{mV})\end{array}$ & $\begin{array}{c}\text { P bifás. } \\
(\mathrm{mV})\end{array}$ & $\begin{array}{c}\mathrm{P} 1 \\
(\mathrm{mV})\end{array}$ & $\begin{array}{l}\mathrm{P} 2 \\
(\mathrm{mV})\end{array}$ & $\begin{array}{c}\mathrm{R} \\
(\mathrm{mV})\end{array}$ & $\begin{array}{c}\mathrm{T} \\
(\mathrm{mV})\end{array}$ \\
\hline 51 & 1 & 0,16 & 0,36 & 0,08 & 0,52 & 0,12 & & & 0,20 & 0,30 & 1,20 & 0,60 \\
\hline 52 & 1 & 0,10 & 0,36 & 0,08 & 0,52 & 0,08 & 0,20 & & & & 1,60 & 0,30 \\
\hline 53 & 1 & 0,08 & 0,36 & 0,08 & 0,52 & 0,08 & 0,10 & & & & 1,10 & 0,30 \\
\hline 54 & 1 & 0,12 & 0,32 & 0,08 & 0,52 & 0,12 & & & 0,10 & 0,20 & 0,60 & 0,70 \\
\hline 55 & 1 & 0,08 & 0,28 & 0,06 & 0,52 & 0,08 & 0,10 & & & & 1,40 & 0,50 \\
\hline 56 & 1 & 0,12 & 0,40 & 0,08 & 0,56 & 0,12 & & & 0,10 & 0,10 & 0,30 & 0,60 \\
\hline 57 & 2 & 0,12 & 0,28 & 0,08 & 0,52 & 0,12 & & & 0,15 & 0,20 & 0,10 & 0,60 \\
\hline 58 & 2 & 0,12 & 0,36 & 0,10 & 0,52 & 0,12 & & & 0,15 & 0,15 & 0,90 & 0,40 \\
\hline 59 & 2 & 0,08 & 0,24 & 0,10 & 0,52 & 0,16 & 0,20 & & & & 1,00 & 0,50 \\
\hline 60 & 2 & 0,12 & 0,32 & 0,08 & 0,52 & 0,12 & & & 0,10 & 0,20 & 0,90 & 0,30 \\
\hline 61 & 2 & 0,12 & 0,32 & 0,08 & 0,48 & 0,12 & & & 0,10 & 0,15 & 0,30 & 0,20 \\
\hline 62 & 2 & 0,08 & 0,44 & 0,08 & 0,52 & 0,12 & 0,10 & & & & 0,50 & 0,40 \\
\hline 63 & 2 & 0,12 & 0,36 & 0,08 & 0,48 & 0,16 & & & 0,10 & 0,20 & 0,15 & 0,40 \\
\hline 64 & 2 & 0,10 & 0,36 & 0,08 & 0,56 & 0,12 & 0,20 & & & & 0,50 & 0,30 \\
\hline 65 & 2 & 0,12 & 0,24 & 0,10 & 0,52 & 0,08 & & & 0,10 & 0,10 & 0,80 & 0,30 \\
\hline 66 & 2 & 0,08 & 0,20 & 0,12 & 0,48 & 0,08 & 0,20 & & & & 1,40 & 0,20 \\
\hline 67 & 2 & 0,16 & 0,36 & 0,06 & 0,48 & 0,08 & & 0,20 & & & 0,40 & 0,30 \\
\hline 68 & 2 & 0,10 & 0,20 & 0,08 & 0,36 & 0,08 & & 0,40 & & & & 0,30 \\
\hline 69 & 2 & 0,12 & 0,28 & 0,12 & 0,48 & 0,12 & 0,30 & & & & 0,70 & 0,80 \\
\hline 70 & 2 & 0,16 & 0,32 & 0,12 & 0,48 & 0,16 & & 0,50 & & & 0,70 & 0,40 \\
\hline 71 & 2 & 0,08 & 0,24 & 0,06 & 0,44 & 0,12 & 0,20 & & & & 1,30 & 0,60 \\
\hline 72 & 2 & 0,08 & 0,24 & 0,08 & 0,40 & 0,08 & 0,20 & & & & 0,70 & 0,20 \\
\hline 73 & 2 & 0,12 & 0,36 & 0,10 & 0,52 & 0,12 & 0,20 & & & & 1,40 & 0,50 \\
\hline 74 & 2 & 0,12 & 0,24 & 0,10 & 0,44 & 0,12 & & 0,20 & & & 1,50 & 0,70 \\
\hline 75 & 2 & 0,12 & 0,28 & 0,12 & 0,52 & 0,16 & & & 0,10 & 0,20 & 0,70 & 0,35 \\
\hline 76 & 2 & 0,12 & 0,28 & 0,08 & 0,40 & 0,12 & & 0,20 & & & 1,00 & 0,30 \\
\hline 77 & 2 & 0,12 & 0,24 & 0,12 & 0,52 & 0,16 & & 0,20 & & & 0,60 & 0,40 \\
\hline 78 & 2 & 0,12 & 0,32 & 0,08 & 0,40 & 0,08 & & & 0,10 & 0,20 & 0,50 & 0,30 \\
\hline 79 & 2 & 0,12 & 0,24 & 0,08 & 0,44 & 0,08 & & & 0,10 & 0,25 & 1,00 & 0,40 \\
\hline 80 & 2 & 0,12 & 0,24 & 0,08 & 0,44 & 0,12 & 0,20 & & & & 2,00 & 0,15 \\
\hline 81 & 2 & 0,12 & 0,36 & 0,08 & 0,52 & 0,12 & & & 0,10 & 0,15 & 0,90 & 0,30 \\
\hline 82 & 2 & 0,08 & 0,36 & 0,08 & 0,48 & 0,08 & 0,20 & & & & 1,10 & 0,20 \\
\hline 83 & 2 & 0,12 & 0,36 & 0,08 & 0,56 & 0,12 & & & 0,10 & 0,20 & 1,00 & 0,40 \\
\hline 84 & 2 & 0,16 & 0,52 & 0,08 & 0,52 & 0,08 & & 0,20 & & & 0,40 & 0,20 \\
\hline 85 & 2 & 0,12 & 0,32 & 0,12 & 0,48 & 0,12 & & & 0,10 & 0,20 & 0,90 & 0,30 \\
\hline 86 & 2 & 0,12 & 0,28 & 0,04 & 0,48 & 0,08 & & 0,20 & & & 0,40 & 0,40 \\
\hline 87 & 2 & 0,12 & 0,28 & 0,08 & 0,48 & 0,12 & 0,25 & & & & 0,80 & 0,50 \\
\hline 88 & 2 & 0,16 & 0,44 & 0,12 & 0,44 & 0,12 & & & 0,10 & 0,20 & 0,40 & 0,40 \\
\hline 89 & 2 & 0,12 & 0,40 & 0,08 & 0,44 & 0,12 & & & 0,10 & 0,15 & 0,50 & 0,30 \\
\hline 90 & 2 & 0,08 & 0,24 & 0,10 & 0,44 & 0,08 & 0,10 & & & & 0,05 & 0,40 \\
\hline 91 & 2 & 0,12 & 0,24 & 0,06 & 0,44 & 0,12 & & & 0,10 & 0,20 & 0,60 & 0,30 \\
\hline 92 & 2 & 0,12 & 0,28 & 0,10 & 0,56 & 0,16 & & & 0,20 & 0,20 & 2,10 & 0,60 \\
\hline 93 & 2 & 0,12 & 0,28 & 0,08 & 0,44 & 0,12 & & & 0,10 & 0,20 & 1,00 & 0,20 \\
\hline 94 & 2 & 0,12 & 0,40 & 0,08 & 0,48 & 0,08 & & & 0,15 & 0,15 & 0,80 & 0,50 \\
\hline 95 & 2 & 0,12 & 0,36 & 0,08 & 0,52 & 0,12 & & & 0,10 & 0,20 & 0,30 & 0,40 \\
\hline 96 & 2 & 0,08 & 0,36 & 0,08 & 0,56 & 0,12 & 0,20 & & & & 0,60 & 0,40 \\
\hline 97 & 2 & 0,12 & 0,32 & 0,04 & 0,48 & 0,08 & & & 0,10 & 0,20 & 0,50 & 0,30 \\
\hline 98 & 2 & 0,08 & 0,24 & 0,12 & 0,40 & 0,08 & 0,20 & & & & 0,80 & 0,20 \\
\hline 99 & 2 & 0,08 & 0,28 & 0,08 & 0,48 & 0,12 & 0,20 & & & & 0,60 & 0,20 \\
\hline 100 & 2 & 0,12 & 0,28 & 0,08 & 0,40 & 0,08 & & & 0,10 & 0,10 & 0,80 & 0,10 \\
\hline
\end{tabular}


APÊNDICE H - Dados individuais de grupo de atividade física e representação morfológica da onda $\mathrm{P}$, nas derivações bipolares I, II e III e unipolares aVR, aVL e aVF, obtido pelo eletrocardiograma de 100 eqüinos de salto criados na cidade de São Paulo - SP - 2006.

(continua)

\begin{tabular}{|c|c|c|c|c|c|c|c|}
\hline $\mathrm{N}$ & Grupo & $\mathrm{P}$ (DI morfo) & $\mathrm{P}$ (DII morfo) & $\mathrm{P}$ (DIII morfo) & P(aVR morfo) & $\mathrm{P}(\mathrm{aVL}$ morfo) & P (aVF morfo) \\
\hline 1 & 1 & $(+)$ & $(-+)$ & $(-)$ & $(-)$ & $(+)$ & $(-)$ \\
\hline 2 & 1 & $(+)$ & $(++)$ & $(++)$ & $(--)$ & $(-)$ & $(++)$ \\
\hline 3 & 1 & $(++)$ & $(++)$ & $(++)$ & $(--)$ & $(--)$ & $(++)$ \\
\hline 4 & 1 & $(++)$ & $(++)$ & $(+)$ & $(--)$ & $(++,-)$ & $(++)$ \\
\hline 5 & 1 & $(++)$ & $(++)$ & $(++)$ & $(--)$ & $(+-)$ & $(++)$ \\
\hline 6 & 1 & $(++)$ & $(+)$ & $(++)$ & $(--)$ & $(++)$ & $(++)$ \\
\hline 7 & 1 & $(+)$ & $(++)$ & $(+)$ & $(--)$ & $(++)$ & $(+)$ \\
\hline 8 & 1 & $(++)$ & $(++)$ & $(+)$ & $(--)$ & $(--)$ & $(+)$ \\
\hline 9 & 1 & $(+)$ & $(++)$ & $(++)$ & $(--)$ & $(--)$ & $(++)$ \\
\hline 10 & 1 & $(-+)$ & $(-+)$ & $(--)$ & $(--)$ & $(++)$ & $(-+)$ \\
\hline 11 & 1 & $(-+)$ & $(++)$ & $(+)$ & $(-)$ & $(-)$ & $(+)$ \\
\hline 12 & 1 & $(++)$ & $(++)$ & $(++)$ & $(--)$ & $(--)$ & $(++)$ \\
\hline 13 & 1 & $(-,++)$ & $(+)$ & $(+)$ & $(-)$ & $(-)$ & $(+)$ \\
\hline 14 & 1 & $(--)$ & $(+)$ & $\frac{1}{(++)}$ & $(++,-)$ & $(-)$ & $(+)$ \\
\hline 15 & 1 & $(++)$ & $(++)$ & $(++)$ & $(--)$ & $(--)$ & $(++)$ \\
\hline 16 & 1 & $(+)$ & $(+)$ & $(++)$ & $(-)$ & $(--)$ & $(+)$ \\
\hline 17 & 1 & $(-+)$ & $(-+)$ & $(++)$ & $(+-)$ & $(-)$ & $(-+)$ \\
\hline 18 & 1 & $(++)$ & $(+)$ & $(+)$ & $(+-)$ & $(++)$ & $(+)$ \\
\hline 19 & 1 & $(++)$ & $\frac{1}{(++)}$ & $\frac{1}{(-+)}$ & $(--)$ & $(+)$ & $(+)$ \\
\hline 20 & 1 & $\frac{1}{(++)}$ & $\frac{1}{(++)}$ & $(+)$ & $(--)$ & $\frac{1}{(+-)}$ & $\frac{1}{(++)}$ \\
\hline 21 & 1 & $(++)$ & $(+)$ & $(++)$ & $(--)$ & $(--)$ & $(+)$ \\
\hline 22 & 1 & $(+)$ & $(+)$ & $(+)$ & $\frac{1}{(-)}$ & $(-)$ & $(-)$ \\
\hline 23 & 1 & $(+)$ & $(+)$ & $(+)$ & $(-)$ & $(-)$ & $(+)$ \\
\hline 24 & 1 & $\frac{1}{(++)}$ & $\frac{1}{(++)}$ & $\frac{1}{(++)}$ & $\frac{1}{(--)}$ & $\frac{1}{(--)}$ & $\frac{1}{(++)}$ \\
\hline 25 & 1 & $(-+)$ & $(+)$ & $(++)$ & $(--)$ & $(--)$ & $(+)$ \\
\hline 26 & 1 & $(+)$ & $(+)$ & $(+)$ & $(-)$ & $(-)$ & $(+)$ \\
\hline 27 & 1 & $(+)$ & $(++)$ & $(--)$ & $(+-)$ & $(+)$ & $(-+)$ \\
\hline 28 & 1 & $(++)$ & $(+)$ & $(+)$ & $(--)$ & $(++)$ & $(+)$ \\
\hline 29 & 1 & $\frac{1}{(+)}$ & $(+)$ & $(+)$ & $\frac{1}{(-)}$ & $(-)$ & $(+)$ \\
\hline 30 & 1 & $\frac{1}{(+)}$ & $(+)$ & $(+)$ & $(-)$ & $(-)$ & $(+)$ \\
\hline 31 & 1 & $(++)$ & $(++)$ & $(--)$ & $(--)$ & $(++)$ & $(++)$ \\
\hline 32 & 1 & $(++)$ & $(++)$ & $(++)$ & $(--)$ & $\frac{1}{(-)}$ & $(++)$ \\
\hline 33 & 1 & $(+)$ & $(+)$ & $(-+)$ & $(--)$ & $(--)$ & $(++)$ \\
\hline 34 & 1 & $(++)$ & $(++)$ & $(-)$ & $(--)$ & $(++)$ & $(+)$ \\
\hline 35 & 1 & $(++)$ & $(+)$ & $(-,++)$ & $(--)$ & $(++)$ & $(++)$ \\
\hline 36 & 1 & $(++)$ & $\frac{1}{(++)}$ & $(+)$ & $(--)$ & $(++)$ & $(++)$ \\
\hline 37 & 1 & $(++)$ & $(+)$ & $(++)$ & $(--)$ & $(++)$ & $(+)$ \\
\hline 38 & 1 & $(++)$ & $(++)$ & $(+++)$ & $(--)$ & $(++)$ & $(++)$ \\
\hline 39 & 1 & $(+)$ & $(++)$ & $(+)$ & $(--)$ & $(-)$ & $(+)$ \\
\hline 40 & 1 & $(++)$ & $(++)$ & $(++)$ & $(--)$ & $(++)$ & $(++)$ \\
\hline 41 & 1 & $(++)$ & $(++)$ & $(++)$ & $(--)$ & $(-)$ & $(++)$ \\
\hline 42 & 1 & $(++)$ & $(+)$ & $(+)$ & $(--)$ & $\frac{1}{(++)}$ & $(+)$ \\
\hline 43 & 1 & $(-+)$ & $(+)$ & $(-)$ & $(+-)$ & $(+)$ & $(-+)$ \\
\hline 44 & 1 & $(+)$ & $(+)$ & $(-+)$ & $\frac{1}{(-)}$ & $(+-)$ & $(+)$ \\
\hline 45 & 1 & $(++)$ & $(++)$ & $(+)$ & $(--)$ & $(+)$ & $(++)$ \\
\hline 46 & 1 & $(++)$ & $(+)$ & $(-,++)$ & $(-)$ & $(++)$ & $(-+)$ \\
\hline 47 & 1 & $(+)$ & $(++)$ & $(-+)$ & $(--)$ & $(+)$ & $(+)$ \\
\hline 48 & 1 & $(++)$ & $(++)$ & $(-+)$ & $(--)$ & $(++)$ & $(+)$ \\
\hline 49 & 1 & $(++)$ & $\frac{1}{(++)}$ & $(++)$ & $(--)$ & $(--)$ & $\frac{1}{(++)}$ \\
\hline 50 & 1 & $(+)$ & $(+)$ & $(+)$ & $\frac{1}{(-)}$ & $\frac{1}{(-)}$ & $(+)$ \\
\hline
\end{tabular}


APÊNDICE H - Dados individuais de grupo de atividade física e representação morfológica da onda $\mathrm{P}$, nas derivações bipolares I, II e III e unipolares aVR, aVL e aVF, obtido pelo eletrocardiograma de 100 eqüinos de salto criados na cidade de São Paulo - SP - 2006.

\begin{tabular}{|c|c|c|c|c|c|c|c|}
\hline $\mathrm{N}$ & Grupo & P (DI morfo) & $\mathrm{P}$ (DII morfo) & P(DIII morfo) & P(aVR morfo) & $\mathrm{P}$ (aVL morfo) & $\mathrm{P}$ (aVF morfo) \\
\hline 51 & 1 & $(++)$ & $(++)$ & $(++)$ & $(--)$ & $(++,-)$ & $(++)$ \\
\hline 52 & 1 & $(++)$ & $(++)$ & $(-,++)$ & $(--)$ & $(++)$ & $(+)$ \\
\hline 53 & 1 & $(++)$ & $(+)$ & $(+)$ & $(--)$ & $(++)$ & $(-)$ \\
\hline 54 & 1 & $(++)$ & $(+)$ & $(++)$ & $(--)$ & $(++)$ & $(++)$ \\
\hline 55 & 1 & $(++)$ & $(++)$ & $(+)$ & $(-)$ & $(+)$ & $(+)$ \\
\hline 56 & 1 & $(+)$ & $(++)$ & $(+)$ & $(--)$ & $(+)$ & $(++)$ \\
\hline 57 & 2 & $(++)$ & $(++)$ & $(++)$ & $(--)$ & $(++)$ & $(++)$ \\
\hline 58 & 2 & $(++)$ & $(++)$ & $(-)$ & $(--)$ & $(+)$ & $(++)$ \\
\hline 59 & 2 & $(++)$ & $(+)$ & $(+)$ & $(--)$ & $(+-)$ & $(+)$ \\
\hline 60 & 2 & $(+)$ & $(+)$ & $(+)$ & $(-)$ & $(-)$ & $(++)$ \\
\hline 61 & 2 & $(++)$ & $(++)$ & $(++)$ & $(--)$ & $(++)$ & $(++)$ \\
\hline 62 & 2 & $(++)$ & $(+)$ & $(+)$ & $(--)$ & $(++)$ & $(+)$ \\
\hline 63 & 2 & $(+)$ & $(++)$ & $(++)$ & $(--)$ & $(-)$ & $(++)$ \\
\hline 64 & 2 & $(++)$ & $(++)$ & $(+)$ & $(-)$ & $(--)$ & $(+)$ \\
\hline 65 & 2 & $(++)$ & $(++)$ & $(++)$ & $(--)$ & $(++)$ & $(++)$ \\
\hline 66 & 2 & $(-+)$ & $(-+)$ & $(--)$ & $\frac{1}{(+-)}$ & $(++)$ & $(+)$ \\
\hline 67 & 2 & $(++)$ & $(++)$ & $(++)$ & $(--)$ & $(+-)$ & $(-+)$ \\
\hline 68 & 2 & $(+-)$ & $(-+)$ & $(-+)$ & $(+-)$ & $(+-)$ & $(-+)$ \\
\hline 69 & 2 & $(++)$ & $(-+)$ & $(++)$ & $(-)$ & $(--)$ & $(+)$ \\
\hline 70 & 2 & $(++)$ & $(-+)$ & $(-+)$ & $(-)$ & $(--)$ & $(-+)$ \\
\hline 71 & 2 & $(++)$ & $(++)$ & $(+)$ & $(--)$ & $(-)$ & $(+)$ \\
\hline 72 & 2 & $(++)$ & $(+)$ & $(+)$ & $(-)$ & $(--)$ & $(+)$ \\
\hline 73 & 2 & $(++)$ & $(++)$ & $(-+)$ & $(--)$ & $(++)$ & $(+)$ \\
\hline 74 & 2 & $(--)$ & $(-++)$ & $(-,++)$ & $(+-)$ & $(--)$ & $(-+)$ \\
\hline 75 & 2 & $(-+)$ & $(-+)$ & $(++)$ & $(--)$ & $(++)$ & $(++)$ \\
\hline 76 & 2 & $(--,+)$ & $(+)$ & $(+-)$ & $(-)$ & $(--)$ & $(+-)$ \\
\hline 77 & 2 & $(++)$ & $(+)$ & $(++)$ & $(--)$ & $(+,--)$ & $(-,++)$ \\
\hline 78 & 2 & $(++)$ & $(++)$ & $(+)$ & $(--)$ & $(--)$ & $(++)$ \\
\hline 79 & 2 & $(++)$ & $(++)$ & $(+)$ & $(--)$ & $(++,-)$ & $(++)$ \\
\hline 80 & 2 & $(+)$ & $(+)$ & $(+)$ & $(-)$ & $(--)$ & $(+)$ \\
\hline 81 & 2 & $\frac{1}{(++)}$ & $\frac{1}{(++)}$ & $\frac{1}{(++)}$ & $\frac{11}{(--)}$ & $(--)$ & $\frac{1}{(++)}$ \\
\hline 82 & 2 & $(++)$ & $(++)$ & $(+)$ & $(--)$ & $(+)$ & $(+)$ \\
\hline 83 & 2 & $(++)$ & $(++)$ & $(+)$ & $(--)$ & $(++)$ & $(++)$ \\
\hline 84 & 2 & $(+)$ & $(+)$ & $(--)$ & $(-)$ & $(++)$ & $(-+)$ \\
\hline 85 & 2 & $(++)$ & $(++)$ & $(+)$ & $(--)$ & $(-)$ & $(++)$ \\
\hline 86 & 2 & $(+)$ & $(-+)$ & $(++)$ & $(+-)$ & $(-)$ & $(-+)$ \\
\hline 87 & 2 & $(+)$ & $(+)$ & $(+)$ & $(--)$ & $(--)$ & $(+)$ \\
\hline 88 & 2 & $(++)$ & $(++)$ & $(+)$ & $(--)$ & $(+-)$ & $(++)$ \\
\hline 89 & 2 & $(++)$ & $(++)$ & $(-,++)$ & $(--)$ & $(++)$ & $(++)$ \\
\hline 90 & 2 & $(++)$ & $(++)$ & $(+)$ & $(--)$ & $(++)$ & $(+)$ \\
\hline 91 & 2 & $(+)$ & $(++)$ & $(--)$ & $(--)$ & $(-+)$ & $(++)$ \\
\hline 92 & 2 & $(++)$ & $(++)$ & $(++)$ & $(--)$ & $(+)$ & $(++)$ \\
\hline 93 & 2 & $(-,++)$ & $(+)$ & $(++)$ & $(--)$ & $(++)$ & $(++)$ \\
\hline 94 & 2 & $(++)$ & $(++)$ & $(++)$ & $(--)$ & $(++)$ & $(++)$ \\
\hline 95 & 2 & $(++)$ & $(++)$ & $(++)$ & $(--)$ & $(++)$ & $(++)$ \\
\hline 96 & 2 & $(++)$ & $(+)$ & $(++)$ & $(--)$ & $(++)$ & $(+)$ \\
\hline 97 & 2 & $(++)$ & $(++)$ & $(++)$ & $(--)$ & $(++)$ & $(++)$ \\
\hline 98 & 2 & $(+)$ & $(+)$ & $(+)$ & $(+-)$ & $(-+)$ & $(+)$ \\
\hline 99 & 2 & $(+)$ & $(+)$ & $(+)$ & $(-)$ & $(--)$ & $(+)$ \\
\hline 100 & 2 & $(++)$ & $(-+)$ & $(+)$ & $(--)$ & $(++)$ & $(++)$ \\
\hline
\end{tabular}

Nota: (+) onda $\mathrm{P}$ única positiva, (++) onda $\mathrm{P}$ bífida e positiva, $(+-)$ onda $\mathrm{P}$ bifásica com primeira porção $(\mathrm{P} 1)$ positiva $e$ segunda porção (P2) negativa, $(-+)$ onda $P$ bifásica com $P 1$ negativa e P2 positiva, (-) onda $P$ única e negativa, (- -) onda $\mathrm{P}$ bífida e negativa, $(--,+)$ onda $\mathrm{P}$ bifásica com $\mathrm{P} 1$ bífida e negativa e $\mathrm{P} 2$ positiva, $(-,++)$ onda $\mathrm{P}$ bifásica com $\mathrm{P} 1$ negativa e P2 bífida e positiva, (++, -) onda P bifásica com P1 bífida e positiva e P2 negativa e (+, - -) onda P bifásica com P1 positiva e P2 bífida e negativa. 
APÊNDICE I - Dados individuais de grupo de atividade física e representação morfológica do complexo QRS, nas derivações bipolares I, II e III e unipolares aVR, aVL e aVF, obtido pelo eletrocardiograma de 100 eqüinos de salto criados na cidade de São Paulo - SP - 2006.

\begin{tabular}{|c|c|c|c|c|c|c|c|}
\hline $\mathrm{N}$ & Grupo & $\begin{array}{r}\text { morfologia } \\
\text { QRS DI }\end{array}$ & $\begin{array}{c}\text { morfologia } \\
\text { QRS DII }\end{array}$ & $\begin{array}{r}\text { morfologia } \\
\text { QRS DIII }\end{array}$ & $\begin{array}{c}\text { morfologia } \\
\text { QRS aVR }\end{array}$ & $\begin{array}{c}\text { morfologia } \\
\text { QRS aVL }\end{array}$ & $\begin{array}{c}\text { morfologia } \\
\text { QRS aVF }\end{array}$ \\
\hline 1 & 1 & QRS & QRS & QR & RS & $\mathrm{R}$ & QRS \\
\hline 2 & 1 & $R$ & $R$ & QR & QS & RS & RS \\
\hline 3 & 1 & QRS & QR & $\mathrm{R}$ & RS & QS & QR \\
\hline 4 & 1 & $\mathrm{QR}$ & QRS & RS & RS & QR & QRS \\
\hline 5 & 1 & $\mathrm{QR}$ & QRS & RS & RS & $\mathrm{R}$ & QRS \\
\hline 6 & 1 & QRS & QRS & RS & QS & QR & RS \\
\hline 7 & 1 & QRS & QR & QR & RS & RS & QR \\
\hline 8 & 1 & QR & $R$ & QRS & RS & $\mathrm{QR}$ & $\mathrm{R}$ \\
\hline 9 & 1 & $\mathrm{R}$ & RS & RS & QS & $\mathrm{QR}$ & $\mathrm{RS}$ \\
\hline 10 & 1 & QR & $R$ & QRS & RS & $R$ & $\mathrm{QR}$ \\
\hline 11 & 1 & QS & QR & RS & RS & QR & QS \\
\hline 12 & 1 & QRS & $\mathrm{R}$ & QR & QS & RS & QR \\
\hline 13 & 1 & QRS & $\overline{Q R}$ & QRS & RS & RS & QRS \\
\hline 14 & 1 & QR & QRS & QRS & RS & RS & QRS \\
\hline 15 & 1 & $R$ & QRS & RS & QS & $R$ & QRS \\
\hline 16 & 1 & RS & QR & $R$ & QS & QS & $\mathrm{QR}$ \\
\hline 17 & 1 & QRS & QR & QR & RS & RS & $\mathrm{QR}$ \\
\hline 18 & 1 & RS & QRS & QR & $\mathrm{QR}$ & RS & QR \\
\hline 19 & 1 & RS & QRS & QRS & QS & QRS & $\mathrm{QR}$ \\
\hline 20 & 1 & RS & QRS & RS & QS & QRS & QRS \\
\hline 21 & 1 & $Q R$ & QRS & QS & RS & $R$ & RS \\
\hline 22 & 1 & RS & QR & $\mathrm{QR}$ & RS & RS & $\mathrm{QR}$ \\
\hline 23 & 1 & RS & QR & $\mathrm{QR}$ & QS & RS & $\mathrm{R}$ \\
\hline 24 & 1 & $Q R$ & QR & QRS & RS & $\mathrm{QR}$ & QR \\
\hline 25 & 1 & QRS & QRS & QRS & RS & $\mathrm{QR}$ & QRS \\
\hline 26 & 1 & $\mathrm{R}$ & QR & $\mathrm{QR}$ & QS & QS & $\mathrm{QR}$ \\
\hline 27 & 1 & QRS & QRS & QR & RS & QRS & QR \\
\hline 28 & 1 & RS & $\mathrm{R}$ & $\mathrm{R}$ & QS & RS & $\mathrm{R}$ \\
\hline 29 & 1 & $R$ & $\mathrm{R}$ & $R$ & QS & $R$ & $\mathrm{R}$ \\
\hline 30 & 1 & RS & $\mathrm{R}$ & RS & QS & QRS & RS \\
\hline 31 & 1 & QRS & QR & RS & RS & QRS & QR \\
\hline 32 & 1 & QS & $\mathrm{R}$ & $R$ & RS & QS & $\mathrm{R}$ \\
\hline 33 & 1 & QRS & QR & QRS & RS & RS & QR \\
\hline 34 & 1 & RS & RS & RS & $\mathrm{QR}$ & RS & RS \\
\hline 35 & 1 & QR & QR & QR & RS & $R$ & QR \\
\hline 36 & 1 & QRS & RS & RS & QS & QRS & RS \\
\hline 37 & 1 & QRS & QR & $\mathrm{R}$ & RS & QS & $\mathrm{R}$ \\
\hline 38 & 1 & QR & QR & RS & RS & QR & $\mathrm{R}$ \\
\hline 39 & 1 & $\mathrm{R}$ & $\mathrm{R}$ & $\mathrm{R}$ & QS & $\mathrm{R}$ & $\mathrm{R}$ \\
\hline 40 & 1 & QRS & QR & QRS & RS & RS & QR \\
\hline 41 & 1 & $\mathrm{R}$ & $\mathrm{R}$ & RS & QS & $\mathrm{R}$ & RS \\
\hline 42 & 1 & QRS & QRS & RS & RS & QS & $\mathrm{QR}$ \\
\hline 43 & 1 & QRS & QR & $R$ & RS & $R$ & $\mathrm{R}$ \\
\hline 44 & 1 & QR & QRS & RS & QS & RS & RS \\
\hline 45 & 1 & QRS & $\mathrm{R}$ & QR & QS & RS & QS \\
\hline 46 & 1 & QS & QRS & $\mathrm{R}$ & $\mathrm{R}$ & QS & QRS \\
\hline 47 & 1 & QRS & QRS & QR & RS & RS & RS \\
\hline 48 & 1 & $\mathrm{R}$ & QRS & RS & RS & $R$ & RS \\
\hline 49 & 1 & RS & $R$ & RS & QS & RS & $R$ \\
\hline 50 & & QRS & & & QS & QR & $\mathrm{R}$ \\
\hline
\end{tabular}


APÊNDICE I - Dados individuais de grupo de atividade física e representação morfológica do complexo QRS, nas derivações bipolares I, II e III e unipolares aVR, aVL e aVF, obtido pelo eletrocardiograma de 100 eqüinos de salto criados na cidade de São Paulo - SP - 2006.

\begin{tabular}{|c|c|c|c|c|c|c|c|}
\hline $\mathrm{N}$ & Grupo & $\begin{array}{r}\text { morfologia } \\
\text { QRS DI }\end{array}$ & $\begin{array}{l}\text { morfologia } \\
\text { QRS DII }\end{array}$ & $\begin{array}{c}\text { morfologia } \\
\text { QRS DIII }\end{array}$ & $\begin{array}{r}\text { morfologia } \\
\text { QRS aVR }\end{array}$ & $\begin{array}{c}\text { morfologia } \\
\text { QRS aVL }\end{array}$ & $\begin{array}{c}\text { morfologia } \\
\text { QRS aVF }\end{array}$ \\
\hline 51 & 1 & RS & $\mathrm{R}$ & $\mathrm{R}$ & $\mathrm{QR}$ & RS & $\mathrm{R}$ \\
\hline 52 & 1 & RS & QR & QR & RS & RS & QR \\
\hline 53 & 1 & QRS & RS & $\mathrm{R}$ & RS & QS & $\mathrm{R}$ \\
\hline 54 & 1 & $Q R$ & $\mathrm{R}$ & RS & RS & QR & RS \\
\hline 55 & 1 & $\mathrm{R}$ & $\mathrm{R}$ & RS & RS & QR & RS \\
\hline 56 & 1 & QR & $\mathrm{R}$ & QR & QS & $R$ & $\mathrm{QR}$ \\
\hline 57 & 2 & QRS & QRS & QR & RS & QRS & $Q R$ \\
\hline 58 & 2 & RS & QR & QR & RS & RS & QR \\
\hline 59 & 2 & QRS & QRS & QR & RS & QRS & $Q R$ \\
\hline 60 & 2 & $\mathrm{R}$ & QRS & RS & RS & QR & RS \\
\hline 61 & 2 & QR & QRS & RS & RS & QRS & RS \\
\hline 62 & 2 & $\mathrm{R}$ & $\mathrm{R}$ & $\mathrm{R}$ & QS & $\mathrm{R}$ & $\mathrm{R}$ \\
\hline 63 & 2 & QRS & QR & QR & RS & RS & QR \\
\hline 64 & 2 & RS & RS & RS & RS & QRS & RS \\
\hline 65 & 2 & QRS & QRS & QRS & RS & QRS & QRS \\
\hline 66 & 2 & QRS & QRS & QR & RS & RS & QR \\
\hline 67 & 2 & QRS & QR & QRS & RS & QRS & QRS \\
\hline 68 & 2 & QR & $\mathrm{QR}$ & QS & RS & RS & QS \\
\hline 69 & 2 & QRS & QRS & RS & RS & QR & QRS \\
\hline 70 & 2 & QR & QR & QRS & RS & $\mathrm{R}$ & QRS \\
\hline 71 & 2 & QR & QR & RS & RS & QR & RS \\
\hline 72 & 2 & QRS & QR & $\mathrm{R}$ & RS & RS & $Q R$ \\
\hline 73 & 2 & QRS & $\mathrm{QR}$ & QR & RS & RS & $Q R$ \\
\hline 74 & 2 & QRS & QRS & QRS & RS & $\mathrm{R}$ & QRS \\
\hline 75 & 2 & $Q R$ & QR & QRS & RS & QR & QRS \\
\hline 76 & 2 & RS & QR & QRS & RS & QR & QR \\
\hline 77 & 2 & RS & QR & QR & RS & RS & $\mathrm{QR}$ \\
\hline 78 & 2 & QRS & QR & RS & RS & QRS & RS \\
\hline 79 & 2 & QR & QR & RS & RS & $R$ & $Q R$ \\
\hline 80 & 2 & RS & $\mathrm{R}$ & $R$ & QS & QS & $\mathrm{R}$ \\
\hline 81 & 2 & $R$ & RS & RS & QR & QR & RS \\
\hline 82 & 2 & RS & RS & RS & RS & QRS & RS \\
\hline 83 & 2 & QRS & QRS & RS & RS & QR & QRS \\
\hline 84 & 2 & RS & $R$ & QR & RS & RS & RS \\
\hline 85 & 2 & QR & QR & $R$ & RS & QS & QR \\
\hline 86 & 2 & RS & QR & QR & QR & RS & $\mathrm{QR}$ \\
\hline 87 & 2 & RS & RS & RS & QS & QRS & RS \\
\hline 88 & 2 & $\mathrm{R}$ & RS & RS & QS & $R$ & RS \\
\hline 89 & 2 & RS & QRS & QRS & QS & QRS & QRS \\
\hline 90 & 2 & QS & QR & RS & RS & QR & QR \\
\hline 91 & 2 & QR & QR & RS & RS & QRS & $\mathrm{QR}$ \\
\hline 92 & 2 & QR & QR & $R$ & RS & RS & $\mathrm{QR}$ \\
\hline 93 & 2 & RS & RS & RS & QR & QR & RS \\
\hline 94 & 2 & QRS & RS & RS & $\mathrm{QR}$ & QRS & $R$ \\
\hline 95 & 2 & QR & RS & QS & QS & $R$ & RS \\
\hline 96 & 2 & $\mathrm{QR}$ & RS & RS & RS & QR & RS \\
\hline 97 & 2 & QR & $\mathrm{R}$ & QS & QS & $\mathrm{R}$ & $\mathrm{R}$ \\
\hline 98 & 2 & QR & QR & $\mathrm{QR}$ & RS & QRS & QR \\
\hline 99 & 2 & $\mathrm{R}$ & RS & QR & QS & RS & RS \\
\hline 100 & 2 & ? & R & 5 & S & RS & \\
\hline
\end{tabular}


APÊNDICE J - Dados individuais de grupo de atividade física e representação morfológica da onda T, nas derivações bipolares I, II e III e unipolares aVR, aVL e aVF, obtido pelo eletrocardiograma de 100 eqüinos de salto criados na cidade de São Paulo - SP - 2006.

\begin{tabular}{|c|c|c|c|c|c|c|c|}
\hline $\mathrm{N}$ & Grupo & T (DI morfo) & T(DII morfo) & T(DIII morfo) & T(aVR morfo) & $\mathrm{T}(\mathrm{aVL}$ morfo) & $\mathrm{T}(\mathrm{aVF}$ morfo) \\
\hline 1 & 1 & $(-)$ & $(-+)$ & $(+)$ & $(+-)$ & $(-)$ & $(+)$ \\
\hline 2 & 1 & $(-)$ & $(-+)$ & $(+)$ & $(+-)$ & $(-)$ & $(+)$ \\
\hline 3 & 1 & $(-)$ & $(+)$ & $(+)$ & $(+-)$ & $(-)$ & $(+)$ \\
\hline 4 & 1 & $(-)$ & $(+)$ & $(+)$ & $(+)$ & $(-)$ & $(+)$ \\
\hline 5 & 1 & $(--)$ & $(+)$ & $(+)$ & $(-+)$ & $(-)$ & $(+)$ \\
\hline 6 & 1 & $(-+)$ & $(-+)$ & $(-+)$ & $(+-)$ & $(-)$ & $(-+)$ \\
\hline 7 & 1 & $(-)$ & $(-)$ & $(+)$ & $(+)$ & $(-)$ & $(+)$ \\
\hline 8 & 1 & $(+)$ & $(-+)$ & $(-+)$ & $(-)$ & $(+)$ & $(-+)$ \\
\hline 9 & 1 & $(-)$ & $(+)$ & $(+)$ & $(-)$ & $(-)$ & $(+)$ \\
\hline 10 & 1 & $(-)$ & $(-+)$ & $(+)$ & $(+)$ & $(-)$ & $(+)$ \\
\hline 11 & 1 & $(+)$ & $(+)$ & $(+)$ & $(-)$ & $(+)$ & $(+)$ \\
\hline 12 & 1 & $(-)$ & $(+)$ & $(+)$ & $(-)$ & $(-)$ & $(+)$ \\
\hline 13 & 1 & $(-)$ & $(+)$ & $(+)$ & $(+)$ & $(-)$ & $(+)$ \\
\hline 14 & 1 & $(+)$ & $(-+)$ & $(-)$ & $(-)$ & $(+)$ & $(-+)$ \\
\hline 15 & 1 & $(-)$ & $(-+)$ & $(+)$ & $(+-)$ & $(-)$ & $(+)$ \\
\hline 16 & 1 & $(+)$ & $(+)$ & $(+)$ & $(-)$ & $(-+)$ & $(+)$ \\
\hline 17 & 1 & $(+)$ & $(+)$ & $(-)$ & $(-)$ & $(+)$ & $(+-)$ \\
\hline 18 & 1 & $(+)$ & $(+)$ & $(+)$ & $(-)$ & $(-)$ & $(+)$ \\
\hline 19 & 1 & $(-)$ & $(-)$ & $(-+)$ & $(+)$ & $(-)$ & $(-)$ \\
\hline 20 & 1 & $(-)$ & $(-+)$ & $(-+)$ & $(+-)$ & $(+-)$ & $(-+)$ \\
\hline 21 & 1 & $(+-)$ & $(+)$ & $(+)$ & $(-)$ & $(--)$ & $(+)$ \\
\hline 22 & 1 & $(-+)$ & $(+)$ & $(+)$ & $(+)$ & $(-)$ & $(+)$ \\
\hline 23 & 1 & $(-)$ & $(-)$ & $(+)$ & $(+)$ & $(-)$ & $(+)$ \\
\hline 24 & 1 & $(-+)$ & $(-+)$ & $(+)$ & $(-+)$ & $(-+)$ & $(+)$ \\
\hline 25 & 1 & $(-)$ & $(-+)$ & $(+)$ & $(+)$ & $(-)$ & $(+)$ \\
\hline 26 & 1 & $(-)$ & $(+)$ & $(+)$ & $(+-)$ & $(-)$ & $(-+)$ \\
\hline 27 & 1 & $(+)$ & $(+)$ & $(-+)$ & $(-)$ & $(+-)$ & $(+)$ \\
\hline 28 & 1 & $(-+)$ & $(+)$ & $(+)$ & $(+-)$ & $(-)$ & $(+)$ \\
\hline 29 & 1 & $(+)$ & $(+)$ & $(+)$ & $(-)$ & $(-)$ & $(+)$ \\
\hline 30 & 1 & $(+)$ & $(+)$ & $(+)$ & $(-)$ & $(-)$ & $(+)$ \\
\hline 31 & 1 & $(-)$ & $(-+)$ & $(+)$ & $(+-)$ & $(-)$ & $(-+)$ \\
\hline 32 & 1 & $(-)$ & $(+)$ & $(+)$ & $(+-)$ & $(-)$ & $(+)$ \\
\hline 33 & 1 & $(-)$ & $(-)$ & $(-)$ & $(+-)$ & $(+)$ & $(-)$ \\
\hline 34 & 1 & $(-+)$ & $(+)$ & $(+)$ & $(+-)$ & $(-)$ & $(+)$ \\
\hline 35 & 1 & $(-+)$ & $(+)$ & $(+)$ & $(-)$ & $(-)$ & $(+)$ \\
\hline 36 & 1 & $(+)$ & $(+)$ & $(+)$ & $(+-)$ & $(-)$ & $(+)$ \\
\hline 37 & 1 & $(+)$ & $(+)$ & $(+-)$ & $(-)$ & $(-+)$ & $(+)$ \\
\hline 38 & 1 & $(+)$ & $(+)$ & $(+)$ & $(-)$ & $(-+)$ & $(+)$ \\
\hline 39 & 1 & $(-)$ & $(+)$ & $(+)$ & $(-)$ & $(-)$ & $(+)$ \\
\hline 40 & 1 & $(-)$ & $(-+)$ & $(+)$ & $(+)$ & $(-)$ & $(+)$ \\
\hline 41 & 1 & $(-)$ & $(+)$ & $(+)$ & $(+-)$ & $(-)$ & $(+)$ \\
\hline 42 & 1 & $(-)$ & $(+)$ & $(+)$ & $(+-)$ & $(-)$ & $(+)$ \\
\hline 43 & 1 & $(-+)$ & $(+)$ & $(+)$ & $(+-)$ & $(-)$ & $(-+)$ \\
\hline 44 & 1 & $(-)$ & $(+)$ & $(+)$ & $(+-)$ & $(-)$ & $(+)$ \\
\hline 45 & 1 & $(-)$ & $(+)$ & $(+)$ & $(+)$ & $(-)$ & $(+)$ \\
\hline 46 & 1 & $(-+)$ & $(+)$ & $(+)$ & $(-)$ & $(-+)$ & $(+)$ \\
\hline 47 & 1 & $(-)$ & $(+)$ & $(+)$ & $(+-)$ & $(-)$ & $(+)$ \\
\hline 48 & 1 & $(-)$ & $(-+)$ & $(-+)$ & $(+)$ & $(-)$ & $(-+)$ \\
\hline 49 & 1 & $(-)$ & $(-+)$ & $(-+)$ & $(+)$ & $(-)$ & $(-+)$ \\
\hline 50 & 1 & $(-)$ & $(-+)$ & $(+)$ & $(+-)$ & $(-)$ & $(+)$ \\
\hline
\end{tabular}


APÊNDICE J - Dados individuais de grupo de atividade física e representação morfológica da onda T, nas derivações bipolares I, II e III e unipolares aVR, aVL e aVF, obtido pelo eletrocardiograma de 100 eqüinos de salto criados na cidade de São Paulo - SP - 2006.

(conclusão)

\begin{tabular}{|c|c|c|c|c|c|c|c|}
\hline $\mathrm{N}$ & Grupo & T (DI morfo) & T(DIl morfo) & T(DIII morfo) & T(aVR morfo) & $\mathrm{T}(\mathrm{aVL}$ morfo) & $\mathrm{T}(\mathrm{aVF}$ morfo) \\
\hline 51 & 1 & $(-)$ & $(-)$ & $(-)$ & $(+-)$ & $(-)$ & $(-)$ \\
\hline 52 & 1 & $\frac{(-+)}{(-+)}$ & $\frac{1}{(-+)}$ & $(+)$ & $\frac{1}{(+-)}$ & $\frac{(-)}{(-)}$ & $\frac{1}{(+)}$ \\
\hline 53 & 1 & $(-)$ & $(-+)$ & $(+)$ & $(+-)$ & $(-)$ & $(+)$ \\
\hline 54 & 1 & $(-+)$ & $(+)$ & $(+)$ & $(-)$ & $(-)$ & $(-)$ \\
\hline 55 & 1 & $(-)$ & $(+)$ & $(+)$ & $\frac{(+-)}{(+)}$ & $\frac{(-)}{(-)}$ & $\frac{1}{(+)}$ \\
\hline 56 & 1 & $(-)$ & $(-+)$ & $(+)$ & $(+)$ & $(-)$ & $(-+)$ \\
\hline 57 & 2 & $(-)$ & $(-+)$ & $(-+)$ & $(+-)$ & $(-)$ & $(-+)$ \\
\hline 58 & 2 & $(-)$ & $(+)$ & $(+)$ & $(+-)$ & $(-)$ & $(+)$ \\
\hline 59 & 2 & $(+)$ & $(+-)$ & $(+)$ & $(+)$ & $(-)$ & $(-+)$ \\
\hline 60 & 2 & $(-)$ & $(-+)$ & $(+)$ & $(+-)$ & $(-)$ & $(+)$ \\
\hline 61 & 2 & $(-)$ & $(-+)$ & $(+)$ & $(+-)$ & $(-)$ & $(+)$ \\
\hline 62 & 2 & $(-)$ & $(+)$ & $(+)$ & $(+-)$ & $\frac{(-)}{11}$ & $\frac{1}{(+)}$ \\
\hline 63 & 2 & $\frac{(1)}{(-)}$ & $\frac{(-+)}{(-+)}$ & $(+)$ & $\frac{(+-)}{(+-)}$ & $\frac{(-)}{(-)}$ & $\frac{(-+)}{(-+)}$ \\
\hline 64 & 2 & $(-)$ & $(-+)$ & $(+)$ & $\frac{1}{(+)}$ & $(-)$ & $(+)$ \\
\hline 65 & 2 & $(-+)$ & $(+)$ & $(+)$ & $(+-)$ & $(-)$ & $(+)$ \\
\hline 66 & 2 & $(-+)$ & $\frac{1}{(-+)}$ & $(+-)$ & $(+-)$ & $(-+)$ & $(-)$ \\
\hline 67 & 2 & $(+)$ & $(+-)$ & $(+)$ & $(-+)$ & $(-)$ & $(+)$ \\
\hline 68 & 2 & $(+)$ & $\frac{1}{(+)}$ & $(-+)$ & $\frac{1}{(-)}$ & $(+)$ & $(+)$ \\
\hline 69 & 2 & $(+)$ & $(+)$ & $(+)$ & $(-+)$ & $(+-)$ & $(+)$ \\
\hline 70 & 2 & $(-)$ & $(-)$ & $(+)$ & $\frac{1}{(+)}$ & $(-)$ & $(-)$ \\
\hline 71 & 2 & $(-)$ & $(+)$ & $(+)$ & $(-)$ & $(-)$ & $(+)$ \\
\hline 72 & 2 & $(-+)$ & $(+)$ & $(+)$ & $(-)$ & $(-)$ & $(+)$ \\
\hline 73 & 2 & $(-+)$ & $(-+)$ & $(+)$ & $(+-)$ & $(-)$ & $(-+)$ \\
\hline 74 & 2 & $\frac{1}{(-)}$ & $(-+)$ & $\frac{1}{(-+)}$ & $(+-)$ & $\frac{1}{(+-)}$ & $(-+)$ \\
\hline 75 & 2 & $(--)$ & $\frac{1}{(-)}$ & $(-+)$ & $(+)$ & $(-)$ & $(-+)$ \\
\hline 76 & 2 & $(-+)$ & $(+)$ & $(+)$ & $(-)$ & $(+)$ & $(+)$ \\
\hline 77 & 2 & $(-)$ & $(-+)$ & $(+)$ & $(+)$ & $(-)$ & $(-+)$ \\
\hline 78 & 2 & $(--)$ & $\frac{1}{(+)}$ & $(+)$ & $(+-)$ & $(-)$ & $\frac{1}{(+)}$ \\
\hline 79 & 2 & $(--)$ & $(+)$ & $(+)$ & $(-)$ & $(-)$ & $(+)$ \\
\hline 80 & 2 & $\frac{1}{(-)}$ & $(+)$ & $(+)$ & $(+)$ & $(-)$ & $(+)$ \\
\hline 81 & 2 & $(-)$ & $(-+)$ & $(+)$ & $(+-)$ & $(-)$ & $(+)$ \\
\hline 82 & 2 & $(-)$ & $(-+)$ & $(+)$ & $(+-)$ & $(-)$ & $(+)$ \\
\hline 83 & 2 & $(-+)$ & $\frac{1}{(+)}$ & $(+)$ & $(-)$ & $(-)$ & $(+)$ \\
\hline 84 & 2 & $(-+)$ & $(+)$ & $(+)$ & $(-)$ & $\frac{11}{(-)}$ & $(+)$ \\
\hline 85 & 2 & $(-)$ & $(+)$ & $(+)$ & $(-)$ & $(-)$ & $(+)$ \\
\hline 86 & 2 & $(+)$ & $(+)$ & $(+)$ & $(-)$ & $(+)$ & $(+)$ \\
\hline 87 & 2 & $(+)$ & $(+)$ & $(+)$ & $(-)$ & $(--)$ & $(+)$ \\
\hline 88 & 2 & $(+)$ & $(+)$ & $(+)$ & $(-)$ & $\frac{1}{(-)}$ & $(+)$ \\
\hline 89 & 2 & $(+)$ & $(+)$ & $(+)$ & $(-)$ & $(-+)$ & $(+)$ \\
\hline 90 & 2 & $(-+)$ & $(+)$ & $(+)$ & $(+-)$ & $\frac{1}{(-)}$ & $(+)$ \\
\hline 91 & 2 & $\frac{1}{(+)}$ & $\frac{1}{(+)}$ & $(+)$ & $\frac{1}{(-)}$ & $\frac{1}{(+)}$ & $(+)$ \\
\hline 92 & 2 & $(-+)$ & $(-+)$ & $(-+)$ & $(+-)$ & $(-)$ & $(-+)$ \\
\hline 93 & 2 & $\frac{1}{(+)}$ & $\frac{1}{(+)}$ & $(+)$ & $\frac{1}{(-)}$ & $(-)$ & $(-+)$ \\
\hline 94 & 2 & $(-+)$ & $(+)$ & $(+)$ & $(+-)$ & $(-)$ & $(+)$ \\
\hline 95 & 2 & $(-)$ & $(-+)$ & $(+)$ & $(+-)$ & $(-)$ & $(-+)$ \\
\hline 96 & 2 & $(-)$ & $(-+)$ & $(+)$ & $\frac{1}{(+)}$ & $(-)$ & $\frac{1}{(+)}$ \\
\hline 97 & 2 & $(-)$ & $(+)$ & $(+)$ & $(+-)$ & $(-)$ & $(+)$ \\
\hline 98 & 2 & $(-)$ & $(+)$ & $\frac{1}{(+-)}$ & $\frac{1}{(+)}$ & $(-+)$ & $\frac{1}{(+-)}$ \\
\hline 99 & 2 & $(-)$ & $(-+)$ & $(+-)$ & $(+-)$ & $(-)$ & $(-+)$ \\
\hline 100 & 2 & $(+-)$ & $\frac{1}{(+)}$ & $(-)$ & $(-)$ & $(+)$ & $\frac{1}{(-)}$ \\
\hline
\end{tabular}

Nota: (+) onda T única e positiva, (-) onda T única e negativa, (- +) onda T bifásica, sendo a primeira porção negativa e a segunda porção positiva, (+ -) onda T bifásica, sendo a primeira porção positiva e a segunda porção negativa e (- -) onda $\mathrm{T}$ bífida e negativa. 